Portland State University

PDXScholar

Spring 5-10-2018

\title{
Using Archival and Archaeofaunal Records to Examine Victorian-era Fish Use in the Pacific Northwest
}

Emily Celene Taber

Portland State University

Follow this and additional works at: https://pdxscholar.library.pdx.edu/open_access_etds

Part of the Anthropology Commons, and the History Commons Let us know how access to this document benefits you.

Recommended Citation

Taber, Emily Celene, "Using Archival and Archaeofaunal Records to Examine Victorian-era Fish Use in the Pacific Northwest" (2018). Dissertations and Theses. Paper 4393.

https://doi.org/10.15760/etd.6277

This Thesis is brought to you for free and open access. It has been accepted for inclusion in Dissertations and Theses by an authorized administrator of PDXScholar. Please contact us if we can make this document more accessible: pdxscholar@pdx.edu. 
Using Archival and Archaeofaunal Records to Examine Victorian-era Fish Use in the

\title{
Pacific Northwest
}

\author{
by \\ Emily Celene Taber
}

\begin{abstract}
A thesis submitted in partial fulfillment of the requirements for the degree of
\end{abstract}

\section{Master of Science \\ in Anthropology}

\section{Thesis Committee:} Virginia L. Butler, Chair

Kenneth M. Ames

Douglas C. Wilson

Portland State University 2018 
(C) 2018 Emily Celene Taber 


\begin{abstract}
Studies of historic fish archaeofaunas can contribute to our understanding of Victorian-era consumer choice and agency. However, most zooarchaeological work focuses on interpreting large mammal remains such as cow (Bos taurus). That fish are overlooked is particularly striking in the Pacific Northwest, where fishing was a major facet of both the bourgeoning industrial economy and local household practices. My thesis addresses this gap through study of archival records (mainly newspapers) and zooarchaeological fish records from a neighborhood in Vancouver, Washington, U.S.A., focusing on the period between 1880 and 1910. My particular goals were to examine how fishes were acquired and their economic role in a market economy.

I conducted archival research through systematic and qualitative reviews of The Oregonian and other newspapers in Oregon and Washington. I recorded 105 different named fishes, which I linked to 46 Linnaean taxa; 76 fishes were listed with price information in advertisements. I connected these fishes to market acquisition, and the remaining fishes to personal catch. I ranked the sixteen most prominent fishes by their price. Largemouth bass (Micropterus salmoides) was the most expensive, and Pacific cod (Gadus macrocephalus) was the least expensive. Five ranked fishes were introduced; all of these were in the top 50\% of the ranking. Chinook salmon (Oncorhynchus tshawytscha) was advertised the most frequently, but was in the lower $50 \%$ of the ranking. Some fishes (e.g., common carp [Cyprinus carpio]) were heavily promoted by federal entities and private entrepreneurs, but viewed negatively by consumers.
\end{abstract}


The zooarchaeological portion of my study focused on privies from the Esther Short neighborhood (Vancouver, WA), which, between 1880 and 1910, was a predominantly middle- and working-class community, occupied by people of European ancestry. The fish fauna (total NISP: 1,282) had previously been documented by Krey Easton. I reanalyzed $\sim 30 \%$ of the fish remains to verify identifications; our results were highly correlated. Ten fish families representing 16 taxa were recorded in the assemblage. Both introduced fishes $(\mathrm{n}=6$ taxa) and native fishes $(\mathrm{n}=10$ taxa) were present. Catfish (Ictaluridae) dominated the assemblage (76\%). Salmonids represented $15 \%$. I recorded five new taxa from specimens previously noted as "unidentified". I documented body part representation and butchering marks to establish the fish portions Esther Short residents acquired. Finally, I compared archaeofaunal fish representation against the fish rank obtained from archival research.

Residents acquired fishes both as market purchases and through personal catch. Eight fish taxa in the assemblage represented market purchases. Four were nonmarket fishes. An additional four could represent either market or nonmarket fishes. Nine taxa recovered from the neighborhood were also fishes included in the ranking. Neighborhood residents were predominantly eating low-cost purchased catfish heads, which were likely incorporated into soups, stews, or chowders. I found some evidence for higher-cost purchases and fish steaks, which I loosely connected to conspicuous consumerism. Evidence of personal catch (sport and subsistence angling) illustrates agency and potential resistance to the systemic Victorian model, in which the middle class generally did not participate in such activities. 
My thesis shows that interpreting fish use provides valuable insights into historical-era consumer choice and agency. On a systemic level, fish use was driven by sources of authority and monied interests. Expression of identity was visible in structural responses to systemic forces, both through consumer choice within the markets, and rejection of the market economy. Fish use in the Esther Short neighborhood showed some household patterns of "purchasing within one's means", as well as several expressions of agency that conformed to or rejected Victorian-era ideals. 


\section{Dedication}

To my sister, Dani, and my brother-in-law, Ron, for all of their support and encouragement.

And to Dr. Sarah K. Campbell and Jana Clark, who inspired me to share stories about people through science and literature. 


\section{Acknowledgements}

First and foremost, I would like to thank my advisor, Dr. Virginia L. Butler, for supporting me, professionally and academically. She has continually excelled at helping me develop my archaeological research through the classroom and through her passion for public archaeology in the broader Portland community. I owe sincerest thanks to my other two committee members, Dr. Douglas C. Wilson and Dr. Kenneth M. Ames. Dr. Wilson's continual optimism, depth of understanding in historical archaeology, and efforts to support my abilities and ideas have been invaluable. My work was greatly aided by the insights that Dr. Ames provided throughout my time at Portland State University (PSU), as he has done for so many other students. I would also like to acknowledge the number of excellent faculty and staff at PSU whose coursework and experience has benefitted my career.

I am indebted to staff both former and present at Applied Archaeological Research (AAR). Krey Easton (AAR) let me adapt so much of his research into my work; without his support, my thesis project would not have been possible. In particular, I'd like to thank Bill Roulette and Kendal McDonald (AAR) for making so much data available to me, and for providing so much support for my research. Additionally, I thank Scott McAleer (Linn-Benton Community College) for his previous archival research on the Esther Short neighborhood.

I am extremely grateful to those who established the Wayne Suttles Graduate Fellowship (Dave Ellis and Paul Solimano [Willamette Cultural Resources], Yvonne Hajda [PSU Anthropology Alumni], Linda Crum [PSU Anthropology Alumni], and Keith 
Gehr [PSU Anthropology Alumni]), and to the members of Dr. Wayne Suttles' family, all of whom have supported both my research and the archaeological community at large. I also received funding from the collaboration between PSU and the National Park Service (NPS) through archaeological work at Fort Vancouver National Historic Site, and from PSU's Laurels Graduate Award. Martin Adams (PaleoInsect Research) supported my work by making available his phenomenal photography skills in documenting butchered fish remains. Martin Plumer (PSU) connected with the contemporary fishing community around Portland to acquire new specimens for the PSU comparative collections. Dr. Anna Neuzil (Environmental Planning Group, LLC.) provided me with additional space and support for completing my thesis research.

I also thank the numerous researchers around the country whose work and advice I benefitted from. Drs. Ken Gobalet (California State University, Bakersfield) and Ryan Kennedy (Indiana University, Bloomington) provided feedback on fish bone identification. Irene Martin (Columbia River Maritime Museum) interpreted unusual pricing data in historical newspapers. Drs. Sherri Gust (Cogstone), Elizabeth Reitz (University of Georgia), and Beth Horton (NPS) provided information from their own research, experience with faunal identifications, and constructing historical meat rankings. Drs. Adrian Praetzellis and Mary Praetzellis (Sonoma State University [SSU]), along with the SSU Anthropology Studies Center, gave me access to research on the I880 Cypress project and other historical fish-related data. Additionally, several members of the International Council for Archaeology (ICAZ) whose research intersected with my own provided useful feedback. Several researchers whom I did not meet directly, but 
from whose work I benefitted greatly, include Dr. Peter Schulz, David Singer (University of Massachusetts, Boston), and Lauren Willis (University of Oregon). I thank all of the graduate students in the PSU Department of Anthropology, in particular Laura Syvertson, Reno Nims, Michelle North, and Justin Junge; their good nature and humor is irreplaceable. Finally, I thank my family. Matt Munsinger showed infinite patience, support, and interest in my research. Danica Taber and Ronald Bakus stepped in at crucial moments with words of support and tools to help me succeed. My parents have always encouraged my interests, wherever those interests have taken me. 


\section{Table of Contents}

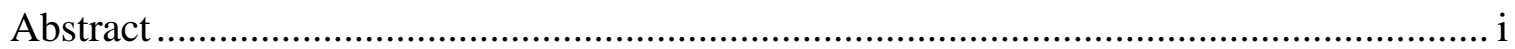

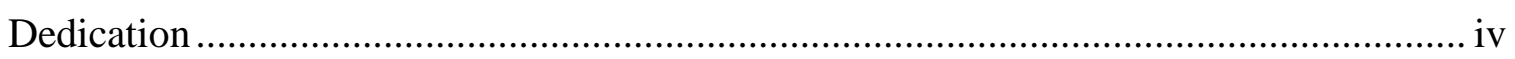

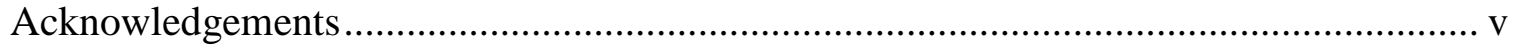

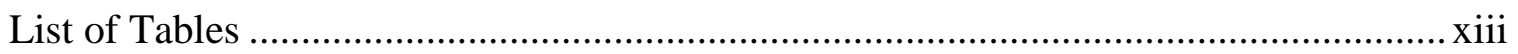

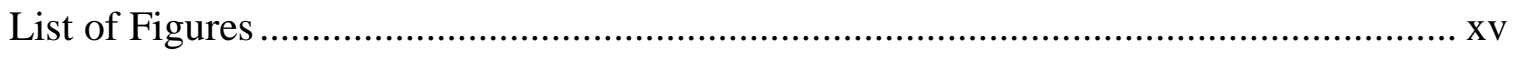

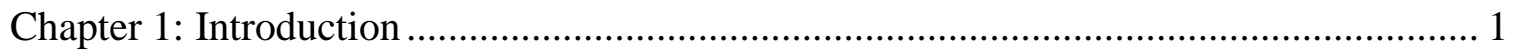

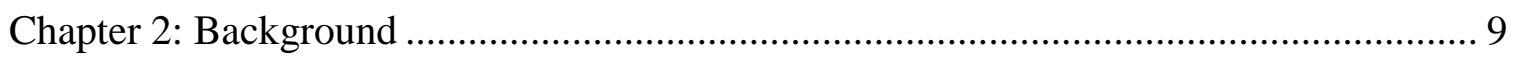

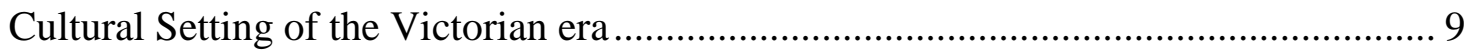

The Pacific Northwest Historical Fishing Industry ...................................................... 13

Determining Fish Acquisition Methods ....................................................................... 19

Middle-Range Theory and Archaeological Biases ................................................... 21

Historical Rankings of Food Faunas ........................................................................... 23

Criteria for Butchery Analysis in Zooarchaeology ……………………………........ 29

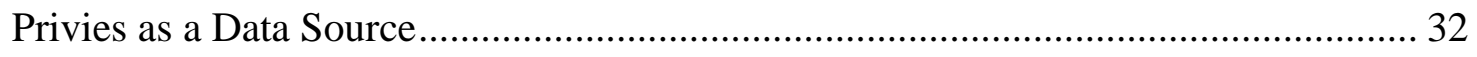

The Esther Short Neighborhood (Sites 45CL646 \& 45CL582)..................................... 34

Archival Research on Household Occupancy........................................................... 37

Chapter 3: Archival Research Methods, Materials, and Results ...................................... 41

Systematic Archival Sampling............................................................................. 42

Qualitative Archival Sampling ………………………......................................... 44

Recording Methods for all Search Types.................................................................. 47

Linking Fishes Noted in Archival Records to Linnaean Taxa...................................... 47 


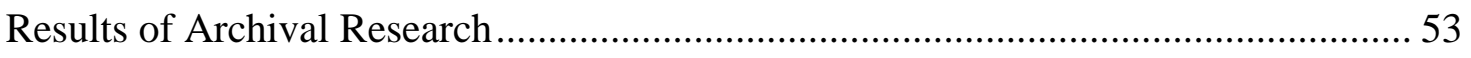

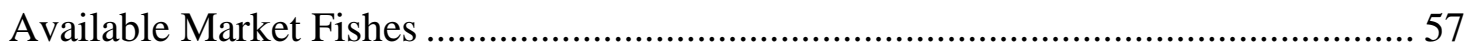

Trends in Frequency of Fish Type Listing and Pricing ......................................... 63

Introduced Fish Trends..................................................65

Native Fish Trends...................................................67

Freshwater, Marine, and Anadromous Fishes............................... 70

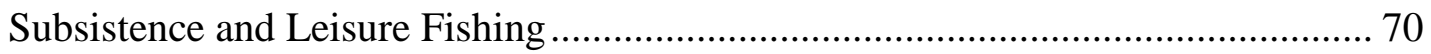

Developing a Fish Ranking from Archival Results ................................................... 72

Inferences from Archival Research ............................................................... 79

Chapter 4: Zooarchaeological Methods, Materials, and Results ...................................... 81

Overview of Faunal Analysis of the Esther Short Neighborhood Assemblage............. 81

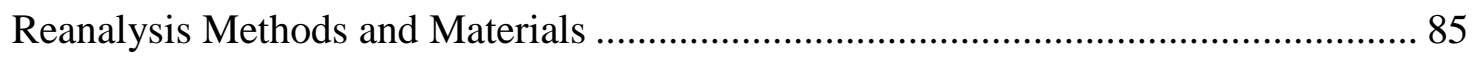

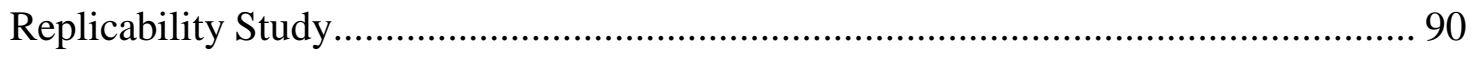

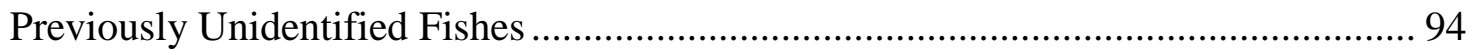

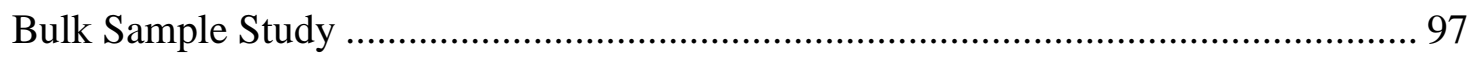

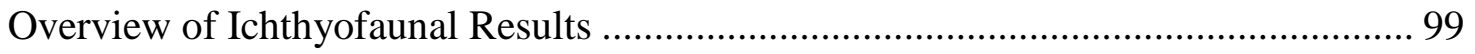

Situating Fish Faunal Remains into the Economic Fish Ranking............................ 103

Insights from Body Part Representation ............................................................. 108

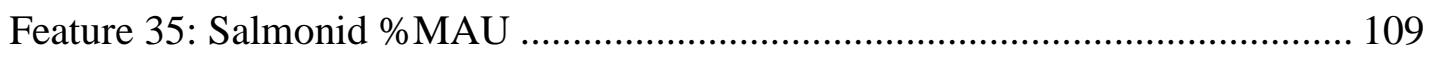

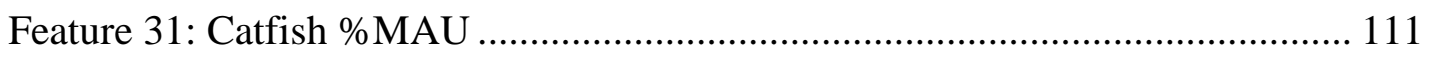

Feature: 76 Catfish \%MAU ........................................................................... 112

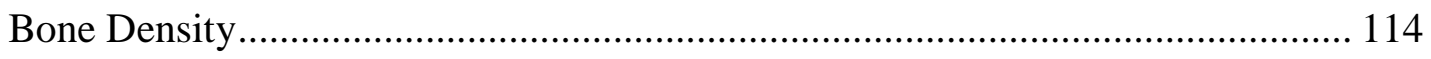




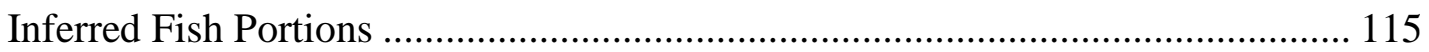

Leisure and Subsistence Catch............................................................................. 117

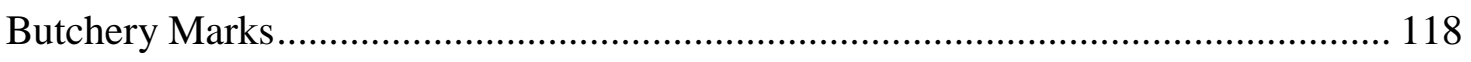

Results of Butchery Analysis ............................................................................. 120

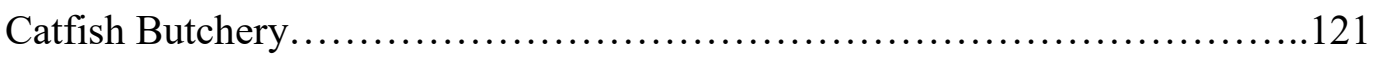

Other Butchered Fishes..................................................123

Distribution of Butchered Fish Remains Across Features.......................125

Conclusions from Zooarchaeological Work …………........................................ 126

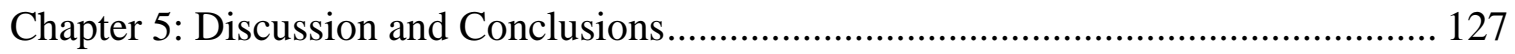

Fish Use in the Esther Short Neighborhood ............................................................ 130

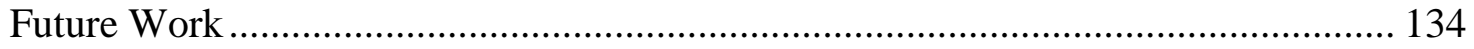

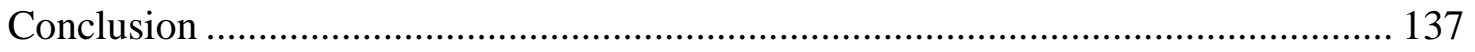

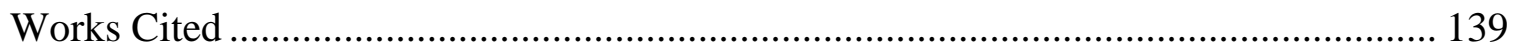

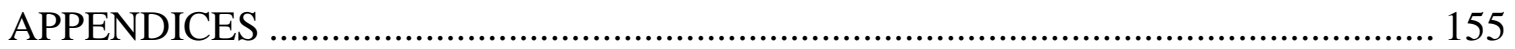

Appendix A: Available Tenant Histories for Fish-Bearing Features in the Esther Short

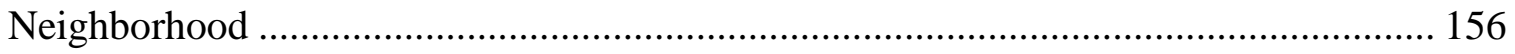

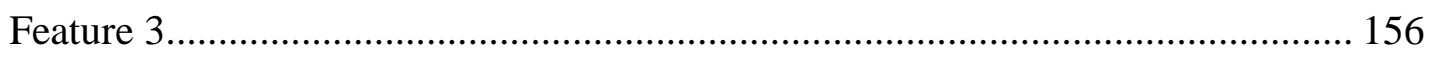

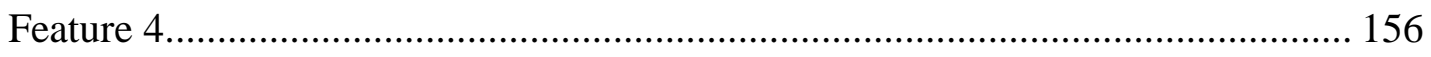

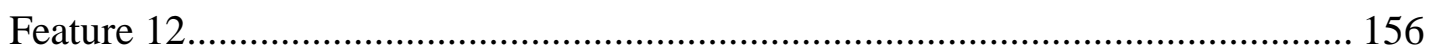

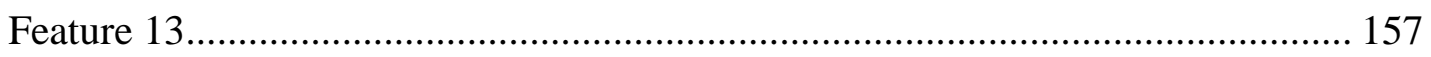

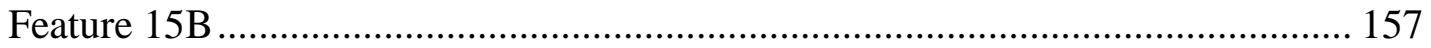

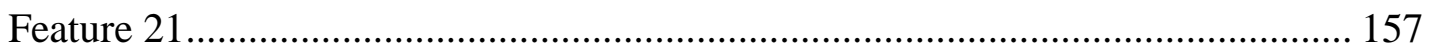




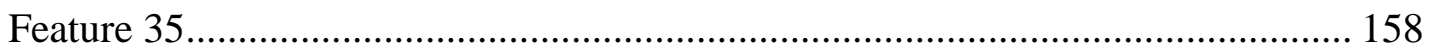

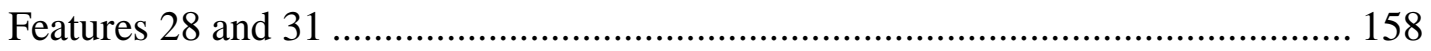

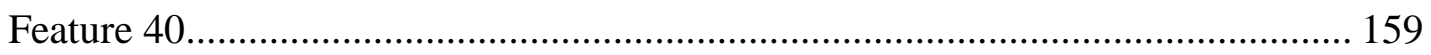

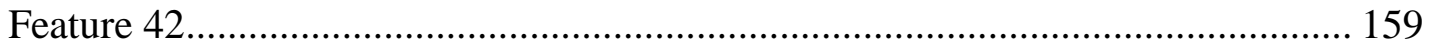

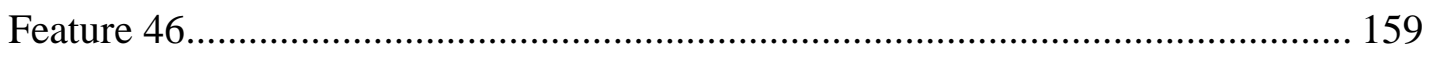

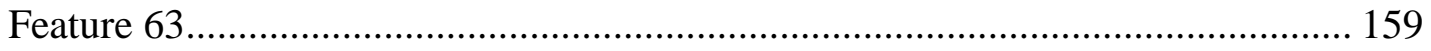

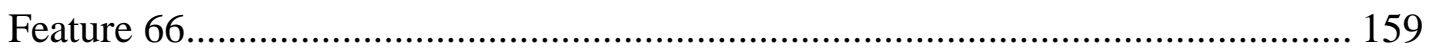

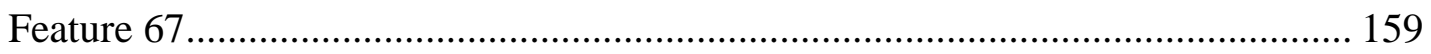

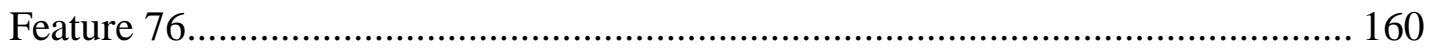

Appendix B: Dates Included in Historical Newspaper Searches..................................... 161

Appendix C: Interpreting "Box-and-Whisker" Plots ................................................... 164

Appendix D: Selection of Ichthyofaunal Elements .................................................. 165

Appendix E: Descriptive Summary of Ichthyofaunal Remains...................................... 167

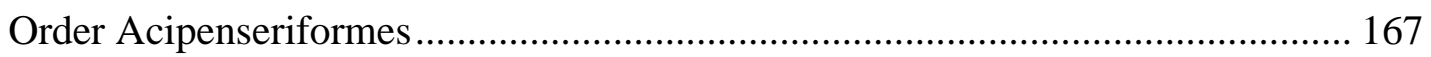

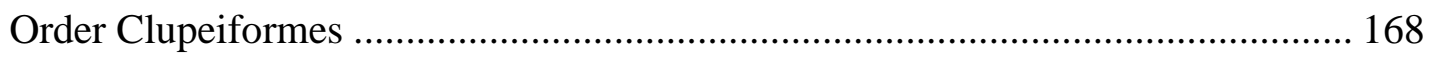

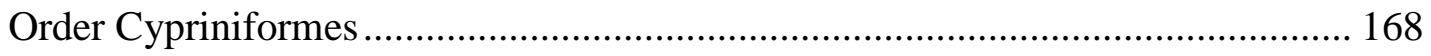

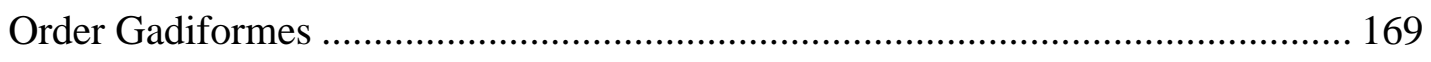

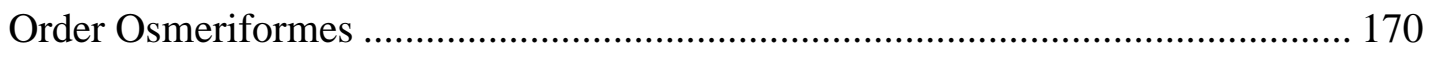

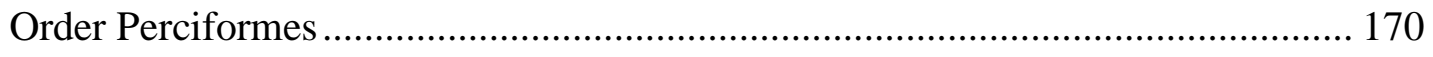

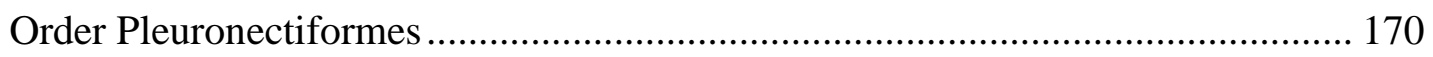

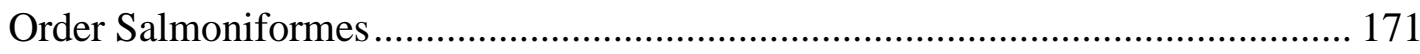

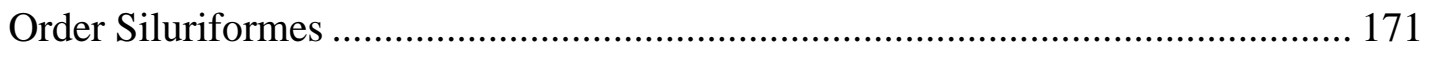


Unidentified Fishes - Small Size Class ............................................................ 172

Unidentified Fishes - Medium Size Class .............................................................. 172

Unidentified Fishes - Large Size Class ............................................................ 172

Appendix F: Notes on Results of Faunal Analyses ..................................................... 173

Differences in Analyst Identifications and Impact on Spearman's Rho Tests ........... 173

Additional Faunas and Elements Noted in Ichthyofaunal Assemblage ...................... 174

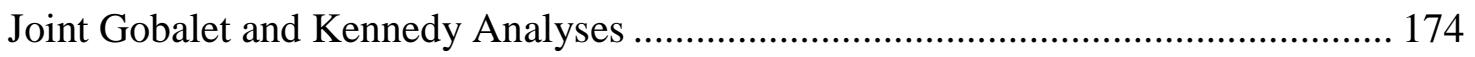

Appendix G: Fish Butchery Documentation........................................................... 175 


\section{List of Tables}

Table 1. Archaeological signatures for fish acquisition.......................................... 31

Table 2. Excavated features with fish faunal remains from the Esther Short neighborhood.

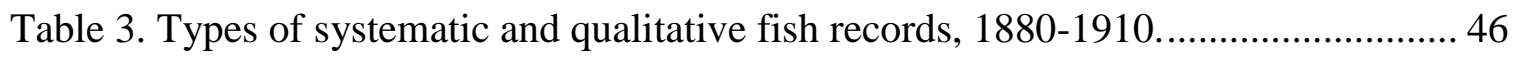

Table 4. Reported average and maximum weights and lengths of salmonid fishes, 1880-

1910.

Table 5. Frequency of units of sale for market-advertised fishes.

Table 6. Frequency of systematically recorded newspaper fish advertisements in each

year.

Table 7. List of main fish taxa documented from archival research and summary of

market records. 58

Table 8. Frequency of fish prices and references for most commonly discussed fishes. . 65

Table 9. Introduced fishes recorded in systematic and qualitative searches. 66

Table 10. Environmental preference for introduced, native, and non-native fishes documented in newspaper listings. 68

Table 11. List of prominent fishes from archival research, ranked by market value. ...... 77

Table 12. Faunal specimens recorded to animal class or finer taxon by Easton in Esther

Short neighborhood features. 83

Table 13. Number of specimens (NSP) recorded by Easton in Esther Short neighborhood features. 85

Table 14. Levels selected for reanalysis and original NSP of ichthyofaunal remains 87 
Table 15. Comparison of Easton and Taber results of fish faunal analyses.

Table 16. Categories and Rankings for Spearman's Rho Test. ................................... 93

Table 17. Fishes identified by Taber, from Easton's unidentified fishes. ...................... 95

Table 18. Fishes identified to size class, from Easton's previously unidentified fishes... 96

Table 19. Information available on bulk sample collections in Esther Short neighborhood excavations 98

Table 20. Representation and relative abundance of fishes by feature in the Esther Short neighborhood from Easton's records and Taber's analysis of formerly unidentified specimens. 102

Table 21. Esther Short neighborhood fish remains and primary market fishes, ranked by economic value (1880-1910). 104

Table 22. Archaeological markers for fish portions acquired in markets or through personal catch 109

Table 23. Acquisition and portions of Esther Short fishes. 116

Table 24. Frequency of butchered fish remains in the Esther Short neighborhood 121 


\section{List of Figures}

Figure 1. Location of 45CL646 and 45CL582 (Esther Short neighborhood) in Vancouver,

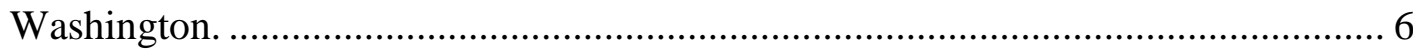

Figure 2. Example of Late Nineteenth-Century Beef Meat Ranking.. ............................ 23

Figure 3. Example of advertisement for market fishes without pricing information........ 45

Figure 4. Newspaper listings for systematic fish prices by decade. ............................. 54

Figure 5. Total number of fish references with at least one price, by season, 1880-1910..

Figure 6. Frequency of systematically recorded newspaper fish advertisements in each

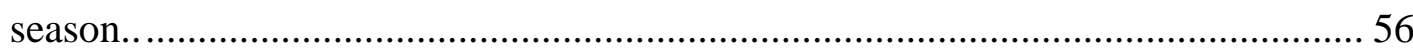

Figure 7. Example of compared pricing for four ranked fishes (Chinook salmon, eulachon, sturgeon, and American shad)

Figure 8. Fish types arrayed by range and median price from highest to lowest, controlled for inflation. 74

Figure 9. Fish types with systematic and qualitative prices, arrayed from highest to lowest price by range and median, controlled for inflation. 75

Figure 10. Relative diversity and abundance of fish taxa (family-level) from Esther Short neighborhood features. 99

Figure 11. Relative distribution of fish faunal remains across Esther Short features.... 100

Figure 12. \%MAU for salmonid remains from Feature 35.................................... 110

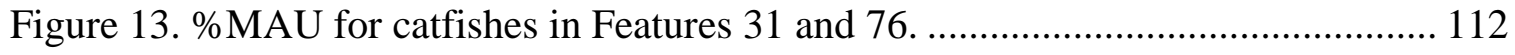


Figure 14. Sample of butchered catfish cleithra (spines removed) from fish faunal assemblage.

Figure 15. Modern example of catfish complete modified second vertebra and two specimens from the Esther Short assemblage 122

Figure 16. Distribution of catfish specimens with redundant butchery marks in the Esther Short neighborhood. 123

Figure 17. Example of butchered salmonid (Oncorhynchus sp.) vertebra. 124

Figure 18. Example of butchered salmonid (Oncorhynchus sp.) vertebra. 124

Figure 19. Frequency of butchered fish specimens by feature fish NISP 125

Figure 20. Frequencies of butchered and non-butchered catfish remains by feature. .... 125 


\section{Chapter 1: Introduction}

Archaeofaunal remains contribute to our understanding of social and economic patterns, including Euroamerican food consumption during the historical period of North America (Huelsbeck 1991; Landon 1996, 2005, Lyman 1977, 1987b, Reitz 1987, 1986; Schmitt and Zeier 1993). Considerable research on large domestic mammal use (e.g., cow [Bos taurus] and pig [Sus scrofa]) in particular has informed food consumption patterns through economic analyses of market-purchased meats (Horton 2010, 2014; Gust 1997; Jones 1997; Schulz and Gust 1983; Reitz 1987). Historical archaeological analyses exploring data from archaeofauna often first establish the economic setting of a household through examination of archival documents, and then assign faunal remains to economically-ranked retail meat cuts. Previous studies have compared faunal data to archival data, determining whether deposits reflect projected household economic settings and how individuals express choice within economic constraints (Gust 1997; Gibson et al. 2001; Praetzellis and Praetzellis 2004; O’Connor 2003; Reitz 1987, 2015; Schulz 1997; Schulz and Gust 1983:45; Schmitt and Zeier 1993; Reitz 1986). Such studies enhance our understanding of consumer choice and diet, and how social, economic, and political settings constrain or mediate those consumer choices. Data produced through economically-based meat rankings can illustrate and enrich nuances in our understanding of human behavior that cannot be seen by archival records or bones alone.

Most historical archaeofaunal studies to-date neither explicitly consider ways fishes were incorporated into diets, nor whether fish use follows the same economic 
patterns as large domestic mammal use (see Gibson et al. 2001; Praetzellis and Praetzellis 2004; Reitz 2015). Changing fish use as new species are introduced and compete with native fishes is infrequently examined (Butler 2004a). Few authors have closely questioned the role of fishes on the Euroamerican table, although doing so could inform the interaction between social classes, the introduction of industrialized food, and humanenvironment interactions in a way that large mammal consumption cannot (Singer 1982a:42). Identifying patterns of conformity and deviation in fish consumption allows for new avenues of research into Victorian foodways and the emerging class-based engagement with local economies and resources. This is of particular relevance in the Pacific Northwest, where fishes have long been - and continue to remain - a major industry and primary food source (Butler 2000; Butler and Campbell 2004; Butler 2004a; Craig and Hacker 1940; Harrison 2008; Lang 1992:243, 2000, 2003; Lichatowich 1999; McKechnie and Moss 2016). The development and growth of the historical fishing industry has also been documented by a wealth of written records that can be incorporated into historical archaeological studies (Lampman 1946; Lockington 1879; MacDonald and Gill 1896; Smith 1896, 1915). Despite the importance of fishes to many Euroamerican households from the $16^{\text {th }}$ to $20^{\text {th }}$ centuries, Landon's (2005) review of historical zooarchaeology cited only two fish studies, one of which was split between fishes, amphibians, and reptiles.

A number of archaeologists across the United States have attempted to join faunal and archival data to examine historical fish usage in the broader context of foodways. Their comparisons of available fishes and fish prices have enriched interpretations of 
historical communities' purchasing habits. While Singer (1982a, 1982b, 1985, 1987) has studied the importance of fishes within historical Euroamerican diets, his works focus on New England. His preliminary ranking, divided into three categories of pricing, provided context of the fishes the working class purchased. Reitz's ichthyofaunal studies generally focus on the southeastern United States and Caribbean $(2015,1986)$, detailing the species richness and abundance associated with class-based purchasing. The I-880 Cypress Freeway Replacement Project (I-880 Cypress Project) in Oakland and Emeryville, California, prompted one of the most detailed examinations of fishes in historical diets todate (Gibson et al. 2001). Faunal analyst Peter Schulz paid substantial attention to fish prices and acquisition method (e.g., market purchase or household catch, identified through archival research, body part representation, and butchery). In addition, the I-880 Cypress Project also addressed the connection of fishes to household socioeconomic settings. In Washington state, Horton (2014) used food-focused archival records in her reconstruction of soldiers' diets at Fort Vancouver in the late 1800s, and included a brief examination of available fishes and assumptions on whether they were purchased whole or as steaks.

Finally, innumerable historians have examined the development of the fishing industry within the Pacific Northwest, and particularly the Columbia River. Vibert's (2010) examination of nineteenth-century foodways on the Columbia Plateau considered fish use within the terminal dates of fur trade activity, into which salmon factored heavily. Lichatowich (1999) and Lichatowich and Zuckerman (2003) examined the historical fishing industry as a lens for its impact on modern salmon populations. 
However, the work of historians rarely incorporates archaeological data, and often is focused primarily on canneries.

A study addressing fish consumption in relation to household class and economics could broaden perceptions of human-environment interactions. Similar zooarchaeological and archival studies focused on beef consumption have enriched our understanding of consumer choice, economic constraints, and diet. Interpreting the role of fishes within historical diets is linked to understanding fish butchery. Fish butchery informs how people along the Columbia River acquired fishes, as compared to the relatively limited ways they could acquire beef. Understanding both the broad incorporation of fishes into diets, and the nuanced expression of self within the bounds of socioeconomic class, inform how historical archaeologists view material markers of agency in the archaeological record. This is particularly true in the highly-structured social setting of the Victorian era, where material possessions carried complex social meanings.

My study uses archival records and zooarchaeological analyses to provide more context on late Victorian- and early Progressive-era lifeways than has existed before in the Pacific Northwest. I address the gap in knowledge on socioeconomic interpretations of Victorian fish consumption in the Pacific Northwest by developing an economicallybased fish ranking for the Pacific Northwest. My goal is to offer a new interpretation of fish consumption between the late Victorian era (1880-1901) and the early Progressive era (1890-1910), with particular focus on establishing whether fishes were purchased in a market economy or acquired through household catch. I also examine which fishes were available in the economy of the Portland area through archival research, and whether any 
trends in zooarchaeological fish remains can be explained by fish acquisition method (e.g., purchased or caught in leisure or subsistence angling). I achieve this through a combination of analyzing physical records of fishes (both archival and archaeofaunal) and drawing inferences from the results in the same way that historical mammal ranking studies have done. This interpretation helps frame how early introduced fishes were viewed in contrast with native fishes, which is important for several reasons: in such a "fish-focused" culture, a study of fish use shows how class, the environment, and the economy all affected one another. Additionally, understanding how these fishes were viewed historically situates how they are dealt with today.

To examine the role of fishes in Victorian-Progressive era households, I applied my ranking to the ichthyofaunal assemblages from two adjacent sites in Vancouver, Washington (45CL646 and 45CL582), in the historical Esther Short Neighborhood (Figure 1). The Esther Short neighborhood provides an ideal context for evaluating nineteenth-century Euroamerican fish usage in the Pacific Northwest. Located at the confluence of the Columbia and Willamette Rivers, the City of Vancouver granted relatively easy access to coastal and inland fishing, prompting an active market economy for fishes (Kincaid et al. 1880; Lampman 1946; MacDonald and Gill 1896). At the turn of the last century, the Esther Short neighborhood was occupied mainly by white middleclass Euroamericans (Roulette et al. 2014). Faunal remains recovered from features in the Esther Short neighborhood include remains of native and non-native fishes. This faunal assemblage, coupled with rich archival records, can be used to provide a much richer understanding of household fish use than is currently available. 
I posit that the consumption of market-purchased fresh fishes in the Esther Short neighborhood will largely reflect the socioeconomic status of the Euroamerican occupants in the form of lower-cost market options. Additionally, I posit that fishes

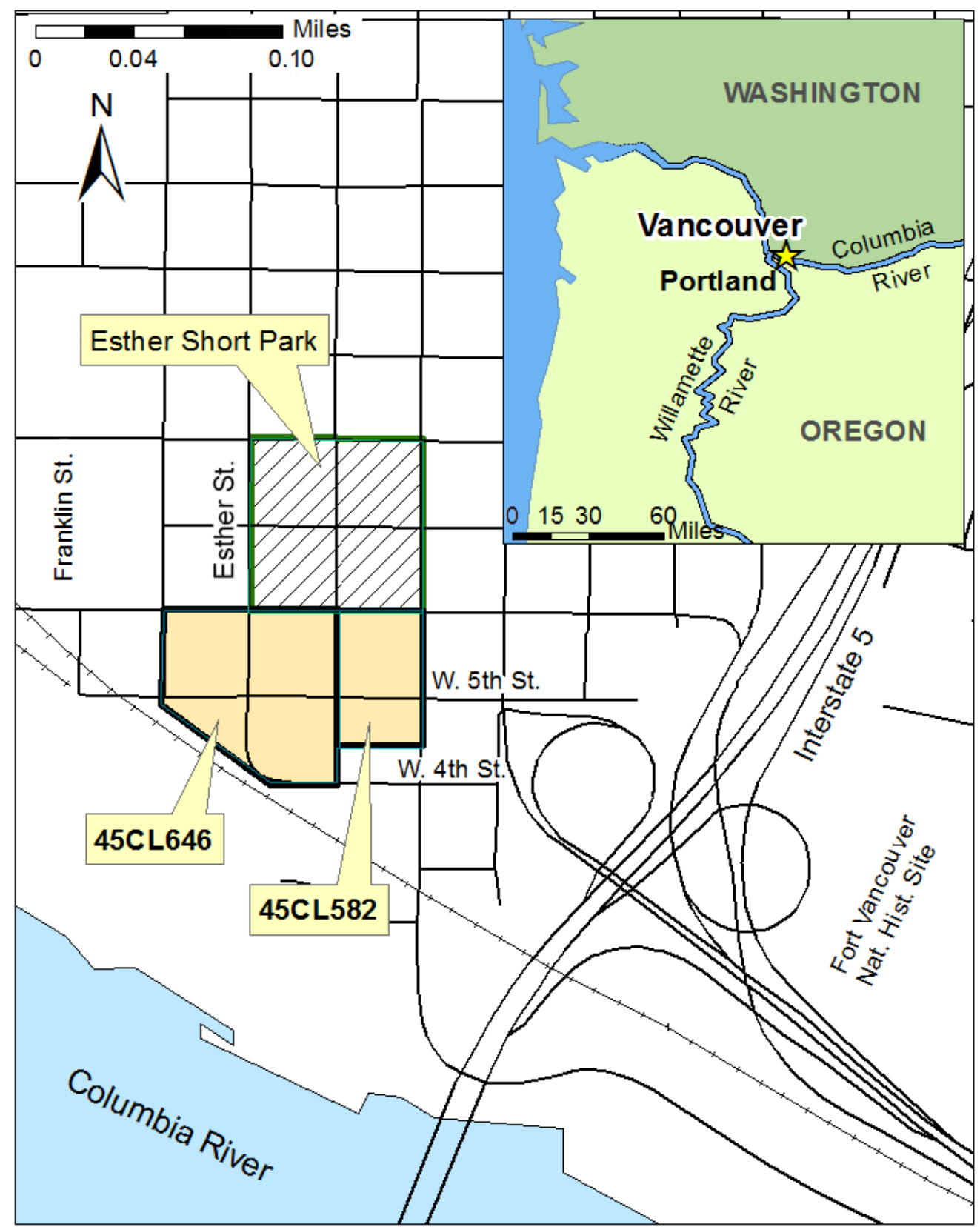

Figure 1. Location of 45CL646 and 45CL582 (Esther Short neighborhood) in Vancouver, Washington. 
acquired outside of market purchases may be identified through a combination of archival work and faunal analyses. Non-market catch are those fishes that are acquired outside of market purchases, such as through fishing by household members.

My work tests these assumptions by comparing the fish rankings I create from historical pricing information and the previously-established socioeconomic level of households within the neighborhood (McAleer 2005; Roulette et al. 2014) to the ichthyofaunal assemblages from the neighborhood. I document fish butchery in the assemblage because of the importance in identifying how fishes in the archaeological record were acquired. My work offers some insights on conformity and agency in the middle and working classes, expressed through fish procurement and consumption. Though I develop a fish ranking and apply it to a Victorian-era ichthyofaunal assemblage, a comprehensive interpretation of the interplay between social class in the Pacific Northwest and fish consumption is beyond the scope of this thesis.

My fish ranking may be used by other archaeologists at local, regional, and national levels as a comparative tool for faunal and socioeconomic class analyses, allowing for a more thorough interpretation of the archaeological record than is currently available. This has important implications for historical archaeological research in the Pacific Northwest, as well as for interpreting the emerging identity of the middle class across the nation.

This thesis is organized into five chapters. Chapter 2 is devoted to the background that informs my research, particularly for archaeologically-driven archival work, consumer choice of faunas, how other price-based faunal rankings have been developed, 
Victorian culture as a backdrop for this study, and the development and impact of the local Euroamerican fishing industry. I also provide background on the archaeological projects in Esther Short neighborhood. In Chapter 3, I describe the methods, materials, and results of my archival work and the steps involved in developing an economic model of fish rank. Chapter 4 presents my zooarchaeological methods, materials, and results, including my replicability study and butchery analysis. I also present ichthyofaunal results by their economic rank as established in my fish ranking. In Chapter 5, I consider the broader implications of the results, present my conclusions, and suggest directions for future work. 


\section{Chapter 2: Background}

This chapter first provides an overview of Victorian-era culture and how fish consumption is situated within it to illustrate ways it guided consumer patterns around food. I then provide a background of the historical fishing industry and its influence both on the local economy and the stability of local fisheries to illustrate the extent and importance of the historical fishing industry. Following that, I address the development of economically-derived historical meat rankings, how those rankings are connected to historical butchery cuts, and what value they have provided in interpreting historical human behaviors. As many of the features within the Esther Short neighborhood were privies, I briefly discuss their use in providing historical-era archaeological information. Last, I introduce previously-conducted archival research on the Esther Short neighborhood as an overview of the neighborhood occupants and their relative standing within Victorian society.

\section{Cultural Setting of the Victorian era}

The Victorian era (1837-1901) was a complex period hallmarked by the rise of the middle class and its aspiration to a genteel lifestyle, with the inevitable push from the elite to further distinguish themselves from lower classes. Elite status was defined by distinct and dominant attitudes about power, gender, morality, the possession and display of appropriate goods, and the role of civilization within the home (Ames 1992a; Coben 1991; Kasson 1987; Stevenson 1991). 
My work is framed in the Victorian era more than the Progressive era. While the final eight years of my study period (1902-1910) are post-Victorian, the cultural values of that era did not abruptly end in 1901. Late Victorianism also loosely coincides with the Gilded Age (1870s to ca. 1900), a term coined by Mark Twain and Charles Dudley Warner (1873) that became synonymous with growing materialism, industrialization, and political corruption. The Progressive era was in part a response to those conditions through political reform and activism (Buenker et al. 1986:3-21; Buenker 1988).

The Victorian world was highly structured and framed almost as a grid. Ames (1992a) explains this structure as comprising many comparable binaries, often openly displayed: the masculine and feminine; domination and subordination; and the role of violence between those seen as civilized (those structured through Victorian ideals) and uncivilized (those unaware of their place and of the cycle of savagery they could not rise above). Binary worldviews such as these are well-framed through Levi-Strauss' (1969) interpretation of basic categorical opposites (such as cooked versus raw, or fresh versus rotten) as a broader tool to understand and reinforce abstract notions about culture, like the Victorian man's obligation to civilize the wild outside world through force, and the Victorian woman's obligation to soften the roughened edges of men through gentle domesticity (Ames 1992b).

Though the Victorian era was highly socially stratified, it is difficult to identify the specific boundaries of the upper, middle, and working classes on a socioeconomic continuum. Even if clear class distinctions were available, Victorian material culture was manipulated to serve different needs by different people and was not a static marker of 
"self" (Praetzellis and Praetzellis 2001). I use "class" in a relational view, where it is derived from underlying social relationships and not a fixed nominal scale (Wurst and Fitts 1999). However, some broad definitions of Victorian socioeconomic classes are useful. As a generalization, the upper classes used material goods to express not just their wealth, but their morality. In concept, the upper class was aware of the astringent standards on which goods espoused which messages. They also had the financial means to get and display these goods appropriately (Ames 1992a). The developing middle class aspired to some of those standards, but also chose goods that were of lower quality or had motifs that the upper class found garish. This was done both in aspiration to and mockery of Victorian upper-class ideals (Ames 1992a). The working class typically lacked the financial means to pursue the traits of upper-class material wealth in a meaningful capacity. Class was also often dependent on ethnicity and religious affiliation. Even amongst Europeans and Euroamericans, ethnicity implied characteristics of morality and wealth inherent to the social order. In the Pacific Northwest, the local divisions of class are too murky to be cleanly delineated. As such, I rely on the general traits of Victorianera classes in my work. I also acknowledge that defining its specific meaning among Vancouverites and Portlanders is beyond the scope of this work.

In the Late Victorian era (ca. 1880 - 1900), the newly-emerging middle-class aspired to genteel class status, attained by expressing social standing through material wealth, entertaining, and structured etiquette, which were particularly important during meal times (Fiddes 1994; Roulette et al. 2014; Schlup et al. 2003:508-509; Williams 1985:5-8). In a typical middle or upper class Victorian household, contrasting themes of 
violence and civilization were openly expressed in artwork. Common examples involved images, usually carved or painted, of bleeding wild game being torn down by packs of snarling hunting dogs (contrasted with the civility of the indoors); or - as a metaphor for sweeping manifest destiny - of smiling Euroamerican women holding armfuls of abundant fruits and vegetables (contrasted with "primitive" living, which implied scrounging). This type of visceral imagery was shown in perhaps the most physically and socially structured of all Victorian areas, rife with the cultural abstraction of the European right to domination: the dining room. The Victorian worldview was predicated around such polarities, and knowing one's place within those polarities (Ames 1992a). While fishes were not often the focal point of these polarities, as part of the natural world they were considered to be another limitless resource available to meet the needs of the civilized (Williams 1996:154).

While food choice played an important role in defining socioeconomic standing for a Victorian household, class distinctions relating to household fishing blurred in the late 1800s as personal and industrial fishing technologies became mass manufactured. This made both manufactured fishing equipment and fishes themselves more accessible to the middle and working classes (Larson 2004:112). Even during this transition, Victorian values across the nation indicated that fishing and hunting were genteel activities, and only the poorest of the working class fished and hunted for subsistence. Other working- and middle-class people were thought not to take much part in either. In reality, both the middle and working class fished for necessity, particularly during the regional economic depression of the 1890s (Landerholm 1966). 
Some national trends on Victorian-era fish consumption have been examined by other archaeologists in the United States. In coastal New England, both archaeology and archival methods show that the nineteenth-century middle class mainly purchased fillets and steaks of larger fishes, and bought smaller whole fishes for broiling, baking, and panfrying (Singer 1987). Working class households purchased smaller whole fishes for panfrying as well, in addition to less-meaty portions (e.g., fish heads) to supplement soups, stews, and chowders (Singer 1982a, 1985, 1987). The distinction between purchasing a whole fish or a portion is important, as fish steaks were typically more expensive, and indicated a larger fish represented archaeologically by vertebrae; smaller fishes were consumed whole by necessity, and evidenced by more complete fish skeletons (Singer 1982a). Though these observations are from the Eastern United States, similar trends may exist in the West, given comparable fish recipes in late nineteenth-century Portland-area cookbooks (Lutz 1991:81-107). Additionally, as the Victorian West emulated other cultural trends from the East (Haywood 2003:515), Western households may also have adopted trends in consuming large mammals and fishes.

\section{The Pacific Northwest Historical Fishing Industry}

Fishes were important to nineteenth-century foodways, particularly on the West Coast where fish habitats were easily-accessible and both native and introduced fishes provided a major industry (Craig and Hacker 1940; Lang 2003; Lockington 1879). The Columbia River was a major salmon fishery, which provided a dominant economic stronghold alongside logging (Lang 2003). Many other native fishes were abundant and 
accessible in the Columbia River, with Fort Vancouver's post surgeon noting in 1879 that the river had plenty of fish, including smelt (Osmeridae), sturgeon (Acipenser spp.), and trout alongside salmon (Salmonidae) (Henry 1982:277). This richness in local fisheries proved to be an attractive bourgeoning market for canneries.

The first cannery on the Columbia River opened in 1866, providing inexpensive canned salmon to the working classes both in the Pacific Northwest and elsewhere in the United States (Lichatowich and Zuckerman 2003). By 1881, there were some 1,200 operating between Astoria and The Dalles. Overall, the 1880s and very early 1890 s represented the zenith of the salmon industry on the Columbia River, with 42 million pounds of Chinook salmon packed in 1883 and 1884 (Harrison 2008:2). However, during the 1880 s, fishermen went on strike in protest of what they saw as low wages ${ }^{1}$ paid by the canneries.

A regional recession in the early 1890 s caused a major downturn in the fish market economy. This depression had a marked effect on the fishing industry at large: canneries dropped the rates paid to fishermen to $45 \notin$ per salmon, meaning that fishermen could be paid as little as $2 \phi / l b$. on a large fish. Though cannery owners eventually came to an agreement with fishermen on wages, this still had a pronounced effect on the fishing industry for both canned fishes and store-bought fresh fishes. Some working-class families from the Portland area later recalled the need for subsistence fishing - often specifically targeting catfish (Ictaluridae) - as a means of supplementing table foods during the recession (Landerholm 1966).

\footnotetext{
${ }^{1}$ Prices paid to fishermen varied between 55c (in 1886) and \$1.25 (1888) per fish.
} 
The late $19^{\text {th }}$ and early $20^{\text {th }}$ centuries saw numerous fish introductions. Beginning in the early 1870s, at least 15 different fish species were introduced into the Pacific Northwest (Butler 2004a:455). These introductions continued into the 1930s, despite a regulation published by Master Fish Warden H. C. McAllister in 1898 that prevented the planting of non-indigenous fishes (McAllister 1909:23). Both the U.S. government and entrepreneurs introduced fishes. The most common reasons were for subsistence, sport, or a combination of both. For example, catfishes (e.g., Ameiurus melas, A. nebulosus, and Ictalurus punctatus) and common carp (Cyprinus carpio) were brought to the region as staple food fish (Lampman 1946). Some fishes were brought to the region to balance a perceived lack of predators (such as the muskellunge [Esox masquinongy]), or even purely by accident when fishes escaped into local waters (Barnas 2006:149; Klippel and Sichler 2004; Lampman 1946; MacDonald and Gill 1896). American shad (Alosa sapidissima) was introduced to the West coast in 1871 by a fish culturalist via railway. In 1872 , one of several private enterprises dedicated to selling carp as a food fish brought 83 of them to the Pacific Northwest by steamer ship; though only five survived the trip, that was enough to create a stable population (Lampman 1946). Between the late 1800s and early 1900s, other fishes introduced along the West coast included yellow perch (Perca flavescens) and a number of centrarchids like crappie (Pomoxis spp.) (Lampman 1946; Palen et al. 2006). Several of these introduced fishes, such as catfish and carp, became a part of commercial fishery operations and entered Portland-area markets for public consumption. 
The public's preference for eating introduced fishes as compared to native fishes varied, and appeared to be somewhat dependent on class. While Lampman (1946) details that recently introduced (and primarily freshwater or brackish water) "exotic" fishes were favored, Whillans (1979) states that in the historic period, much of high-class society preferred marine fishes (presumably including anadromous fishes). In 1880, several federal institutions and private entrepreneurs encouraged communities in the Pacific Northwest to fish for or buy recently-introduced fishes like carp and catfish alongside native fishes like salmon (Oncorhynchus sp.), citing their high value and superior flavor (Lampman 1946; MacDonald and Gill 1896). In either case, the perceived exotic nature of a fish affected both its market value and social value. In an expression of Victorian-era work ethic, middle class households tended to work longer hours, with less leisure time that could be spent fishing. Doing this presumably gave them greater income, and the combination of fewer free hours and a higher income would most likely lead to more reliance on market systems, and a reduction in fishing or hunting in the middle classes as compared to working-class or elite households (Huelsbeck 1991; Rothschild 1989).

Marketing greatly affected how often fishes would appear on the table, and how they were perceived societally. Some institutions and community business leaders strongly encouraged the public to purchase introduced fishes as they became more available in local waters and markets (Lampman 1946:13,22). This supported the underlying logic that introductions were not just harmless, but necessary. If a fish was initially identified as a good game piece or table food (as with stating that the flavors of carp and salmon were comparable), a market for consumption was more likely to evolve 
around that fish. A continuing market then promoted further introduction attempts as the species was increasingly seen as lucrative (Lampman 1946).

Non-native species often went through a boom-bust popularity, in which they were initially popular because they were seen as exotic and new. Once their exotic nature wore off, their market declined. By the mid-1890s, carp was advertised as a fertilizer at $\$ 5$ per ton. The U.S. Fishing Commission repeatedly stated to the public that the carp was globally considered one of the premiere edible fishes. They held to this statement despite being lambasted by the public both then and in later years for introducing some of the most "hated and worthless" fishes to the West Coast (Lampman 1946:23; MacDonald and Gill 1896). The California Fish Commission reported in 1880 that most people preferred catfish to carp as a table food (Lampman 1946:57), and The Oregonian noted eleven years later that "Farmers along the Columbia slough are bringing in wagonloads of catfish, all alive and packed in fresh-cut grass. The demand for catfish is increasing" (cited in Lampman 1946:59). A commercial catfish operation based near Sauvie Island saw an increase from 75,000 lbs. of dressed catfish in 1893 to $116,000 \mathrm{lbs}$. in 1895 , but then dropped to $66,000 \mathrm{lbs}$. by 1898 . Ultimately, both directed market interactions and broader social perceptions influenced how marketable an introduced fish could be.

In the late 1800s, several fishes became more important to the general economy than others. The first of these, unsurprisingly, was salmon (Craig and Hacker 1940; Smith 1915). While records of many fish sales were irregular before 1900, my archival research shows that newspapers and reports documented and compared the poundage and profits for yearly salmon pack. The amount of information generated about salmon as compared 
to other fishes illustrates its importance to the local economy as a source of both income and food.

Euroamerican appreciation and market values for sturgeon varied dramatically between the 1850s and early 1900s. By the late 1880s, it became the second most lucrative fish for the local industry. The highest sturgeon packing year was in 1892 . The Oregon Department of Fish and Wildlife (2015) recorded that some 35,000 sturgeon were landed; research conducted by Harrison (2008) showed that 52 million pounds were included in the sturgeon pack that year. However, its rise in the late $19^{\text {th }}$ century was predated by a reputation as one of the most inedible fishes available. Craig and Hacker (1940) noted the value of sturgeon was so low that in the 1850s an entire sturgeon could be purchased for $1 \frac{1}{2} \phi$. Their report stated that fishermen routinely slaughtered any sturgeon they encountered, as sturgeon were large enough to severely damage industry fishing equipment. One observer described the banks of the Columbia as being rank with rotting sturgeon carcasses, as the population of this seemingly pestilent fish was so great (Harrison 2008). As sturgeon became an important market fish, its population severely declined from over-fishing (Harrison 2008:3). By 1909, federal regulators tried to limit catch to those over four feet in length (McAllister 1909:24-25).

There were many other factors that influenced fish consumption beyond market trends. The laws and regulations governing personal fishing by household members affected fish consumption. Household fishing generally took two forms: leisure fishing (generally associated with the upper classes) and subsistence fishing (generally associated with the lower classes). Subsistence fishing in times of economic duress was discussed 
briefly by Landerholm (1966), who recalled fishing for catfishes to try and fill in subsistence gaps during the recession of the 1890 s.

Active marketing in a consumer economy, relative availability through commercial operations, and household fishing efforts indicate which fishes may appear in a historical archaeofaunal assemblage. By interpreting whether fishes in these assemblages were caught or bought by households, and whether household-caught fishes were targeted for subsistence or sport, archaeologists can better understand the relationship between class and fish consumption.

\section{Determining Fish Acquisition Methods}

It is useful to identify archaeological fishes that were purchased (and thus subjected to market economies) versus fishes caught by household members, as these fish acquisitions were not determined by per-pound cost. Since fishes can be caught by the individual, they are not constrained by purely purchase-oriented distinctions of luxury and staple foods (Van der Veen 2003).

Determining fish acquisition methods is aided by Huelsbeck's (1991) discussion of structural and systemic variation. Systemic variation is defined as the relationship between regional markets and local communities, in which the regional markets often determine local availability (Huelsbeck 1991). Systemic variation is affected not just by the established price of the meat cut, but also by the associated shipping costs. However, because of fish abundance and access, the Pacific Northwest often acted as the regional market and determined local availability for inland U.S. and Canadian communities 
through railcar shipments. For people living in the Pacific Northwest, particularly with access to major watersheds like the Columbia River, fishes could also be acquired independently of regional markets. Local fish purchases were not influenced by other regional or national trends to the same degree as was, for example, the beef market. While systemic variation did influence local Pacific Northwest fish markets, it likely had a less profound impact on economically-driven fish acquisitions than structural variation.

Structural variation affects how the community, household level included, chooses to get food once it becomes available locally (Huelsbeck 1991). Structural variation can influence whether or not a food is chosen for consumption once it is available at the local level. Examples of local level economy-based acquisitions include restaurants, grocery stores, and border-style houses where communal food is prepared for a non-familial group (Huelsbeck 1991:23). Because I am only considering fish remains deposited in a residential neighborhood, my study examines fish consumption at the household level and within the Esther Short neighborhood. As such my consideration of structural variation is limited to locally-bought or freshly-caught fishes prepared within the home.

My study of fish acquisition also addresses most of Lubinski and Partlow’s (2012) factors in establishing local fish catch: records of fishing; site setting and assemblage; biological and environmental parameters of fishes; fish skeletal abundance; and otolith analysis (which I did not incorporate). 


\section{Middle-Range Theory and Archaeological Biases}

My examination of fish acquisition is part of a multiscalar analysis situated in middle-range theory. The two scales of analysis I use - archival and zooarchaeological data - are independent, but serve to inform one another. Multiscalar analyses have provided insights into how historical-era people negotiated their identities in complex social settings (Horton 2014; Lightfoot et al. 1998; Wilkie and Farnsworth 1999). I incorporate both systemic market forces and structural local interactions in fish consumption and identity. I approach systemic and structural forces through two independent but complimentary record sources. This allows me to interpret fish consumption on a multiscalar level.

I view systemic market forces in several ways. First, as broad geographical interactions influenced by overarching Victorian ideals (such as conspicuous consumerism and deference to authority); and second, as interactions between these and consumer fish market economics, wherein conspicuous consumerism is developed in advertising. The structural local interactions I examine are at the household level and focus on how individuals expressed agency in household practices under systemic constraints.

I situate these examinations in middle-range theory. Middle-range theory poses that making meaningful inferences about past human history can be done by correlating historically-recorded behaviors; actualistic archaeological tests; and archaeological data (Trigger 2006:32-33, 414-415). Other theoretical perspectives could be applied in this study, but I find it is most suited as an exercise in middle-range theory. 
As the terms "agency", "identity", and "household practices" receive more attention in historical archaeology, their meanings have become increasingly complex (Dobres and Robb 2000a, 2000b; McGuire and Wurst 2002; Mullins 2011; Shackel 2000). My use of these terms is not meant to connect directly to larger bodies of work. I use agency as the expression of choice that an individual may have, given the social and economic constraints of their environment. Identity is how one navigates a complex social environment to define their role(s) within it. Household practices refer to the ways those choices are expressed - in this case, around fish acquisition.

There are several biases inherent in this work. The bridge between archival market prices and archaeological data assumes that people express identity through goods in support of the Victorian social environment. Victorian-era socioeconomics influenced the larger market economy, and vice versa. This scale of analysis cannot be uniformly correlated with local expression of identity and agency through only market purchases. Further, the sources I used were biased themselves: the newspapers I included in archival research were predominantly aimed at an upper- and middle-class Euroamerican audience. This is reflected in some of my results, where the activities of the working class go largely unmentioned, as do other ethnic cultural values around fish consumption.

Finally, while I can identify the role of systemic and structural forces in fish acquisition, I cannot account for personal taste. Biases of personal taste in historical and pre-contact records are often inherent in archaeology food studies, and archaeologists must accept these limitations. 


\section{$\underline{\text { Historical Rankings of Food Faunas }}$}

One way archaeologists have addressed the persistent questions about the intersection between food and economics is by developing an independent rank of meat cut value based on cost. Historical meat rankings are models created from synthesizing the availability and cost of any particular fauna, and viewing those factors through a socioeconomic lens. Such models provide a way to interpret changes in the expression of class through time, and can enlighten specific inquiries like how individuals in the same class, but different geographical regions, spent money on foods.

Archival records play a fundamental role in the development of historical meat rankings. To create these rankings, archaeologists compile period-appropriate market pricing of raw meat cuts, the value of prepared cuts at local restaurants, and sometimes contemporary cookbook recipes, to identify a range of values associated with different carcass portions (as illustrated with beef in Figure 2).

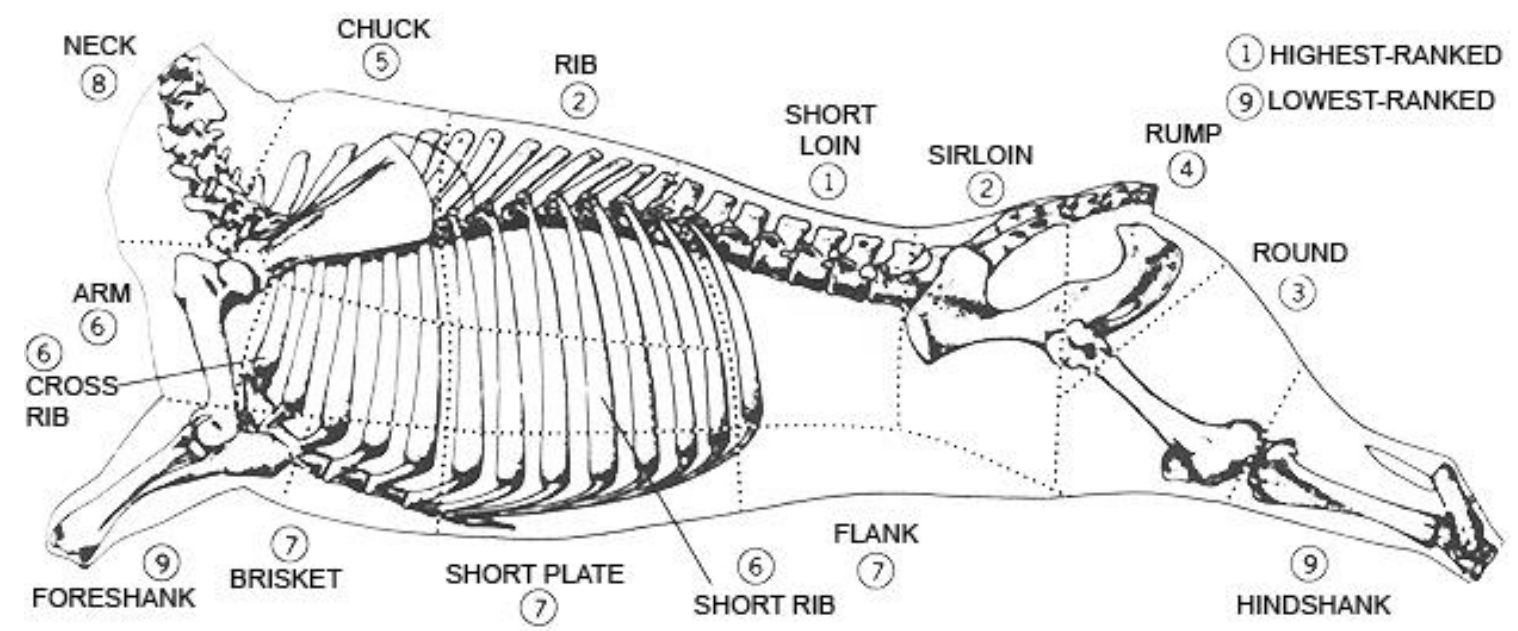

Figure 2. Example of Late Nineteenth-Century Beef Meat Ranking. Epiphyseal portions (inexpensive; poorly-ranked) not included. Adapted from Schulz and Gust (1983:48). 
Meat rankings evaluate what the upper-, middle-, and working classes were consuming based on disposable income available for food purchases. Specific cuts of meat are associated with specific faunal elements (e.g., cervical vertebrae with neck brisket). According to the model, the social elite purchased the most expensive cuts, typically tender cuts cooked to order (e.g., short loin, Figure 2). Establishments catering to the middle class would tend to sell mostly easily prepared cuts of moderate cost (e.g., short rib, Figure 2) or cuts with higher, but less tender, meat yields to economize their purchases. Those at the social nadir are expected to use neck and epiphyseal portions with scant meat yields (e.g., neck, Figure 2) in soups and minces (Horton 2014:383-4; Schulz and Gust 1983).

Archaeologists have created rankings for multiple animals, such as pig, chicken (Gallus gallus domesticus), and sheep (Ovis sp.), but most previous historical zooarchaeology studies focus on beef rankings. This is because of cultural expressions about beef and the dominance of cow skeletal remains in archaeofaunal assemblages. Beef was a widespread food in late nineteenth-century diets due to its increased availability with the introduction of refrigerated railroad cars (Hittell 1882:268, cited in Schulz and Gust 1983; Levenstein 2003:21,56). The cultural value for beef is exemplified in the popular Victorian housewives' guide Practical Housekeeping, which noted that beef was "a diet for real workers" (Wilcox and Clow 1883:597). At the same time, however, beef was often so expensive it could only be regularly bought by the social elite, and a single meal featuring beef could cost half the day's wages in 1880 (Anderson 
2015:94). The cost of beef in the late $19^{\text {th }}$ century gradually declined, driven down by increased accessibility and advances in refrigeration. Its reduced cost influenced its prevalence in diets (Hittell 1882:268, cited in Schulz and Gust 1983). However, beef was still sometimes considered a higher-class food than pork, and there is some evidence that pork was consumed by the middle and working classes in higher quantities than beef (McIntosh 1995:93; Williams 1985:100). In any case, the popularity of beef across class lines resulted in active and regular advertising, making it an ideal species to base a ranking off of because of abundant historical pricing information.

Fishes played an important role in historical coastal and riverine communities, and some archaeologists in the United States have investigated the relationship between fish consumption and class in ways similar to that of beef consumption and class. Singer (1987) created a three-tiered fish ranking for fishes of the northeastern North America, dating from 1832 to 1887 . He divided select fishes from the east coast into three categories based on his archival research: high-priced fishes, middle-priced fishes, and low-priced fishes.

Historical documentation of fishes from overseas markets can also offer limited comparison to markets in the United States. For example, Isabella Beeton (1861:300) recorded the British per-pound market prices for 45 fishes in her tome for the proper household and kitchen management for English women in the 1800s. Beyond recording the average prices of those fishes, she also wrote extensively about their preparation and consumption. 
There are differing opinions on how working- and middle-class Euroamerican families spent money on their food, and on whether meat rankings are a valid proxy for consumer choice and socioeconomic status. Some archaeologists have suggested other methods provide a more accurate representation of socioeconomic status than meat rankings do, such as species richness and abundance, ceramics ranked by price, and edible meat yield per market cut (Lyman 1987b; Schmitt and Zeier 1993).

However, these criticisms are predicated on the idea that the rankings are simply factual statements that link meat cuts with class. Such criticisms are reduced when researchers are clear about the logic and role of meat rankings in their research. Meat rankings provide a record of monetary value for foodstuffs in a consumer market, and indicate how income was spent regardless of class. To use faunal remains organized in a meat ranking to establish socioeconomic class is to assume that elite households only purchase expensive foods; middle-class households only purchase mid-priced foods; and working-class households only purchase the cheapest foods available. This is not necessarily the case: Van der Veen (2003) stated that when lower-class families were able to ascend the social ladder to any substantial degree, rather than purchasing higher quality foods, they would continue to buy the same low-quality foods, but in higher quantities. Praetzellis and Praetzellis (2004:83) posited that eating higher quality food that surpassed one's economic means fit into the Victorian ideal of conspicuous consumerism. While social status could be reflected in food choice, the abundance or lack of certain foods can often lead to only general consensus (Schmitt and Zeier 1993; Singer 1987; Klippel and Sichler 2004). 
Historical archaeologists and sociologists have also made valuable observations about the interplay between consumer choice and identity (Cook et al. 1996; McGuire and Wurst 2002; Mullins 2011; Praetzellis and Praetzellis 2001; Wurst and Fitts 1999; Wurst and McGuire 1999; Wurst 1999; Zukin and Maguire 2004). Consumer choice is embedded in social processes, and not purely a factor of them (Wurst and McGuire 1999:193). While consumers find ways to violate their social roles, they do so within a system defined by those roles. At a basic level, consumer choice has been portrayed as capitalism on a universal scale, where all consumer choices and ability to consume are equal. Further, focusing solely on consumer choice obscures the ramifications of those choices on the individual and the community, often by assuming a dichotomous split between production and consumption (Wurst and McGuire 1999:194).

Discussions of consumer choice, and the use of ranked faunas and artifacts in particular, do not always address these complexities. My study is not strictly connected to a divide between production and consumption, as fishes can be acquired both as consumer purchases, and outside of consumer markets. Capitalism and choice are neither universal nor equal in fish acquisition. I rely on two arguments: First, consumer choice and class are best viewed as how a community rejects, accepts, manipulates, and alters the prevalent social ideology, and that both consumer choice and class operate at more than one level of abstraction (Wurst and Fitts 1999; Wurst 1999). Second, consumer choice is an imperfect model where consumers can express some agency, but not equally so. The products in a market economy assume new meanings based on local and national structural processes, and these meanings are not evenly applied to every consumer 
(Mullins 2011). My work also acknowledges the inequalities inherent in consumption, and the empowered interests that promote consumption of some goods over others. While I do not address the role of canneries in food fish production and consumption, clearly the fish canning industry played a major role in both the systemic and structural interactions of the Pacific Northwest fish markets.

A final concern is that many studies identifying consumer behavior through faunal assemblage patterns both do not identify the variables that affect meat availability and consumer decisions; and they lack consistent units of measurement between studies (Huelsbeck 1991). This problem is addressed when researchers are clear about their methods and assumptions, and is not a problem inherent to the use of meat rankings.

Ultimately, zooarchaeological assemblages situated in historical price-based meat rankings provide an independent record of food cost. That record may not always reflect archaeologists' expectations for what should be present in an assemblage based on archival records of class or income. However, these differences do not invalidate the usefulness of meat rankings in understanding consumer choice. Avoiding circularity wherein household class indicates that a cut of meat should be in the assemblage, and if found, that cut of meat then expresses household class - is perhaps best achieved when the archaeologist is clear about what they are testing and which tools they are using. Meat rankings are one set of independent measures of consumer choice within a market economy. When used properly, they provide independent means of testing our assumptions about historical human behaviors and the archaeological record. 


\section{Criteria for Butchery Analysis in Zooarchaeology}

In some highly socially-stratified societies in urban settings, the presence of professionally-butchered domesticated animals and home-butchered wild animals can be assigned to either the upper or lower classes. In urbanizing and industrial areas, upperclass households generally acquired wild animals through leisure hunting or fishing, as well as eating more imported or exotic species (e.g., Huelsbeck 1991; Rothschild 1989). Working classes, and particularly the poor, had reduced access in cities both to a greater variety and quantity of meat than was available to other classes. Assemblages associated with the working class should have both fewer remains and fewer types of faunas than higher classes as a result. The middle class was moderated between the two poles (Huelsbeck 1991:24; Rothschild 1989:92-93). Butchery marks can be a strong indicator of how the faunas were processed, which can be linked to market purchases or personally-caught fishes.

Market-bought animals from the Victorian era have specific characteristics that often distinguish them in archaeological assemblages from those butchered at home. Market cuts tend to have a consistent pattern of butchery location on skeletal elements. While the exact location and angle of the butchery marks may vary between cows, a rump roast will involve the same portion of the cow and be butchered consistently each time. Faunas butchered at the household level were subjected to the butcher's level of skill and knowledge about where and how to best cut and portion that fauna (see Willis et al. 2008; Willis 2014; Willis and Boehm 2014, 2015). 
Professional butchery marks are commonly used in protocols for sorting elements into meat rankings. Particular cut points on a bone will link that bone to a particular cut of ranked meat. Appropriate identification of meat cuts is necessary to sort a faunal assemblage by a ranking system. The characteristics and placement of butchery marks are often the visible hallmarks of specific historical meat cuts, and whether those cuts were professionally produced (Huelsbeck 1991:23). From here, archaeologists can infer patterns in consumer behavior, as represented by the types and associated values of any meat cuts represented in the archaeological record.

Fishes caught by household members and purchased in a market may be differentiated in several ways, and should be visible archaeologically (Table 1). The recovery of scales, skeletal representation, and location of butchery marks can indicate whether the fish was purchased whole or as a portion; caught and prepared whole; or caught and prepared as portions. For example, purchased fishes have typically already been cleaned, thus few or no scales will be deposited (Singer 1982a). If there are no notable butchery marks and most or all skeletal elements are present, the archaeologist may infer the fauna was caught and minimally processed or prepared whole.

Butchery marks have been little studied in fishes. This is due in part to the differences in both size and structural property between mammal and fish bones. Fish elements are generally less robust than mammal elements, and there is much more variation in structural properties across fishes than mammals. The difficulty in recognizing cut fish bone is clearly reflected in archaeological studies, where cut marks 
Table 1. Archaeological signatures for fish acquisition.

\begin{tabular}{|c|c|c|}
\hline $\begin{array}{l}\text { Historical Human } \\
\text { Behavior }\end{array}$ & $\begin{array}{l}\text { Archaeological and Archival } \\
\text { Signature(s) }\end{array}$ & Citation \\
\hline \multirow[t]{6}{*}{ Household fishing } & Scales present & Singer (1987) \\
\hline & Crania present & Singer (1987) \\
\hline & Variable/novice butchery ${ }^{1}$ & Willis (2015) \\
\hline & $\begin{array}{l}\text { Fishing equipment in artifact } \\
\text { assemblage }\end{array}$ & premise, this study \\
\hline & Absent in newspaper advertising & premise, this study \\
\hline & Illegal to purchase in markets & premise, this study \\
\hline \multirow[t]{4}{*}{ Market purchase } & Uniform butchery marks & Willis (2015) \\
\hline & High frequency of vertebrae & Singer (1987) \\
\hline & $\begin{array}{l}\text { Fish species not easily accessible to } \\
\text { non-commercial vessels (e.g., from } \\
\text { offshore fisheries) }\end{array}$ & premise, this study \\
\hline & Present in market advertisements & premise, this study \\
\hline $\begin{array}{l}\text { Market purchase } \\
\text { (steaks) }\end{array}$ & Butchered vertebrae of larger fishes & Horton (2014), Singer (1987) \\
\hline
\end{tabular}

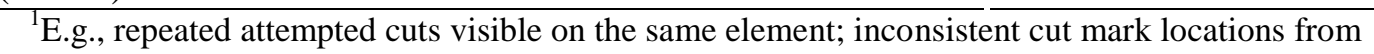
specimen to specimen.

are regularly reported on bird and especially mammal bones (e.g., Colley 1990:216-217;

DeFrance 2005; Domínguez-Rodrigo and Yravedra 2009; Lyman 1987a, 1994:439;

Steadman et al. 2002; Willis 2014:17), but fish bone cut marks are rarely noted (e.g., Archer and Braun 2013; Butler 1990; Colley 1990:216-217; Lyman 1994:439; Willis 2014:21; Willis et al. 2008). Recent work by Willis and her colleagues (2014) suggests that butchering fishes can result in abundant cut marks. Cut marks on fish bones tend to be small and shallow (Archer et al. 2014; Willis et al. 2008), and appear more frequently on vertebrae, ribs, and pterygiophores (Willis 2014). However, as fish ribs can typically only be identified at level of order at best, they do not receive much scrutiny from faunal analysts (Willis 2014:27-29). 


\section{$\underline{\text { Privies as a Data Source }}$}

Outhouses were an essential household structure prior to indoor plumbing. Beyond being used as a receptacle for human waste, privies were the main place for household trash disposal prior to the development of municipal trash pickup. Unwanted household trash, food remains, and contraband were deposited in privies (Rose et al. 2007; Schablitsky 2002). The widespread use of privies as disposal areas for trash makes them important for historical data around the globe (e.g., Brown and Bowen 1998; Ciolek-Torrello et al. 1997; Crist 2005; Dalglish 2008; Geismar 1993:58; Jones 1997; Koloski-Ostrow 2015; Rose et al. 2007; Schablitsky 2002; Starr 2001; Stottman 2000). Household refuse and other materials were deposited into privies in two main ways: day-to-day and clean-out events (Wheeler 2000). Most food refuse was deposited in day-to-day events alongside broken household objects like toys and bottles. Day-today deposits of faunal remains provide specific dietary information on the households or groups using a particular privy (Brown and Bowen 1998). Clean-out events typically marked a tenancy change or the need to backfill a privy, and resulted in mass discard of accumulated household objects, like multiple pairs of shoes and complete tea sets (Rose et al. 2007; Schablitsky 2002; Wheeler 2000).

Archaeological signatures of consumer choice are often seen in privy stratigraphy and recovered faunal remains. Day-to-day deposits, clean-out events, and layers of ash and lime deposited to mitigate scent in privies can result in well-stratified deposits. Stratigraphy can often be connected to tenancy periods or specific families, where recovered faunal remains then reflect day-to-day consumer habits and socioeconomic 
status (Ciolek-Torrello et al. 1997; Crane 2000; Crist 2005; Huelsbeck 1991:21; Pena and Denmon 2000). Different socioeconomic class purchasing values can be visible in faunal assemblages (Schulz and Gust 1983). For example, by using an economic meat rank model, class may be connected to element abundance, where a higher percentage of vertebrae suggests more costly steaks (Gibson et al. 2001; Singer 1982a; Schulz 1997). Privies also have ideal preservation regarding two of the primary post-depositional processes that destroy faunal remains: trampling, and animals gnawing on bone. Because privy soil was undesirable for walking on, or retrieving food from, faunal remains have a better chance of remaining intact and presenting signatures of human behavior.

Privies were constructed and used in different ways depending on the class of the users. Middle- and upper-class families often had a privy designated for their use only. When a vault in a large upper- or middle-class yard had been filled, its users capped it with gravel or soil, and then often ash, before constructing a new privy nearby. Moving privy locations like this was an option only available to larger lots with enough excess space. Privies with undisrupted stratigraphy like this provide archaeologists with a relatively complete picture of household activities and purchasing habits, particularly when archival information can evidence the occupational history of the privy's primary users, and intact stratigraphy is coupled with a large assemblage of diagnostic artifacts.

However, stratigraphy in privies cannot always reliably be used to define tenancy periods or discrete households. Multiple $19^{\text {th }}$-century families and boarders sometimes shared a single outhouse in working- and middle-class neighborhoods, with the outhouse placed between several houses (Roulette et al. 2014; Wheeler 2000). In instances where 
one privy was shared between multiple tenants and boarders, assemblages may be mixed and reflect the community's purchasing habits rather than one family's habits. In neighborhoods with a low occupancy period and highly mobile families, strata may not be distinct enough to reflect one family's consumer choices prior to another family moving in. For example, in smaller lots lacking the space to construct new privies, residents might opt to periodically remove fill from privy vaults to allow reuse of space at the same vault location. Shoveling out or otherwise removing a large volume of the deposit substantially disrupted the original stratigraphy and resulted in mixed artifact assemblages (Crane 2000).

In Vancouver and Portland, privies were used regularly into the early 1900s, and sparingly into the 1930s. The first sewer lines were constructed in the City of Vancouver in 1890, and the following year an ordinance was passed instructing all residents to connect privies to the sewer line when they were within 100 feet of it (Clark County Historical Museum, Anonymous 2013:8); by the 1920s, most households had gradually complied with this rule. The decline of privy usage is one of the primary factors determining the time frame of my project (1880-1910).

\section{The Esther Short Neighborhood (Sites 45CL646 \& 45CL582)}

What is commonly referred to as the Esther Short neighborhood is located in downtown Vancouver, Washington (Figure 1). The city of Vancouver developed around Fort Vancouver and the Pacific Northwest fur trade in the early- to mid- $19^{\text {th }}$ century, and the Fort's transition from the Hudson's Bay Company to the U.S. Army. The faunal 
assemblages used in this study came from one original neighborhood that has been divided into two separate archaeological sites (45CL646 and 45CL582). The assemblages from these sites are derived from two archaeological projects, but were excavated by the same company (Applied Archaeological Research, Inc. [AAR]) with similar protocols. Because the site boundaries represent an arbitrary distinction, hereafter the assemblages from 45CL646 and 45CL582 are treated together.

Between 1999 and 2005, AAR and Archaeological and Historical Services (AHS) investigated and excavated six blocks of the Esther Short neighborhood as part of the Vancouver Convention Center and Columbian Campus expansion projects. Over 140 features were recorded, of which 32 were fully hand-excavated. Features were excavated in arbitrary 5" to $12 "$ levels, conforming to stratigraphy where possible. Excavated materials were screened through $1 / 4$ " mesh. Bulk samples were collected from some features to facilitate collection in $1 / 8$ " or finer mesh screens. Privies were the dominant excavated feature type $(n=27)$ and were given preference in excavation because they were generally undisturbed and contained a higher percentage of complete artifacts than were present in other features.

The fill in excavated features was largely reflective of one of several depositional processes: primary household deposits as day-to-day and clean-out events; mixtures of primary mineral soil deposits and household debris; mixtures of primary mineral soil deposits and yard midden debris; structural debris; ash deposits; and clean fill (Roulette 2014a; Table 2). 
Table 2. Excavated features with fish faunal remains from the Esther Short neighborhood.

\begin{tabular}{|c|c|c|c|c|}
\hline Fea. & Location & Feature Type & Dates of Use ${ }^{1}$ & $\begin{array}{l}\text { Primary Deposit } \\
\text { Type }\end{array}$ \\
\hline 3 & 440 West $5^{\text {th }}$ St. & Privy (brick-lined) & Late $19^{\text {th }}$ c. -1916 & Unknown \\
\hline 4 & 440 West $5^{\text {th }}$ St. & Cesspool (brick-lined) & 1908 - ca. 1930 & Unknown \\
\hline 12 & 416 West $4^{\text {th }}$ St. & Privy (wood-lined) & $1890 s-1918$ & $\begin{array}{l}\text { Clean-out \& day- } \\
\text { to-day }\end{array}$ \\
\hline 13 & 404 West $4^{\text {th }}$ St. & Privy (wood-lined) & $1890 s-1906$ & $\begin{array}{l}\text { Clean-out \& day- } \\
\text { to-day }\end{array}$ \\
\hline $15 B$ & 308 West $5^{\text {th }}$ St. & Burn Pit (wood-lined) & ca. $1890-1910$ & $\begin{array}{l}\text { Unk. (6 deposit } \\
\text { episodes) }\end{array}$ \\
\hline 21 & 502 West $5^{\text {th }}$ St. & Cesspool (brick-lined) & $1870 \mathrm{~s}$ & $\begin{array}{l}\text { Unk. (2 deposit } \\
\text { episodes) }\end{array}$ \\
\hline 28 & 501 West $5^{\text {th }}$ St. & Privy (wood-lined) & $1880 s-1916$ & $\begin{array}{l}\text { Clean-out \& day- } \\
\text { to-day }\end{array}$ \\
\hline 31 & 501 West $5^{\text {th }}$ St. & Privy & 1880 & Clean-out \\
\hline 35 & 505 West $5^{\text {th }}$ St. & Trash & 190 & Unknown \\
\hline 40 & 405 West $5^{\text {th }}$ St. & Privy (wood-lined) & $1882-1930 \mathrm{~s}$ & Unknown \\
\hline 42 & 400 West $4^{\text {th }}$ St. & Privy (wood-lined) & Late $19^{\text {th }}$ c. $-1930 \mathrm{~s}$ & Unknown \\
\hline 46 & 405 West $5^{\text {th }}$ St. & Trash Sc & & Unknown \\
\hline 63 & 415 West $5^{\text {th }}$ St. & $\begin{array}{l}\text { Privy (wood- and } \\
\text { brick-lined) }\end{array}$ & a. 1929 & Unknown \\
\hline 66 & 507 Franklin St. & Privy (wood-lined) & 1890 & Unknown \\
\hline 67 & 515 Franklin St. & Privy (wood-lined) & Late $19^{\text {th }}$ c. - & $\begin{array}{l}\text { Clean-out \& day- } \\
\text { to-day }\end{array}$ \\
\hline & 507 Franklin St. & ined) & $1880 \mathrm{~s}-1930$ & Clean-out \\
\hline
\end{tabular}

${ }^{\mathrm{T}}$ As determined by diagnostic artifacts from the listed feature, archival records of associated households, and diagnostic artifacts from other features likely associated with the feature given above, if other information is lacking. Dates are estimated. While some feature usage dates into the mid $20^{\text {th }}$ century, the majority of usage dates to ca. 1880s-1910s.

Artifacts from privies show the Esther Short neighborhood was rooted in Victorian ideals at the end of the $19^{\text {th }}$ century (see Roulette et al. 2014 for historical context). Household purchases often reflected conspicuous consumerism in some areas (e.g., ownership of automobiles and formal clothing) and thrifty behavior in others (e.g., evidence of in-house repairs of household items; ownership of more plain tea sets than embellished). Families often purchased goods that emulated fashionable clothing, but were constructed from less expensive materials. Both genteel and non-genteel behaviors 
were apparent in artifact assemblages, through tea sets and alcohol bottles. Residents participated in leisure activities like fishing, hunting, and driving (Roulette and White 2005; Roulette et al. 2014; White et al. 2004).

AAR archaeologist Krey Easton inventoried the faunal remains recovered from both projects, recording 20,495 faunal specimens. Of these, Easton identified 1,275 as fish remains (see Chapter 4 for more background on faunal remains). My study focuses on privies and other features with fish remains, which were recovered from 16 of the 32 fully-excavated features (Table 2). Eleven of the fish-bearing features were privies.

The gradual reduction in privy usage through the early third of the $20^{\text {th }}$ century is reflected in the diagnostic artifact assemblages from the Esther Short neighborhood. The artifact terminus post quem (TPQ; the earliest date of manufacture) and terminus ante quem (TAQ, the terminal manufacturing date) show feature use from the 1870 s to 1930. However, artifacts reflected most use from 1880 to 1910 (Roulette et al. 2014), which dictated the main period of my market analysis of fish sales (1880 to 1910).

\section{Archival Research on Household Occupancy}

Archival research carried out by Scott McAleer and staff at AAR provided context for the Esther Short neighborhood in the late $19^{\text {th }}$ and early $20^{\text {th }}$ centuries, particularly for household occupancy records and the economic background of the neighborhood. McAleer and AAR staff used the U. S. Census (recorded every 10 years, beginning in 1900) and the Vancouver City Directories (published annually by the R.L. Polk Company beginning in 1900) as their primary historical sources on lot tenancy. 
They gathered additional biographical data on household occupants from a genealogy of Clark County's citizens (Harshman 1989, 1993); secondary histories (e.g., Alley et al. 1885; Ficken and LeWarne 1989; Van Arsdol 1986); and obituaries and other primary accounts from local newspapers such as The Columbian, when available (McAleer 2005; Roulette 2014b). Maps produced by the Sanborn Map and Publishing Company were used to chart how the houselots and structures on each lot changed over time, beginning with maps dating to 1890 (McAleer 2005; Roulette 2014b). None of the available sources could create a comprehensive reconstruction of household occupancy, and gaps remain in the constructed residential histories for each houselot included in excavations.

McAleer and Roulette documented occupancy patterns for at least 46 tenancy periods within the project areas. Only some occupancy information could be established prior to the 1890s, but trends in residency could still be created from the available information. Household occupancy across all blocks was marked by a general transience amongst the known residents. Between 1880 and 1910, all recorded residents were white. The common length of recorded occupation was two or fewer years, and many houselots had four or more families recorded as residents within a one-year period. Multiple families often lived together and took on boarders. The highest number of documented residents in a household was 10. Some residents were recorded as first-generation immigrants to the United States. By 1910, approximately $11 \%$ of the neighborhood population were first-generation immigrants, while as many as $40 \%$ of the occupants were born in Washington State. Most neighborhood inhabitants had ancestry in Western Europe (England, Germany, Denmark, Finland, or Ireland) or Canada, and several people 
with ancestry in Romania or Hungary. The only recorded religious affiliation was that of one resident co-founding a Lutheran church (Appendix A). The gender ratio was generally evenly split between women and men. Children were documented in multiple households. The variety of ethnicities recorded in archival sources, and the dearth of religious information for neighborhood occupants, makes it difficult to connect fish use to specific ethnic or religious cultural patterns. The high occupancy turnover in the Esther Short neighborhood is emblematic of many neighborhoods in the late $19^{\text {th }}$ and early $20^{\text {th }}$ centuries. Expanding railroads and industrial production brought a large influx of immigrants to the West Coast, which in turn led to rapid demographics changes.

The Esther Short neighborhood residents had diverse occupations: unskilled laborers (e.g., laundress), skilled laborers (e.g., sawmill laborer), and professionals (e.g., engineer). However, overall recorded residents were unskilled or skilled laborers, employed in industrial or service-oriented positions (McAleer 2005). Due to the incomplete nature of early census and other records, socioeconomic status can only be roughly estimated from tenant occupations. No single year has enough information to establish the economic standing of any complete city block included in excavations. Despite the range of occupations, archival records generally indicate a working- to middle-class setting. The artifact assemblages are overwhelmingly indicative of projected low- to middle-class purchasing habits as well, providing independent evidence of the class setting (Roulette and White 2005; Roulette et al. 2014; White et al. 2004). A summary of available tenant histories for properties associated with fish-bearing features can be found in Appendix A. 
Ultimately, I do not connect privy usage to specific tenants. The high turnover rate within households, the potential for shared trash refuse areas and privy usage, and the characteristics of the privy deposits excavated in the Esther Short neighborhood make it difficult to link any one strata within a feature - or any one feature at all - to any specific family or year of occupation. 


\section{Chapter 3: Archival Research Methods, Materials, and Results}

My archival research was focused on developing an economic model of fish rank that I could then assign Linnaean taxa to and use to interpret fish remains from historical archaeological sites. My goal was to develop a relative ranking that showed the estimated market value of fishes between 1880 and 1910. Archival research of historical newspapers and other documents is useful for creating a relative model of fish rank reflecting several decades of fish pricing trends. Because the archaeological deposits in my study span this time period, I needed a market ranking appropriate to these decades. Archival research involved several steps. First, I determined which fishes were available in Portland and Vancouver area markets, and thus likely candidates to appear in an archaeological assemblage. I accomplished this through two newspaper searches, one systematic and the other qualitative. Once I had a list of available fresh market fishes, I collected pricing information for each fresh fish type, preferably in a standardized unit of per-pound pricing. I attached Linnaean taxonomic names to the fish names listed in market advertisements so archaeological fish remains could be associated with ranked market fishes. This process also allowed me to combine multiple market listings into one Linnaean name, providing me with a larger sample size of prices for that fish taxa. I then established whether the prices for each individual Linnaean-associated market fish consistently maintained its economic rank in position to other fishes for the 30 -year period. If some fish prices shifted dramatically while others did not, I examined why those shifts occurred. I then decided which market-listed fishes had sufficient listings to generate a robust cost estimate. 


\section{Systematic Archival Sampling}

I developed a fish rank using systematic searches of newspapers dating to between 1880 and 1910. I considered Portland-area and Vancouver-area newspapers for my archival research. I focused on Portland newspapers, especially The Oregonian (TO), because a continuous run of newspapers for 1880 to 1910 was available in digital form. I compiled and analyzed information from newspaper searches to establish relative price per pound for a variety of fishes available in Portland and Vancouver markets. All issues published between 1880 and 1910 were available digitally either on America's Historical Newspapers or Chronicling America. Both databases employ algorithms that allow users to search for key terms; to limit searches to specific newspapers and cities; and to search within specific days, dates, months, and years. Because America's Historical Newspapers had more available issues, I used it for all searches of The Oregonian. For my qualitative analysis (see below), I used additional papers, which - because of incomplete series - did not allow for a consistent review of fish availability, sales, or purchasing.

I developed a set of 24 search terms to use in searching digitized papers. These terms located fish pricing information based on locally available fishes. I read the ads and articles returned by the algorithm to find any fresh fish prices. I occasionally came across a new fish term in historical papers. When I encountered a new relevant term I had not yet incorporated into my searches, I added it and re-examined previously searched issues for any instances of the newly-added term. Altogether, the targeted search of The Oregonian included the following key search terms: fish, sturgeon, cod, halibut, salmon, eulachon, smelt, shad, carp, catfish, sardine, eel, herring, mackerel, trout, perch, roe, 
chinook, sole, sockeye, steelhead, bass, crappie, and flounder. I initially included the search terms market, price, pound, lb., cost, and cents, but these generated a large number of irrelevant listings (e.g., advertisements for a lowered price for fabrics) so I dropped these search terms. Sometimes a single fish was referenced ten or more times in an article (as with "salmon", for full-page spreads discussing the most recent salmon pack). Because of this I did not track individual fish references within an article for each colloquially-named fish. Instead I noted the first instance of any fish in an article. In developing a sampling strategy, I needed to consider project need (a rank of fish value for the 30-year period) against time constraints. I reasoned that I needed to sample several times in a given year, as fish supply would likely affect cost, and fish abundance varies seasonally. I wanted to obtain samples from multiple years between 1880 and 1910. I sampled one year from each decade of the time period - 1880, 1890, 1900 , and 1910 - and then one month from each season of the selected year. The months I searched were January, April, July, and October. Thus, using the 24 search terms, I searched papers for 492 days. The newspaper dates with positive results are included in Appendix B.

Additionally, I read every Wednesday and Friday issue in its entirety from the four target months in 1880,1890,1900, and 1910, regardless of the results returned in algorithm searches. Doing so ensured that I was not missing any key search terms that should be included, and verified that the algorithms were properly identifying all relevant ads and articles. I found very few instances of information that had not already been identified in my broader systematic search, and no new search terms. I selected 
Wednesday because my initial algorithm searches returned slightly higher results for Wednesday papers. I chose Friday to test for any increase in advertisements connected to the Catholic tradition of "Fish Fridays". Though observance of "Fish Fridays" was not universal in Christian faith, some Portland and Vancouver advertising may have targeted those who did. Using this method, I read 142 newspaper issues in their entirety.

\section{Qualitative Archival Sampling}

I collected additional data in a more qualitative fashion through studying regional papers, and general fish-related information not connected to pricing per se, that was returned in systematic searches. I used the same 24 search terms to conduct a general fish pricing search across newspapers in Washington and Oregon. This search included all months and days between 1880 and 1910. I also recorded fish-related data from The Oregonian both that was returned in systematic searches using the 24 search terms, but that was not pricing-related (e.g., Figure 3); and fish data (pricing and otherwise) that was identified in all months and years between 1880 and 1910. Twelve newspapers in Washington and Oregon returned positive results in my qualitative regional search (Appendix B).

General fish-related data I collected from all newspapers covered a variety of topics (Table 3). I recorded restaurant prices for cooked fishes because restaurant prices featured heavily in the creation of Schulz and Gust's (1983) beef ranking; information from canneries (which could indicate overall market fluctuations); other fish sales (such as those that listed fishes without pricing information [Figure 3], canned fishes, or salted 
fishes); data on natural conditions (e.g., fish abundance); and miscellaneous information that indicated societal views on catching and preparing fishes (e.g., recipes, accounts of fishing expeditions, costs of fishing equipment, and fishing regulations). For example, I used fishing regulations to assess whether a fish in the archaeological record was legal to sell in markets, or if it could only be caught individually and not professionally sold (as was the case with trout in the early 1900s). Altogether, this additional context helped me interpret certain shifts in fish pricing. For example, articles on the 1890s economic depression and its effects on the fishing industry helped explain the relative absence of any fish pricing in that year. Because the content in qualitative searches varied so greatly, I have not included a synthesis of it here.

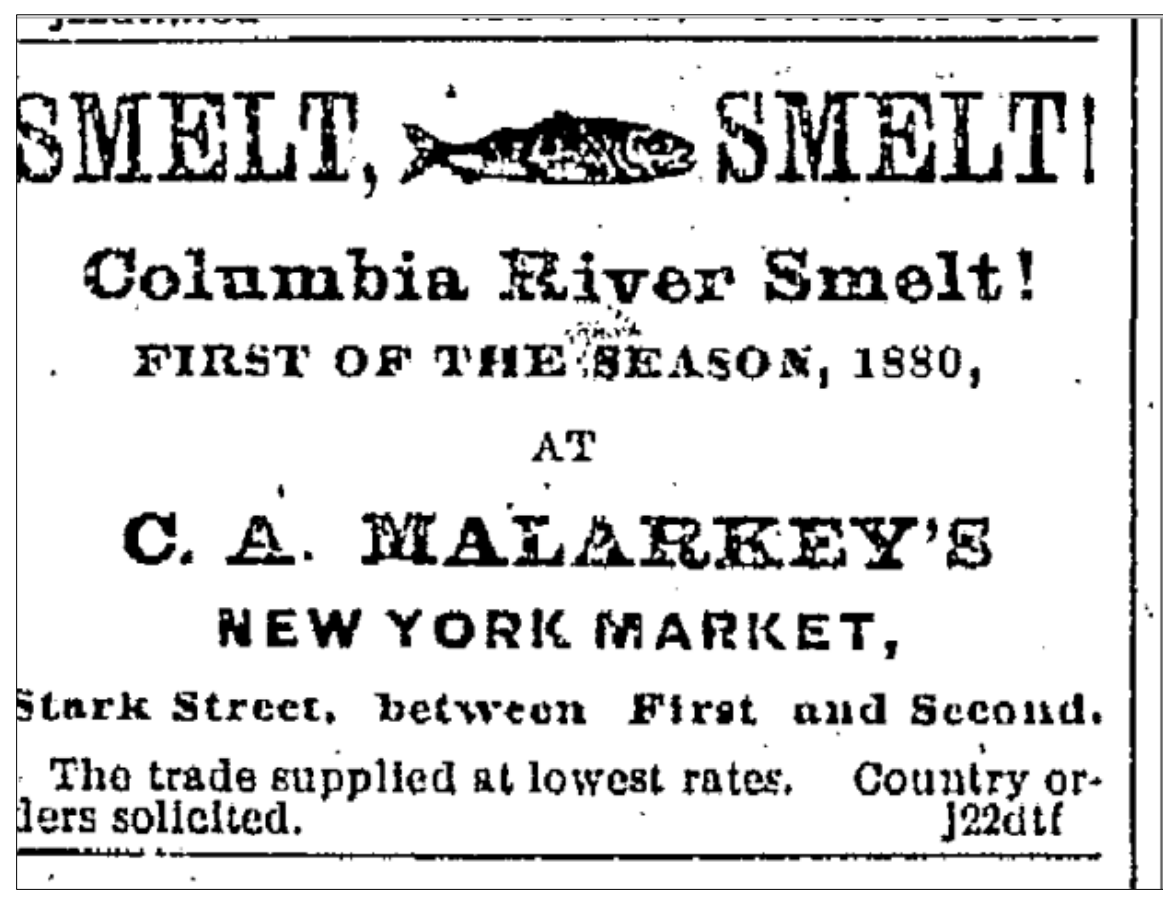

Figure 3. Example of advertisement for market fishes without pricing information (TO, Jan. 22, 1880). 
Table 3. Types of systematic and qualitative fish records, 1880-1910.

\begin{tabular}{|c|c|c|c|}
\hline Record Type & Summary & Format Type & $\begin{array}{r}\text { N. of } \\
\text { Sources } \\
\end{array}$ \\
\hline \multirow{6}{*}{$\begin{array}{l}\text { Fresh Fish } \\
\text { Prices } \\
\text { (Systematic) }\end{array}$} & \multirow{6}{*}{$\begin{array}{l}\text { Primary information used to develop an economic model } \\
\text { of fish rank (shown through market prices for raw fish, } \\
\text { typically listed per pound, and occasionally per } \\
\text { individual whole fish). }\end{array}$} & Total & 132 \\
\hline & & Advertisement & 29 \\
\hline & & Article & 68 \\
\hline & & Fiction (Story) & 2 \\
\hline & & Market Report & 32 \\
\hline & & $\begin{array}{l}\text { Shipping } \\
\text { Report }\end{array}$ & 1 \\
\hline \multirow{3}{*}{$\begin{array}{l}\text { Fish Ads, No } \\
\text { Prices } \\
\text { (Qualitative) }\end{array}$} & \multirow{3}{*}{$\begin{array}{l}\text { Fishes available for purchase, but shown only as } \\
\text { present/absent and without pricing provided (e.g., Figure } \\
\text { 3). }\end{array}$} & Total & 40 \\
\hline & & Advertisement & 38 \\
\hline & & Article & 2 \\
\hline \multirow{5}{*}{$\begin{array}{l}\text { Other Fish } \\
\text { Sales } \\
\text { (Qualitative) }\end{array}$} & \multirow{5}{*}{$\begin{array}{l}\text { Prices for other non-fresh fishes available outside of a } \\
\text { restaurant setting, indicating general availability and } \\
\text { prevalence of multiple fish types (shown in advertised } \\
\text { market prices, such as for kippered fish, bloater herring, } \\
\text { and dried fish). }\end{array}$} & Total & 30 \\
\hline & & Advertisement & 8 \\
\hline & & Article & 16 \\
\hline & & Market Report & 1 \\
\hline & & $\begin{array}{l}\text { Produce } \\
\text { Receipt }\end{array}$ & 5 \\
\hline \multirow{4}{*}{$\begin{array}{l}\text { Cannery } \\
\text { Information } \\
\text { (Qualitative) }\end{array}$} & \multirow{4}{*}{$\begin{array}{l}\text { Broader fishing industry trends than were visible } \\
\text { through only fresh fish records, such as recession } \\
\text { information (e.g., prices paid to fishermen per fish; } \\
\text { information about fishing industry strikes; lbs. in yearly } \\
\text { cold pack; changes in canned fish prices). }\end{array}$} & Total & 131 \\
\hline & & Advertisement & 14 \\
\hline & & Article & 24 \\
\hline & & Market Report & 93 \\
\hline \multirow{3}{*}{$\begin{array}{l}\text { Preparation } \\
\text { (Qualitative) }\end{array}$} & \multirow{3}{*}{$\begin{array}{l}\text { Both in restaurants and in households. Provided a } \\
\text { qualitative evaluation of which fishes people were } \\
\text { encouraged to buy (e.g., market advertisements with } \\
\text { preparation recommendations). }\end{array}$} & Total & 64 \\
\hline & & Advertisement & 39 \\
\hline & & Article & 25 \\
\hline \multirow{3}{*}{$\begin{array}{l}\text { Regulations } \\
\text { (Qualitative) }\end{array}$} & \multirow{3}{*}{$\begin{array}{l}\text { Which fishes were legal to catch or sell during particular } \\
\text { seasons or years, and thus whether archaeological faunas } \\
\text { were likely bought, or caught by household members } \\
\text { (e.g., fishing season dates; catch limits; fishes illegal to } \\
\text { catch or sell). }\end{array}$} & Total & 46 \\
\hline & & Advertisement & 2 \\
\hline & & Article & 44 \\
\hline \multirow{3}{*}{$\begin{array}{l}\text { Nature } \\
\text { (Qualitative) }\end{array}$} & \multirow{3}{*}{$\begin{array}{l}\text { Seasonal effects on fish populations and general } \\
\text { environments for successful fish propagation, which } \\
\text { affected fish availability (fish observations as related to } \\
\text { natural environment). }\end{array}$} & Total & 93 \\
\hline & & Article & 92 \\
\hline & & $\begin{array}{l}\text { Produce } \\
\text { Receipt }\end{array}$ & 1 \\
\hline \multirow{4}{*}{$\begin{array}{l}\text { Miscellaneous } \\
\text { (Qualitative) }\end{array}$} & \multirow{4}{*}{$\begin{array}{l}\text { Other observations on public perception of fishes, } \\
\text { providing qualitative data on how Victorian-era people } \\
\text { in the Pacific Northwest generally viewed fishes and fish } \\
\text { consumption (social etiquette in preparing or serving } \\
\text { fish dishes; artistic pieces about fishes; the cost of } \\
\text { fishing equipment). }\end{array}$} & Total & 88 \\
\hline & & Advertisement & 24 \\
\hline & & Article & 61 \\
\hline & & Fiction (Poem) & 3 \\
\hline Grand Total & & & 624 \\
\hline
\end{tabular}

${ }^{1}$ Each individual source may include multiple discrete prices (e.g., a single market advertisement may contain pricing information for five fishes). 


\section{$\underline{\text { Recording Methods for all Search Types }}$}

I recorded a standardized set of information for each positive search result. I organized both systematic and qualitative records into categories so I could more easily interpret the information I encountered (Table 3). For each record, I recorded the newspaper's name; the issue date and season; the date on which I accessed the paper; the category that best matched the fish data (Table 3); a brief description of the information (e.g., "notes start of eulachon run"); whether or not a fish price was listed; and the type of any listed prices (e.g., per pound; per each). Information I recorded specifically for the fish rank included colloquial fish name(s) as recorded in the newspaper, the number of fish prices within the article or ad, the price, the portion cost (when available), and the issue date.

\section{$\underline{\text { Linking Fishes Noted in Archival Records to Linnaean Taxa }}$}

I needed to connect the listings of fishes in archival records to Linnaean taxonomy, so the market fishes could be linked to archaeological fish identifications. Then, identified archaeological fish remains from historic sites within the Pacific Northwest could be compared against the fish rank and other historical records.

If the name of an archival fish matched a commonly accepted fish name used by fishery biologists, I simply matched that name to the Linnaean taxon. About $68 \%$ of the named fishes could be linked to Linnaean taxa in this way (e.g., eulachon with

\section{Thaleichthys pacificus).}

Where a Linnaean taxon could not easily be associated with a listing, I inferred 
the associated taxon based on several factors: the seasonal patterns of each taxa as compared to seasons where the fish was named in papers; the historic abundance of the named taxa; and historic and modern observations regarding fish range and methods of capture. ${ }^{2}$ If I couldn't make a clear association between a colloquial name and a taxon, I labeled the fish as unknown and noted possible taxonomic associations.

There were four common complications that arose in assigning taxonomic identifications to colloquial names. First, the name could refer to more than one species. Second, the name could refer to more than one genus, which could represent two or more western North American species. Third, the colloquial name could refer to more than one family of fishes. Fourth, sometimes different colloquial names could be linked to one Linnaean taxon.

When several Linnaean taxa might be associated with a single colloquial name, I determined which of the possible taxa were most common in the region historically. I looked at whether each of the possible taxa was ever considered to be a food fish, and compared the season in which the colloquially-named fish was referenced to the life cycle of the taxa. One example of this is with sturgeon, which I ultimately associated with white sturgeon (Acipenser transmontanus) and not green sturgeon (A. medirostris). Both archival fishing industry records (Craig and Hacker 1940; MacDonald and Gill 1896) and recent biological studies (Dauble 2009; Farr and Ward 1993; Hart 1973; Wydoski and Whitney 2003) note that white sturgeon is more sought after than green sturgeon as a food fish. Moreover, white sturgeon is much more abundant than green

\footnotetext{
${ }^{2}$ There were still several fishes I could only loosely associate with a taxa, where I was not fully confident in the assignment (such as associating "baby salmon" and steelhead trout).
} 
sturgeon in the Columbia River system, the main source for sturgeon fisheries in the Portland area (Farr and Ward 1993). Similarly, "black bass" is a term for both smallmouth bass (Micropterus dolomieu) and largemouth bass (M. salmoides). While smallmouth bass was introduced in California in 1874, it does not appear to have been present in Oregon or Washington in any substantial numbers until the 1920s (Lampman 1946; La Vigne et al. 2008). Largemouth bass, however, was introduced to the Pacific Northwest by the late 1880s (McGuire 1894:72; Smith 1896). From this I inferred that listings for "black bass" most likely referenced largemouth bass.

I used the same methods to link colloquial names from archival records with Linnaean taxa, when the names could be tied to multiple species or families. For example, "perch" could be Pacific ocean perch (Sebastes alutus); embiotocids like pile perch (Rhacochilus vacca) and walleye surfperch (Hyperprosopon ellipticum); or introduced freshwater fishes from the family Percidae, like yellow perch (Perca flavescens). I suggest that "perch" is most likely Pacific ocean perch (Sebastes alutus) because this species was part of commercial food fishing in the late $19^{\text {th }}$ century, whereas other fishes referred to as "perch" generally were not (Hart 1973:305-310, 397). Additionally, "perch" was a semi-frequent market listing, particularly post-1900. Though introduced perch could be sold in markets, the population of introduced freshwater perch was less likely to consistently support industrial fishing than Pacific ocean perch were.

When multiple colloquial names could be associated with a single Linnaean taxa, I combined all prices for that fish under the single Linnaean name. For example, I identified both "cod" and "true cod" as Pacific cod [Gadus macrocephalus]. I did not 
combine listings that referenced other kinds of cod because there are several species, from different families, that may be connected to market listings for cod. Black cod, for example, does not refer to a fish within family Gadidae at all but instead references sablefish (Anoplopoma fimbria) or other rock fish (Sebastidae) (Nims 2016). By identifying the seasonality, environmental abundance, market availability, and overall yearly yields of fishes, I could usually determine which taxa should be linked to multiple but similar colloquial names.

Linking specific listings of "trout" to a species had additional challenges. I found that newspaper identification of trout was dependent on their relative sizes. Trout was sold - or determined illegal to sell - based on size and not taxa. Newspapers assumed the size to be reflective of the species. Smaller-bodied trout (for example, those with an average length ${ }^{3}$ of around 9 to $11 ”$, or $23-28 \mathrm{~cm}$ [Table 4]) were generally identified in newspapers as introduced taxa, regardless of whether or not they truly were introduced. Trout that were clearly and correctly identified as introduced - for example, Eastern brook trout - were illegal to sell. Steelhead trout - a larger-bodied salmonid than most introduced species - was often identified in newspapers as both a salmon and a trout in the $19^{\text {th }}$ and early $20^{\text {th }}$ centuries; it was also the only fish identified as trout that was exempt from the market sale ban (Table 7). While I did not find any average or maximum lengths for steelhead trout in newspapers, modern biologists have recorded an average fork length of steelhead trout at around 21-29” (or 55-75 cm.) (Gallagher 2003:47, 63), larger than the newspaper-listed average length of "trout" by about 10" (Table 4). Dolly

\footnotetext{
${ }^{3}$ Newspapers never identified whether the given length was fork length or total length.
} 
Table 4. Reported average and maximum weights and lengths of salmonid fishes, 18801910.

\begin{tabular}{|c|c|c|c|c|}
\hline Fish & Average Weight & Maximum Weight & Avg. Length & Max. Length \\
\hline Steelhead trout & $\begin{array}{l}15 \text { lbs. (TO, Apr. } \\
11,1900)\end{array}$ & Unlisted & Unlisted & Unlisted \\
\hline Trout & Unlisted & $\begin{array}{l}8.5 \text { lbs. (TO, Oct. } \\
12,1900)\end{array}$ & $\begin{array}{l}9 \text { to } 11 \text { in. }(T O, \\
\text { April } 27,1900)\end{array}$ & $\begin{array}{l}25 \text { in. }(T O, \\
\text { Apr. } 12,1900)\end{array}$ \\
\hline $\begin{array}{l}\text { Salmon } \\
\text { (generic) }\end{array}$ & $\begin{array}{l}20 \text { lbs. (VI } I^{1}, \text { Jan. } \\
26,1882)\end{array}$ & $\begin{array}{l}50 \text { lbs. (TO, July } \\
22,1880)\end{array}$ & Unlisted & Unlisted \\
\hline $\begin{array}{l}\text { Chinook } \\
\text { salmon }\end{array}$ & $\begin{array}{l}15 \text { lbs. }(T O, \text { Apr. } \\
20,1890)^{2}\end{array}$ & $\begin{array}{l}80 \text { lbs. (TO, Oct. } \\
12,1900)\end{array}$ & Unlisted & $\begin{array}{l}4.5 \text { ft. }(T O, \\
\text { July } 4,1910)\end{array}$ \\
\hline
\end{tabular}

${ }^{1}$ Vancouver Independent.

${ }^{2}$ Average calculated from price paid to fishermen per pound ( $5 \not / \mathrm{lb}$.; recession pricing) and average price paid per fish $(75 \mathrm{c})$.

varden was not local to the area; it was only ever discussed as privately angled, and only around central and northern Washington state.

In choosing to combine multiple market listings or taxa into a single position on my ranking, I also considered the range in pricing. Some market listings could be associated with the same family (such as "trout" and "salmon" both being in family Salmonidae) or the same genus (such as salmon genera in the Pacific Northwest being Oncorhynchus spp.). However, if the pricing for those fishes was very different, my interpretation was that the fishes were considered to be different by the fishing industry, the general public, or both. Where this happened, combining the pricing from multiple fish listings into one ranking position was inappropriate. The prices for colloquiallynamed fishes, once grouped into Linnaean taxa, generally did not vary by more than 5 $ф / \mathrm{lb}$. within a given month. Therefore, if the prices for multiple fish taxa within the same family or genus were separated by more than $5 \notin / \mathrm{lb}$. within a single month (e.g., Chinook salmon listed twice in July, for $5 \notin / \mathrm{lb}$. and $20 ф / \mathrm{lb}$.), I applied one of two solutions. 
First, if the colloquial names were clearly from the same taxon, I identified whether price differences were based on variables like seasonal conditions. Where prices for a single fish varied within one month by more than $5 \phi$, for most fishes I could connect the price changes to seasonal availability. In such cases, I combined the colloquial names into one Linnaean category, but considered the farthest-removed prices as exceptions and not a common representation of the average fish price. I still included irregular price points to show the full range and variation in prices through time for that fish, and to identify connections between those irregular prices and variables like seasonality. I did not consider such prices to be accurate reflections of the overall pricing during my study period. Therefore, I did not include them towards the number of data points a fish needed to be included in the ranking.

Second, I re-examined my Linnaean identifications if the colloquial names were from the same family or genus, but could be from different species (as with multiple market listings for different kinds of salmonids, such as "brook trout", "silver trout", and "steelhead salmon"). In cases where I could not justify linking the market listings and a single taxon, I kept the market listings separate. This occasionally meant that a fish which might have had enough counts of discrete pricing information to be included in the relative ranking was otherwise excluded because I could not establish prices that I felt accurately reflected cost over the 30-year study period. Even after this process, I could still not sort some fishes into any plausible Linnaean unit (e.g., "laughing salmon"; "laugh-eye salmon"). I differentiated between references to native trout (e.g., steelhead trout) and introduced trout (e.g., Eastern brook trout) in part through context: where the 
fish was not named more explicitly than "trout", my archival work had shown that native trout could be sold in markets, while introduced trout could not. I recorded listings for both "steelhead salmon" and "steelhead trout" in newspapers.

After organizing colloquially-named fishes into Linnaean taxa, I combined the pricing for the different colloquial names. Seventy-six percent of the prices from systematic searches were from 1910. Due to the high number of data points for 1910, I used the Consumer Price Index to account for inflation and adjust all of the prices from 1880, 1890, and 1900 to match 1910 prices. Adjusting the prices for inflation resulted in very few changes, all of which were minor enough (e.g., $4 / 10$ of a penny) that they would have been invisible to consumers and did not impact market sales. I rounded each tenth of a penny up or down towards the nearest half-cent.

\section{$\underline{\text { Results of Archival Research }}$}

In systematic searches, and to a lesser extent in qualitative searches, I noted several trends in the number and types of fish advertisements. Fresh fishes accounted for $21 \%$ of the fish pricing I recorded (Table 3). Few fish prices were printed in newspapers before 1900 (Figure 4). Between 1880 and 1899, almost all fresh fishes in newspaper ads were presented only as generally available in markets (e.g., Figure 3). Altogether, I found 65 instances of such fishes for sale without any prices listed (out of a total 73). When prices were available, they were listed as by the pound or per each (Table 5). Fifty-eight 


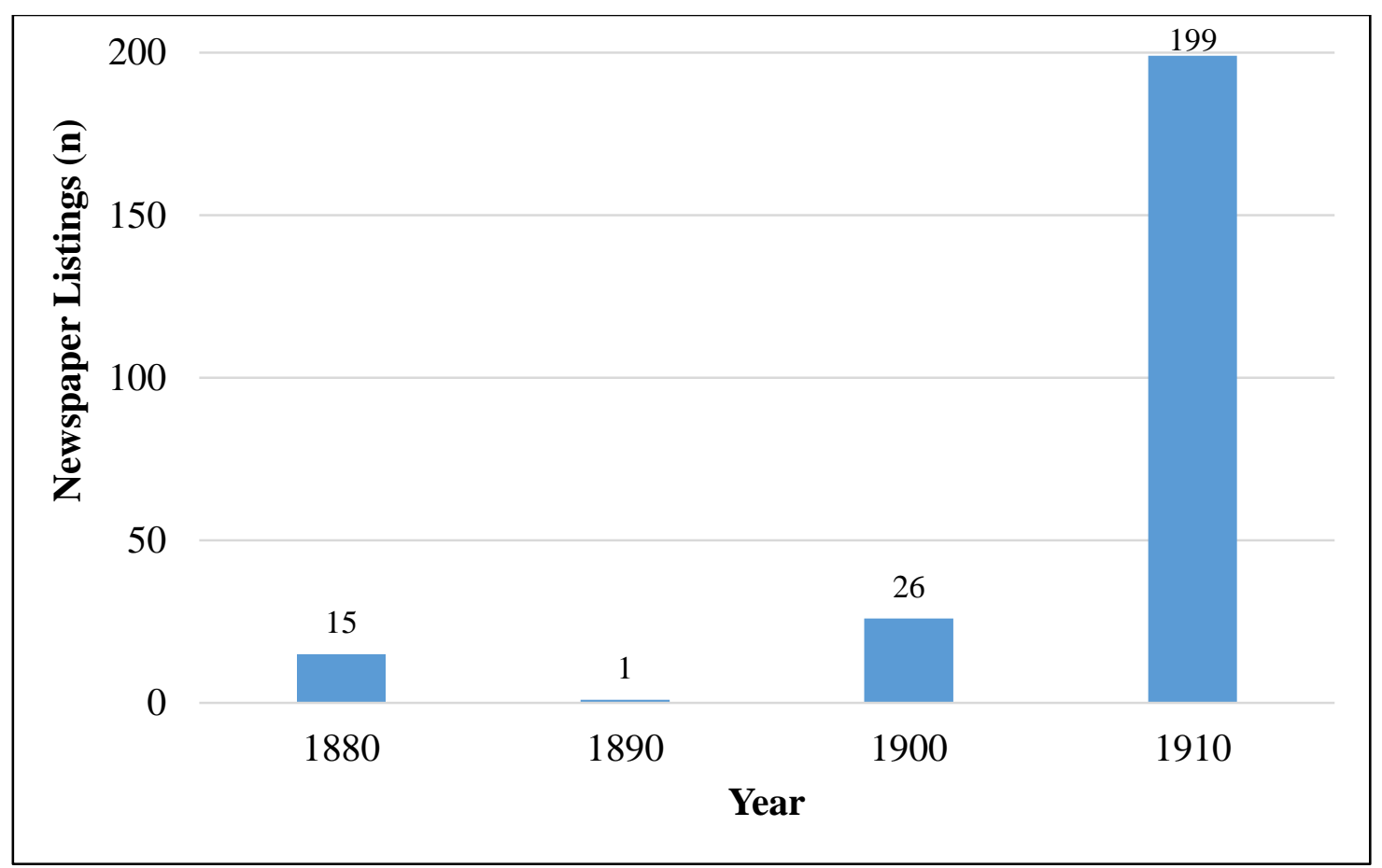

Figure 4. Newspaper listings for systematic fish prices by decade. Frequency reflects multiple discrete fish prices listed within advertisements.

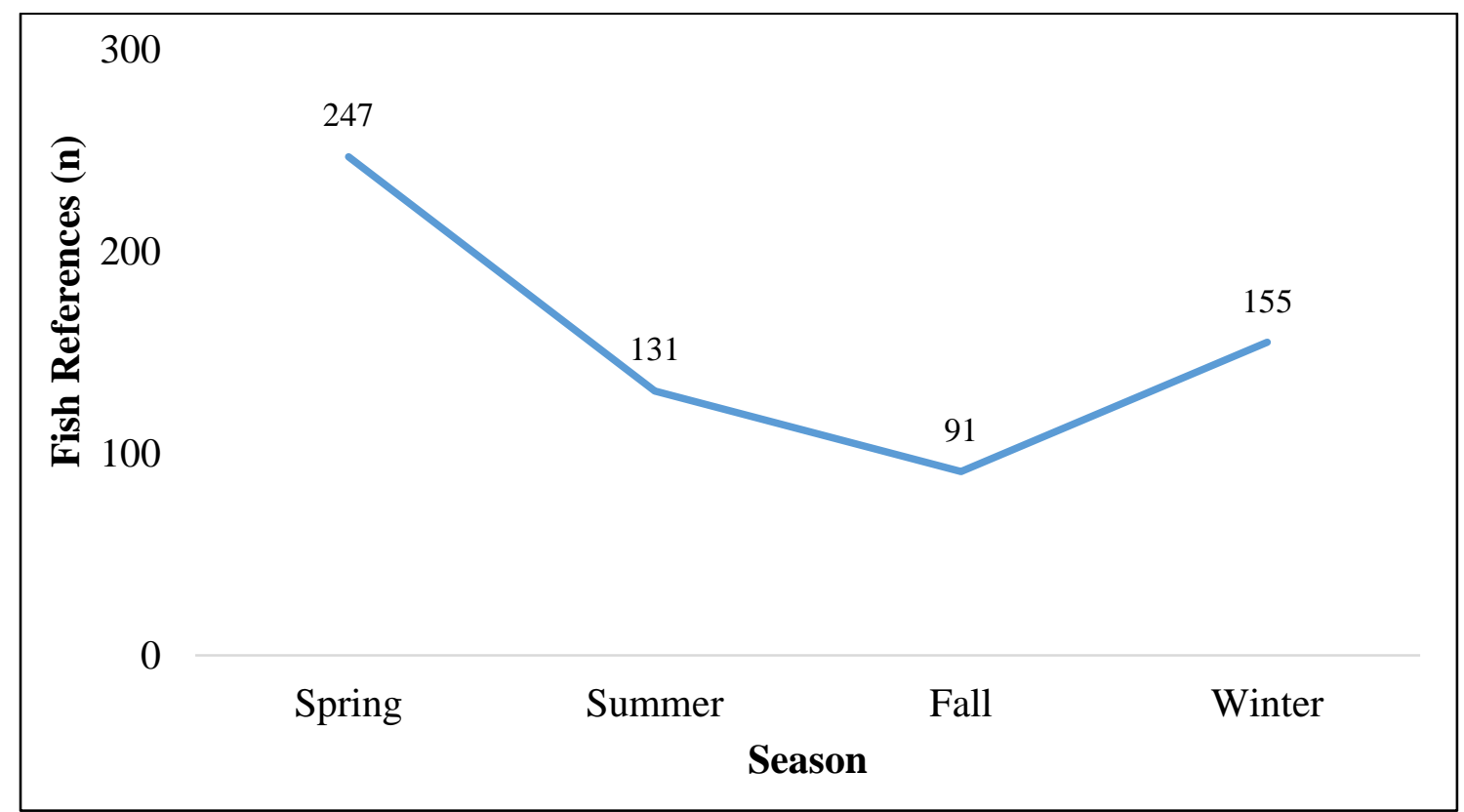

Figure 5. Total number of fish references with at least one price, by season, 1880-1910. Includes both systematic and qualitative searches. 
Table 5. Frequency of units of sale for market-advertised fishes.

\begin{tabular}{lrrr}
\hline \multicolumn{1}{c}{ Unit of Fish Sale } & Systematic Prices & Qualitative Prices & Total \\
\hline Per pound (unspecified portion) & 210 & 74 & 284 \\
Per pound (specific portion) & 5 & 0 & 5 \\
Per each & 28 & 11 & 39 \\
No price (presence only) & 63 & 6 & 69 \\
Total & 306 & 84 & 397 \\
\hline
\end{tabular}

Note: Total systematic prices, and sum of systematic and qualitative prices, shown in the last row of Table 7 do not include "presence only" advertisements; this is the cause of the differing totals between the two tables.

were printed in newspapers dating to 1880 . In the recession of 1890 , all fish pricing dropped substantially, as did the number of advertisements (Figure 4). By 1900, the preferred advertising method for all fresh fishes in the Portland area was by the pound.

Seasonality affected fish availability within the markets. Spring fish sales represent $40 \%$ of all fish-related information I recorded from both systematic and qualitative searches (Figure 5). This coincides with the starting migrations of several anadromous fishes. Fall fish sales comprised approximately $14 \%$ of all advertisements, likely because it represented the end of the yearly salmon pack, and the end of several migrations. Summer fish sales may have been influenced by markets competing with the start of the sport and leisure fishing season for some species (e.g., trout). Salmon still played a large role in summer listings. The eulachon run often began in January, which contributed to the number of winter ads I recorded, as did steelhead trout (e.g., TO, July 22, 1910; article by J. M. Cranford, the General Superintendent of Washington State Fish Hatcheries).

In my systematic searches, I found no clear trends in fish sales between days of the week from 1880 to 1910 , with the exception of Saturdays (Figure 6). This was true 
both seasonally (e.g., only Wednesdays in summer) and year-round (e.g., Wednesdays in spring, summer, fall, and winter) (Figure 6). Saturdays accounted for 33\% of the advertisements $(n=49)$. More than half of all Saturday advertisements were from 1910 (Table 6). The frequency of advertisements by year (Table 6) was similar to the frequency of fish pricing by year (Figure 3) in that 1910 accounted for the greatest amount of both (approximately $80 \%$ of all fresh fish prices, and $42 \%$ of all fresh advertisements), and 1890 accounted for the least amount of both (less than 5\% of discrete prices, and $14 \%$ of advertisements). Because of the Catholic tradition of "Fish

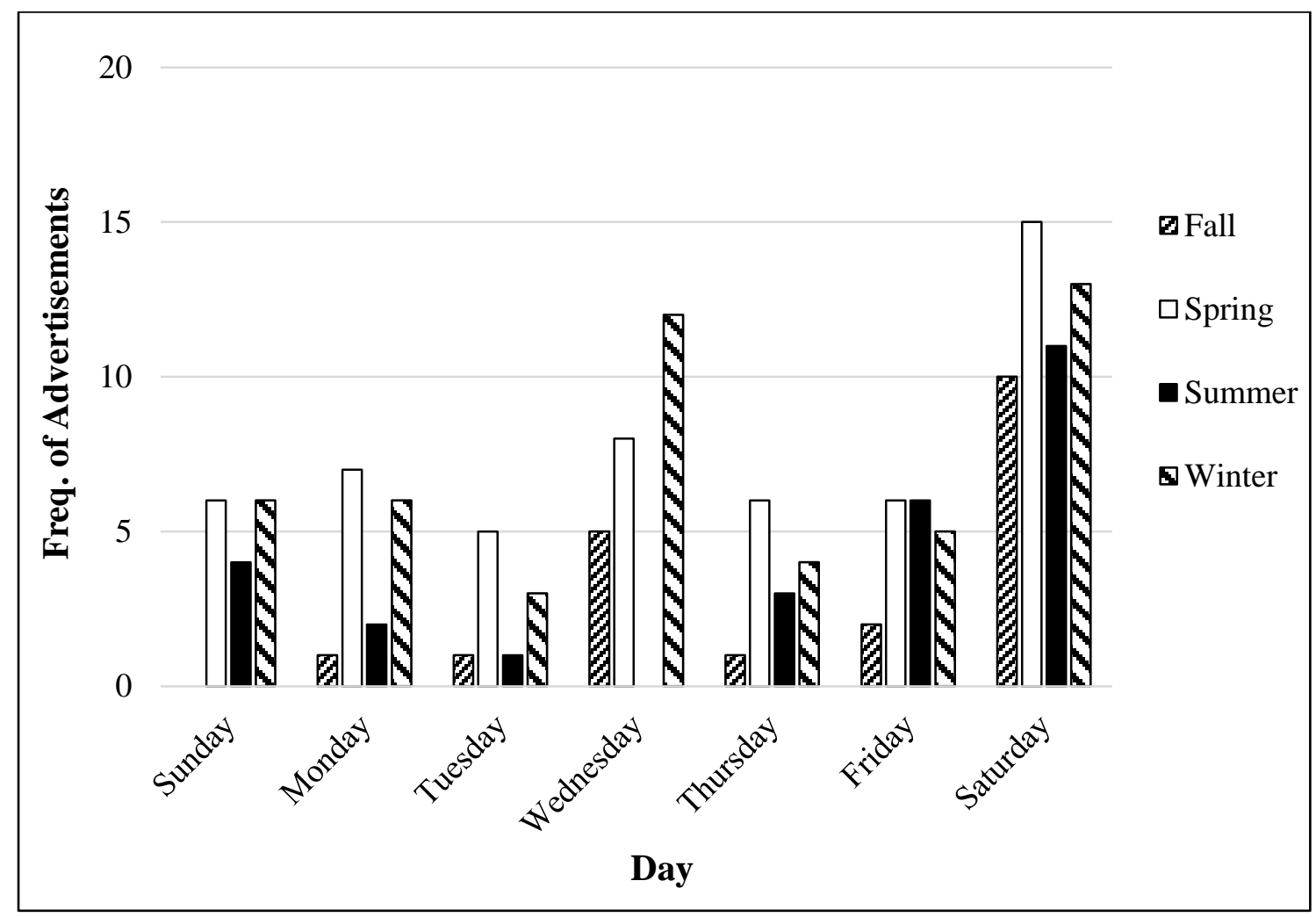

Figure 6. Frequency of systematically recorded newspaper fish advertisements in each season. Counts reflect individual advertisement listings, not multiple fishes listed for sale within a single listing. 
Table 6. Frequency of systematically recorded newspaper fish advertisements in each year.

\begin{tabular}{lrrrrr}
\hline Day & 1880 & 1890 & 1900 & 1910 & Total \\
\hline Sunday & 0 & 1 & 4 & 11 & 16 \\
Monday & 1 & 3 & 5 & 7 & 16 \\
Tuesday & 3 & 1 & 3 & 3 & 10 \\
Wednesday & 8 & 5 & 7 & 5 & 25 \\
Thursday & 7 & 2 & 1 & 4 & 14 \\
Friday & 7 & 2 & 3 & 7 & 19 \\
Saturday & 10 & 7 & 5 & 27 & 49 \\
Total & 36 & 21 & 28 & 64 & 149 \\
\hline
\end{tabular}

* Counts reflect 1) individual advertisement listings, not the number of fishes listed within a single listing, and 2) all fish advertisements, including those showing fishes for sale without pricing information.

Fridays", I had anticipated finding both more raw fish sale prices for Friday, and more fish advertisements leading up to Friday. Though there were occasional advertisements aimed at Friday sales (e.g., Sealy-Lowell Co., "FRIDAY IS FISH DAY" [The Oregonian, Oct. 21, 1910]), I found no clear weekly patterns for Friday fish sales (Figure 6, Table 6).

\section{$\underline{\text { Available Market Fishes }}$}

A total of 105 distinct fish names were listed in the newspapers for both the systematic and qualitative study (Table 7). I linked all but six of these to one of 46 Linnaean taxa to at least an order-level taxon. Forty-two of these were linked to at least a family level, and a further ten to either genera or species (Table 7). Approximately $62 \%$ of the colloquial names $(n=64)$ were associated with native fishes, and an additional $18 \%$ were associated with introduced fishes $(n=20$; Table 7$)$. The remaining fishes were 


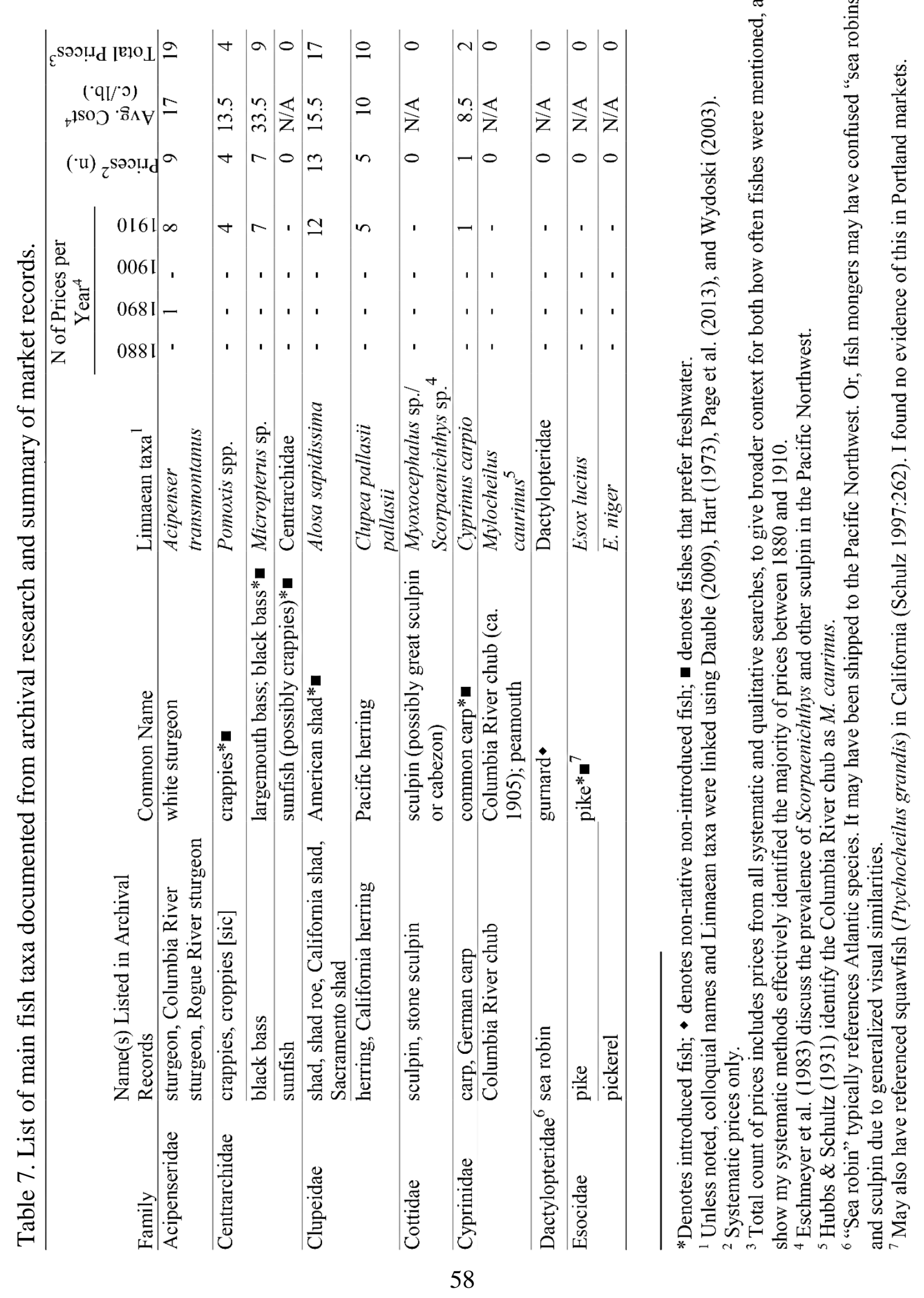




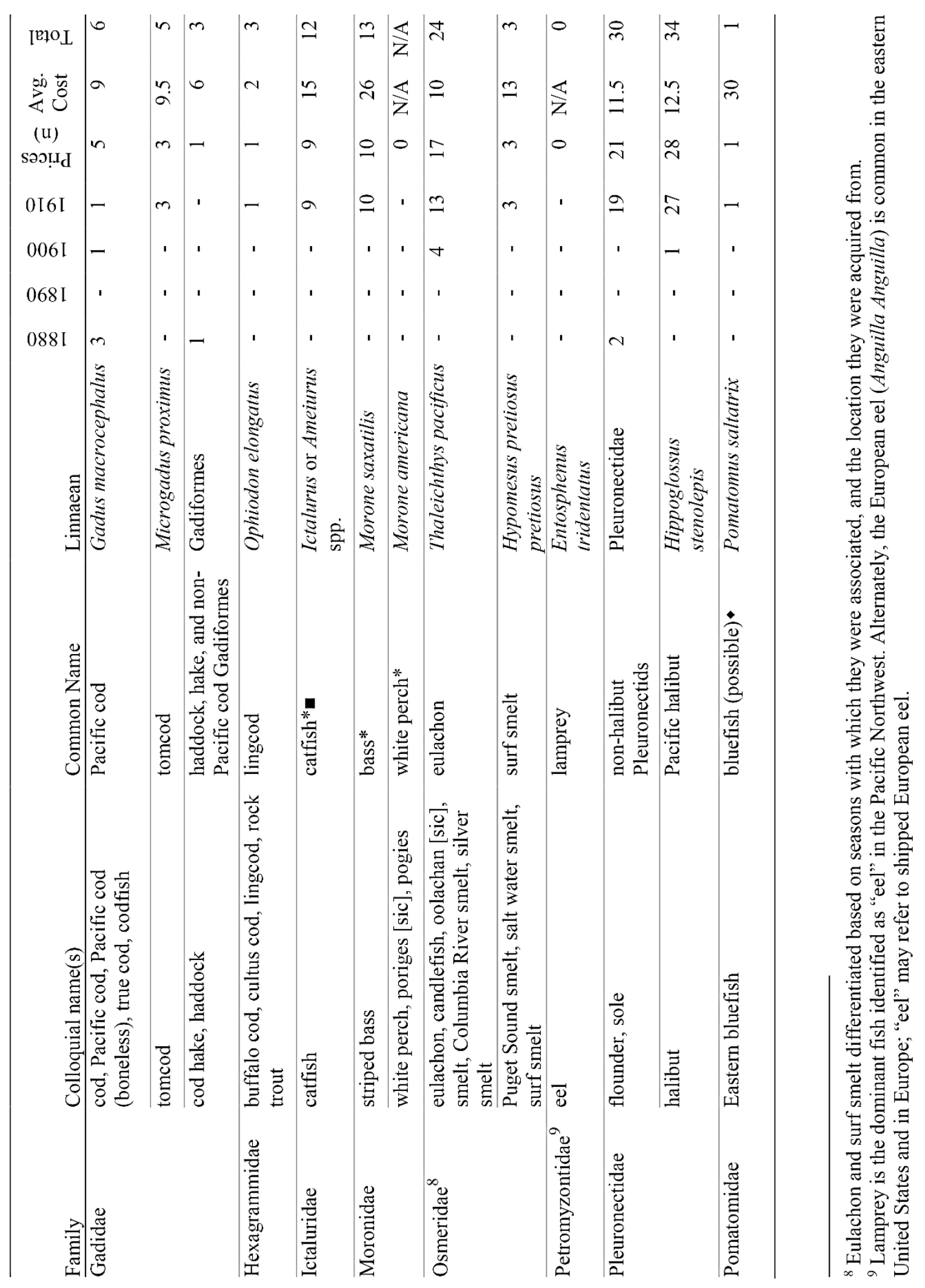




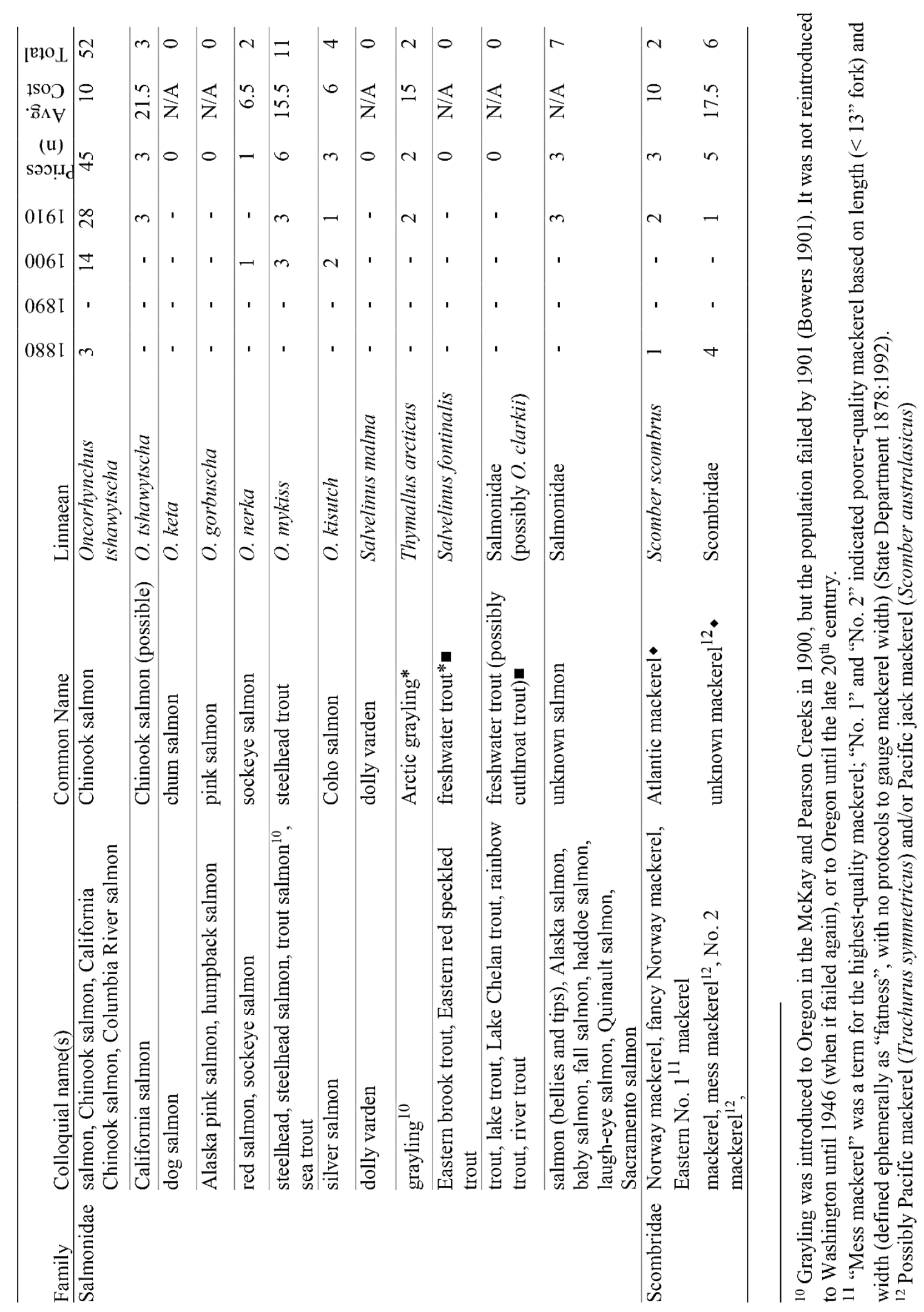




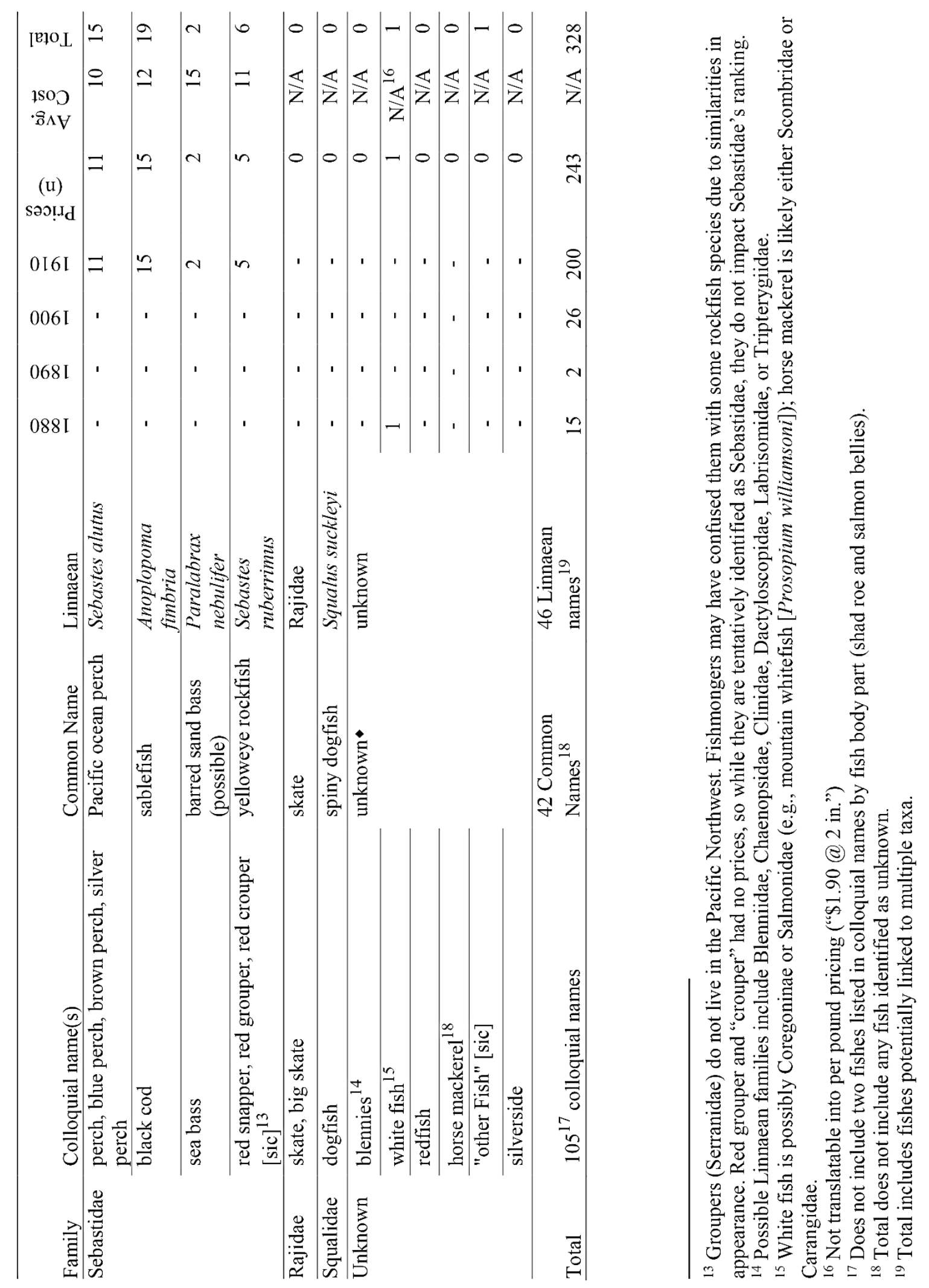


more difficult to place. Four fish types were not native, but also had no records of introduction prior to 1910: gurnard, Eastern bluefish, Atlantic mackerel, and unknown mackerel. I inferred these fishes were shipped into the Portland markets from elsewhere. One fish - Arctic grayling - was introduced into Umatilla county in 1900, but stocks had failed by 1901 (Bowers 1901), so it is likely the fish was shipped in from elsewhere. Some of these fishes may not have been sold fresh (e.g., they were salted) and were erroneously listed in the papers among the fresh fishes. I noted four fishes as either introduced or native because I could not link them with a taxon: blennies, white fish, redfish, and silverside.

Only 10 fishes had prices listed in more than one systematically-searched decade (Table 7). All of these except for two - both types of mackerel (Scombridae) - were native fishes. The remaining eight fishes had at least four price listings, so were included in my ranking. The two most frequently listed of these fishes were Chinook salmon and halibut. Of the fishes with pricing information, two fishes - white fish and Eastern bluefish - had only one price associated with them. Every other priced fish had two or more prices.

Twenty-five fishes I recorded in newspapers had no prices associated with them whatsoever (Table 7). These fishes were discussed in the context of personal fishing (e.g., sport fishing). Fourteen were native fishes and five were introduced fishes. The remaining six fishes were both not local to the area, and had no record of attempted introductions (Table 7). 
Except two fishes (one native and one introduced), I did not find any evidence of fishes sold in specific portions (Table 5). Rather, they were sold generically as "per pound" or, less frequently, "per each" (Table 5). This was the case for both native and introduced fishes. Singer's (1987) work indicated that fish head portions (which to Euroamerican Victorian audiences were considered low-quality, and used for soups, stews, and chowders) would not be sold under the same "per pound" pricing used for whole fishes or more desirable portions like steaks or fillets. Rather, fish heads would be considerably cheaper (Singer [1987] assigned a static $1 \notin /$ lb. cost to fish heads, which he noted inflated their actual market value). I could not determine whether fish heads were considered too low-quality to warrant advertisements in papers, or they were simply not available. The few exceptions were for sales I linked to salmon and American shad (Table 7). I recorded five distinct portion prices for these fishes (Table 5), all in 1910. Salmon bellies were advertised as distinct portions twice, and sold at a higher price than other salmon portions (at $35 \varnothing / \mathrm{lb}$.). Salmon "tips" were also advertised once, at $50 \varnothing / \mathrm{lb}$. Shad roe was advertised twice, also at higher prices than shad regularly cost (at $40 \varnothing / 1 b$.).

\section{Trends in Frequency of Fish Type Listing and Pricing}

The relative prices of each fish, and how those prices compare with one another, can inform on whether they were market purchases or noncommercial fishes by way of illustrating which fishes were cheap market staples, or rare luxury items also available in local waters. Additionally, understanding trends in fish values is a marker for how wellreceived introduced and native fishes were in comparison to one another. These patterns 
do not necessarily link directly to class-based purchases (e.g., that unskilled laborers buy only cheap foods, while wealthy professionals buy only expensive foods). Rather, the assignments of food value show how people spent their disposable income and what they placed importance on, within the constraints of their station.

I looked at the changes in fish pricing and fish references through time to find trends for individual fishes. Native salmon and flounders accounted for almost 50\% of the listings. Sturgeon comprised 3\% of the total listings, but newspapers showed sturgeon prices and public reception to sturgeon changed drastically between 1880 and 1910. In contrast, flounders had a substantive number of references (e.g., 20\% of all fresh fish prices, Table 8), but their prices remained largely unchanged during the 30-year period (see discussions below).

I documented 20 named fishes that I assigned to 12 Linnaean taxa for introduced fishes, some of which could only be linked to a genus- or family-level taxa (Table 7). Introduced fishes - including introduced salmonids - accounted for $14 \%$ of the total listings (Table 8). Pricing information for these fishes was present in 1910 only (Table 7). However, I recorded articles about almost all of the introduced fishes from the approximate time of their introduction onward, focused on introduction efforts or personal catch. The two exceptions to this were Arctic grayling, which was mentioned only once, and striped bass, which was mentioned only as a market fish. 
Table 8. Frequency of fish prices and references for most commonly discussed fishes.

\begin{tabular}{|c|c|c|c|c|}
\hline \multirow[b]{2}{*}{ Fish } & \multicolumn{2}{|l|}{ Systematic } & \multicolumn{2}{|l|}{ Total } \\
\hline & Prices $(n)$ & Systematic \% & References & Total $\%$ \\
\hline Salmon $^{1}$ & 63 & 26 & 374 & 39 \\
\hline Halibut, flounder, sole & 49 & 20 & 81 & 9 \\
\hline Eulachon & 17 & 7 & 32 & 3 \\
\hline Sturgeon & 9 & 4 & 28 & 3 \\
\hline Cod, hake & 9 & 4 & 37 & 4 \\
\hline Introduced fishes ${ }^{1}$ & 46 & 19 & 133 & 14 \\
\hline Other fishes & 50 & 20 & 264 & 28 \\
\hline Total & 243 & 100 & 949 & 100 \\
\hline
\end{tabular}

Includes all native anadromous salmonids (e.g., Coho and Chinook salmon; steelhead trout).

${ }^{2}$ Includes all introduced trout (e.g., Eastern brook trout); see Table 9.

Introduced Fish Trends

Five of the 12 introduced taxa accounted for $80 \%$ of the newspaper listings for introduced fishes (Table 9): introduced trout, American shad, two introduced bass, and catfish. Introduced trout was commented on the most frequently, but never with an associated sale price. In both 1900 and 1910, I recorded newspaper articles that identified trout as illegal to sell commercially, and only available for consumption through private fishing efforts. Common discussions included where trout were being planted and the sizes of trout being caught. Twice, a fish monger was identified in the newspapers as illegally selling trout under a different label (e.g., smelt).

American shad was the second-most commented on, and had the highest count of price listings for an introduced fish (Table 9). When prices from qualitative records are included, shad also had the greatest range in prices of any introduced fish, from as little as $2 ф / 1 b$. to as much as $40 ф / 1 b$. American shad popularity fluctuated between its introduction to California in 1871, its appearance in Pacific Northwest waters by the 1880s, and 1910 (Figure 7). Based on pricing and availability, American shad was most 
Table 9. Introduced fishes recorded in systematic and qualitative searches.

\begin{tabular}{lrrr}
\hline Introduced fish & Listing by Price $^{1}$ & Total References & Total \% \\
\hline Freshwater trout & 0 & 44 & 33 \\
American shad & 12 & 18 & 14 \\
Largemouth bass & 8 & 15 & 11 \\
Striped bass & 14 & 14 & 11 \\
Catfish & 11 & 15 & 11 \\
Common carp & 2 & 10 & 8 \\
Crappies & 4 & 6 & 5 \\
Sunfish & 0 & 4 & 3 \\
White perch & 0 & 3 & 2 \\
Arctic grayling & 2 & 2 & 2 \\
Pike & 0 & 1 & 1 \\
Pickerel & 0 & 1 & 1 \\
Total & 53 & 133 & $100 \%$ \\
\hline Includes prices from both systematic and qualitative searches. &
\end{tabular}

popular in the summer of 1900. While prices dropped towards the end of 1900, by 1910 its value was rising in tandem with other fishes (Figure 7; see discussion below).

Carp was in the papers regularly, but with an increasingly poor reputation after its introduction to local waters and markets. For example, an early 1880 article describes a Eugene resident attempting to stock Oregon waters with carp, "a particularly valuable fish" (TO, April 28, 1880). However, by 1900 one article had catalogued carp as "ugly as sin" (TO, July 1, 1900); another stated that most local fishermen "want[ed] carp to die from lead poisoning" (TO, April 7, 1900). Three articles mentioned intentionally stocking carp in local waters for personal fishing. I recorded only two carp market prices, and they were some of the lowest fish prices I recorded for the entire 30-year period (5 $\varnothing / \mathrm{lb}$. in $1895 ; 7 \not / l b$. in 1910). Altogether, discussion of carp fishing was very rare in newspapers ( $n=4$, two of which were biased against carp). 
Catfish was viewed more favorably than carp. This was visible both in market pricing and in newspaper discussions of fishing (see discussion below). For example, three articles (published in 1890, 1900, and 1910 respectively) all viewed catfish positively as food or sport fishes. This showed that, unlike carp, there was continuing demand for catfish past its initial debut in the Pacific Northwest in the early 1880s.

Native Fish Trends

There were more than twice as many native fishes than introduced fishes (Table 10). Anadromous salmon (Oncorhynchus spp.) dominated records in both my systematic and qualitative searches. Salmon comprised $26 \%$ of the discrete systematic prices I recorded (Table 8). Altogether, salmon was mentioned in 39\% of the systematic and qualitative archival fish references, both in advertisements and other record types (Table 8). Among the multiple discrete salmon listings, I found pricing information for salmon under at least ten different colloquial names (Table 7). I identified abundant discrete prices for canned salmon (Table 3), but the usefulness of this information was limited because zooarchaeological records cannot track canned fish use. While the relationship between canned and fresh fish purchases is important, information on canned pricing was so abundant that systematically recording it was an ineffective use of time, so I did not systematically record canned salmon prices.

Sturgeon accounted for just $4 \%$ of both discrete systematic pricing and overall newspaper references (Table 8). Sturgeon had the greatest monthly range in prices for any fish I recorded (Figure 7). During the 30-year period, its price fluctuated between as 
Table 10. Environmental preference for introduced, native, and non-native fishes documented in newspaper listings.

\begin{tabular}{|c|c|c|c|}
\hline Common name(s) & Linnaean taxon & $\begin{array}{l}\text { Preferred } \\
\text { Environment }\end{array}$ & Status \\
\hline Crappies & Pomoxis spp. & Freshwater & Introduced \\
\hline Largemouth bass & Micropterus salmoides & Freshwater & Introduced \\
\hline Striped bass & Morone saxatilis & Freshwater & Introduced \\
\hline Sunfish & Centrarchidae & Freshwater & Introduced \\
\hline American shad & Alosa sapidissima & Freshwater & Introduced \\
\hline Common carp & Cyprinus carpio & Freshwater & Introduced \\
\hline Pike & Esox lucius & Freshwater & Introduced \\
\hline Pike & E. niger & Freshwater & Introduced \\
\hline Catfish & Ictalurus or Ameiurus spp. & Freshwater & Introduced \\
\hline Freshwater trout & Salvelinus fontinalis & Freshwater & Introduced \\
\hline Arctic grayling & Thymallus arcticus & Freshwater & $\begin{array}{l}\text { Non-native, failed } \\
\text { introduction }\end{array}$ \\
\hline Columbia River chub & Mylocheilus caurinus & Freshwater & Native \\
\hline Dolly varden & Salvelinus malma & $\begin{array}{l}\text { Freshwater to } \\
\text { Anadromous }\end{array}$ & Native \\
\hline Other trout & Oncorhynchus spp. & $\begin{array}{l}\text { Freshwater to } \\
\text { Anadromous }\end{array}$ & Native \\
\hline White sturgeon & Acipenser transmontanus & Anadromous & Native \\
\hline Eulachon & Thaleichthys pacificus & Anadromous & Native \\
\hline Surf smelt & Hypomesus pretiosus pretiosus & Anadromous & Native \\
\hline Lamprey & Entosphenus tridentatus & Anadromous & Native \\
\hline Chinook salmon & O. tshawytscha & Anadromous & Native \\
\hline Chum salmon & O. keta & Anadromous & Native \\
\hline Coho salmon & O. kisutch & Anadromous & Native \\
\hline Pink salmon & O. gorbuscha & Anadromous & Native \\
\hline Sockeye salmon & O. nerka & Anadromous & Native \\
\hline Steelhead trout & O. mykiss & Anadromous & Native \\
\hline White perch & Morone americana & Anadromous & Introduced \\
\hline Barred sand bass & Paralabrax nebulifer & Marine & Native \\
\hline Pacific herring & Clupea pallasii pallasii & Marine & Native \\
\hline Sculpin & $\begin{array}{l}\text { Myoxocephalus sp. or } \\
\text { Scorpaenichthys sp. }\end{array}$ & Marine & Native \\
\hline Pacific cod & Gadus macrocephalus & Marine & Native \\
\hline Tomcod & $\begin{array}{l}\text { Microgadus proximus; } \\
\text { M. tomcod }\end{array}$ & Marine & Native \\
\hline Haddock $^{1}$; hake & Gadiformes & Marine & Native \\
\hline Lingcod & Ophiodon elongatus & Marine & Native \\
\hline Flounder; sole & Pleuronectidae & Marine & Native \\
\hline
\end{tabular}

${ }^{\mathrm{T}}$ While "haddock" is a common term for non-native fishes, I found it was inappropriately applied to gadids in local markets. 


\begin{tabular}{llll}
\hline Common name(s) & Linnaean taxon & $\begin{array}{l}\text { Preferred } \\
\text { Environment }\end{array}$ & Status \\
\hline Pacific halibut & Hippoglossus stenolepis & Marine & Native \\
Pacific ocean perch & Sebastes alutus & Marine & Native \\
Sablefish & Anoplopoma fimbria & Marine & Native \\
Yelloweye rockfish & Sebastes ruberrimus & Marine & Native \\
Skate & Rajidae & Marine & Native \\
Spiny dogfish & Squalus suckleyi & Marine & Native \\
Gurnard & Dactylopteridae & Marine & Non-native, not \\
& introduced \\
Bluefish & Pomatomus saltatrix & Marine & Non-native, not \\
& & & introduced \\
Atlantic mackerel & Scomber scombrus & Marine & Non-native, not \\
introduced & Non-native, not \\
Mackerel & Unknown & Marine & introduced \\
Blennies & Unknown & Unknown & Unknown \\
White fish & Unknown & Unknown & Unknown \\
Horse mackerel & Unknown & Unknown & Unknown \\
Redfish & Unknown & Unknown & Unknown \\
Silverside & Unknown & Unknown & Unknown \\
"Other fish" [sic] & Unknown & Unknown & Unknown \\
\hline
\end{tabular}

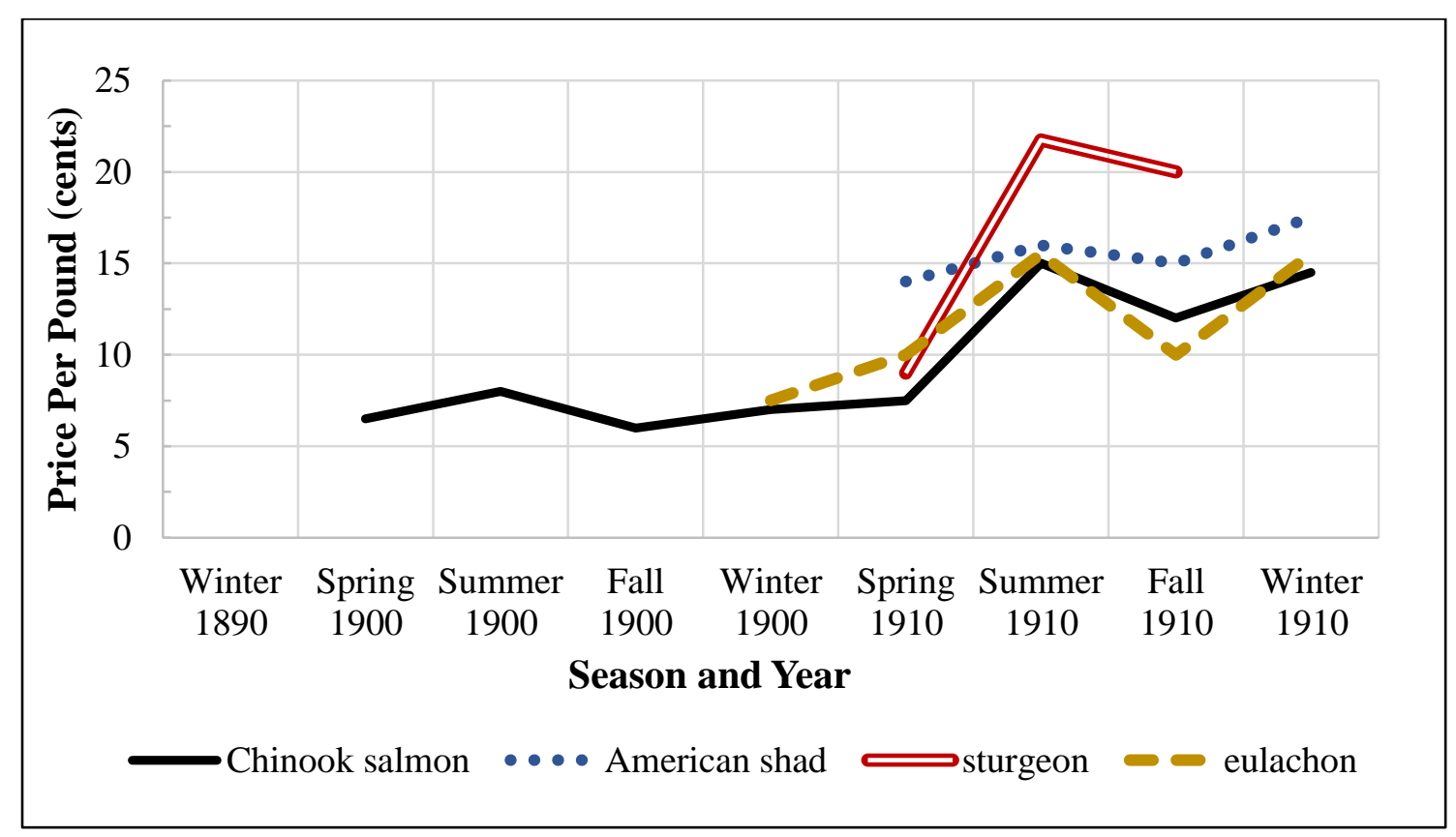

Figure 7. Example of compared pricing for four ranked fishes (Chinook salmon, eulachon, sturgeon, and American shad). This figure only treats a subset of the pricing data ( $1 / 4$ of ranked fishes shown). 
much as $30 \phi / l b$., and as little as $1 / 2 \varnothing / l b$. Unlike with other outlying fish prices, variations of sturgeon prices larger than $5 \phi / l b$. did not clearly appear to be connected to variables like seasonality.

Eulachon was the most prominent example I encountered of pricing influenced by seasonal availability. With the exception of three July prices in 1910, eulachon was seasonally available from January to March, and runs were relatively short. Eulachon prices varied greatly on the first day of the run (e.g., more than $25 \phi / l b$.) but stabilized and remained relatively consistent one or two days into the run ( $8 \notin / \mathrm{lb}$.). I considered the latter pricing to be more reflective of the overall pattern for eulachon sales.

Freshwater, Marine, and Anadromous Fishes

Thirty-three fishes spent at least part of their lives in marine environments (some were anadromous) (Table 10). A further $23 \%$ preferred freshwater environments. Some (e.g., carp) are resilient and can survive in multiple aquatic environments, but tend to proliferate more in freshwater environments (Lampman 1946; Palen et al. 2006; Whillans 1979). I could not clearly link the remaining fishes (approximately 7\%) to a taxon, and thus could not establish their environmental range (Table 10).

\section{Subsistence and Leisure Fishing}

Newspapers never explicitly mentioned Euroamerican subsistence fishing. Three times subsistence fishing was discussed in the context of traditional Native American fishing, and presented with disparaging undertones, as an activity 'beneath' 
Euroamerican intellect or effort. Otherwise, discussion of subsistence fishing was absent in newspapers. Importantly, secondary sources (e.g., Lampman 1946; Landerholm 1966) have confirmed that subsistence fishing was common for some working-class Euroamericans in the late 1800s and early 1900s.

In contrast, Euroamerican leisure and sport fishing was discussed in newspapers. Of the 44 references of trout fishing, 12 focused on sport fishing expeditions from primarily upper-class, and some seemingly middle-class, households. These accounts often included the number and lengths of all fishes caught. Overall, approximately $14 \%$ of the qualitative fish references I recorded recounted such fishing trips (Table 3). A further 10 articles focused on trout fishing in general (e.g., good locations for seasonal trout fishing). Thirteen articles referenced sport fishing for other fishes, both native and introduced. For example, one travel advertisement stated that if trout fishing was too mild a sport, the daring fisherman should travel to Coos Bay and try fishing for halibut, lingcod, "redfish", flounder, and "many other varieties" of marine fishes (TO, July 31 , 1910). Sport fishing was even promoted at a Portland-area hotel where visitors could "catch their own dinner" by fishing in a large tank stocked with black bass and trout (TO, April 7, 1910). Finally, newspapers noted the stocking of eight introduced fishes besides trout in local waters (catfish, bass, pickerel, pike, crappie, sunfish, perch, and carp), presumably for noncommercial fishing.

Based on the number of articles discussing freshwater sport fishing, freshwater fishes - and freshwater trout in particular - were targeted over marine fishes for sport. Introduced trout was the overwhelming focus of sport fishing, followed by native 
salmonids (including steelhead trout) at a roughly 3:2 ratio. Eleven articles reported sport fishing for marine and anadromous fishes, and these were typically at locations over 200 miles away from Portland, or included introduced fishes in their recommendations as well. Newspapers presented a clear bias towards sport fishing for smaller-bodied trout.

\section{Developing a Fish Ranking from Archival Results}

After organizing colloquially-named fishes into Linnaean taxa, I chose fishes to incorporate into a ranking with four or more discrete prices. Of the 99 fishes linked to Linnaean taxa, 16 had four or more data points. My goal was to incorporate records from these 16 fishes and create a fish ranking reflective of fish pricing trends between 1880 and 1910. Because of the high frequency of pricing in 1910 (Figure 4), my fish ranking is most reflective of that year. For years when pricing data was available, all ranked fishes except for Chinook salmon and sturgeon maintained their relative price position in relation to one another for the duration of the 30 -year study period (see discussion below). Altogether I used 210 discrete prices to develop my ranking.

Eleven of the fishes I included in the ranked are native fishes, and five are introduced fishes. The introduced fishes are higher-priced than native fishes. Largemouth bass (an introduced fish) is the most expensive fish, costing $25-40 \not / \mathrm{lb}$. Pacific cod (a native fish) is the cheapest, costing $5.5-8.5 \phi / 1 b$. Halibut and other pleuronectids are listed separately because in eleven of the price listings for flounders and sole, halibut was listed concurrently, and at a different price. The smallest range in pricing was for an 
introduced fish (crappie) and two native fishes (sablefish and yelloweye rockfish), each with a range of $5 \phi$.

I tracked the prices of each ranked fish (controlled for inflation) against the other ranked fishes to identify pricing trends between years (e.g., Figure 7). The price of each fish changed over time, but its relative position in relation to other fishes was overall consistent. While Figure 7 only treats a subset of the pricing data trends for the 16 fishes, all other fishes followed the same seasonal and yearly trends (i.e., higher summer costs; lower winter costs; an overall cost increase through time; and costs scaling up and down together).

To build a ranking, I identified patterns in the median, range, and average of pricing for each fish. Given the nature of records, I created a two-scale ranking for highand low-priced fishes. This was similar to Singer's (1987) ranking, which established a group of high-cost, medium-cost, and low-cost fishes. I included both the average prices and the range of prices so future comparisons of ranked fishes against other cost-ranked faunas, or against cost-ranked artifacts, would show more nuance in consumer choice for stratified social settings.

I arrayed the 16 taxa based on their range and median prices in a box-and-whisker plot $^{4}$ to see overall trends in fish cost and identify patterns (Figure 8). The median and range of prices showed largemouth bass to be the most expensive fish, and Pacific cod to be the least expensive. Five of the fishes had higher prices; the remaining 11 were more uniformly modest in pricing. The division between higher- and lower-priced fishes was between steelhead trout and American shad (Figure 8). Sturgeon had the largest range in

\footnotetext{
${ }^{4}$ More information on box-and-whisker plots is shown in Appendix C.
} 
systematic prices $\left(22 \frac{1 / 2}{)}\right.$ ), reflecting its changing status in the markets as it went from a reviled fish to a highly valued one. However, most sturgeon prices were tightly clustered within that range ( $80 \%$ of prices had a range of $7 \frac{1}{2} \varnothing$, and $45 \%$ of prices had a range of only 1 cent). If only the price ranges were considered, and not the averages, sturgeon would be more difficult to place within the ranking.

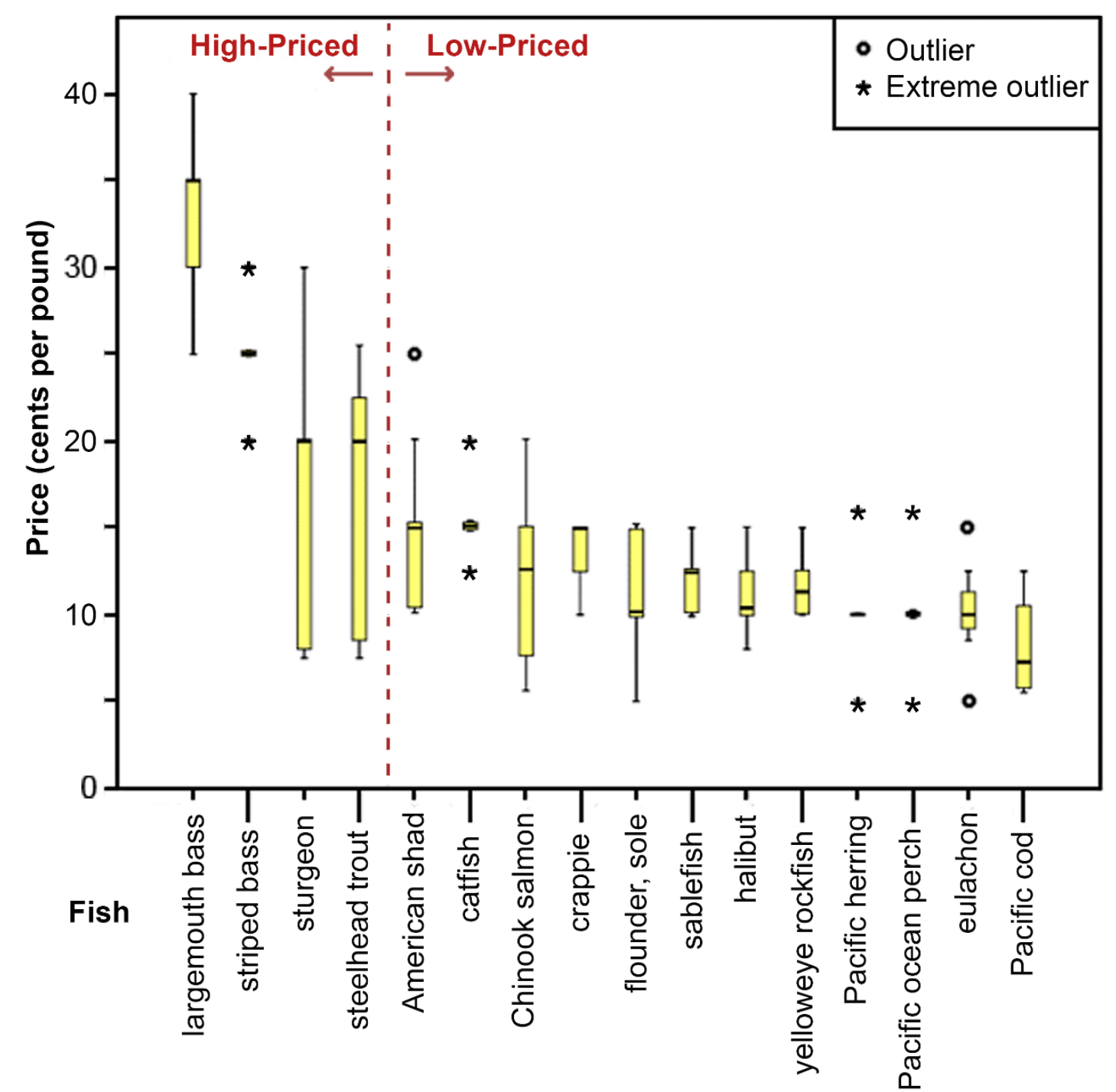

Figure 8. Fish types arrayed by range and median price from highest to lowest, controlled for inflation. 
I also charted individual data points, including qualitative data, to illuminate data clusters that were not visible in the median pricing of each ranked fish (Figure 9). Qualitative data points showed the same general pricing trends, with several more extreme outliers and a lower overall pricing range for most fishes. Sturgeon still had the greatest range in prices of any fish. The higher prices I recorded from qualitative records

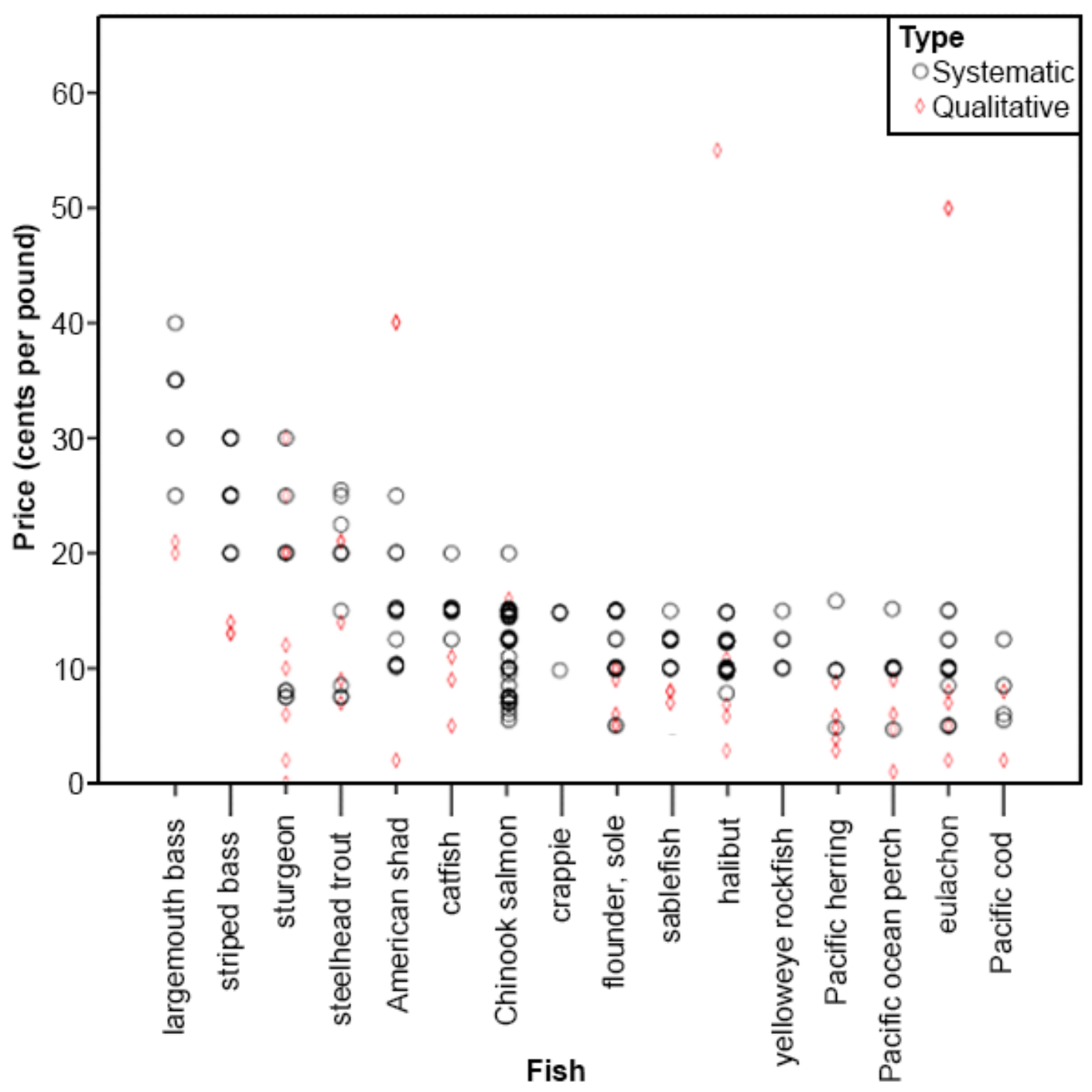

Figure 9. Fish types with systematic and qualitative prices, arrayed from highest to lowest price by range and median, controlled for inflation. 
for American shad, halibut, and eulachon were irregular data points linked to variables like seasonality (Figure 9). Sources I used in qualitative data included non-systematically searched newspapers (Appendix B) and other archival sources, such as fisheries reports (e.g., Craig and Hacker 1940).

Finally, I calculated the mean pricing of each fish (Table 11). Mean prices also showed largemouth bass to be the most expensive fish, and Pacific cod to be the cheapest. When organized by average, fishes were placed in the same order of rank, except for Chinook salmon and pleuronectids (Table 11). While Chinook is in the upper half of the ranking by median and range (Figure 8), it is the fourth-lowest when ranked by average (Table 11). The mean prices were higher than the median prices for five fishes; the remaining fishes were either the same cost $(n=4)$ or averaged lower $(n=7)$. The greatest difference was for steelhead salmon, which was $20 \phi / \mathrm{lb}$. by median, and 15 $1 / 2 \notin /$ lb. by average.

Considering these differences, I ranked the fishes by mean. Other ranked faunas have been organized by average prices (e.g., Schulz and Gust 1983); I found no examples of faunas ranked by median prices. Because most of the pricing data is skewed, ranking the fishes based on their median prices is still useful (Figure 8), so I have included the median prices for comparison (Table 11). However, ranking the fishes by average makes the results more easily comparable to the results from other meat rankings.

Once fishes were ordered by average cost, the averages showed several possible pricing divisions for high-cost and low-cost fishes, all of which were separated by at least $2 \frac{1}{2} \phi$ : first, between the two basses that topped the ranking; second, between striped bass 


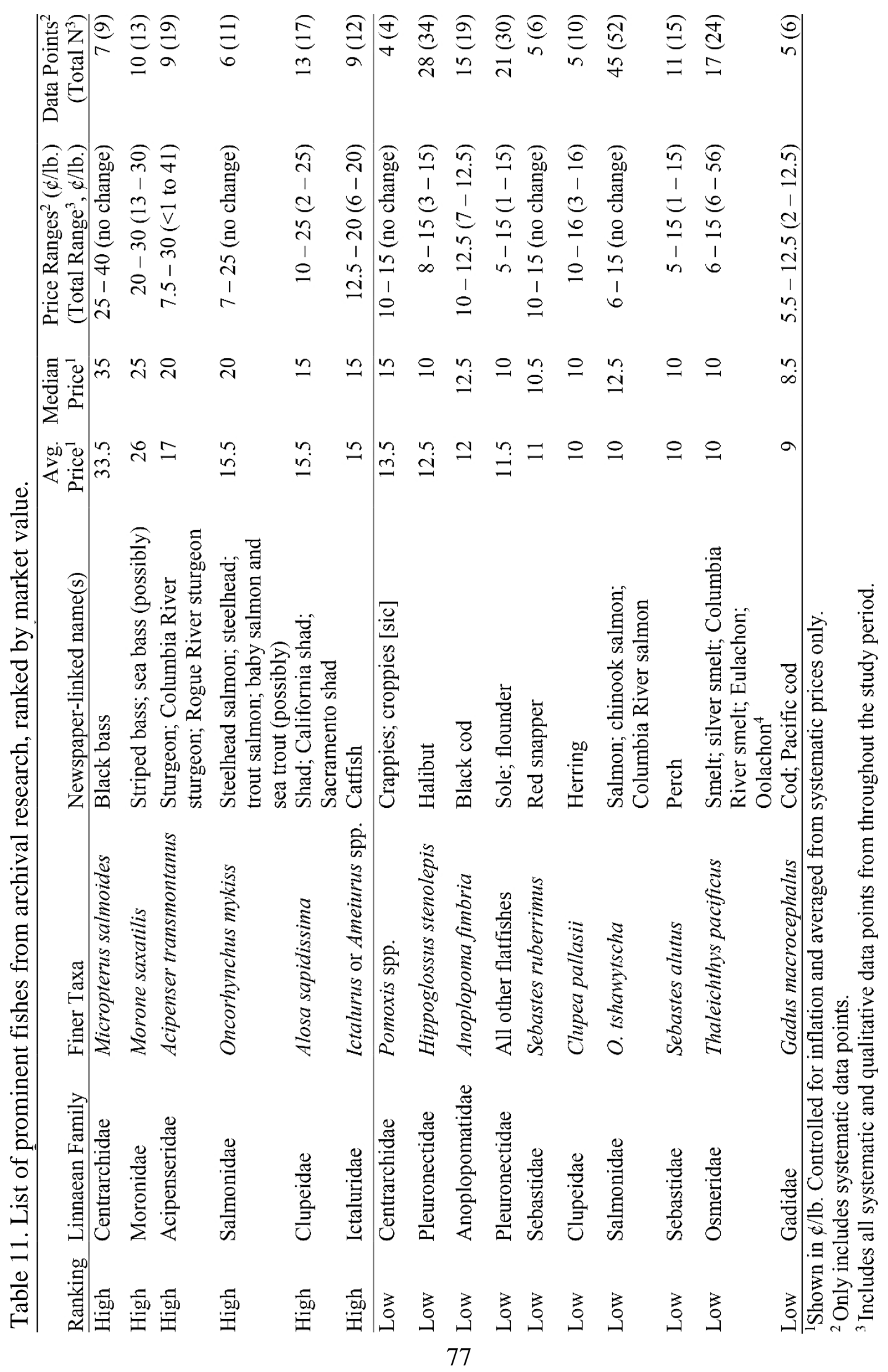


and sturgeon; third, between sturgeon and steelhead; and finally, between crappies and halibut.

I defined high-priced fishes as those costing $15 \notin / \mathrm{lb}$. or more, and low-priced fishes as those costing less than $15 \varnothing / l b$. (Table 11). Largemouth bass, striped bass, sturgeon, and steelhead trout were more visibly high-cost fishes (Figure 8, Figure 9). Similarly, the nine lowest-ranked fishes (all $12 \frac{1}{2}$ or fewer $\phi / l b$.) were all visibly patterned as low-cost fishes. Four fishes in the middle of the ranking (steelhead trout, American shad, catfishes, and crappies) were neither clearly high-cost nor low-cost fishes. While I recorded crappies as low cost, and the remaining three fishes as high cost, because their context is not distinct they should be treated with some reservation.

Notable pricing fluctuation was only visible for two fishes: Chinook salmon and sturgeon. While eulachon prices were affected by seasonality, that pattern in systematic and qualitative data was relatively consistent. However, in 1910 as prices for Chinook salmon were raised locally and globally, the cost of salmon began meeting - and then exceeding - the costs for eulachon (Figure 7). The price of sturgeon also changed drastically: in the 1890s, qualitative data showed sturgeon at $5 \notin / \mathrm{lb}$. By 1910, it was one of the most costly fishes (Figure 7, Figure 8). Outlier prices were rare; these were any prices more than $1 \frac{1}{2}$ times removed from the interquartile range in a given fish's pricing $(\mathrm{n}=11[5 \%$ of total], Figure $8 ; n=8$ [2.4\% of total], Figure 9). Because such outlier prices were not more than $5 \phi$ removed from any other prices in a given month in systematic searches, all prices shown in Figure 8 were included in the ranking. 


\section{Inferences from Archival Research}

I made several inferences about social perceptions of ranked fishes, and their role within the markets. Because market advertisements showed the prices of each ranked fishes consistently scaling against other ranked fishes through market changes and seasons, I inferred the overall fish market was relatively stable for the most commonlyadvertised fishes. I also found that fishes not mentioned in market advertisements were less likely to be sold in markets altogether. Alternately, fishes listed in market ads could represent either purely market purchases, or a mix of market purchases and personal catch, depending on the accessibility of their environments. Archaeologically, this can be used to show whether fish remains represent market or noncommercial fishes.

Introduced fishes appear to have been more highly desired overall during the 30year period than native fishes, based on cost in both qualitative and systematic records (Table 11, Figure 9), availability, and qualitative data broadly framing both the systemic and structural viewpoints of fishes. Due to expense, introduced fishes such as largemouth bass might have been reserved for special occasions by the middle and working classes, and possibly not purchased at all. When remains from expensive introduced fishes appear in assemblages, archaeologists should identify any local waters stocked with those introduced fishes before identifying them as only market purchases.

While Chinook salmon was not a high-ranked fish in markets, the frequency of listings shows that it was a staple market fish (Table 7). With few exceptions, salmon appears to have been treated as a common table fare until at least 1910. Occasionally salmon appeared as a menu item at upper-class restaurants. Generally it was marketed in 
Euroamerican communities to the middle- and working classes. After 1900, salmon prices were increasing, and by 1910 a market columnist stated that salmon might become too expensive for anyone but the "luxury class" to afford. Packers on the Columbia River and in Alaska were opening prices for the 1910 pack at a much higher rate "than in recent years" due to increasing salmon purchases both in the region and abroad (TO, Jan. 16, 1910). The following day, a Chinook salmon was privately sold for $\$ 1.00 / \mathrm{lb} .{ }^{5}$ The article noted it was early in the year to find Chinook salmon, and by summer salmon would likely bring only $10 ф / 1 b$. Given available trends, I inferred that after 1910 Chinook salmon would probably become a more expensive fish, and thus more highly ranked.

From both systematic and qualitative market records, sturgeon become more popular in the late $19^{\text {th }}$ century, which supports the rise in popularity shown by Craig and Hacker (1940) (Figure 7). The growing positive public reception of sturgeon was the most plausible cause for its price fluctuations.

The identification of smaller-bodied trout as illegal in markets, and larger-bodied trout as legal, provides some evidence that smaller salmonid remains from the turn of the century likely represent personal catch and not market sales. Given that I only found two references to illegal trout sales, it is unlikely that small salmonid remains represent illegal market sales. Large salmonid remains, including those from steelhead, could represent either localized personal catch or market purchases. I use a synthesis of archival and zooarchaeological data to identify which fishes were most likely market purchases (and bought in what portions), sport catch, and subsistence catch at the end of Chapter 4.

\footnotetext{
${ }^{5}$ Price not included in systematic or qualitative pricing data; reported cost of private sale, not market sale.
} 


\section{Chapter 4: Zooarchaeological Methods, Materials, and Results}

The goal of the zooarchaeological portion of my thesis project is to examine the Esther Short neighborhood faunal records through a socioeconomic lens - in particular, to assess whether the records of fish remains correspond to independent archival records

of class by reflecting purchasing trends expected for the neighborhood. More generally, I want to compare my archival research on Euroamerican use of fish, and views of fishing, with the archaeological record for fish use.

My zooarchaeological work uses the previously-analyzed fish faunal collection, recovered from 16 features in the Esther Short neighborhood, documented by Krey Easton (formerly employed by AAR). I reanalyzed approximately $30 \%$ of the ichthyofaunal collection to assess reproducibility in faunal identifications. I conducted a body part representation analysis on the most abundant fishes to identify the portions deposited, and post-depositional processes affecting remains. I reanalyzed the entire ichthyofaunal assemblage for butchery marks. These records clarified which fishes were commercial or noncommercial, and provided independent evidence for fish portions.

I then compared the fish remains from the features against my market rankings and other historical context. This allowed me to evaluate neighborhood residents' consumption habits.

Overview of Faunal Analysis of the Esther Short Neighborhood Assemblage

Between 2005 and 2010, AAR archaeologist Easton analyzed remains from the 
Esther Short neighborhood. As noted in Chapter 2, most remains were recovered from 1/4" mesh screens in the field. At least three bulk samples were taken from fish-bearing features and analyzed in part (see discussion below). Easton identified all remains to the most specific taxonomic level and element possible, as well as portion, degree of burning, and cut marks. Easton used comparative collections from Portland State University's (PSU) Anthropology and Biology departments, and the comparative collection housed in AAR's lab, all in Portland, Oregon. Easton's faunal report did not include details on analytic decisions and protocols (e.g., Driver 1992). But faunal tables, including Excel spreadsheets, were available for each feature. AAR made these files accessible to me, along with previous background research, excavation documentation, and reports generated during the project. AAR loaned the faunal collection to me for the duration of my faunal analyses, which I completed in the PSU zooarchaeology laboratory.

I reconstructed the criteria Easton used in his fish faunal analyses in two ways. I discussed with Easton any protocols he could recall from his analyses. Also, I compared the data in the Excel files with a comprehensive list of fish elements. From this I was able to reconstruct some analytical decisions. I developed a list of elements he had included in analysis from elements identified in his results (Appendix D). Easton recorded any element he could positively identify, and added new elements into his protocols during analysis once he felt confident in his ability to identify them.

Easton recorded a total of 20,495 specimens. Of these, 4,882 were assigned to some taxon (Table 12), which are referred to as the number of identified specimens (NISP). An additional 12,821 were identified only to class (Table 13), which are referred 
Table 12. Faunal specimens recorded to animal class or finer taxon by Easton in Esther Short neighborhood features.

\begin{tabular}{|c|c|c|c|}
\hline Taxa & Common name & NISP & Percentage \\
\hline \multicolumn{4}{|l|}{ Turtles and Amphibians } \\
\hline Testudines & turtle & 1 & $<0.1$ \\
\hline cf. Anura & frog & 14 & 0.3 \\
\hline \multicolumn{4}{|l|}{ Invertebrates } \\
\hline Anthozoa & coral & 1 & $<0.1$ \\
\hline Cancer magister & $\mathrm{crab}$ & 3 & 0.1 \\
\hline Mollusca & shell & 1 & $<0.1$ \\
\hline Gastropoda & snail & 1 & $<0.1$ \\
\hline Polinices lewisii (now Neverita lewisii) & Lewis' moon snail & 1 & $<0.1$ \\
\hline Bivalvia & bivalves & 5 & 0.1 \\
\hline Petricolaria pholadiformis & American piddock & 1 & $<0.1$ \\
\hline Clinocardium sp. & cockle & 178 & 3.6 \\
\hline Mytilus sp. & mussel & 8 & 0.2 \\
\hline Osteridae & oyster & 101 & 2.1 \\
\hline Crassostrea gigas (now Magallana gigas) & Pacific oyster & 45 & 0.9 \\
\hline Saxidomus sp. & Washington clams & 22 & 0.5 \\
\hline Siliqua patula & razor clam & 119 & 2.4 \\
\hline cf. Siliqua sp. & & 2 & $<0.1$ \\
\hline Protothaca sp. (now Leukoma sp.) & Littleneck clams & 73 & 1.5 \\
\hline \multicolumn{4}{|l|}{ Fishes } \\
\hline Acipenser sp. & sturgeon & 13 & 0.3 \\
\hline Cyprinus sp. & carp & 21 & 0.4 \\
\hline Cyprinus carpio & common carp & 6 & 0.1 \\
\hline cf. Acrocheilus alutaceus & chiselmouth & 1 & $<0.1$ \\
\hline Gadus sp. & $\operatorname{cod}$ & 4 & 0.1 \\
\hline Hippoglossus sp. & halibut & 11 & 0.2 \\
\hline Ictalurus sp. & catfish & 850 & 17.4 \\
\hline cf. Ictalurus sp. & & 27 & 0.6 \\
\hline Salmonidae & salmon and trout & 117 & 2.4 \\
\hline cf. Salmonidae & & 56 & 1.1 \\
\hline cf. Clupeidae & sardines & 29 & 0.6 \\
\hline \multicolumn{4}{|l|}{ Mammals } \\
\hline Bos sp. & cow & 1297 & 26.6 \\
\hline cf. Bos sp. & & 256 & 5.2 \\
\hline Odocoileus sp. & deer & 1 & $<0.1$ \\
\hline Ovis sp. & goat & 529 & 10.8 \\
\hline cf. Ovis sp. & & 176 & 3.6 \\
\hline Sus sp. & pig & 630 & 12.9 \\
\hline
\end{tabular}




\begin{tabular}{llrr}
\hline Taxa & Common name & NISP & Percentage \\
\hline cf. Sus sp. & & 142 & 2.9 \\
Canis sp. & dog & 5 & 0.1 \\
cf. Canis sp. & & 19 & 0.4 \\
Felis sp. & cat & 37 & 0.8 \\
cf. Felis sp. & rabbit & 31 & 0.6 \\
Leporidae & black-tailed & 18 & 0.4 \\
Lepus californicus & jackrabbit & 1 & $<0.1$ \\
Rattus sp. & rat & 27 & 0.6 \\
Rattus norvegicus & brown rat & 2 & $<0.1$ \\
\hline Total & & 4882 & \\
\hline
\end{tabular}

${ }^{1}$ One human tooth (Euroamerican) was also recorded.

to as the number of specimens (NSP). The remaining 2,792 could not be identified to any vertebrate class. The collection had a high level of fragmentation. Because of this, Easton assigned 12,291 remains to body size categories (small, medium, and large; Table 13). The assemblage was also heavily weighted towards several types of faunas (Table 12, Table 13). Unidentified mammals dominate the assemblage, followed by identified mammals. Identified mammals were primarily domesticated mammals such as cow (Bos taurus), pig (Sus scrofa), and goat (Ovis sp.), which collectively accounted for $62 \%$ of the total NISP. Fishes were the second most common animal type, with a NISP of 1,135 (comprising $23 \%$ of the total NISP). Easton identified seven family-level taxa for fishes in the assemblage. The remaining $15 \%$ of the faunal NISP was represented by other mammals, gastropods and mollusks, birds, coral, crustaceans, amphibian, and turtle (Table 12).

There were three separate groups of unidentified fish remains in Easton's analyses. The first were those that he had attempted to analyze but could not, and entered into the faunal database as "unidentified fish" or "fish". The second group were fish 
Table 13. Number of specimens (NSP) recorded by Easton in Esther Short neighborhood features.

\begin{tabular}{llrr}
\hline \multicolumn{1}{c}{ Taxa } & Common name & NSP & Percentage \\
\hline Birds & & & \\
\hline Aves, no size identified & bird & 6 & $<0.01$ \\
Aves, medium-sized & & 2 & $<0.01$ \\
Aves, medium/large-sized & & 4 & $<0.01$ \\
Aves, large-sized & & 3 & $<0.01$ \\
Fishes & fish & 140 & \\
\hline Osteichthyes, no size identified & & & 1.1 \\
Mammals & mammal & 384 & \\
\hline Mammalia, no size identified & & 8 & 0.1 \\
Mammalia, small-sized & & 44 & 0.3 \\
Mammalia, small/medium-sized & & 4203 & 32.8 \\
Mammalia, medium-sized & & 7081 & 55.2 \\
Mammalia, medium/large-sized & & 946 & 7.4 \\
Mammalia, large-sized & & 12821 & \\
Total & & & \\
\hline
\end{tabular}

specimens Easton could not identify, and did not note as unidentified specimens in the database. The third group comprised specimens he was able to conduct some analysis on, but the analysis was either incomplete or he was uncertain of his identifications. Easton separated these specimens out from their level bags and included physical notes with the specimens that summarized his analysis efforts. Specimens in the third group were also not recorded in the database. Altogether, for fish Easton noted 624 unidentified remains either in the database or on labels in bags, and 1,135 identified remains.

$\underline{\text { Reanalysis Methods and Materials }}$

Zooarchaeologists are becoming increasingly concerned about quality assurance and quality control (QA/QC) in their work (Allen 2003:338-339; Butler and Lyman 
1996; Driver 2011; Gobalet 2001; Lawrence 1973; Nims 2016:12; Nims and Butler 2017; Wolverton et al. 2016:9-12; Wolverton 2013). Given that my project relies and builds on records generated by another researcher, I sought to determine the extent to which his identifications were replicable. In addition, I learned that Easton had not identified several bags of fish remains, and wanted to include these remains in the study. Therefore, I developed a plan to reanalyze a subsample of the fish bone assemblage, and tried to identify the remains that Easton had not assigned to any taxon.

I reanalyzed 29\% of the fish remains (a NISP of 367) through random and judgmental sampling (Table 14). I did not sample any bags from Feature 76, because the fish NISP of each bag from that feature was greater than $15 \%$ of the entire fish assemblage, or the bag could not be located. Three of the level bags selected were missing, amounting to a NISP of 8 (Table 14).

My random sample focused on remains by feature level. Sixty levels from the 16 features included fish remains. I assigned a number to each level with fish remains and used a random number generator to select levels from within features for re-analysis. Based on previous guidelines for sampling in archaeology (e.g., Orton 2000) I selected a third of the levels that contained fishes ( $\mathrm{n}=20$ levels) for reanalysis. The level bags that could be located produced a NISP of 146 (approximately 12\% of the assemblage).

In my judgmental sample, I chose one additional level of fish remains to reanalyze. Judgmental sampling was included to provide additional analyses on features with a high frequency of fish remains on Butler's recommendation. The NISP from this bag was 221. 
Table 14. Levels selected for reanalysis and original NSP of ichthyofaunal remains.

\begin{tabular}{|c|c|c|c|c|c|}
\hline $\begin{array}{l}\text { Feature } \\
\text { (Level) }\end{array}$ & Study Type & $\begin{array}{r}\text { Easton } \\
\text { NSP }\end{array}$ & $\begin{array}{l}\text { Feature } \\
\text { (Level) }\end{array}$ & Study Type ${ }^{1}$ & $\begin{array}{r}\text { Easton } \\
\text { NSP } \\
\end{array}$ \\
\hline \multicolumn{3}{|c|}{ Feature 03} & \multicolumn{3}{|l|}{ Feature 35} \\
\hline B3S & Random sample & 1 & 2 & Random sample & 12 \\
\hline \multicolumn{3}{|c|}{ Feature 04} & \multirow{2}{*}{$\begin{array}{l}4 \\
\text { Feature } 40\end{array}$} & \multirow[t]{2}{*}{ Random sample } & \multirow[t]{2}{*}{8} \\
\hline - [sic] & Random sample & 2 & & & \\
\hline \multicolumn{3}{|c|}{ Feature 12} & \multirow{2}{*}{$\begin{array}{c}\text { A2W } \\
\text { Feature } 42\end{array}$} & \multirow[t]{2}{*}{ Random sample } & \multirow[t]{2}{*}{2} \\
\hline F3E & Random sample & 1 & & & \\
\hline \multicolumn{3}{|c|}{ Feature 13} & \multirow{2}{*}{$\begin{array}{c}\mathrm{A}^{1} \mathrm{aW} \\
\text { Feature } 46\end{array}$} & \multirow[t]{2}{*}{ Random sample } & \multirow[t]{2}{*}{1} \\
\hline $\mathrm{A} 1 \mathrm{E}$ & Random sample & 2 & & & \\
\hline D1E & Random sample & 6 & \multirow{2}{*}{$\begin{array}{c}2 \mathrm{E}^{1 / 2} 2 \\
\text { Feature } 63\end{array}$} & \multirow[t]{2}{*}{ Random sample } & \multirow[t]{2}{*}{2} \\
\hline F1W & Random sample & 1 & & & \\
\hline \multicolumn{3}{|c|}{ Feature 15B } & \multirow{2}{*}{$\begin{array}{l}5 \\
\text { Feature } 66\end{array}$} & \multirow[t]{2}{*}{ Random sample } & \multirow[t]{2}{*}{15} \\
\hline 1 & Random sample & 35 & & & \\
\hline $\begin{array}{l}1 \& 2 \\
\text { Feature }\end{array}$ & Random sample & 1 & $\begin{array}{l}\text { A1N } \\
\text { Feature } 67\end{array}$ & Random sample & 1 \\
\hline $1 N^{1}$ & Random sample & 1 & \multirow[t]{7}{*}{$\mathrm{A} 1 \mathrm{~W}$} & \multirow[t]{7}{*}{ Random sample } & \multirow[t]{7}{*}{7} \\
\hline \multicolumn{3}{|c|}{ Feature 28} & & & \\
\hline $\mathrm{A} 1 \mathrm{E}$ & Random sample & 1 & & & \\
\hline \multicolumn{3}{|c|}{ Feature 31} & & & \\
\hline DS & Judgmental sampling & 221 & & & \\
\hline D3 & Random sample & 42 & & & \\
\hline $\mathrm{DN}^{1}$ & Random sample & 5 & & & \\
\hline \multicolumn{3}{|c|}{ Total NSP } & & & 367 \\
\hline
\end{tabular}

${ }^{1}$ Level bag missing; level total not included in total NSP.

As part of my reanalysis, I also re-examined approximately 1 liter of matrix from one bulk sample for additional remains in a judgmental sample. I included a reexamination of the bulk sampling to check for additional small-bodied fish species which may have been lost through the $1 / 4$ " field mesh screens. I noted two bags of matrix from bulk sampling in fish-bearing features. Unfortunately, specific information about bulk sample processing, mesh size used, and volume is not known. Limitations of the sample records is considered below. Based on specimen sizes, I assume the mesh size used to wet screen bulk samples was $1 / 8$ " or finer. 
After selecting fish faunal remains for re-analysis, I coded each bag to create a blind and separated the coded contents of each bag into trays. Because screen size greatly affects faunal frequency and representation, I summarize results I inferred to be from bulk sampling separately from samples collected from field screens (see discussion below).

I also re-analyzed the 624 specimens that Easton had labeled as unidentified. This included the 140 specimens previously listed as fish in the Excel databases (Table 12, Table 13).

I needed to develop a simple analytic protocol to guide my analysis. Easton did not provide a listing of elements he recorded, so I created a list based on work by Butler, who has analyzed multiple fish faunal assemblages on the lower Columbia River (see Butler and Martin 2013), and most recently for the Číix wicən project, Port Angeles, WA. Altogether I targeted 44 elements in my analysis (Appendix D). From reviewing the Excel files of Easton's faunal analysis, I established that he recorded 32 elements. Eighty-seven percent of the elements I included in analysis were also identified in Easton's work (Appendix D). I did not include some elements that Easton did because the elements were difficult to identify to species (e.g., fish ribs; branchial rays).

In reconstructing Easton's fish analysis protocols, I found that he did not record all fish elements separately. Easton identified all articulated dorsal fish cranial elements as "crania" and did not differentiate nor tally separate cranial elements unless they were disarticulated (e.g., a parasphenoid in a partially intact crania was recorded only once with all other articulated cranial elements in the specimen as "crania", but a single 
parasphenoid specimen was recorded individually as "parasphenoid"). Easton recorded other articulated elements by noting only one of the elements present (e.g., an articulated epihyal and ceratohyal were recorded as a ceratohyal). I expanded on his list of identifications and recorded articulated elements individually, noting if they articulated with any other element on my list (e.g., I recorded an articulating epihyal and ceratohyal as two separate specimens, and noted that they articulated). I selected five dorsal cranial elements to include in analysis (vomer; parasphenoid; basioccipital; frontal; supraoccipital), and noted if they articulated with a partial or complete crania.

I used the comparative collections housed at Portland State University, Department of Anthropology. These collections included examples of 102 fish species that represent the majority of native fishes present in the waters of the lower Columbia River, and most of the families of introduced fishes present in the waters by the $1880 \mathrm{~s}$ (e.g., Centrarchidae, Ictaluridae). The collections lacked one important introduced fish, American shad. With help from another graduate student, Martin Plumer, I obtained one and prepared its skeleton. I used Mundell (1975) to aid in identifying catfish remains.

For each specimen, I recorded the finest level of taxon possible; the element; side; completeness (complete element had all major landmarks, and only minor damage; incomplete elements had at least two major landmarks, and moderate damage; fragments had one or no major landmarks visible, and severe damage); presence and type of burning; butchery marks; and whether or not the element was articulated with other elements. Finally, I noted any unusual modifications or other characteristics of the 
specimen (e.g., very small salmonid remains indicative of a trout and not a juvenile largebodied salmon species).

When I could not positively identify a specimen to taxon, I compared the specimen to similarly-sized elements from fishes in the comparative collection. I then recorded the specimen as an unidentified large, medium, or small fish, based on the sizes of the comparative fish specimen(s) that the specimen most closely resembled. I measured the centrum diameter on vertebrae associated with the comparative skeleton, and determined the fish size class based on the vertebral measurements. I categorized small-bodied fishes in the comparative collection as those having centra less than $1 / 2 \mathrm{~cm}$ wide. Medium-bodied fishes had centra between $1 / 2$ and $1 \mathrm{~cm}$. The centra of large-bodied fishes were greater than $1 \mathrm{~cm}$.

After I assigned each specimen to taxon (or size class), element, and burn category, Butler verified my assignments. I recorded the data in Excel. I then compared Easton's analyses to my own by conducting a Spearman's Rho Rank Correlation Coefficient Test (Spearman's Rho test; $\rho$ ). Given known differences in methods (e.g., I recorded each element in an articulated set, whereas Easton listed one element in the set), for the comparison, I adjusted my records to conform with his approach.

\section{Replicability Study}

The NISP from my random and judgmental sampling was 597 (Table 15). I recorded 230 more specimens than Easton, a substantial increase. This increase could relate to two main factors. First, I counted each element separately, whether it was part of 
Table 15. Comparison of Easton and Taber results of fish faunal analyses.

\begin{tabular}{|c|c|c|c|}
\hline Taxa & Common Name & Easton & Taber \\
\hline \multicolumn{4}{|l|}{ Acipenseridae } \\
\hline Acipenser sp. & sturgeon & 2 & 1 \\
\hline \multicolumn{4}{|l|}{ Clupeiformes } \\
\hline cf. Sardinops sp. ${ }^{2}$ & pilchards & 29 & 0 \\
\hline \multicolumn{4}{|l|}{ Cyprinidae } \\
\hline cf. Cyprinus carpio & common carp & 4 & 4 \\
\hline cf. Acrocheilus alutaceus & chiselmouth & 1 & 1 \\
\hline \multicolumn{4}{|l|}{ Ictaluridae } \\
\hline Ictalurus sp. or Ameiurus sp. & catfishes & 260 & 472 \\
\hline Ictalurus sp. or Ameiurus sp. (small) & catfishes & 32 & 0 \\
\hline cf. Ictaluridae & catfishes & 0 & 2 \\
\hline \multicolumn{4}{|l|}{ Gadidae } \\
\hline Gadidae (no finer taxa) & codfishes & 4 & 0 \\
\hline cf. Gadus macrocephalus & Pacific cod & 0 & 1 \\
\hline \multicolumn{4}{|l|}{ Pleuronectidae } \\
\hline Hippoglossinae (cf. Hippoglossus stenolepis) & Pacific halibut & 3 & 4 \\
\hline \multicolumn{4}{|l|}{ Osmeridae } \\
\hline cf. Thaleichthys pacificus ${ }^{2}$ & eulachon & 0 & 22 \\
\hline \multicolumn{4}{|l|}{ Salmonidae } \\
\hline Salmonidae (no finer taxa) & salmon \& trout & 27 & 4 \\
\hline Salmonidae (small trout-like) & small trout & 3 & 17 \\
\hline Oncorhynchus sp. & salmon & 0 & 38 \\
\hline \multicolumn{4}{|l|}{ Unidentified } \\
\hline Large Fish (size class only) & & 2 & 6 \\
\hline Medium Fish (size class only) & & 0 & 3 \\
\hline Small Fish (size class only) ${ }^{2}$ & & 0 & 22 \\
\hline Total & & 367 & 597 \\
\hline
\end{tabular}

${ }^{1}$ Grayed fields denote primary differences between Easton and Taber analyses.

${ }^{2}$ Given the small specimen size, I assume these remains are from bulk samples.

an articulated set or not, whereas Easton counted an articulated set as one. Second, articulated sets may have disarticulated in the 12-15 years since excavation.

Overall, the taxa identified are similar (Table 15). The chief difference at the nominal scale relates to Sardinops sp., which Easton identified and I did not; and 
Thaleichthys pacificus, which I identified and Easton did not. As well, approximately $66 \%$ of what Easton identified as small catfish remains, I identified as small trout-like salmonid remains. The other taxon level differences relate to specificity. For example, I identified specimens to genus Oncorhynchus, whereas Easton identified specimens to family Salmonidae. Additionally I was more conservative than Easton for identifications of several specimens. Thus, I identified 31 specimens as unidentified small-, medium-, or large-bodied fishes that Easton had previously identified to family-level taxa (Table 15). I recorded one fewer sturgeon specimen than Easton, not because I reclassified the specimen, but because the level bag only included one specimen when I examined it, so some of the differences appear to be basic recording errors. For three other fishes (gadids, salmonids, and large-bodied fishes similar to salmonids) my NISP was lower than Easton's because I reclassified the specimens to other taxa. Our analyses otherwise reflected the same fishes, and in relatively similar proportions when ordered by NISP (Table 15). For example, we both identified the same cyprinid specimens, and to the same elements.

For the Spearman's Rho Test, I addressed our methodological differences in several ways. Where Easton had recorded multiple articulated elements only once, and I recorded the articulated elements separately, I only counted one of my recorded articulated elements. I did not include elements that only Easton recorded (ribs; branchials). Finally, I did not include the very small vertebrae that Easton had recovered from bulk samples because the protocols for how bulk samples were addressed was unclear (see discussion below). This reduced his NISP from 367 to 238, and my NISP 
Table 16. Categories and Rankings for Spearman's Rho Test.

\begin{tabular}{lrrrrrr}
\hline \multicolumn{1}{c}{ Period } & Easton & \multicolumn{1}{c}{ Taber } & & & $\mathrm{di}^{2}$ \\
\hline Ictaluridae & NISP & Rank & NISP & Rank & $\mathrm{di}$ & 0 \\
Salmonidae & 193 & 1 & 308 & 1 & 0 & 0 \\
Cyprinidae & 31 & 2 & 49 & 2 & 0 & 0 \\
Gadidae & 5 & 3 & 5 & 3 & 0 & 0 \\
Pleuronectidae & 4 & 4 & 1 & 5 & -1 & 1 \\
Acipenseridae & 3 & 5 & 4 & 4 & 1 & 1 \\
Total & 2 & 6 & 1 & 6 & 0 & 0 \\
\hline
\end{tabular}

from 597 to 368 (Table 16). Because most of our specimens were identified to family, in comparing our results I examined all taxa at the family level (e.g., common carp [Cyprinus carpio] and chiselmouth [Acrocheilus alutaceus] are both Cyprinidae).

The results of the Spearman's Rho test (Table 16) indicated our identifications were highly correlated and statistically significant $\left(\mathrm{r}_{\mathrm{s}}=0.899 ; p=0.015\right)$. Four of the six taxa Easton and I recorded held the same rank (Table 16). Only ranks of gadids and pleuronectids differed, and only by one place.

Overall Easton's records were reliable. Our fish identifications diverged more for both fishes with lower NISPs, and for smaller-bodied taxa. My identification of eulachon (assumed from bulk sampling, and excluded from Spearman's Rho Test) and smallbodied salmonids shows that there may be other small-bodied fishes in the remaining $70 \%$ of the assemblage that Easton and I would identify to different taxa. Easton likely overestimated catfish and underestimated the frequency of small salmonids. Since at least some of the small salmonid remains are probably from bulk samples, and most of the fish specimens were recovered from field screens, this difference will not affect the overall study. Additionally, where Easton differentiated between some vertebrae types for all 
fishes (e.g., caudal and terminal vertebrae), he did not differentiate the catfish modified second vertebrae. This vertebral type has implications on fish acquisition and fish butchery (see discussions below). I recorded 13 modified second vertebrae during my replicability study, and an additional 6 from previously unidentified fishes (see discussion below). Beyond this observation, I did not statistically treat the analytical differences between elements Easton and I identified. Even considering these differences, the correlation between our analyses shows that Easton's work provides a good record of the dominant taxa present.

\section{$\underline{\text { Previously Unidentified Fishes }}$}

I examined the 624 specimens that Easton had not previously been able to identify. Of these, I identified 171 to a taxon or size class (Table 17). The remaining specimens were either in very poor condition and had no clear landmarks, or were identified to elements I did not include in analysis (e.g., ribs). I did not formally record these specimens.

Approximately $90 \%$ of the remains I identified were linked to fish taxa that both Easton and I had recorded previously (Table 17). As in the replicability study, the remains were dominated by catfish (58\% of identified remains) and salmonids (19\%). I identified 17 small trout-like salmonid remains, which supports data from the replicability study showing small trout-like fishes are underrepresented in the assemblage. The remaining fishes that were already recorded in the assemblage - carps, flatfishes, and cods - comprised $11 \%$ of the fishes I identified to a taxon. 
Table 17. Fishes identified by Taber, from Easton's unidentified fishes. Asterisk denotes newly-identified taxa.

\begin{tabular}{|c|c|c|}
\hline Taxa & Common Name & NISP \\
\hline \multicolumn{3}{|l|}{ Centrarchidae } \\
\hline cf. Micropterus sp. $*^{1}$ & freshwater bass & 1 \\
\hline \multicolumn{3}{|l|}{ Clupeiformes } \\
\hline cf. Engraulidae* & anchovies & 2 \\
\hline Alosa sapidissima* & American shad & 10 \\
\hline \multicolumn{3}{|l|}{ Cyprinidae } \\
\hline Cyprinus carpio & common carp & 1 \\
\hline cf. Cyprinus carpio & common carp & 10 \\
\hline cf. Ptychocheilus oregonensis* & northern pikeminnow & 2 \\
\hline \multicolumn{3}{|l|}{ Ictaluridae } \\
\hline Ictalurus sp. or Ameiurus sp. & catfishes & 86 \\
\hline \multicolumn{3}{|l|}{ Gadidae } \\
\hline cf. Gadus macrocephalus & Pacific cod & 3 \\
\hline \multicolumn{3}{|l|}{ Pleuronectidae } \\
\hline Pleuronectidae (no finer taxa) & flounders & 2 \\
\hline \multicolumn{3}{|l|}{ Osmeridae } \\
\hline Thaleichthys pacificus* & eulachon & 2 \\
\hline \multicolumn{3}{|l|}{ Salmonidae } \\
\hline Salmonidae (no finer taxa) & salmon \& trout & 1 \\
\hline Salmonidae (small trout-sized) & small trout & 17 \\
\hline Oncorhynchus sp. & salmon & 7 \\
\hline Total & & 147 \\
\hline
\end{tabular}

${ }^{1}$ Likely represents largemouth bass (Micropterus salmoides), as smallmouth bass was not reported in local waters until the 1920 s.

I could not identify to taxon $14 \%(\mathrm{n}=24)$ of the specimens that I recorded (Table 18). Ten specimens I associated with large-bodied fishes compared favorably to salmonids; all of these were fragmented cleithra. The remaining specimens comprised one dentary, one opercle, one parasphenoid, and nine vertebrae. Two specimens I suggested were from medium-bodied fishes compared favorably to centrarchids. Finally, one specimen I suggest was from a small-bodied fish compared favorably to perch. The remainder I could only associate with a size class of fish. These fishes linked only to a 
Table 18. Fishes identified to size class, from Easton's previously unidentified fishes.

\begin{tabular}{llr}
\hline Taxa & Common Name & NSP \\
\hline Unidentified Taxa & & 3 \\
Large Fish (size class only) & - & 10 \\
Large Fish (cf. Salmonidae) & salmon \& trout & 7 \\
Medium Fish (size class only) & - & 2 \\
Medium Fish (cf. Centrarchidae) & sunfishes & 1 \\
Small Fish (size class only) & - & 1 \\
Small Fish (cf. Perciformes) & perch-like fishes & 24 \\
Total & & \\
\hline
\end{tabular}

size category are included in later analyses as unidentified small, medium, and large fishes.

I identified five additional fish species that Easton had not recorded elsewhere in the assemblage, represented in three additional taxa (Table 17). This brought the total number of families present in the assemblage from seven to 10 (Table 15, Table 17). Two of them (freshwater bass and American shad) were introduced fishes (Table 17). I had previously recorded one taxon (eulachon) in the replicability study. These five taxa had relatively low NISPs and accounted for only $10 \%$ of the previously unidentified fishes (Table 17). Taxonomic differences between our results were largely associated with rare fishes. These newly identified fishes were added to the final tally of fish remains from features, taking Easton's NISP from 1,135 to 1,271.

My analyses indicate that Easton consistently set aside fishes he could not identify. As such, my identification of Easton's unidentified fishes reiterates that his analysis effectively highlighted the major taxa present in the ichthyofaunal assemblage. 


\section{Bulk Sample Study}

There is no specific information on mesh size linked to faunal analysis except for some remains in Features 31 and 35, and likely Feature 15B (Table 19). I assume that most fish remains were recovered from field screening through $1 / 4$ " mesh, given the relatively large size of most fish specimens. During my work I could not confirm the volumes of fill or the total number of bulk samples taken. As such, I cannot accurately make comparisons between faunal remains recovered from bulk sampling and field screening. I noted the faunal remains that Easton stated were from bulk samples, and I identified the additional remains that were likely from bulk samples.

I found evidence for bulk samples taken from three features (Table 19). First, available Excel records listed a total of 108 remains from Feature 35 (Layer 3) as recovered from a bulk sample. Second, the 29 very small vertebrae Easton identified as Sardinops (all from Feature 15B) averaged $2 \mathrm{~mm}$ in diameter; it is very unlikely that these specimens were recovered from $1 / 4$ " or $1 / 8$ " field screens. No information on recovery methods were connected to these specimens. Due to their size, I assume they were recovered from a bulk sample. Third, I located a bag of screened bulk sample matrix excavated from Feature 31 (Layer DS). Field forms for all three features did not note the collection of bulk samples. The only record of bulk samples listed in the Excel database were for select elements from Feature 35. I did not reexamine all specimens Easton identified or I inferred to be from bulk samples. Fifteen specimens from Feature 35 were ribs (an element I did not include in analysis); another 10 Easton identified as being badly fragmented (Table 19). 
Table 19. Information available on bulk sample collections in Esther Short neighborhood excavations.

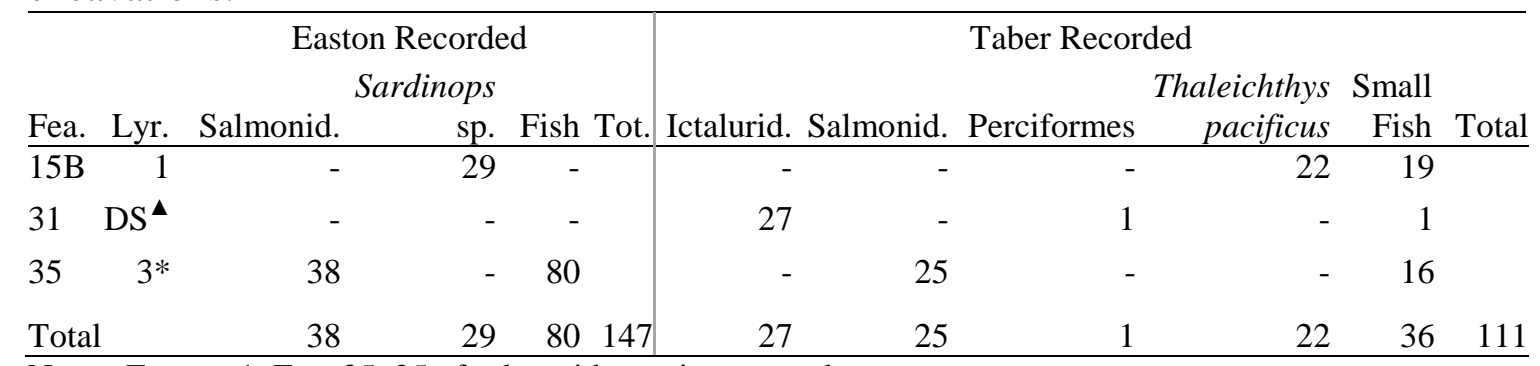

Notes, Easton: 1. Fea. 35, 25 of salmonid remains are scales.

Notes, Taber: 1. Fea. 15B, 3 remains noted as small fish cf. to Sardinops sp. 2. Fea. 35, 25 salmonid remains are cycloid scales, cf. Salmonidae.

I identified 29 additional specimens than what Easton had identified from the Feature 31 bulk sample (Table 19). I identified 27 of the 29 specimens as catfish - a species that was both already abundantly noted in the assemblage, and which is not a fish so small that its elements are most likely to be encountered in fine mesh screens (Table 19). One of the remaining two specimens was most similar to centrarchid remains. Centrarchids were also represented outside of bulk samples (Table 19). I could not identify the final specimen to a taxon and classified it as from a small fish (Table 19). The small vertebrae that Easton identified as sardine-like, and I identified as eulachon, were represented only through bulk sample collection.

The 25 scales recovered from bulk sampling allowed me to suggest some fish acquisition patterns. Easton identified the scales as salmonid; they compared favorably to salmonid scales, or minimally cycloid scales. If the scales are indeed for salmonids, the fish(es) that produced the scales likely do not represent a market purchase. Based on Singer's (1987) interpretation of scales in an assemblage, these scales could indicate personal catch of salmon or trout (see discussion below). 


\section{Overview of Ichthyofaunal Results}

A total of 1,306 specimens are in the ichthyofaunal assemblage (Figure 10). This count included 24 specimens identified only as a size class of fish. I identified an additional three fish families: Centrarchidae, Engraulidae, and Osmeridae. This expanded the total number of families represented in the assemblage to 10 (Figure 10). Catfishes dominated the assemblage (74\%). Salmonids accounted for an additional 15\%. The remaining families and sub-families accounted for $9 \%(\mathrm{n}=119$; Figure 10). I also recorded new species within taxa Easton had previously recorded (e.g., Easton identified sardines, and I identified anchovies and American shad, all of which are clupeids). Fishes

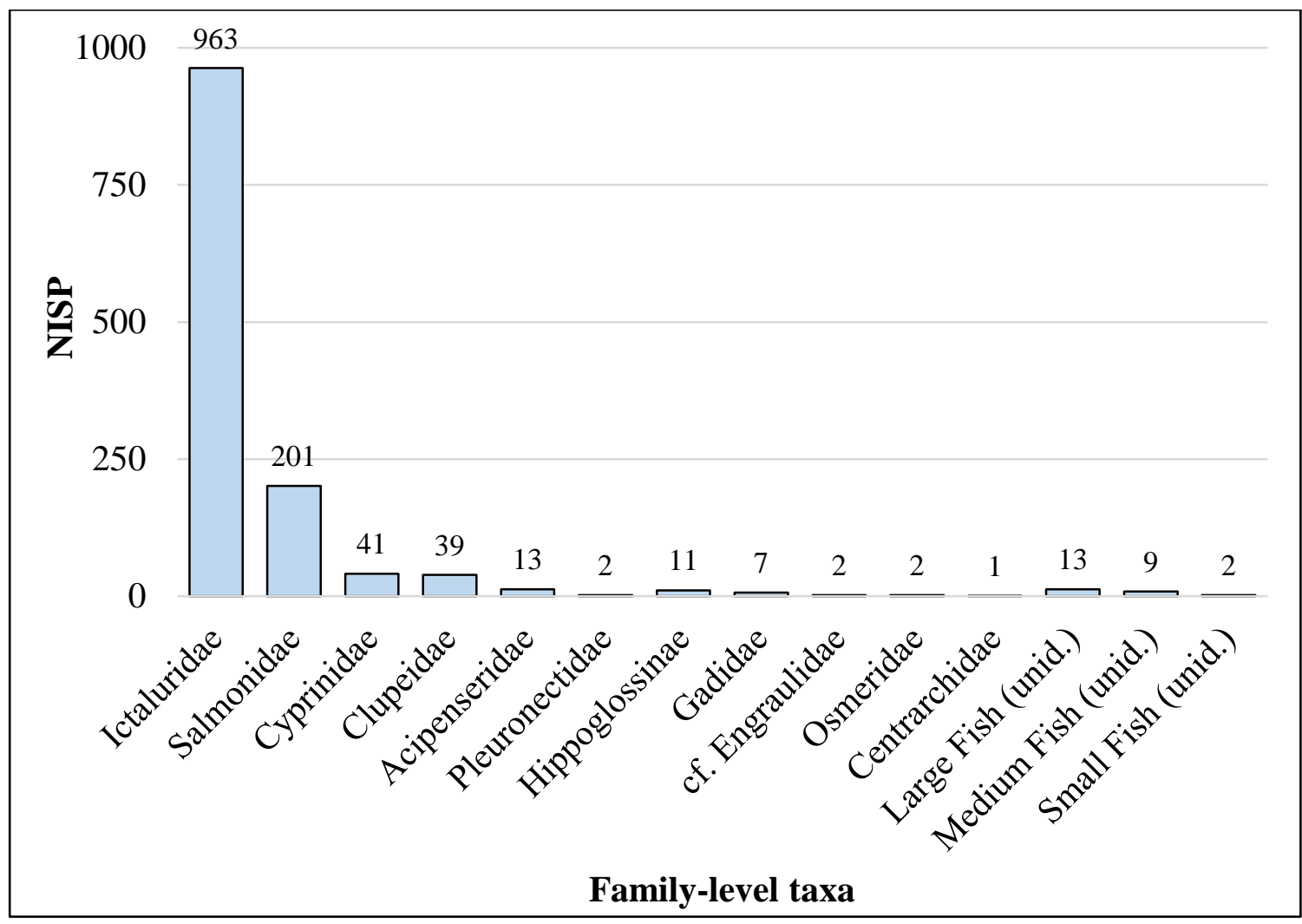

Figure 10. Relative diversity and abundance of fish taxa (family-level) from Esther Short neighborhood features. Tally includes specimens collected through bulk sampling. 
identified only to a size class comprised less than $2 \%$ of the assemblage, and fishes identified through bulk sampling accounted for less than $3 \%$ of the assemblage $(n=36)$. A descriptive summary of the ichthyofaunal remains is included in Appendix E.

Several striking trends are visible when looking at the distribution of fish remains across features (Figure 11; Table 20). Seventy-eight percent of all fish remains were recovered from three features: Features 31, 35, and 76 (Figure 11; Table 20). Features 31 and 76 accounted for most of the neighborhood's catfish remains, and Feature 35 accounted for most of the neighborhood's salmonid remains (Table 20). As such, these features were ideal for a more detailed examination of the neighborhood's prominent fish consumption patterns. Body part representation for catfishes and butchered fish remains in these features are discussed later in this Chapter. Tenant histories associated with these three features are included in Appendix A.

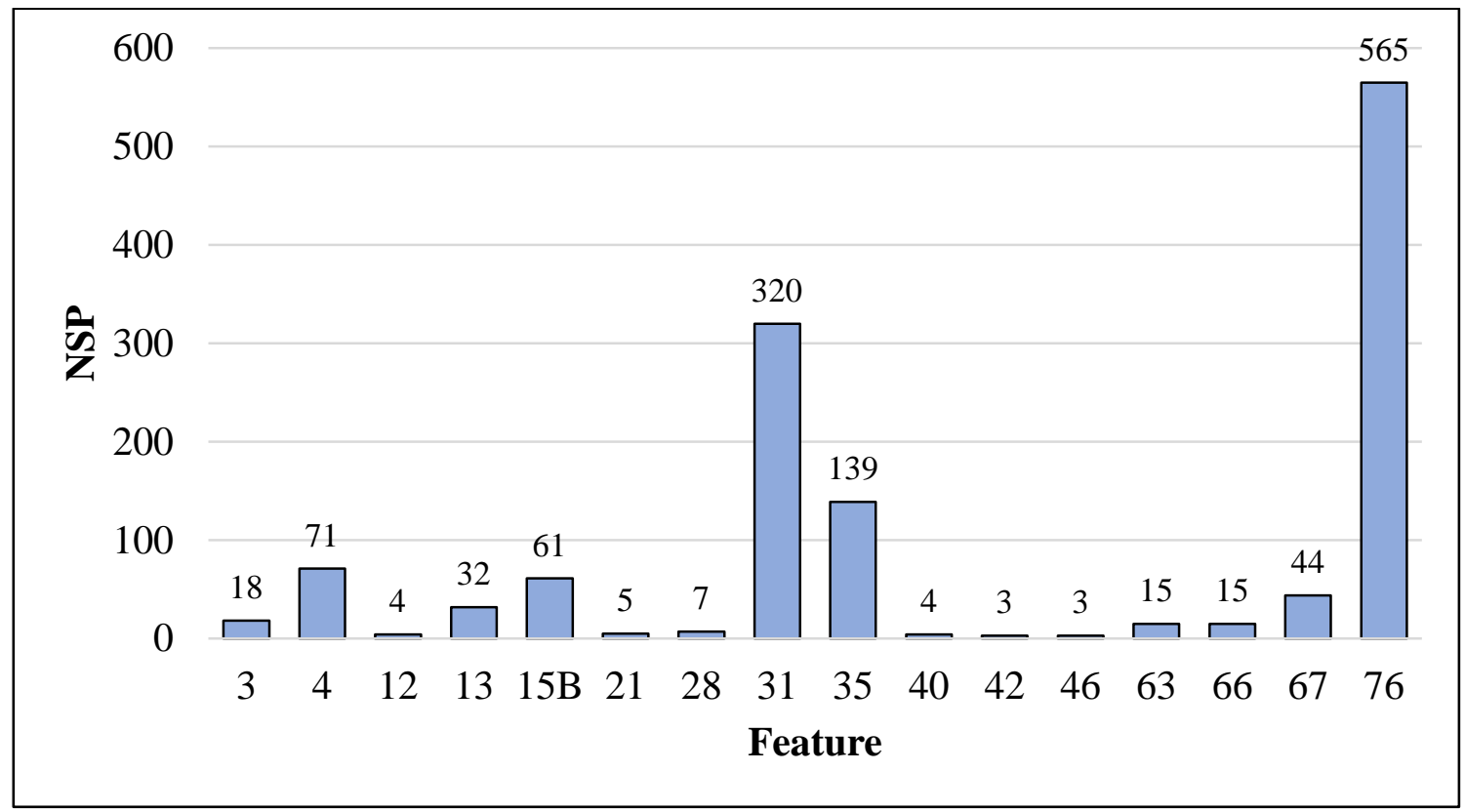

Figure 11. Relative distribution of fish faunal remains across Esther Short features. 
Thirteen of the 16 features included introduced fishes (Table 20). The most common introduced fish was catfish. (Table 20). It was also the most ubiquitous introduced fish, and was recorded in nine features. Carp had the second-highest NISP for any introduced fish, accounting for $3 \%$ of the fish assemblage. Carp was also present in more features $(n=5)$ than any of the remaining introduced fishes. The remaining four introduced taxa were recorded in seven features (Table 20).

Fourteen of the 16 features included native fishes. The most commonly recovered remains were identified as salmonids. Twenty-four of the salmonid remains were similar to remains from small-bodied trout, and could be from non-native fishes stocked in local waters, or smaller-bodied native fishes (e.g., Eastern brook trout; see Newspaper Trends discussion above). In my replicability study, I recorded an additional 10 small trout-like specimens, further indicating small trout may be under-represented in the NISP.

Though catfish remains were more dominant, salmonid remains were more ubiquitous: every feature except for Feature 63 included at least one specimen identified as salmon or trout (Table 20). Fifty-five percent of the total salmonid remains were recovered from Feature 35. Small salmonid remains (associated with small-bodied trout, and presumed to be part of personal catch) were primarily recorded in Features 31 and 76. All 32 specimens Easton identified as "small catfish" were from Feature 31; I reclassified many of his "small catfish" specimens as "small trout", providing evidence that small trout-like remains are probably underrepresented across the site. 


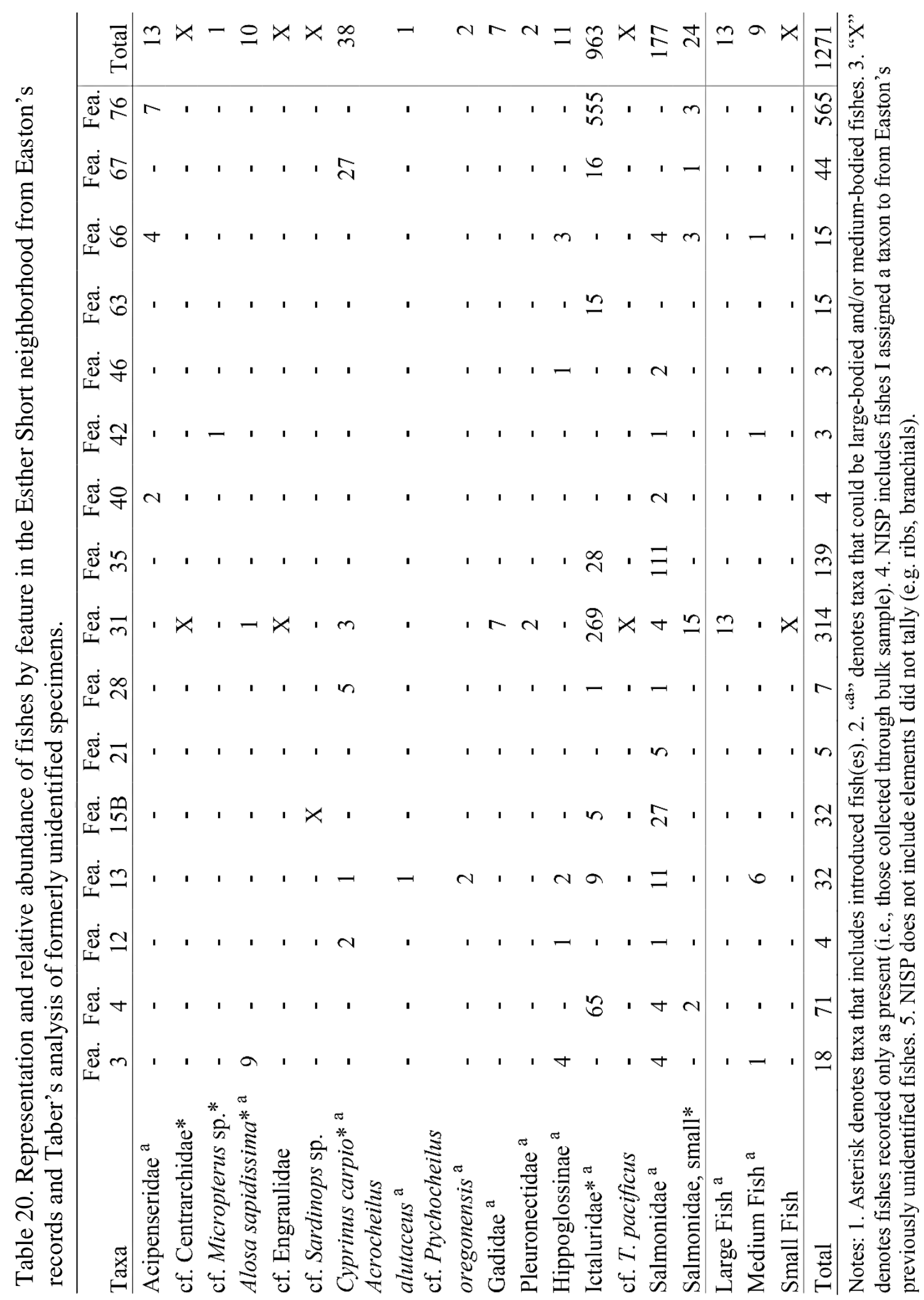


The remaining fish families each accounted for less than $10 \%$ of the total NISP (Table 12; Table 20). Five of the ten families identified in the assemblage included introduced fishes: catfishes, carp, shad, sunfishes, and potentially some small trout. Feature 31 had the largest variety of taxa $(n=9$, Table 20). Four of these were newlyidentified taxa: generalized centrarchids, American shad, fishes resembling engraulids, and eulachon. Feature 31 also had the largest number of introduced taxa. Because bulk samples were collected from Feature 31, the broader variety of taxa - particularly of small-bodied fishes associated with fine mesh screening - are likely the result of field methods, and the absence of these fishes in other features may not be the result of historical human behavior. Altogether, medium- and large-bodied fish taxa were more prevalent than smaller-bodied fishes.

In comparison, Feature 76 (from which no bulk samples were collected) included only three taxa, all of which can be associated with medium- to large-bodied fishes (sturgeon, catfish, and salmonids). Ninety-eight percent of the fish NISP in Feature 76 was identified as catfish.

\section{Situating Fish Faunal Remains into the Economic Fish Ranking}

Whether or not a fish was ranked, and how costly that fish was (including market fishes that were not ranked) has implications on whether the fishes were part of personal catch or market purchases. Situating fish remains in the economic ranking allowed me to interpret which fishes were market-purchased and which were noncommercial, as well as identify trends in use of disposable income. This included any patterns of residents 
Table 21. Esther Short neighborhood fish remains and primary market fishes, ranked by economic value (1880-1910).

\begin{tabular}{|c|c|c|c|c|c|c|}
\hline \multirow[b]{2}{*}{ Taxa } & \multirow[b]{2}{*}{ Common Name } & \multirow[b]{2}{*}{ NISP } & \multirow[b]{2}{*}{ Ranking } & \multicolumn{2}{|c|}{ Newspaper } & \multirow{2}{*}{$\begin{array}{r}\text { Inferred } \\
\text { acquisition } \\
\end{array}$} \\
\hline & & & & Price & Ref. & \\
\hline cf. Micropterus sp. & freshwater bass & 1 & High & - & $\mathrm{X}$ & market/personal \\
\hline Morone saxatilis & striped bass & - & High & $\mathrm{X}$ & $\mathrm{X}$ & market/personal \\
\hline Acipenser sp. & sturgeon & 13 & High & $\mathrm{X}$ & $\mathrm{X}$ & market \\
\hline Alosa sapidissima & American shad & 10 & High & $\mathrm{X}$ & $\mathrm{X}$ & market/personal \\
\hline Ictalurus or Ameiurus spp. & catfishes & 963 & High & $\mathrm{X}$ & $\mathrm{X}$ & market \\
\hline Salmonidae (medium/large) & salmon \& lg. trout & 177 & High/Low & $\mathrm{X}$ & $\mathrm{X}$ & market/personal \\
\hline Pomoxis spp. & sunfishes & - & Low & $X$ & $\mathrm{X}$ & market/personal \\
\hline Hippoglossinae & Pacific halibut & 11 & Low & $\mathrm{X}$ & $\mathrm{X}$ & market \\
\hline Anoplopoma fimbria & sablefish & - & Low & $X$ & $\mathrm{X}$ & market \\
\hline Pleuronectidae & flounders & 2 & Low & $\mathrm{X}$ & $\mathrm{X}$ & market \\
\hline Sebastes ruberrimus & yelloweye rockfish & - & Low & $\mathrm{X}$ & $\mathrm{X}$ & market \\
\hline Clupea pallasii & Pacific herring & - & Low & $\mathrm{X}$ & $\mathrm{X}$ & market/personal \\
\hline Sebastes alutus & Pacific ocean perch & - & Low & $\mathrm{X}$ & $\mathrm{X}$ & market \\
\hline Thaleichthys pacificus & eulachon & 2 & Low & $\mathrm{X}$ & $\mathrm{X}$ & market/personal \\
\hline Gadus macrocephalus & Pacific cod & 4 & Low & $\mathrm{X}$ & $\mathrm{X}$ & market \\
\hline cf. Sardinops sp. & pilchards & 29 & - & - & $\mathrm{X}$ & market \\
\hline cf. Engraulidae & anchovies & 2 & - & - & $\mathrm{X}$ & market \\
\hline Cyprinus carpio & common carp & 38 & - & $\mathrm{X}$ & $\mathrm{X}$ & market/personal \\
\hline cf. Centrarchidae & sunfishes & 1 & - & - & $\mathrm{X}$ & market/personal \\
\hline Salmonidae (small) & small trout & 24 & - & - & $\mathrm{X}$ & personal \\
\hline cf. Ptychocheilus oregonensis & Northern pikeminnow & 2 & - & - & - & personal \\
\hline cf. Acrocheilus alutaceus & chiselmouth & 1 & - & - & - & personal \\
\hline Total & & 1280 & & 9 & 13 & \\
\hline
\end{tabular}

Notes: NISP includes all fishes Easton recorded (including from bulk samples) and all previously unidentified specimens Taber assigned to a taxon.

focusing more heavily on introduced or native fishes, and whether such patterns were connected to the price of the fish.

I linked nine taxa to fishes represented in the economic model of ranked fishes: black bass, sturgeon, salmonids (not including small trout-like remains), American shad, catfish, halibut, other flounders, eulachon, and Pacific cod (Table 21). These nine fishes comprised $84 \%$ of the fish remains from the Esther Short neighborhood (Table 21). Four 
of these were low-ranked fishes, three were high-ranked fishes, and one (Salmonidae) could represent either a high- or low-cost purchase, if bought. Catfishes had the highest NISP of the ranked fishes (by an approximate ratio of 3:4). Salmon and large trout had the second most abundant remains of the ranked fishes (Table 21). Anchovies, pilchards (i.e., sardines), carp, and small trout were recorded in the assemblage and discussed or advertised in newspapers, but were not included in the economic ranking (Table 21). It is possible that anchovy represented a bait fish, another indication of noncommercial angling (Gibson 2009:265). The high frequency of remains associated with taxa assigned to the ranking shows a high potential for purchased fishes.

Most of the fish remains associated with taxa ranked by market ads reflect lowcost purchases (Table 21). Two of the fishes were ranked as high (black bass and sturgeon). A third fish (Salmonidae) may represent either high or low ranked (mediumand large-bodied salmonids, which might represent steelhead trout [high cost], Chinook salmon [low cost], or an unranked salmonid). The remaining fish remains were not assigned a ranking, either because they were not advertised or had fewer than four market prices apiece.

Six fishes represented in the assemblage likely represent only market purchases (Table 21). Due to its size, sturgeon required more specialized equipment than was likely available to neighborhood residents (and which newspapers identified as more costly than "basic" equipment like "trout hooks"). Pilchards and anchovies were represented as uncommon locally. Accessing fishing environments for pleuronectids and Pacific cod would have required substantial travel in addition to specialized equipment. It is unlikely 
that neighborhood residents were arranging ocean fishing trips off of coastal Washington and Oregon. Of all six fishes, only anchovies and pilchards were not ranked (Table 11, Table 21). These two fishes were listed in newspaper advertisements as canned fishes, so inferences on acquiring them fresh in markets is not as well-evidenced as for other market-bought fishes.

An additional seven fishes could represent either market purchases or personal catch: freshwater bass, salmon and large trout, American shad, catfishes, eulachon, sunfishes, and common carp (Table 21). These fishes were both available in markets (Table 7), accessible in local waters (Table 10), and could be caught with basic fishing equipment. Four of these fishes were linked to a ranked taxon (Table 21). Eulachon were often targets in noncommercial fishing. The cost of black bass may have deterred market purchases in favor of personal catch. There is not strong evidence in archival or zooarchaeological data to show whether the American shad was more likely bought or personally caught. While catfishes could be caught, there were more indications they were purchased from markets, primarily as low-cost head portions to be used in soups and stews (see discussion below).

Salmon and large trout could be either caught or purchased. Remains from largerbodied specimens are more likely market purchases. They were readily available in markets (Chinook salmon especially so), and the sizes of larger salmonids may have made them unsuitable for personal catch with basic equipment. While the NISP for small salmonid remains was relatively low (see discussion above), because small trout could not legally be sold (see Chapter 3), small trout represented in the assemblage are most 
likely from personal catch. While the salmonid scales are associated with noncommercial fishing, they could be from either salmon, large trout, or small trout.

Fishes that were not ranked (i.e., had fewer than four advertised prices), and particularly fishes that were not referenced in newspapers at all, were associated with personal catch. Remains from generalized centrarchids and cyprinids (including carp) were not explicitly ranked. Centrarchid remains not identified as black bass could represent either a ranked or a non-ranked fish. While common carp was a market fish, its reputation became so negative that carp may have been caught in subsistence fishing more often than purchased. However, because the Esther Short neighborhood included some working-class residents, it is still possible that carp was purchased simply because it was one of the lowest-cost fishes in markets. Other cyprinids (Northern pikeminnow and chiselmouth) represented noncommercial fishes because they were neither advertised in newspapers, nor even discussed.

Six taxa assigned a ranking in the archival study were not represented in the assemblage: striped bass, crappie (which could be a centrarchid), sablefish, yelloweye rockfish, Pacific herring, and Pacific ocean perch (Table 11, Table 21). All of these unrepresented fishes were assigned a low ranking, with the exception of striped bass.

When organized by economic rank, fish taxa from the Esther Short neighborhood were more frequently associated with low-cost fishes than high-cost fishes. This was true both by taxon and by the NISP of each ranked fish. Though seven taxa could be associated with either market purchases or noncommercial fishing, my work shows that catfishes were probably market purchases (see discussion below). Thus, taxa associated 
with market-bought fishes comprised a higher percentage of the total fish assemblage, indicating an overall pattern of low-cost fish purchases with some variation in higherpriced purchases and noncommercial fishing.

\section{$\underline{\text { Insights from Body Part Representation }}$}

Singer (1982a, 1985, 1987) illustrated that body part representation can both broadly inform both fish acquisition and, if fishes were purchased, the units in which they were bought (Table 22). Professionally-butchered and store-bought fishes were typically scaled before being sold (Table 22). When only partial skeletons are recovered, they indicate the fish was most likely purchased in portions (Table 22).

To create a measure of body part representation, I calculated the minimum animal unit (MAU) and percentage of minimal anima unit (\%MAU) for catfish and salmonids in the three features they were most common in (Features 31, 76, and 35). The MAU is a measure of body part representation that normalizes the number of times an element occurs in an assemblage by the number of times it appears in a complete skeleton for that fauna (Lyman 1994). The \%MAU calculates the frequency of the MAU for each represented element as a percentage of the highest MAU (which is set at 100\%). I did not calculate \%MAU for other taxa in the assemblage because of small sample sizes (the NISP in all other features was fewer than 75, and in nine features the NISP was fewer than twenty [Table 20]). By examining body part representation of catfish and salmonids, I can better reconstruct the original human behavior that resulted in the deposition of fish remains, and if possible differentiate between human behavior and post-depositional 
Table 22. Archaeological markers for fish portions acquired in markets or through personal catch, adapted from Singer (1982a, 1985, 1987)

\begin{tabular}{|c|c|c|c|c|}
\hline $\begin{array}{l}\text { Body part } \\
\text { representation }\end{array}$ & $\begin{array}{l}\text { Element(s) } \\
\text { present }\end{array}$ & $\begin{array}{l}\text { Inferred } \\
\text { portion }\end{array}$ & Inferred acquisition & Inferred cost \\
\hline Full body & whole skeleton & whole fish & market/personal catch & medium/high \\
\hline Scales & - & whole fish & market/personal catch & medium/high \\
\hline Post-cranial & vertebrae & fish steaks & market & high \\
\hline $\begin{array}{l}\text { Post-cranial } \\
\text { (potentially) }\end{array}$ & $\begin{array}{l}\text { ribs } \\
\text { (potentially) }\end{array}$ & fillets & market & medium/high \\
\hline Head & $\begin{array}{l}\text { cranial } \\
\text { elements }\end{array}$ & heads & market & low \\
\hline
\end{tabular}

Notes: 1. There are few archaeological markers for fillets. 2. It is less likely, but abundant cranial elements (head portions) could also represent purchased whole fishes that were cleaned and decapitated at home. This would still require that post-cranial remains be deposited elsewhere, or otherwise absent from the assemblage.

effects on body part representation within the assemblage.

I tallied the abundance of catfish and salmonid elements to establish MAU in

Features 31, 35, and 76. I then compared the total for each element to the frequency that should be present in a whole fish. For example, a complete fish includes two cleithra and one parasphenoid. If I recorded four parasphenoids, portions from at least four individuals were deposited. Some elements in fishes are meristic, or vary from species to species (e.g., a carp will not have the same number of vertebrae as a salmonid). To determine the number of vertebrae in a given taxon, I used both biology and fisheries sources and comparative specimens.

Feature 35: Salmonid \%MAU

Salmonids were largely represented by body portions involving vertebrae (Figure 12). Cranial and pectoral elements were equally represented, showing that salmonid heads and pectoral fins were deposited with similar frequency (Figure 12). Multiple 
elements from Feature 35 were inappropriate to use in calculating \%MAU, but further signified depositing salmonid heads (e.g., branchial arches). Additionally, cranial elements accounted for $13 \%$ of the salmonid NISP across the neighborhood (Appendix E). The high cranial and vertebral recovery rates show salmonid heads and bodies were being deposited, either whole or in separate portions.

Because trout could not be legally sold, and the majority of trout-like remains are cranial elements, small salmonid remains probably represent noncommercial fishing. While medium- and large-bodied salmonids could have been purchased whole, the presence of salmonid scales provides limited evidence of salmonids as personal catch. However, salmonid scales were recovered from one bulk sample and accounted for a very

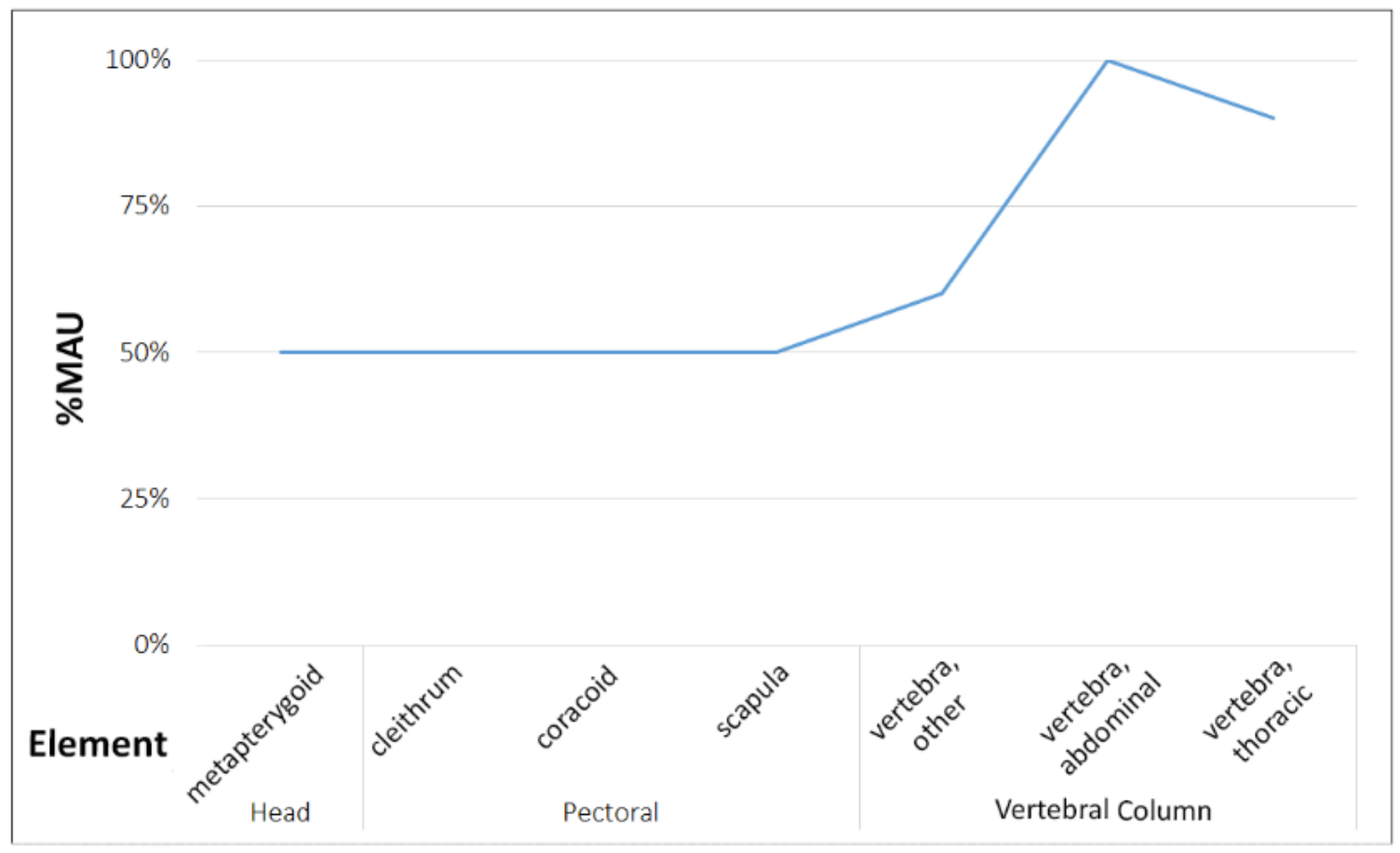

Figure 12. \%MAU for salmonid remains from Feature 35. 
small portion of the assemblage; they are not useful in tracking \%MAU, so were not included, and interpretations based on presence or absence of remains should be conservative.

Relative to many other archaeological sites in the Pacific Northwest, recovering salmonid cranial elements in such high frequency is very rare (Butler and Chatters 1994). This supports the argument that faunal remains deposited in privies preserve very well, and that the remains recovered evidence human behaviors without being greatly affected by post-depositional processes.

\section{Feature 31: Catfish \%MAU}

A high frequency of catfish cleithra were recovered from Feature 31 (Figure 13). Other elements in the pectoral fin portion of the fish were also recorded in high frequency (Figure 13). This indicates a high rate of depositing pectoral fins, but market portions including pectoral fins are only associated with whole fishes. The cleithrum is relatively close to the fish head, and it could have been included in a "head" market portion of a catfish, depending on how the catfish was butchered.

Whole or partial crania accounted for over half of the \%MAU, along with disarticulated cranial elements like the mesoethmoid and hyomandibula (Figure 13). This shows that a large number of catfish heads were deposited. As with salmonids, the presence of articulated (and often complete) catfish crania indicates good preservation.

Vertebrae were very under-represented for what would be expected if remains from whole catfish or catfish body portions were frequently deposited. In Feature 31, vertebrae account for $4 \%$ of the MAU, none of which were modified second vertebrae 
(Figure 13). In order to get such a low bone representation, vertebrae would either be very low-density, or - more likely, given the state of preservation (i.e., articulated fish crania) - vertebrae were never deposited. As such, there is little evidence of purchasing catfish bodies. Instead, the \%MAU from Feature 31 indicates that fish heads and some elements adjacent to fish heads were deposited, evidencing market purchases of fish heads.

Feature: 76 Catfish \%MAU

The patterns of body part representation for catfishes in Features 76 and 31 were very similar (Figure 13). As with Feature 31, the abundance of cleithra in Feature 76 showed a high depositional rate of pectoral fin segments, and cleithra accounted for the highest \%MAU.

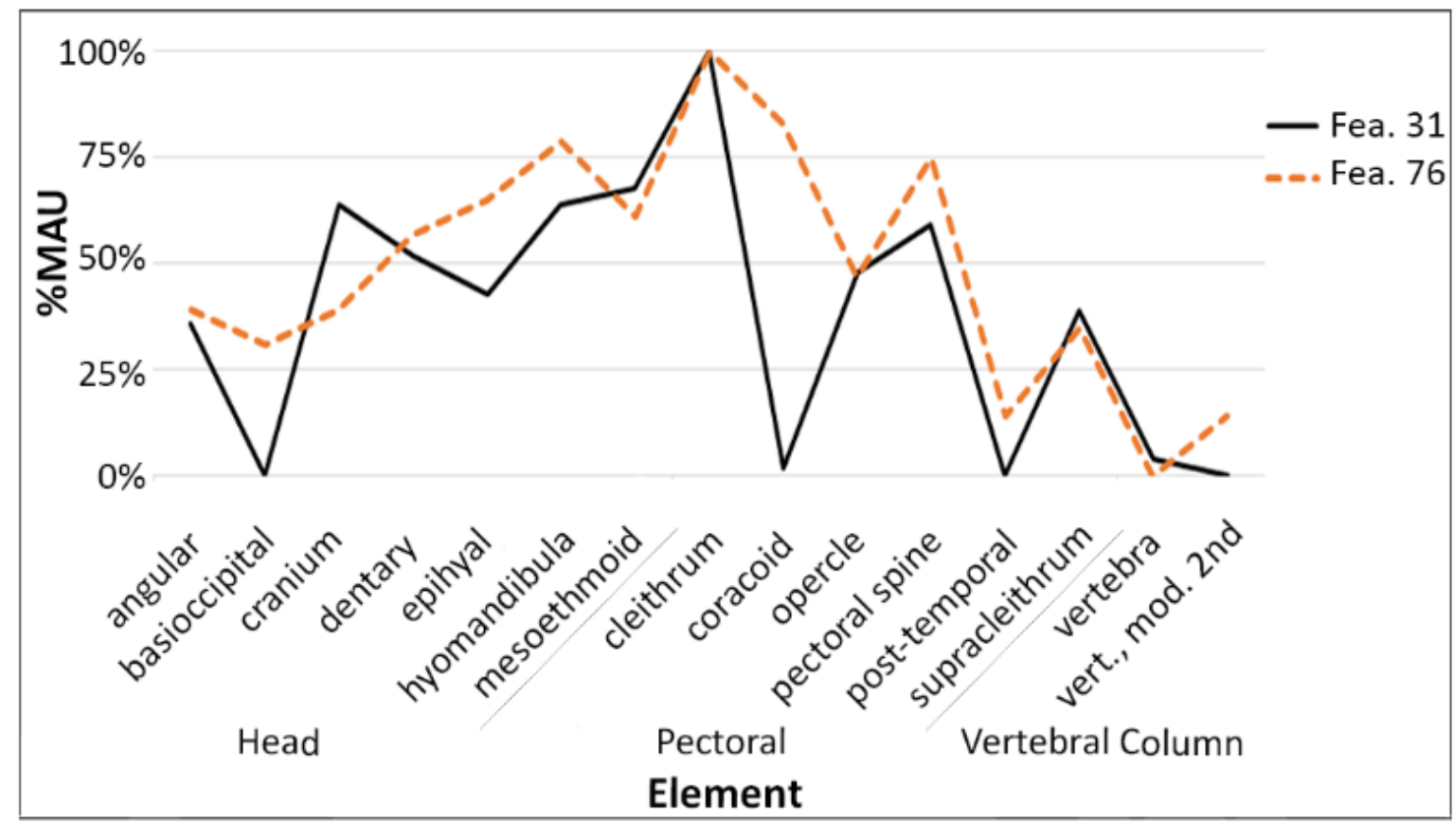

Figure 13. \%MAU for catfishes in Features 31 and 76. "Cranium” denotes Easton's tally of articulated catfish cranial elements (typically a partial or complete dorsal cranium). 
The \%MAU for cranial elements in Feature 76 showed the same general trend with varying representation depending upon the element (Figure 13). Partially or wholly intact crania were represented at a lower percentage than in Feature 31. Feature 76 had higher percentages of most cranial elements. This still evidences overall good preservation, and a high representation of catfish head portions.

Fourteen percent of the MAU was represented by the modified second vertebrae (Figure 13). No other vertebrae were recorded in this feature at all. The modified second vertebrae is adjacent to the skull; as with cleithra, this element could have been included in "head" portions of a catfish, depending on how the fish was butchered.

As with Feature 31, Feature 76 had high depositional rates for catfish heads (and adjacent body sections). Feature 76 had no representation for the post-cranial body (Figure 13). The absence of vertebrae shows that while catfish heads were being deposited, catfish bodies were infrequently deposited, if at all.

There were notable differences between catfish portions in Features 31 and 76 and salmonid portions in Feature 35. Head portions had somewhat similar representation. This was true both in that the high \%MAU for fish crania is somewhat unusual, and that it indicates frequent fish head deposits. Catfish vertebrae were almost entirely absent from the sitewide assemblage $(n=81)$; this was reflected in Features 31 and 76 . The high representation of other elements in both catfishes and salmonids - and the high \%MAU for salmonid vertebrae - indicates that catfish vertebrae should have preserved, were they deposited. 


\section{Bone Density}

Element survivorship is also of concern to zooarchaeologists. When archaeologists use animal portions to track human behavior (as is the case with meat rankings), they need to consider element survivorship for each animal portion. If the bones associated with each portion do not have the same density, then portions with less robust bones may not be recovered in the same frequency in which they were deposited. Given this, the density of fish elements must be considered in interpreting what the variable frequency of different body parts in an assemblage means (Butler and Chatters 1994; Faith and Gordon 2007; Lubinski 1996; Nicholson 1996a, 1996b; Smith et al. 2011). However, fish bone density has only been established for four taxa in the Esther Short assemblage (salmonids, cyprinids, flat fishes, and codfishes). Most of these taxa have poor representation in the assemblage (Table 20), and lack the sample sizes to address the role of bone density in body part representation. Independent records of catfish element density have not been generated.

In previous studies, salmonid cranial elements have been shown to have a lower bone density than post-cranial elements (Butler and Chatters 1994). The abundance of salmonid vertebrae in the Esther Short assemblage may in part be caused by this. However, because partially articulated heads (with lower bone density) are in the assemblage as well, post-depositional decomposition likely does not explain salmonid body part representation, and the elements present are instead a reflection of human behavior. 
Given the empirical records of the fish faunal assemblage (high frequency of articulated and low-density elements; elements showing very little damage), even considering limitations in bone density knowledge for catfishes, I suggest that these features evidence limited post-depositional destruction. As such, bone density is not of major concern in interpreting the \%MAU.

\section{Inferred Fish Portions}

Fishes represented in the Esther Short assemblage illustrate a mix of purchased fish heads, fish steaks, and whole fishes (Table 23). Caught fishes would logically represent acquiring whole individuals. Whether whole fishes were then butchered offsite, with desired portions then brought into the household, can be interpreted through the quality of butchery marks. However, doing so is beyond the scope of my study here. Given available data, I also cannot address whether any market-linked fishes from the assemblage were likely bought as fillet portions. Though I don't discuss it further, it is a possibility for all medium- and large-bodied market fishes.

Salmon were probably purchased as steaks. Additionally, some were purchased

either whole, as head portions, or caught whole (Table 23). The high representation of salmonid vertebrae is a marker for steak purchases. Cranial elements signify whole market purchases, a combination of fish head and fish steak purchases, or of sport fishing for smaller salmonids.

Catfishes were bought from markets as heads (Table 23). As noted, recorded elements positioned close to the crania may have been included in catfish "head" 
Table 23. Acquisition and portions of Esther Short fishes.

\begin{tabular}{|c|c|c|c|c|c|c|}
\hline Taxa & Common name & $\begin{array}{l}\text { Archival } \\
\text { Acquisition }\end{array}$ & $\begin{array}{l}\text { Freq. of } \\
\text { remains }\end{array}$ & $\begin{array}{l}\text { Portion } \\
(\% \mathrm{MAU})\end{array}$ & $\begin{array}{c}\text { Portion } \\
\text { (butchery) }\end{array}$ & Market portion \\
\hline Hippoglossinae & Pacific halibut & $\mathrm{L} / \mathrm{M}$ & low & - & - & whole \\
\hline T. pacificus & eulachon & M & low & - & - & whole \\
\hline cf. Engraulidae & anchovies & M & low & - & - & whole \\
\hline cf. Sardinops sp. & pilchards & M & mod. & - & - & whole \\
\hline Pleuronectidae & flounders & $\mathrm{L} / \mathrm{M}$ & low & - & steaks & steaks \\
\hline G. macrocephalus & Pacific cod & $\mathrm{L} / \mathrm{M}$ & low & - & steaks & steaks or whole \\
\hline Ictaluridae & catfishes & $\mathrm{L} / \mathrm{S} / \mathrm{M}$ & high & $\begin{array}{l}\text { heads or } \\
\text { whole }\end{array}$ & $\begin{array}{l}\text { heads or } \\
\text { whole }\end{array}$ & heads or whole \\
\hline cf. Centrarchidae & sunfishes & $\mathrm{L} / \mathrm{S}$ & low & - & - & $\begin{array}{r}\text { whole (or } \\
\text { noncommercial) }\end{array}$ \\
\hline A. sapidissima & American shad & $\mathrm{L} / \mathrm{S} / \mathrm{M}$ & low & - & - & $\begin{array}{r}\text { whole (or } \\
\text { noncommercial) }\end{array}$ \\
\hline $\begin{array}{l}\text { Salmonidae } \\
\text { (medium/large) }\end{array}$ & salmon, lg. trout & $\mathrm{L} / \mathrm{S} / \mathrm{M}$ & high & $\begin{array}{l}\text { heads or } \\
\text { whole }\end{array}$ & $\begin{array}{l}\text { steaks or } \\
\text { whole }\end{array}$ & $\begin{array}{r}\text { steaks or whole (or } \\
\text { noncommercial) }\end{array}$ \\
\hline Acipenser sp. & sturgeon & M & low & - & - & unknown portion \\
\hline cf. A. alutaceus & chiselmouth & $\mathrm{L}$ & low & - & - & noncommercial \\
\hline cf. P. oregonensis & N. pikeminnow & $\mathrm{L}$ & low & - & - & noncommercial \\
\hline Salmonidae (sm.) & small trout & $\mathrm{L}$ & low & $\begin{array}{l}\text { heads or } \\
\text { whole }\end{array}$ & whole & noncommercial \\
\hline cf. Micropterus sp. & freshwater bass & $\mathrm{L} / \mathrm{S} / \mathrm{M}$ & low & - & - & noncommercial \\
\hline C. carpio & common carp & $\mathrm{S} / \mathrm{M}$ & mod. & - & - & noncommercial \\
\hline
\end{tabular}

Notes: 1. Inferred catch: (L)eisure, (S)ubsistence, (M)arket. 2. General frequency of remains: low (25 or fewer), moderate (26-100), high (101+).

portions. Butchery analysis provides additional evidence of this practice (see discussion below).

I inferred the portions of the remaining fishes in the assemblage largely from archival research. Butchery information also informed on some of my portion assignments (Table 23). I identified pleuronectids, sturgeon, all small-bodied fishes, and Pacific cod as market purchases (Table 23). Halibut and other flounders were most likely purchased as steaks. All small-bodied fishes would have been sold whole. Pacific cod could represent either steaks or whole fish purchases. I could not link sturgeon to a specific portion, though it was most likely bought in portions. Archival data provided no 
indication on market portions of sturgeon in the Portland area, beyond by-the-pound sales (Table 5), and sturgeon remains were too limited for meaningful analyses (Table 20). Some fishes were available both in local waters as personal catch and from markets (Table 23). All cyprinids were likely acquired whole through personal angling. When they were bought from markets, American shad was likely bought whole.

\section{Leisure and Subsistence Catch}

The distinction between leisure and subsistence fishing was not prominent in a lower-middle class to working class setting. Leisure and subsistence fishing are activities defined by societal standards, which cannot always be linked to clear archaeological markers. When interpreting social actions that aren't set either within the absolute social apex or nadir of a community, terms like 'leisure fishing' and 'subsistence fishing' are difficult to use independently because the activity can encompass both.

Altogether, nine fishes were available in personal catch: freshwater bass and other sunfishes, salmon, trout, American shad, catfish, eulachon, common carp, chiselmouth, and Northern pikeminnow (Table 21). I found all of these represented a mix of leisure and subsistence fishing, with the possible exception of small trout and common carp. For example, catfishes were noted as targets of both subsistence and leisure fishing in archival sources. They were popular food fishes, and a common target in subsistence fishing for middle- and working-class neighborhoods like the Esther Short neighborhood (Landerholm 1966). Artifact assemblages from Features 31 and 76 evidenced schoolaged children; at least one modern examination of cultural food values in the Victorian 
and Progressive eras (Anderson 2015) stated that at the turn of the century it was popular for young boys to fish for catfishes in the Columbia River, which neighborhood occupants could access with relative ease. There were few to no direct statements about the remaining fishes.

While small trout could be part of subsistence catch, they were referenced so frequently as popular sport fishes that I inferred they would be more commonly targeted as leisure catch. I categorized common carp as a subsistence fish due to how notably unpopular it was (see discussion below).

Marine fishes identified as good for leisure- or sport-catch (e.g., lingcod; rockfish) were largely absent from the assemblage. Remains of marine fishes, when recovered, were mostly vertebrae (Appendix E). This supports my inference that neighborhood residents were making limited purchases of marine fishes as steaks, and not targeting these fishes in personal marine angling trips.

\section{$\underline{\text { Butchery Marks }}$}

Butchery marks are an important factor in determining fish acquisition method. The qualities of butchery marks can indicate whether a fish was part of personal catch, or purchased from a market. Interpreting butchery marks relies on similar markers to body part representation: butchered post-cranial elements indicate processing a whole fish, butchered vertebrae indicate a steak portion, and so on.

I based identification of butchery marks on studies by several archaeologists (Binford 1981; Horton 2010, 2014; 2017 personal communication; Lyman 1987a; Walker 
and Long 1977; Willis 2014; Willis and Boehm 2014, 2015; Willis et al. 2008). I examined all ichthyofaunal specimen in the collection for cut marks using an optical magnifying visor with $2.5 \mathrm{x}$ lens magnification. If an element had unclear or indistinct markings, I examined it further under a 45x magnification Nikon SMZ 2T microscope. A small number of potential cut marks were not clearly distinguishable from natural processes when examined under the microscope. The pictures could then be used to further differentiate between naturally-damaged elements, elements with potential butchery marks, and elements with definitive cuts. I included all specimens in my examination, even those elements I was not otherwise recording for taxonomic purposes (e.g., ribs). I closely studied all vertebrae and ribs twice to ensure I had identified any cut marks. While it is possible to differentiate between professional and novice butchery skills (Willis and Boehm 2015; Horton 2017, personal communication). I did not incorporate these data into my study.

After positively identifying a cut element, or identifying a potential cut mark, I further characterized butchery marks as sawn, chopped, or sliced when possible. I did not distinguish sawn cuts beyond presence or absence. The occurrence of a cut mark placed at the same position on multiple examples of the same element increased the likelihood that it was the result of butchery and not a natural process. When I saw repetitive marks, I re-analyzed those elements within the collection to look for additional instances of butchery marks that I might have missed previously.

Butler checked my butchery identifications and suggested revisions where necessary. Following the completed analysis, archaeologist Martin Adams photographed 
the specimens using a Nikon SMZ 2T microscope equipped with a Zeiss AxioCam ERc 5 s camera ${ }^{6}$ (Appendix G).

\section{Results of Butchery Analysis}

A total of 44 of the specimens in the entire fish faunal assemblage (NSP $=1,306)$ had unambiguous butchery marks (Table 24). An additional six specimens had ambiguous or possible cut marks (Table 24). Twelve of the butchery marks were on specimens Easton had not identified to taxon. Altogether, 3\% of the fish NSP for the neighborhood displayed a clear or potential butchery mark. Even with magnification, I could not reliably discern the tools used, which is not surprising given fish bone structure.

Butchered remains predominantly represented catfish or large-bodied marine and anadromous fishes. Seventy percent of the documented butchered elements were recorded on catfishes (Table 24). Catfishes also represented the widest array of butchered elements $(n=4$, of 7 total). The sample sizes for butchered salmonid remains were not large enough to make any substantive inferences about salmonid butchery by feature. All vertebrae associated with large-bodied fishes (including salmonids) were generally butchered in a manner that would produce steaks (Appendix G).

\footnotetext{
${ }^{6}$ Camera CCD basic resolution $2560 \times 1920,5.0$ megapixels.
} 
Table 24. Frequency of butchered fish remains in the Esther Short neighborhood.

Element

\begin{tabular}{|c|c|c|c|c|c|c|c|c|}
\hline Taxa & Cleithrum & $\begin{array}{l}\text { Modified } \\
2^{\text {nd }} \text { Vert. }\end{array}$ & $\begin{array}{r}\text { Other } \\
\text { Vertebra }\end{array}$ & $\begin{array}{r}\text { Supra- } \\
\text { occipital }\end{array}$ & Scapula & Crania & Rib & Total \\
\hline Ictaluridae & $16^{*}$ & 15 & 0 & 3 & 0 & $1 *$ & 0 & 35 \\
\hline Pleuronectidae & 0 & 0 & 2 & 0 & 0 & 0 & 0 & 2 \\
\hline Salmonidae & 1 & 0 & 4 & 0 & 1 & 0 & 0 & 6 \\
\hline Cyprinidae & 0 & 0 & 0 & 0 & 0 & 0 & $1 *$ & 1 \\
\hline Large Fish & $3 *$ & 0 & 3 & 0 & 0 & 0 & 0 & 6 \\
\hline Total & 20 & 15 & 9 & 3 & 1 & 1 & 1 & 50 \\
\hline
\end{tabular}

Note: Includes butchery marks recorded during all parts of study, including replicability study.

*Indicates possible cut marks, and identifications by Easton. Ribs are not typically identified to family.

\section{Catfish Butchery}

The catfish elements most frequently noted with butchery marks were cleithra and modified second vertebrae, both of which are loosely associated with fish head portions. Fifteen cleithra showed the same repetitive butchery pattern, where spines were removed (Figure 14). These butchery cuts either left some portion of the spines showing $(\mathrm{n}=10)$ or removed all spines and an adjacent portion of the cleithrum $(n=5)$.

Modified second vertebrae (only present in catfishes) were butchered into halves or quarters. A halved vertebra probably represented severing the head from the body. A quartered vertebra involved an additional anterior-to-posterior cut along the spine of the fish, for unknown reasons (Figure 15).

Cleithra and modified second vertebrae with these butchery marks were recorded in multiple features (Figure 16). This is striking for several reasons. Catfishes can be processed in a variety of ways (Lampman 1946). Because the same processing methods are visible in multiple features, these catfish remains may indicate heads purchased from 
the same butcher. Minimally, this redundancy across features indicates a cultural norm in processing catfishes.

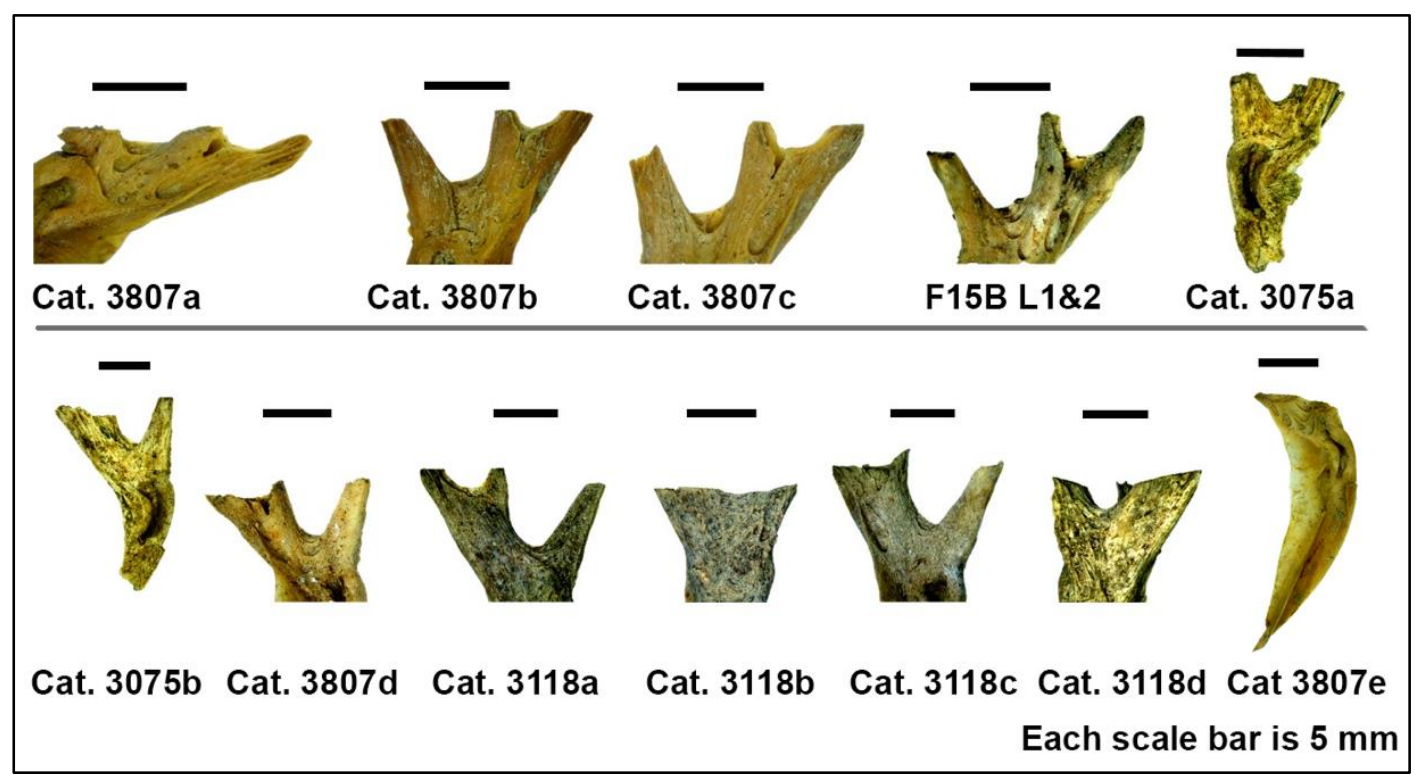

Figure 14. Sample of butchered catfish cleithra (spines removed) from fish faunal assemblage.
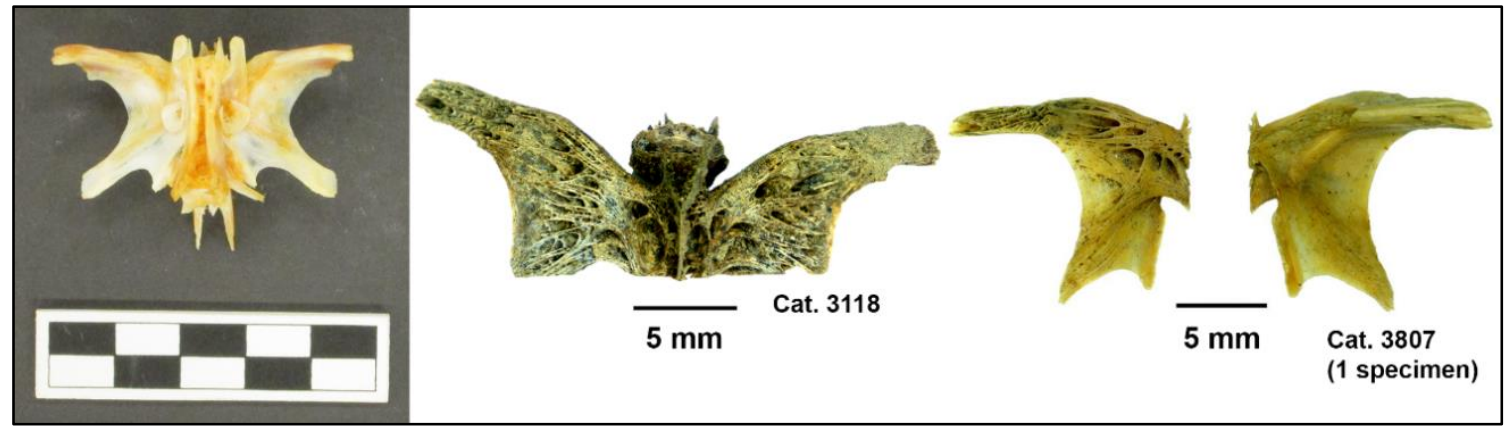

Figure 15. Modern example of catfish complete modified $2^{\text {nd }}$ vertebra (left) and two specimens from the Esther Short assemblage (halved, center; quartered, ventral and dorsal views, right). 


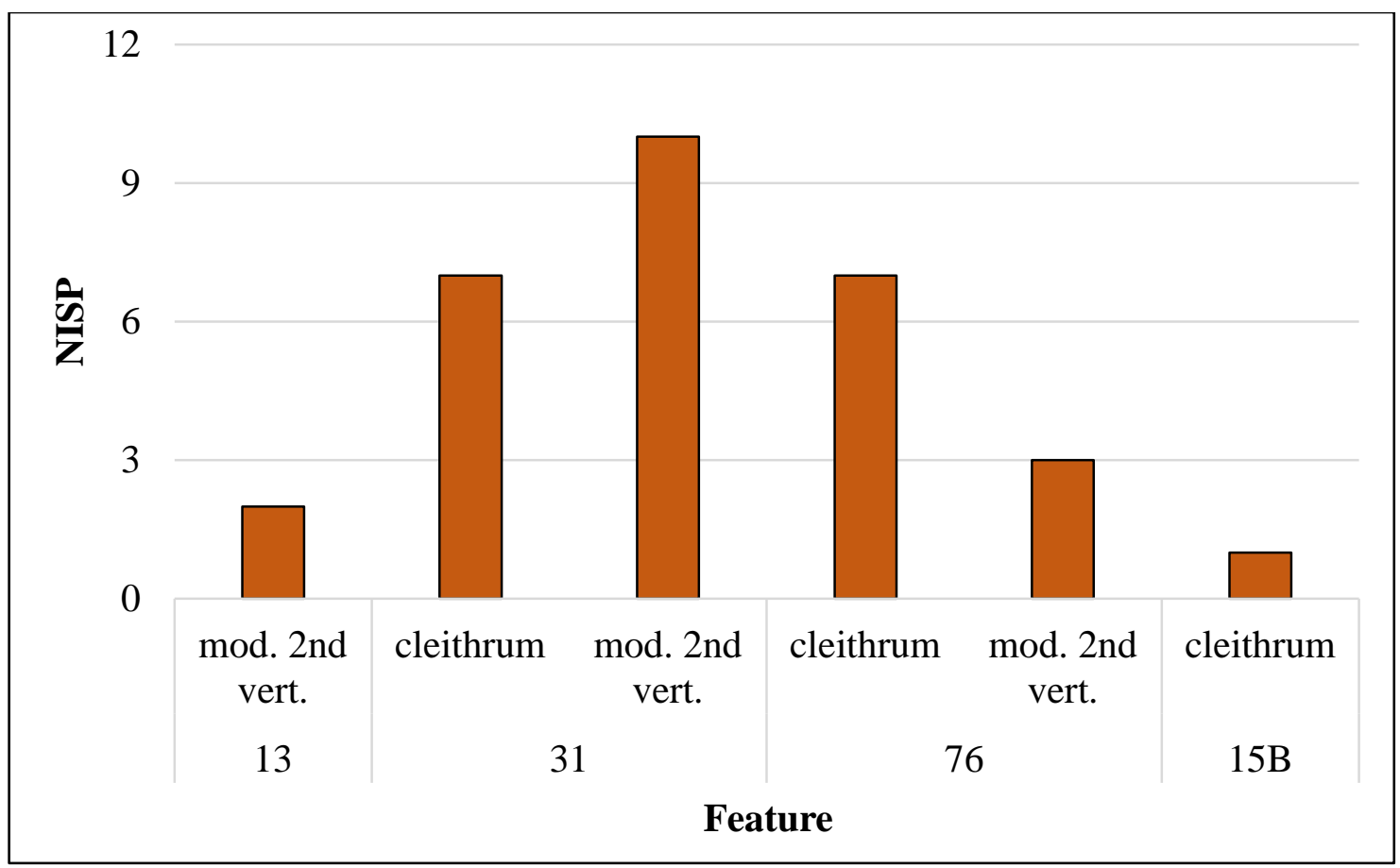

Figure 16. Distribution of catfish specimens with redundant butchery marks in the Esther Short neighborhood.

Other Butchered Fishes

The remaining butchery marks appeared on several different elements (Table 24; Appendix G). All non-ictalurid butchered vertebrae appeared as vertical cuts, or verticaldiagonal cuts (e.g., Figure 17; Figure 18). This type of butchery mark is generally associated with fish steaks, particularly for large-bodied fishes such as salmon and halibut. The rib (not photographed) had a possible knife mark, appearing as little more than a scratch. It did, however, match the description and location of butchered ribs that Willis et al. (2008) had noted previously. The remaining five cleithra were butchered in disparate ways with no clear pattern (Appendix G). 


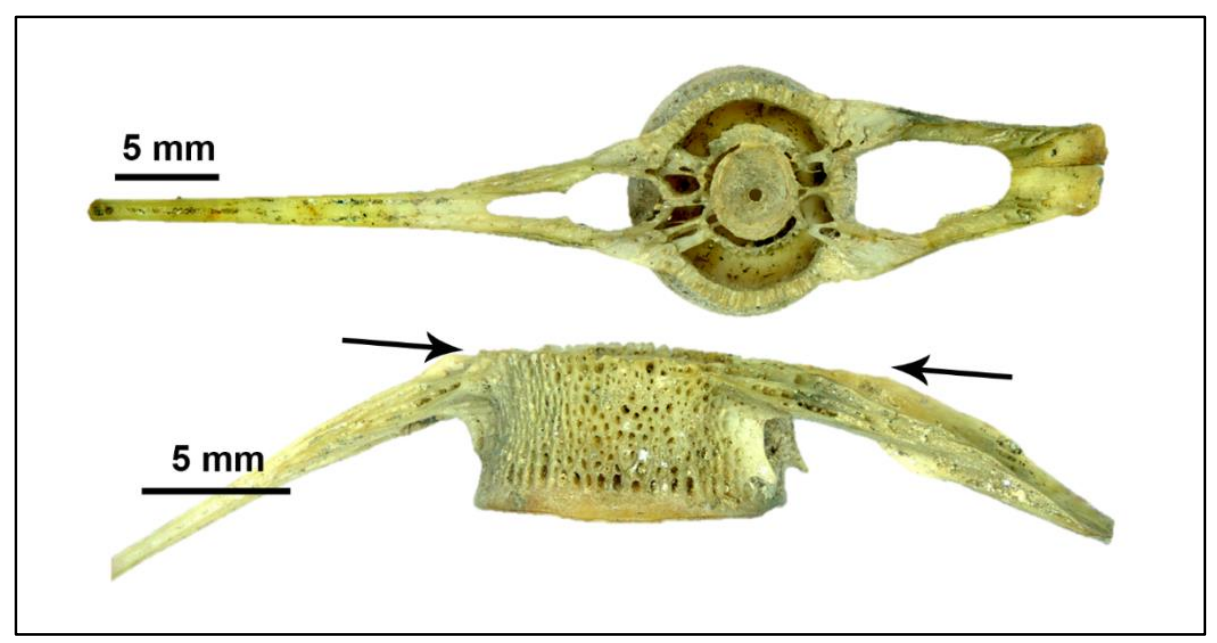

Figure 17. Example of butchered salmonid (Oncorhynchus sp.) vertebra. Cat. 6246.

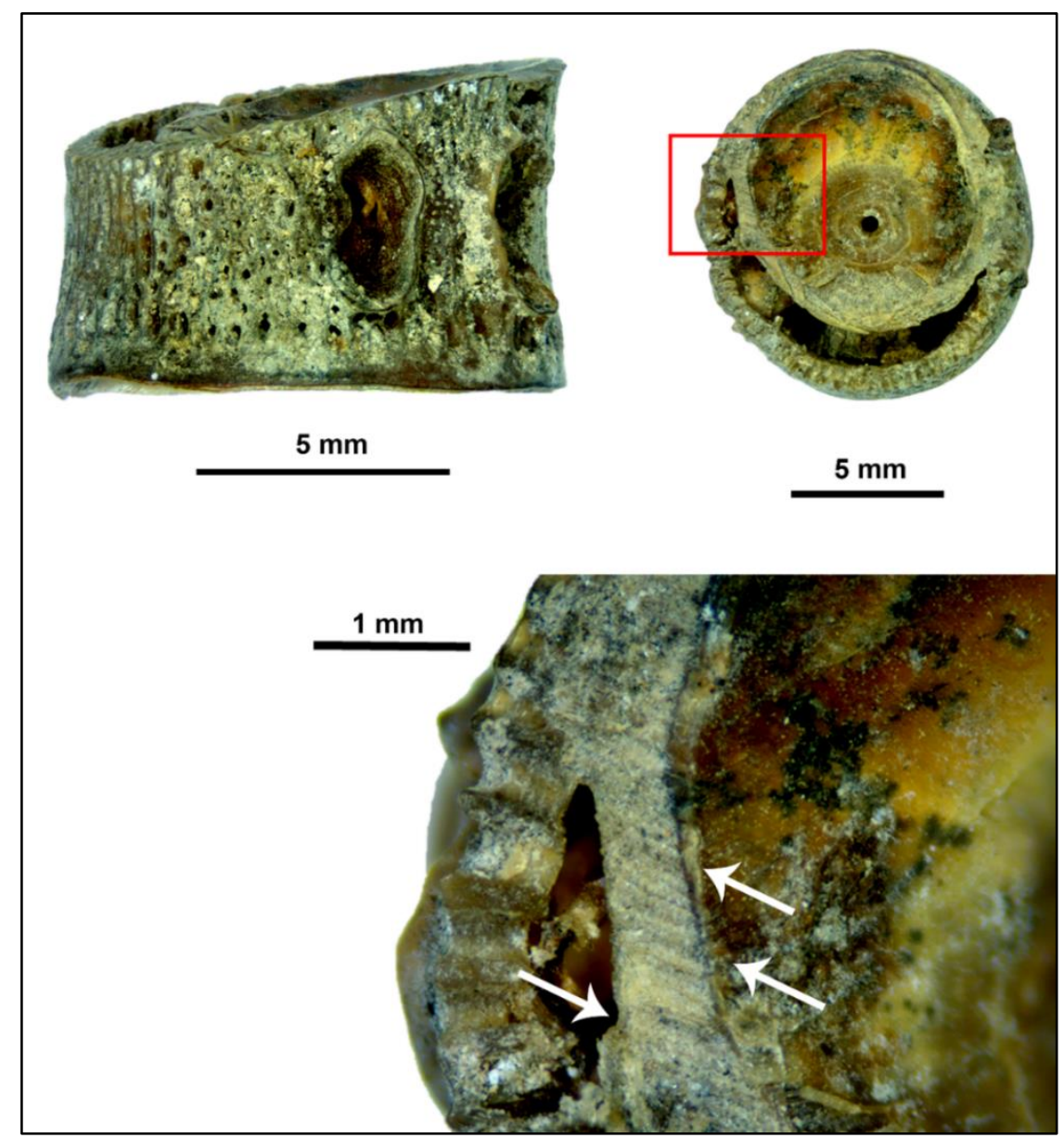

Figure 18. Example of butchered salmonid (Oncorhynchus sp.) vertebra. Inset shows striations from butchering. F35 L5. 
Distribution of Butchered Remains across Features

Butchered specimens were recovered from nine features (Figure 19). Most butchered remains were recovered from Features 31 and 76 (Figure 19). Feature 31 included almost half of the total butchered catfish remains (Figure 20), as well as

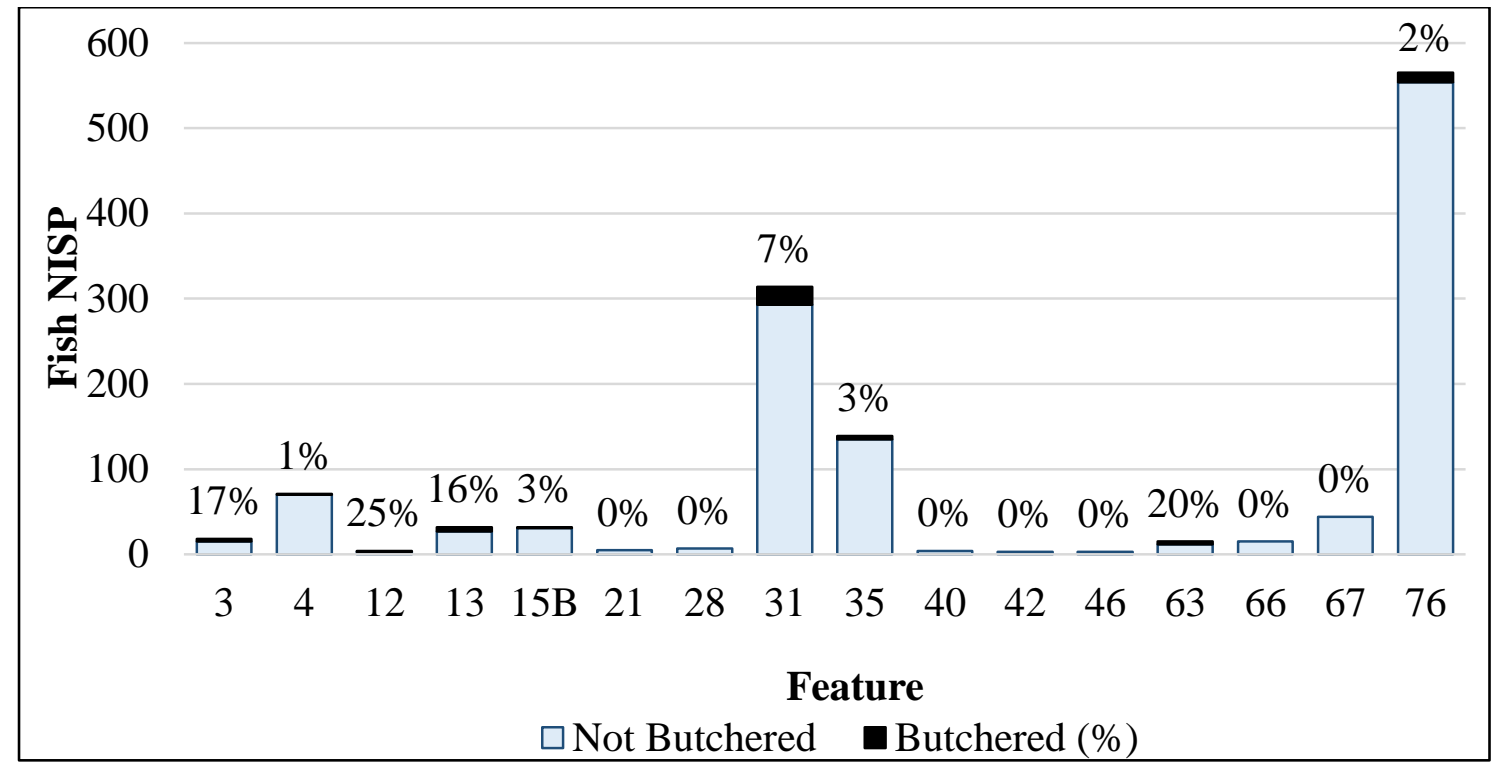

Figure 19. Frequency of butchered fish specimens by feature fish NISP.

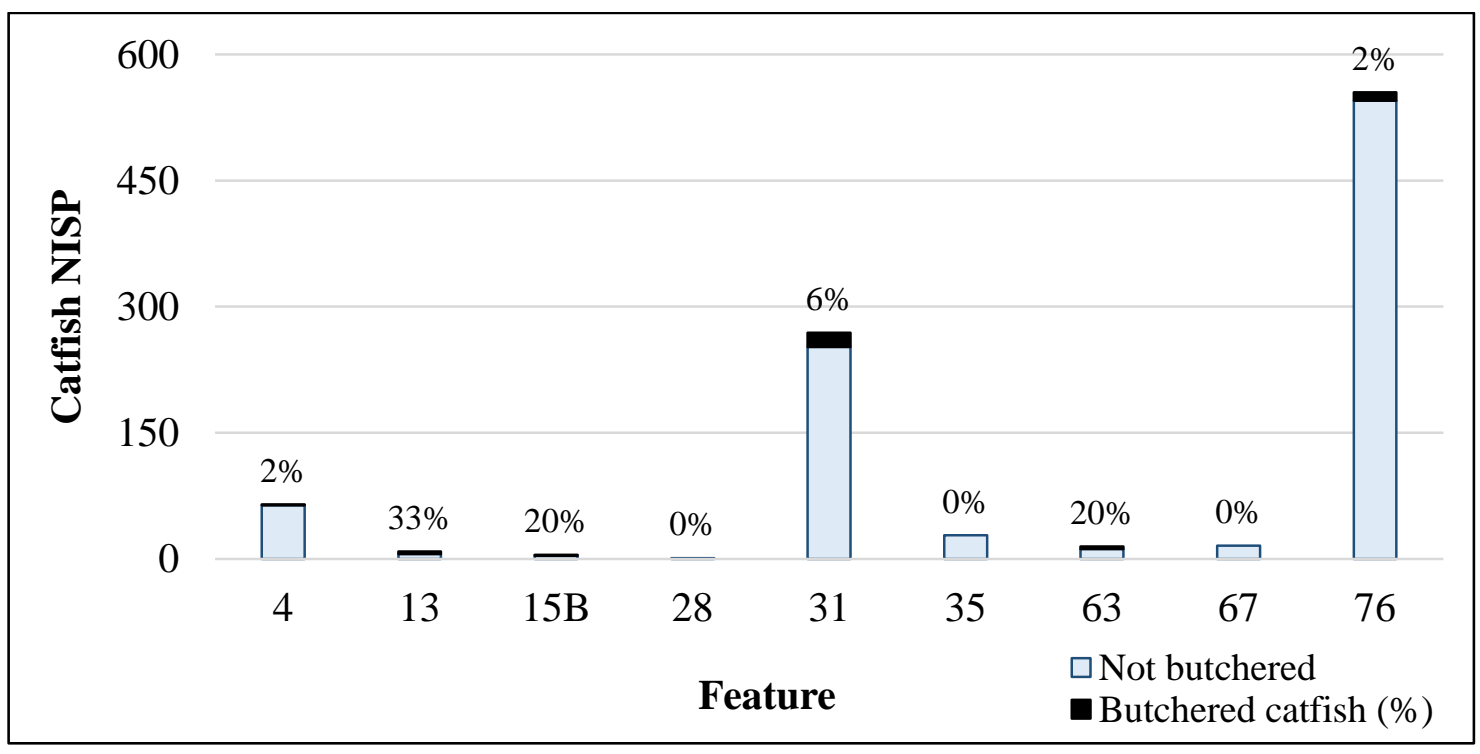

Figure 20. Frequencies of butchered and non-butchered catfish remains by feature. 
butchered remains from large-bodied fishes (e.g. salmon) and the potential carp specimen (Table 24). All of the butchered remains from Feature 76 were from catfish. These specimens represented a third of the total butchered catfish remains (Figure 20). All but one of the catfish cleithra had the same pattern of butchery marks (Figure 14); these, and the butchered catfish vertebrae, were distributed across multiple features (Figure 16).

\section{Conclusions from Zooarchaeological Work}

My faunal analysis expanded the fish taxa recorded in the Esther Short neighborhood by three families, which included both introduced and native fishes. Fish consumption in the neighborhood covered a broader range of species than had been previously established. My work also emphasizes the usefulness in collecting bulk samples and screening fill through fine mesh screens, as field methods undoubtedly influenced the high recovery rate of taxa and small remains from Feature 31.

My zooarchaeological data showed that fishes recovered from the Esther Short neighborhood represent a mix of native and introduced fishes. Introduced fishes were more common, both by the number of fishes represented and the NISP for each taxon. Five higher-cost fishes (sturgeon, catfish, freshwater bass, American shad, and possibly steelhead trout) and two higher-cost portions (steaks and whole fishes) were recorded in the assemblage. However, most fishes were low-cost market purchases, by the value of the fish, the value of the portion, or both. Additionally, the distribution of butchered remains, particularly cleithra, indicates some shared cultural behaviors (see Chapter 5). 


\section{Chapter 5: Discussion and Conclusions}

Studies of historical-era archaeofaunas have largely emphasized the consumption of large mammals, particularly cows. In the Pacific Northwest, oral traditions and archival records show fishes occupied a major role in household economics and foodways. Developing methods for incorporating fish archaeofaunas into historical food studies is critical in providing more complete interpretations of Pacific Northwest communities than have existed.

To address this gap, I include two data sets in my work: archival market and archaeological data. I provided evidence of fish acquisition methods and the market role of fishes using a multiscalar approach. My examination of Portland fish markets evaluated two processes in consumer choice: First, the widespread systemic influences of Victorianism and capitalism, and second, the agency available to producers and consumers at the local level within the systemic setting. This information is important in understanding agency and identity; in how historical communities used their changing environments; and in the role of introduced fishes in the Pacific Northwest today. As an examination of consumer choice, my work identifies both the interests of empowered producers and consumers (for example, sources of authority extolling the benefits of some fishes over others), and the agency that consumers expressed within the social theater by rejecting certain fishes or operating outside of market economies. I connected evidence of purchased and personally-caught fishes to some income and class associations. In doing so, I emphasized that such connections are neither static, nor universally applicable. Agency, though not equally available to all Portlanders and 
Vancouverites, was still expressed in how - or if - surplus income was spent on market fishes.

My study had several goals. First, I determined the role of native and non-native fishes by examining fish use as a part of Victorian-era foodways. I have shown that at the turn of the $20^{\text {th }}$ century in the Pacific Northwest, most non-native fishes were promoted more than, and were costlier than, native fishes. Native fishes filled a staple role both in markets and in public perception of fishes. They were regularly available and cheap. Sometimes native fishes were viewed dismissively. At the systemic level and to some extent the structural level, Euroamericans generally preferred introduced fishes. For example, of the 16 ranked fishes, introduced fishes were consistently costlier than native fishes. This may be for several reasons. For example, at the systemic level, economic connections between markets, government entities, and entrepreneurs connected to introduced fishes, combined to form powerful interests in favor of non-native fishes. From a purely economic standpoint, more native taxa were available than non-native taxa, although scarce native taxa were often not highly-favored either. At the structural level, the context of salmon as a daily menu item for many historical Euroamericans may have contributed to fatigue in consuming it.

My second goal was to determine the relative roles of market purchases and personal catch in foodways. I connected fishes not referenced in newspaper ads to personal catch. When remains from these fishes are present in an archaeological assemblage, they probably do not represent market purchases, and instead highlight human-environment interactions through noncommercial fishing activities. 
In formally comparing Easton's work with my own, I identified several key aspects to making faunal analyses more replicable. I found that replicability was enhanced when faunal analysts were explicit about their methods and protocols, including which comparative specimens they had available during analysis; what elements and taxa they were including in identification; which field methods produced which collections; and what qualities constituted the affirmative identification of a specimen. When faunal analysts operate using different methods, detailed notes on their processes can help to standardize results and minimize those differences.

My work also provided a template for the criteria a faunal analyst can use in identifying butchered fish remains, as well as how to interpret some of those remains. Because fish butchery has minimal attention in archaeology, contributions that build up literature around butchery mark identification fills a gap in archaeological knowledge. This knowledge frames how communities procured fishes and interacted with their environments; the role of introduced fishes in human diets; and the choices consumers made when food faunas were available both locally and in markets. In the Esther Short neighborhood, butchery marks on fish specimens independently confirmed other data showing which fish portions were acquired. Fish butchery additionally informs discussions on consumer choice and agency. Low-cost catfish heads purchased in large quantities played a dominant food role in several households, alongside some higher-cost fish steaks. Without incorporating butchery analysis, these consumer choices would be more difficult to substantiate. 
I have shown that a stable fish rank based on period economic costs can be developed. More broadly, I provided archaeologists in the Pacific Northwest with the means to easily sort archaeological ichthyofaunal remains for 16 prominent fishes into an economic ranking, and to infer whether or not countless other fishes were available in markets. Developing the ranking offered important context on how to historically situate food fishes and interpret their remains as expressions of consumer choice. The role of market fishes was complex, driven by numerous factors in the broader regional markets and the ideals of Victorian culture. Whether any fish could be sold in markets was determined by set variables such as seasonal availability and regulations; and more nebulous cultural constructs around authority, advertising, and the layered meanings ascribed to different fishes. Both the ranking and the data I gathered while creating it illustrate the cultural complexity of food fishes in the Pacific Northwest.

\section{Fish Use in the Esther Short Neighborhood}

Within the Esther Short neighborhood, I found limited archaeological evidence that occupants operated fully within the notion of an "intrinsically right" social order. They did not uniformly apply all genteel symbols to material trappings, goods, and practices. Further, food purchases were still constrained by larger market forces (Huelsbeck 1991). While the archival data told a story of production and consumption driven by authority, capitalism, and the morality of possession, that same story was not told wholesale in the archaeological record. The presence of non-market fishes attests to this (see discussion below). 
The residents' choices to adapt, reject, or modify Victorian values represents an expression of agency that has been documented in other communities (e.g., Praetzellis and Praetzellis 2001). Occupants generally consumed lower-cost fishes and portions, and caught their own fishes through sport and subsistence efforts. This should not be taken only as evidence of "living within one's means", when class and income represent just a part of how identity is constructed. Some reflections of conspicuous consumerism are still visible in recovered fish remains, through limited costlier market purchases. As well, the higher-cost market purchases may reflect some Victorian ideals, but to accept this outright as the reason those remains were deposited would be a simplification.

The neighborhood's purchasing patterns were similar to those recorded by Singer $(1985,1987)$ on the East coast: lower middle-class and working-class residents appeared to be buying fish heads (mostly of introduced fishes) and some fish steaks and whole fishes, and supplementing their purchases with some fishes caught through personal angling. In this sense, both communities evidenced similar choices. To what extent these choices were driven by Victorian middle- and working-class identities, and systemic and structural influences, is more contextual.

My work showed that personal fishing was not an activity for just the poorest of the working class (as subsistence only) or elites (as leisure only). I linked fish remains in the assemblage to non-market fishes. Even without the faunal assemblages, instances of fishing paraphernalia (e.g., a fishing reel) recovered during excavations indicated that some neighborhood residents got fishes outside of the market economy. The fishing equipment recovered also showed participation in conspicuous consumerism; artifacts 
like the fishing reel were embellished, and emulated costlier products but were often made with cheaper materials. Variability in fish consumption may be related to the rapid demographic changes in the Pacific Northwest, and the high turnover rate in the Esther Short neighborhood. Home preservation of fishes required equipment that may have been infeasible for many residents to continually move or replace, while cheaper fishing equipment was both easily acquired and replaced (and did not even need to be purchased, but could be made by enterprising children). The consistent repeated patterns of butchery marks on catfish remains shows residents may have visited the same butcher. Minimally, the same cultural standard for fish butchery was present in several households. This is noteworthy when the neighborhood had such a high turnover rate, and there are a myriad of ways to process catfish in particular.

In the context of Victorianism, neighborhood occupants participated in these genteel-style activities while supplementing their own diets with leisure and subsistence fishing. The concepts of leisure and subsistence activities are based on cultural values. I can make some inferences from advertisements and qualitative newspaper data, but these inferences do not translate into clear archaeological markers. In the Esther Short neighborhood, the boundary between subsistence and leisure fishing is indistinct because personal fishing likely fulfilled aspects of both. Common carp was the only example of a fish so societally reviled that I linked it to only subsistence fishing, or very low-cost market purchases. Given the transient nature of the neighborhood, some residents may have placed more value on the occasional higher-quality food than higher-quality Victorian material goods (e.g., tea sets). In any case, the rift between advertisements 
meant to guide consumption, and the household food practices of residents, shows expression of identity by manipulating the Victorian social theater.

Considering the societal focus on fishes in the Pacific Northwest, it is worth noting that fishes did not play a larger role in Euroamerican diets. Fishes did still comprise the second-highest NISP of the Esther Short faunal assemblage, and fish remains were recovered from 16 of the 32 excavated features. However, the low recovery rate of fish remains across most of the 16 features showed that fishes were prominent table items for several households (described in Appendix A), but featured sparingly in most of them. The recovery of larger fish remains such as pleuronectids were not associated with screen size biases. The low recovery rate of remains from smaller-bodied fishes such as eulachon was. Smaller fish taxa - including small trout-like salmonid remains - are likely under-represented in features where no bulk sampling was conducted.

Fish use in the Esther Short neighborhood, and larger patterns of fish use in the Portland area, showed a level of human-environment interactions that is not as readily available today. Targeting both native and introduced fishes in the Columbia River and its tributaries were well-documented activities in archival data. Though many people still fish in the Columbia River and streams that intersect with it, fishes are not as abundant as they historically were. As well, it is inadvisable to eat many of the same fishes that locals targeted in the late 1800s and early 1900s, such as shad, carp, and steelhead, if they come from polluted waters of the Columbia River (Epstein 2014). Industrialized activities have changed the way humans can safely utilize resources from the Columbia River. Native 
fishes face additional pressures, as the non-native fishes introduced over a century ago continue to proliferate. Victorian-era people took advantage of environments that have since changed too markedly to support either extensive industrialized or personal fishing to the extent that they once did.

\section{$\underline{\text { Future Work }}$}

Records of fish faunal remains recovered during the San Francisco West Approach/I-880 Cypress Project (San Francisco Bay area to Oakland area, California) provide a good basis for comparison with the Esther Short assemblage (Gibson 2009; Gibson et al. 2001). Abundant fish remains were recovered. For example, one privy produced over 22,000 fish specimens. Features documented during the I-880 Cypress project spanned the late 1800s and early 1900s. Documented household occupations ranged from unskilled laborers to wealthy professional occupants (Owen 2009:F.3), providing a variety of socioeconomic classes for comparing fish consumption and identity.

Households in both Vancouver and the Bay area showed evidence of market fishes and personal catch to varying extents. Both regions have easy access to fishing environments and prominent fishing industries (Gibson 2009:263). As some of the same trends are apparent in both areas - the kinds of food purchases generally expected for each station; purchased fishes; some evidence of noncommercial fishes - a more thorough comparison of these two regional areas could illuminate west coast systemic and structural patterns in commercial and noncommercial fish use. A wide array of 
professions and inferred class associations were documented in the I-880 Cypress archaeology project. This provides ample opportunity for interpreting agency through fish use as it may relate to class, as well as the role of systemic and structural forces in West Coast markets. At the local level, comparing the percentages and types of native and non-native fishes recorded in both projects could highlight trends in fish introductions, the fishing industry, and the overall value and importance of fishes as a menu option along the West Coast.

Beef and fish consumption highlight different aspects of human behavior and utilization of local and regional environments. Cow remains from the Esther Short neighborhood have already been previously assigned rankings using a modified version of Schulz and Gust's (1985) beef ranking. However, contrasting patterns between fishbearing and non-fish-bearing features, and identifying the social factors that influenced menu choices between fishes and beef, was beyond the scope of my work here. Future studies could benefit from better understanding the relationship between meat purchases and fish purchases. Comparing the results of economically ranked fish remains with those of other economically ranked faunas may highlight food-related consumer choices specific to faunas, and situate those choices in socioeconomic and cultural contexts.

Further, a comparison of multiple approaches (multiple ranked faunas; ranked artifacts; species richness and diversity) applied to the Esther Short neighborhood or at other archaeological sites could advance interpretations of class and consumer choice. As well, this comparison could provide archaeologists with a clearer picture of how consumer choice and agency are visible in the archaeological record. The data generated 
by ranked faunas and artifacts allows new insight into how historical peoples spent their resources in market economies, and what role socioeconomic status played in those exchanges.

It may be useful to adjust this fish ranking to reflect local income information, or to include an index to more easily compare assemblages. Doing so could tailor the fish ranking to more accurately reflect food choice within a given socioeconomic setting than empirical high- and low-ranked values do. My rankings are not relative to socioeconomic conditions (e.g., they do not consider the average monthly income for Vancouverites or Portlanders in the late $19^{\text {th }}$ and early $20^{\text {th }}$ centuries). Rather, the rankings show how the fishes themselves are priced against one another. Additional research could alter the ranks to directly reflect local or regional household practices.

Finally, creating a clear record of analysis protocols is a major component of standardizing faunal work and addressing zooarchaeologists' QA/QC concerns (Allen 2003:338-339; Butler and Lyman 1996; Driver 2011; Gobalet 2001; Lawrence 1973; Nims 2016; Nims and Butler 2017; Wolverton et al. 2016:9-12; Wolverton 2013). This includes identifying qualifications for which landmarks must be present for a positive identification, or one that just compares favorably to a taxa or element. Additionally, if elements are grouped together (e.g., cranial elements as crania), researchers should identify their standards for which elements must be present and articulated to assign a specimen to the grouping. My work also supports the argument that in order to accurately track faunas, especially in privies, future studies should use bulk sampling (recommended 
through nested screens) to better identify the distributions of faunas, and reduce the likelihood that taxa are represented because of field methods and not human behavior.

\section{$\underline{\text { Conclusion }}$}

Fishes are one of the few faunas that have the capacity to represent both noncommercial and market food exchanges in urban areas. Markers for these exchanges are visible archaeologically. The increasing attention paid to these faunas by historical and faunal archaeologists, ecologists, and historians illustrates the continuing importance of their role in Pacific Northwest culture and society.

In the primarily lower middle- and working-class Esther Short neighborhood, fishes were incorporated into diets as staple and supplementary foods, varying by household. Occupants primarily bought low-cost fishes and fish portions from markets. When they acquired noncommercial fishes, doing so met both leisure and subsistence needs. The favor with which introduced fishes were viewed encouraged human efforts to help these fishes propagate through local waters. Several native fishes like sturgeon and salmon became more popular and expensive, particularly after the turn of the century. This placed additional pressure on native fish populations and environments as fish harvesting efforts intensified.

The role of native and introduced fishes both in markets and on tables frames multiple topics. Chief amongst these are how the targeting of specific fishes changed the environments in which they lived, and how food availability and choice is managed in a stratified socioeconomic setting. Understanding how introduced and native fishes were 
viewed socially when they first began sharing their environments illuminates patterns of historical behavior, and informs how those patterns have evolved into contemporary behavior. Human behavior in a complex social system can be examined in historical-era fish use. Systemic and structural factors influence how identity is developed and agency is expressed, particularly when markets are not the only option for food acquisition. In this setting, consumer choice takes on new roles. Examining Victorian-era fish use illuminates how these complex systems were navigated. By providing an overview of how fishes were situated within a developing urban environment, this study makes an important contribution to understanding social, environmental, and economic patterns. 


\section{Works Cited}

Allen, Melinda S.

2003 Human Impact on Pacific Nearshore Marine Ecosystems. In Pacific Archaeology: Assessments and Prospects. Proceedings of the International Conference for the 50th Anniversary of the First Lapita Excavation, Kone, Noumea, edited by C. Sand, pp. 317-325. Vol. 15. Service des Musees et du Patromonie de Nouvelle-Caledonie, Noumea.

Alley, B. F., J. P. Munro-Frasier, and Mark E. Parsons 1885 Clarke County Washington Territory. Parsons Publishing Company, Republished in 2011 as "Pacific Coast History: Washington/Oregon History to $1885 . "$

Ames, Kenneth L.

1992a Death in the Dining Room \& Other Tales of Victorian Culture. Temple University Press, Philadelphia.

1992b Death in the Dining Room. In Death in the Dining Room \& Other Tales of Victorian Culture, pp. 44-96. Temple University Press, Philadelphia.

Anderson, Heather Arndt

2015 Portland: A Food Biography. Rowman \& Littlefield Publishing, Boulder, CO.

Anonymous

2013 Vancouver Uncovered. Clark County Historical Museum. Electronic document.

2015 ODFW History, 1792-2011. Oregon Department of Fish and Wildlife.

Archer, Will, and David R. Braun

2013 Investigating the Signature of Aquatic Resource Use within Pleistocene Hominin Dietary Adaptations. PLoS ONE 8(8): e69899.

Archer, Will, David R. Braun, J.W.K. Harris, J. T. McCoy, and B. G. Richmond 2014 Early Pleistocene Aquatic Resource Use in the Turkana Basin. Journal of Human Evolution(http://dx.doi.org/10.1016/j.jhevol.2014.02.012).

Van Arsdol, Ted 1986 Vancouver on the Columbia. Windsor Publications, Northridge, CA. 
Barnas, Katie W.

2006 American Shad; Largemouth Bass; Rock Bass; Smallmouth Bass; Black Bullhead; Brown Bullhead; Channel Catfish. In Invasive Species in the Pacific Northwest, edited by P. D. Boersma, S. H. Reichard, and A. N. Van Buren, pp. 148-155. University of Washington Press, Seattle.

Beeton, Isabella

1861 Mrs. Beeton's Book of Household Management: A Guide to Cookery in All Branches. Reprinted 1907. Ward, Lock \& Co., Limited, London.

Binford, Lewis R.

1981 Bones: Ancient Men and Modern Myths. Academic Press, New York.

Bowers, G. M.

1901 Report of the commissioner of fish and fisheries for the year ending June 30, 1900. Part XXVI. Washington, D.C.

Brown, Gregory J., and Joanne Bowen

1998 Animal Bones from the Cross Street Back Lot Privy. Historical Archaeology 32(3): 72-80.

Buenker, John D.

1988 Historical Dictionary of the Progressive Era, 1890-1920. Ed. John D. Buenker and Edward R. Kantowicz. Greenwood Press, New York.

Buenker, John D., John C. Burnham, and Robert M. Crunden 1986 Progressivism. Schenkman Publication Company, Cambridge, MA.

Butler, Virginia L.

1990 Distinguishing Natural from Cultural Salmonid Deposits in Pacific Northwest North America. University of Washington, Seattle.

2000 Resource Depression on the Northwest Coast of North America. Antiquity 74: 649-661.

2004a Where Have All the Native Fish Gone? The Fate of Fish that Lewis and Clark Encountered on the Lower Columbia River. Oregon Historical Quarterly 105(3): 438-463.

2004b Fish Remains. In Marmes Rockshelter: A Final Report on 11,000 Years of Cultural Use, edited by Brent A. Hicks, pp. 319-337. Washington State University Press, Pullman, WA.

Butler, Virginia L., and Sarah K. Campbell

2004 Resource Intensification and Resource Depression in the Pacific Northwest of North America: A Zooarchaeological Review. Journal of World Prehistory 18(4): 327-405. 
Butler, Virginia L., and James C. Chatters

1994 The Role of Bone Density in Structuring Prehistoric Salmon Bone Assemblages. Journal of Archaeological Science 21: 413-424.

Butler, Virginia L., and R. Lee Lyman

1996 Taxonomic Identifications and Faunal Summaries: What Should We Be Including in Our Faunal Reports? Society for American Archaeology Bulletin 14(1): 22.

Butler, Virginia L., and Michael A. Martin

2013 Aboriginal Fisheries of the Lower Columbia River. In Chinookan Peoples of the Lower Columbia, pp. 80-105. University of Washington Press, Seattle, WA.

Ciolek-Torrello, Richard, Mark T. Swanson, James E. Ayres, Walter H. Birkby, Linda Scott Cummings, William L. Deaver, Karen G. Harry, Lisa W. Huckell, Angie Kay Huxley, Bruce A. Jones, and Stephanie M. Whittlesey

1997 Pit House, Presidio, and Privy: 1,400 Years of Archaeology and History on Block 180, Tucson, Arizona. Ed. Richard Ciolek-Torrello, Mark T. Swanson, Linda M. Gregonis, and Jeffrey H. Altschul. Statistical Research, Inc.: Technical Series, Tuczon.

Coben, Stanley

1991 Rebellion against Victorianism: The Impetus for Cultural Change in 1920s America. Oxford University Press, Oxford.

Colley, S. M.

1990 The Analysis and Interpretation of Archaeological Fish Remains. Archaeological Method and Theory 2: 207-253.

Cook, Lauren J., Rebecca Yamin, and John P. McCarthy

1996 Shopping as Meaningful Action: Toward a Redefinition of Consumption in Historical Archaeology. Historical Archaeology 30(4): 50-65.

Craig, Joseph A., and Robert L. Hacker

1940 Bulletin No. 32 of the Bureau of Fisheries: The History and Development of the Fisheries of the Columbia River. Bureau of Fisheries, Washington D.C. 
Crane, Brian D.

2000 Filth, Garbage, and Rubbish: Refuse Disposal, Sanitary Reform, and Nineteenth Century Yard Deposits in Washington, D.C. Historical Archaeology 34(1 (Special Issue: View from the Outhouse: What We Can Learn from the Excavation of Privies)): 20-38.

Crist, Thomas A.

2005 Babies in the Privy: Prostitution, Infanticide, and Abortion in New York

City's Five Points District. Historical Archaeology 39(1 (Special Issue:

Sin City)): 19-46.

Dalglish, Chris

2008 Urban Myths: Rethinking the Archaeology of the Modern Scottish City.

Scottish Archaeological Journal 27(2).

Dauble, Dennis D.

2009 Fishes of the Lower Columbia Basin: A guide to their natural history and identification. 1st ed. Keokee Books, Sandpoint, ID.

DeFrance, S. D.

2005 Late Pleistocene Marine Birds from Southern Peru: Distinguishing Human Capture from El Niño-Induced Windfall. Journal of Archaeological Science 32: 1131-1146.

Dobres, Marcia-Anne, and John E. Robb 2000a Agency in Archaeology. Routledge, New York, NY.

2000b Agency in Archaeology: Paradigm or Platitude? In Agency in Archaeology, edited by Marcia-Anne Dobres and John E. Robb, pp. 1-17. Routledge, New York.

Domínguez-Rodrigo, M., and J. Yravedra

2009 Why Are Cut Mark Frequencies in Archaeofaunal Assemblages So Variable? A Multivariate Analysis. Journal of Archaeological Science 36: 884-894.

Driver, Jonathan C.

1992 Identification, classification and zooarchaeology. Circara 9: 35-47.

2011 Identification, Classification and Zooarchaeology. Ethnobiology Letters 2: 19-39.

Epstein, Lorri

2014 “Is your Fish Toxic?” Study Phase II Results. Portland, OR. 
Eschmeyer, W. N., E. S. Herald, and H. Hammann

1983 A field guide to Pacific coast fisheries of North America. Houghton Mifflin Company, Boston, MA.

Faith, J. Tyler, and Adam D. Gordon

2007 Skeletal element abundances in archaeofaunal assemblages: economic utility, sample size, and assessment of carcass transport strategies. Journal of Archaeological Science 34(6): 872-882.

Farr, Ruth A., and David L. Ward

1993 Fishes of the Lower Willamette River, Near Portland, Oregon. Northwest Science 67(1): 16-21.

Ficken, Robert E., and Charles P. LeWarne

1989 No TitleWashington: A Centennial History. University of Washington Press, Seattle, WA.

Fiddes, Nick

1994 Social Aspects of Meat Eating. Proceedings of the Nutrition Society 53: 271-280.

Gallagher, Sean P.

2003 Distinguishing between coho salmon (Oncorhynchus kisutch) and steelhead (Oncorhynchus mykiss) redds and estimate adult population sizes from spawning surveys in several coastal Mendocino county streams, Project $1 d 2$. Redding, CA.

Geismar, Joan H.

1993 Where Is Night Soil? Thoughts on an Urban Privy. Historical Archaeology 27(2): $57-70$

Gibson, Erica S.

2009 Life at Home. In South of Market: Historical Archaeology of 3 San Francisco Neighborhoods, Vol. I, edited by Mary Praetzellis and Adrian Praetzellis, pp. 263-301. Anthropological Studies Center, Sonoma State University, Roehnert Park.

Gibson, Erica S., Sherri M. Gust, Virginia Hellman, Madeline Hirn, Jack McIlroy, Michael D. Meyer, Adrian Praetzellis, Mary Praetzellis, Sunshine Psota, Maria Ribeiro, Peter D. Schulz, Margo Schur, Elaine-Maryse Solari, Suzanne B. Stewart, Michael Stoyka, and Rose White

2001 Block Technical Report: Historical Archaeology I-880 Cypress Replacement Project, Blocks 19, 20, 21, and 37. Ed. Mary Praetzellis. Sonoma State University, Rohnert Park. 
Gobalet, Kenneth W.

2001 A Critique of Faunal Analysis: Inconsistency Among Experts in Blind Tests. Journal of Archaeological Science 28(4): 377-386.

Gust, Sherri M.

1997 Analysis of Animal Bones. In Historical Archaeology of an Overseas Chinese Community in Sacramento, California, edited by Adrian Praetzellis and Mary Praetzellis, pp. 221-258. Sonoma State University Academic Foundation, Inc., Roehnert Park.

Harrison, John

2008 Commercial Fishing. Northwest Council. Electronic document.

Harshman, Rose Marie

1989 Clark County Pioneers: A Centennial Salute. Clark County Genealogical Society, Vancouver, WA.

1993 Clark County Pioneers: Through the Turn of the Century. Clark County Genealogical Society, Vancouver, WA.

Hart, J. L.

1973 Pacific Fishes of Canada: Bulletin 180. Ed. J. Watson, Johanna M.

Reinhart, D. G. Cook, and Lorraine C. Smith. Minister of Supply and Services Canada, Ottawa.

Haywood, C. Robert

2003 Victorian West. In Historical Dictionary of the Gilded Age, edited by Leonard Schlup, James G. Ryan, and Vincent de Santis, pp. 514-515. M.E. Sharpe, New York.

Henry, Craig

1982 Fauna in HBC Kanaka Village/Vancouver Barracks 1977. Ed. Caroline D. Carley. University of Washington Reports in Highway Archaeology 8, Seattle.

Horton, Elizabeth

2010 Faunal Analysis. In Results of National Park Service Archaeological Testing on the Vancouver National Historic Reserve for the CRC Project, pp. 1-47. National Park Service, Vancouver.

2014 Space, Status, and Interaction: Multiscalar Analyses of Officers, Soldiers, and Laundresses at 19th-Century Fort Vancouver, Washington. Washington State University. 
Hubbs, Carl L., and Leonard P. Schultz

1931 The Scientific Name of the Columbia River Chub. No. 232, Occasional Papers of the Museum of Zoology. Ann Arbor, MI.

Huelsbeck, David R.

1991 Faunal Remains and Consumer Behavior: What Is Being Measured? Historical Archaeology 25(2): 62-76.

Jones, Bruce

1997 Historical Faunal Remains. In Pit House, Presidio, and Privy: 1,400 Years of Archaeology and History on Block 180, Tucson, Arizona, edited by Richard Ciolek-Torrello and Mark T. Swanson, pp. 469-502. Statistical Research, Inc.: Technical Series, Tuczon.

Kasson, John F.

1987 Rituals of Dining: Table Manners in Victorian America. In Dining In America, 1850-1900, edited by Kathryn Grover, pp. 114-142. Strong Museum, Rochester, N.Y.

Kincaid, Harrison R., Joel Ware, and William Thompson 1880 A Sly Old Fish. Oregon State Journal, July 31.

Klippel, Walter E, and Judith A Sichler 2004 Period North Atlantic Fishes in Inland Context: Pickled Mackerel Historic Period (Scomber scombrus) in the Historic Period. Historical Archaeology 38(4): 12-24.

Koloski-Ostrow, Ann Olga

2015 The Archaeology of Sanitation in Roman Italy: Toilets, Sewers, and Water Systems. University of North Carolina Press, Chapel Hill, NC.

Lampman, Ben Hur

1946 The Coming of the Pond Fishes. Metropolitan Press, Portland.

Landerholm, Carl

1966 Stories of Early Days: Catfishing. In Fort Vancouver Historical Society, pp. 181. Volume VII. Pioneer Printing, Vancouver.

Landon, David B.

1996 Feeding Colonial Boston: A Zooarchaeological Study. Historical Archaeology 30: 1-153.

2005 Zooarchaeology and Historical Archaeology: Progress and Prospects. Journal of Archaeological Method and Theory 12(1): 1-36. 
Lang, William L.

1992 Creating the Columbia: Historians and the Great River of the West, 18901935. Oregon Historical Quarterly 93(3): 234-261.

2000 The Columbia River's Fate in the Twentieth Century. Montana: The Magazine of Western History 50(1): 44-55.

2003 Beavers, Firs, Salmon, and Falling Water: Pacific Northwest Regionalism and the Environment. Oregon Historical Quarterly 104: 151-165.

Larson, Todd E. A.

2004 Fishing. In Encyclopedia of the Victorian Era, Vol. II, edited by James Eli Adams, Tom Pendergast, and Sara Pendergast, pp. 112. Grolier Academic References, Danbury.

Lawrence, Barbara

1973 Problems in the Inter-Site Comparison of Faunal Remains. In Domestikationforschung und Geschichte der Haustiere, edited by Janos Matolcsi, pp. 397-402. Akademiai Kiado, Budapest.

Lee, D. S., C. R. Gilbert, C. H. Hocutt, R. E. Jenkins, D. E. McAllister, and J. R. Stauffer Jr.

1980 Atlas of North American Freshwater Fishes. North Carolina Museum of Natural History. Raleigh, NC.

Levenstein, Harvey A.

2003 Revolution at the Table: The Transformation of the American Diet. University of California Press, Berkeley, CA.

Levi-Strauss, Claude

1969 The Raw and the Cooked: Mythologiques Volume 1. Ed. John Weightman, Doreen Weightman, and Translators. University of Chicago Press, Chicago.

Lichatowich, Jim

1999 Salmon Without Rivers: A History of the Pacific Salmon Crisis. Island Press, Washington D.C.

Lichatowich, Jim, and Seth Zuckerman

2003 Muddied Waters, Muddled Thinking. In Salmon Nation: People, Fish and Our Common Home, edited by Edward C. Wolf and Seth Zuckerman. Second Ed. Ecotrust, ePublication. 
Lightfoot, Kent G, Antoinette Martinez, and Ann M Schiff

1998 Daily Practice and Material Culture in Pluralistic Social Settings: An Archaeological Study of Culture Change and Persistence from Fort Ross, California. American Antiquity 63(2): 199-222.

Lockington, W. N.

1879 Notes on Pacific Coast Fishes and Fisheries. The American Naturalist 13(11): 684-687.

Lubinski, Patrick M.

1996 Fish Heads, Fish Heads: An Experiment on Differential Bone Preservation in a Salmonid Fish. Journal of Archaeological Science 23: 175-181.

Lubinski, Patrick M, and Megan A Partlow

2012 Evidence for Local Fish Catch In Zooarchaeology. Journal of Ethnobiology 32(2): 228-245.

Lyman, R. Lee

1977 Analysis of Historic Faunal Remains. Historical Archaeology 11: 67-73.

1987a Archaeofaunas and Butchery Studies: A Taphonomic Perspective. Advances in Archaeological Method and Theory 10: 249-337.

1987b On Zooarchaeological Measures of Socioeconomic Position and CostEfficient Meat Purchases. Historical Archaeology 21(1): 58-66.

1994 Vertebrate Taphonomy. University of Cambridge Press, Cambridge.

MacDonald, Marshall, and Herbert A. Gill

1896 United States Commission of Fish and Fisheries Part XXI: Report of The Commissioner for The Year Ending June 30, 1895. Washington DC.

McAleer, Scott

2005 Residence History for Blocks 60, 62, 64, 65, 66. Vancouver, Washington. Draft. Vancouver, WA.

McAllister, H. C.

1909 Laws of Oregon Pertaining to Fish and the Fishing Industry. Willis S. Duniway, state printer, Salem, OR.

McGuire, Hollister D.

1894 First and Second Annual Reports of the Oregon Fish and Game Protector to the Governor. Salem, OR.

McGuire, Randall H., and LouAnn Wurst 2002 Struggling with the past. International Journal of Historical Archeology 6(2): 85-94. 


\section{McIntosh, Elaine N.}

1995 American Food Habits in Historical Perspective. Praeger, Westport, CT.

McKechnie, Iain, and Madonna L. Moss

2016 Meta-analysis in zooarchaeology expands perspectives on Indigenous fisheries of the Northwest Coast of North America. Journal of Archaeological Science: Reports 8: 470-485.

Mullins, Paul R.

2011 The Archaeology of Consumption. Annual Review of Anthropology 40(1): 133-144.

Mundell, Raymond L.

1975 An Illustrated Osteology of the Channel Catfish (Ictalurus punctatus). Lincoln, NE.

Nicholson, R. A.

1996a Fish bone diagenesis in different soils. Archaeofauna 5: 79-91.

1996b Bone Degradation, Burial Medium and Species Representation:

Debunking the Myths, an Experiment-based Approach. Journal of Archaeological Science 23: 513-533.

Nims, Reno

2016 Sablefish (Anoplopoma fimbria) Scarcity and Zooarchaeological Data

Quality in Northwest Coast Archaeological Sites. Portland State

University.

Nims, Reno, and Virginia L. Butler

2017 Assessing reproducibility in faunal analysis using blind tests: A case study from northwestern North America. Journal of Archaeological Science: Reports 11: 750-761.

O'Connor, T. P.

2003 The Analysis of Urban Bone Assemblages. In The Archaeology of York.

Vol. 19. Council for British Archaeology, York, U.K.

Orton, Clive

2000 Cambridge Manuals in Archaeology: Sampling in Archaeology. Cambridge University Press, Cambridge. 
Owen, Bruce

2009 Consumption and Status in Nineteenth-Century San Francisco and Oakland: Statistical Analyses for the San Francisco West Approach Project. In South of Market: Historical Archaeology of 3 San Francisco

Neighborhoods, Vol. I, edited by Mary Praetzellis and Adrian Praetzellis, pp. F.3-F.292. Anthropological Studies Center, Sonoma State University, Roehnert Park.

Page, Lawrence M., Héctor Espinosa-Pérez, Lloyd T. Findley, Carter R. Gilbert, Robert N. Lea, Nicholas E. Mandrak, Richard L. Mayden, and Joseph S. Nelson

2013 Common and Scientific Names of Fishes from the United States, Canada, and Mexico. Special Publication 34. 7th ed. American Fisheries Society, Bethesda, MD.

Palen, Wendy J., Jonathan W. Moore, Monkia Winder, Joan Cabreza, Maureen P. Small, Daniel E. Schindler, Jackie L. Carter, and Katie W. Barnas 2006 Invasive Species in the Pacific Northwest. Ed. P. D. Boersma, S. H. Reichard, and A. N. Van Buren. University of Washington Press, Seattle.

Pena, Elizabeth S., and Jacqueline Denmon

2000 The Social Organization of a Boardinghouse: Archaeological Evidence from the Buffalo Waterfront. Historical Archaeology 34(1 (Special Issue: View from the Outhouse: What We Can Learn from the Excavation of Privies)): 79-96.

Praetzellis, Adrian, and Mary Praetzellis

2001 Mangling Symbols of Gentility in the Wild West: Case Studies in Interpretive Archaeology. American Anthropologist 103(3): 645-654.

2004 Putting the "There" There: Historical Archaeologies of West Oakland. Anthropological Studies Center, Sonoma State University, Roehnert Park.

Reitz, Elizabeth J.

1986 Urban/Rural Contrasts in Vertebrate Fauna From the Southern Atlantic Coastal Plain. Historical Archaeology 20(2): 47-58.

1987 Vertebrate Fauna and Socioeconomic Status. In Consumer Choice in Historical Archaeology, edited by Suzanne M. Spencer-Wood, pp. 101119. Plenum Press, New York.

2015 Charleston, South Carolina (USA): A Case Study of Fish as Evidence of Social Status and Environmental Impact. In 18th International Conference of Archaeozoology Fish Remains Working Group. Lisbon. Article in press.

Rose, Chelsea, Christopher L. Ruiz, Tom Connolly, and Julie Schablitsky 2007 Portrait from a Privy: A 19th Century Working Class Household, Naito Parkway Privy, Portland, Oregon. Eugene. 
Rothschild, Nan A.

1989 The Effect of Urbanization on Faunal Diversity: A Comparison Between

New York City and St. Augustine, Florida, in the Sixteenth to Eighteenth Centuries. In Quantifying Diversity in Archaeology, edited by Robert D. Leonard and G. T. Jones, pp. 92-99. Cambridge University Press, Cambridge.

Roulette, Bill R.

2014a Introduction. In Columbian Campus, Historical Blocks 60, 61, 64, and 65 of Vancouver, Washington, pp. 1-10. Unpublished Draft, on file at Applied Archaeological Research, Inc., Portland, OR.

2014b Methods. In Columbian Campus, Historical Blocks 60, 61, 64, and 65 of Vancouver, Washington, pp. 11-21. Unpublished Draft, on file at Applied Archaeological Research, Inc., Portland, OR.

Roulette, Bill R., Jessica A. Hale, Julie Wilt, William White, Krey Easton, Aimee Finley, Melissa Lehman, Kendal McDonald, Robert McCurty, Amanda Pietz, Paul Solimano, and Brandy Tollefson

2014 An Archaeology of Victorian Vancouver: Archaeological Investigations on Blocks 62 and 66, Vancouver Convention Center Draft Report. Portland.

Roulette, Bill R., and William G. White

2005 Results of Inventory Phase Archaeological Investigations on Historic Vancouver Blocks 61 and 65 at the Proposed Site of the Columbian Newspaper's Downtown Campus, Vancouver, Washington. Portland.

Schablitsky, Julie

2002 Profile of a Prominent Portland Family: The Archaeology and History of the John D. Coleman Family, ca. 1895. Portland.

Schlup, Leonard, James G. Ryan, and Vincent: Eds. de Santis

2003 Historical Dictionary of the Gilded Age. M.E. Sharpe, New York.

Schmitt, Dave N., and Charles D. Zeier

1993 Not by Bones Alone: Composition and Socioeconomic Status in an Isolated

Historic Mining Community. Historical Archaeology 27(4): 20-38.

Schulz, Peter D.

1997 Mid-19th-Century Fish Remains. In Historical Archaeology of an Overseas Chinese Community in Sacramento, California, edited by Mary Praetzellis and Adrian Praetzellis, pp. 258-268. Sonoma State University Academic Foundation, Inc., Roehnert Park. 
Schulz, Peter D, and Sherri M Gust

1983 Faunal Remains And Social Status in 19th Century Sacramento. Historical Archaeology 17(1): 44-53.

Shackel, Paul A.

2000 Craft to wage labor: Agency and resistance in American historical archaeology. In Agency in Archaeology, edited by Marcia-Anne Dobres and John E. Robb, pp. 232-246. Routledge, New York, NY.

Singer, David A.

1982a Ichthyofauna as an Interpretative Tool in Historic Sites Archaeology. University of Massachusetts, Boston.

1982b Fish in Foodways Systems-Data Integration and Patterning. Northeast Historical Archaeology 11(1): 39-47.

1985 The Use of Fish Remains as a Socio-Economic Measure: An Example from 19th Century New England. Historical Archaeology 19: 110-113.

1987 Threshold of Affordability: Assessing Fish Remains for Socioeconomics. In Consumer Choice in Historical Archaeology, edited by Suzanne M. Spencer-Wood, pp. 85-98. Plenum Press, New York.

Smith, Hugh M.

1896 A Review of the History and Results of the Attempt to Acclimatize Fish and other Water Animals in the Pacific States. Washington D.C.

1915 Bureau of Fisheries Report of the United States Commissioner of Fisheries for the Fiscal Year 1914 with Appendixes. Washington D.C.

Smith, Ross E., Virginia L. Butler, Shelia Orwoll, and Catherine Wilson-Skogen

2011 Pacific Cod and Salmon Structural Bone Density. In The Archaeology of North Pacific Fisheries, edited by Madonna L. Moss and Aubrey Cannon, pp. 45-56. University of Alaska Press, Fairbanks.

Starr, Fiona

2001 Convict artefacts from the Civil Hospital privy on Norfolk Island. Australasian Historical Archaeology 19: 39-47.

State Department

1878 Award of the Fishery Commission Documents and Proceedings of the Halifax Commission, 1877, Under the Treaty of Washington of May 8, 1871, In Three Volumes. Volume II.

Steadman, D. W., A. Plourde, and D. V. Burley

2002 Prehistoric Butchery and Consumption of Birds in the Kingdom of Tonga, South Pacific. Journal of Archaeological Science 29: 571-584. 
Stevenson, Louise L.

1991 The Victorian HomeFront: American Thought and Culture, 1860-1880.

Cornell University Press, Ithaca.

Stottman, Michael J.

2000 Out of Sight, Out of Mind: Privy Architecture and the Perception of Sanitation. Historical Archaeology 34(1 (Special Issue: View from the Outhouse: What We Can Learn from the Excavation of Privies)): 39-61.

Trigger, Bruce $\mathrm{G}$.

2006 A History of Archaeological Thought. 2nd ed. Cambridge University Press, Cambridge.

Twain, Mark, and Charles Dudley Warner

1873 No TitleThe Gilded Age: A Tale of Today. Sun-Times Media Group/Hollinger International, Chicago, IL.

Van der Veen, Marijke

2003 When is food a luxury? World Archaeology 34(3): 405-427.

Vibert, Elizabeth

2010 The Contours of Everyday Life: Food and Identity in the Plateau Fur Trade.

In Gathering Places: Aboriginal and Fur Trade Histories, edited by Carolyn Podruchny and Laura Peers, pp. 119-148. UBC Press, Vancouver, BC.

La Vigne, H. R., R. M. Hughes, R. C. Wildman, S. V. Gregory, and A. T. Herlihy

2008 Summer distribution and species richness of non-native fishes in the mainstream Willamette River, 1944-2006. Northwest Science 82: 83-93.

Walker, P. L., and J. C. Long

1977 An Experimental Study of the Morphological Characteristics of Tool Marks. American Antiquity 42: 605-616.

Wheeler, Kathleen

2000 Theoretical and Methodological Considerations for Excavating Privies. Historical Archaeology 34(1: View From The Outhouse: What We Can Learn from the Excavation of Privies): 3-19.

Whillans, Thomas H.

1979 Historic Transformations of Fish Communities in Three Great Lakes Bays. Journal of Great Lakes Research 5(2): 195-215. 
White, William, Bill R. Roulette, Aimee Finley, Julie Wilt, Megan Harris, Paul

Solimano, Christina Aucutt, and Daniel Martin

2004 The Results of Archaeological Monitoring and Salvage Excavations at Block 342 at the Helen Gordon Child Development Center Expansion Project Area, Portland State University Campus, Southwest Portland, Oregon. Portland.

Wilcox, Estelle Woods, and Bertha Clow

1883 Practical Housekeeping: A Careful Compilation of Tried and Approved Recipes. Buckeye Publishing Co., Lisbon.

Wilkie, Laurie a., and Paul Farnsworth

1999 Trade and the Construction of Bahamian Identity: A Multiscalar Exploration. International Journal of Historical Archaeology 3(4): 283320.

Williams, Jacqueline B.

1996 The Way We Ate: Pacific Northwest Cooking, 1843-1900. Washington State University Press, Pullman, WA.

Williams, Susan

1985 Savory Suppers and Fashinable Feasts: Dining in Victorian America. University of Tennessee Press, Knoxville, TN.

Willis, Lauren M.

2014 The Taphonomy of Archaeological Fish Remains: Experimental Approaches to Understanding the Effects of Natural and Cultural Processes on the Presence and Identification of Cut Marks. University of Oregon.

Willis, Lauren M., and Andrew R. Boehm

2014 Fish bones, cut marks, and burial: implications for taphonomy and faunal analysis. Journal of Archaeological Science 45: 20-25.

2015 Evaluating the Role of Skill Level in Fish Butchery. Journal of Taphonomy 13(1): $1-15$.

Willis, Lauren M., Metin I. Eren, and Torben C. Rick

2008 Does butchering fish leave cut marks? Journal of Archaeological Science 35: $1438-1444$.

Wolverton, Steve

2013 Data Quality in Zooarchaeological Faunal Identification. Journal of Archaeological Method and Theory 20: 381-396. 
Wolverton, Steve, Lisa Nagaoka, and Torben C. Rick

2016 Introduction. In Applied Zooarchaeology: Five Case Studies, edited by Steve Wolverton, Lisa Nagaoka, and Torben C. Rick, pp. 1-19. Eliot Werner Publications, Inc., New York, NY.

Wurst, Louann

1999 Internalizing Class in Historical Archaeology. Historical Archaeology 33(1): 7-21.

Wurst, Louann, and Robert K. Fitts

1999 Introduction: Why Confront Class? Historical Archaeology 33(1): 1-6.

Wurst, Louann, and Randall H. McGuire

1999 Immaculate Consumption: a Critique of the "Shop "Till You Drop" School of Human Behavior." International Journal of Historical Archaeology 3(3): 191-199.

Wydoski, Richard S., and Richard R. Whitney 2003 Inland Fishes of Washington. Second edi. American Fisheries Society, Bethesda, MD.

Zukin, Sharon, and Jennifer Smith Maguire

2004 Consumers and Consumption. Annual Review of Sociology 30(1): 173-197. 
APPENDICES 


\section{Appendix A: Available Tenant Histories for Fish-Bearing Features in the Esther Short Neighborhood}

This information was produced by staff at AAR and archaeologist Scott McAleer.

\section{Feature 3}

Very little information was available for tenant histories for the property adjacent to Feature 3. However, the presence of some toys in the artifact assemblage indicates that at least one young child lived there. A number of pharmaceutical and patent medicine bottles show someone in the household may have been regularly ill. Ceramics and glassware included decorative tea service and tablewares. This, along with other embellished items and elaborate clothing-related artifacts, hints that the family using this privy was spending money on goods associated with the middle class. A number of alcohol bottles and a poker chip show at least one of the occupants was involved in some less-than-genteel behaviors.

\section{Feature 4}

By 1907, a city directory shows James and Josephine Crowley as the primary occupants at the property associated with this feature. Their sons Albert and Orin were listed as boarders. By 1910, the sons are not mentioned, and the property is listed instead under James and Ada Crowley. Feature 4 appears to represent a clean-up event and may be associated with the Crowleys.

\section{Feature 12}

Records for the northwest corner of Esther Street and West $4^{\text {th }}$ Street likely refers to the address where Feature 12 is located. These census records identify the Weavers and Homans as occupants in two separate lots. The Homans likely contributed more to the feature than the Weavers did: the Weavers are first listed in the census records beginning in 1909, but records for the Homans (Charles [1847-1918] and Anna [lifespan unknown]) first begin in 1892, and continue at least until 1898. Sometime between 1904 and 1908, the corner property was sold to the Portland and Seattle Railyards. Before this, the Homans lived in a converted shed in the yard lot, which likely belonged to the Weavers.

Charles Homan was a civil engineer, originally from Canada, but who had moved to the United States before age 15, when he first enlisted in the Union army and participated in Major General Sherman's Savannah Campaign. He re-enlisted at the age of 30 to fight the Nez Perce, and subsequently served in Alaska. Once retired from the 
military, he was credited as contributing to a number of civil projects. The mean artifact date (MAD) for Feature 12 indicates the Homans were on the property during the feature's primary use dates, although it is possible the Weavers used it as well. A garage was built atop the privy sometime after 1911.

There were four Weavers listed in census records: the husband, William (an engineer and driver for a local laundromat); his wife Ada (a "laundry mangler" for the same laundromat); and their two children Hazel and Alice. Both parents were in their late fifties, and the girls were aged 18 and 11, respectively.

Background information on both families indicates that they were in the emerging middle-class, with the Weavers situated above the Homans. Based on available archival data, the Weavers likely did not contribute as much material to Feature 12 as the Homans did. Following Charles Homan's death, the shed was converted into a garage for the Weavers' car, rather than kept open for another tenant.

\section{Feature 13}

Archival research indicated that Feature 13 was in a lot associated with Joseph Barbeau and his family. Joseph was involved with both the Ohio and Vancouver infantries, and some of the artifacts recovered from this privy appear to be associated with Fort Vancouver or another military post, including a Civil War-era button displaying a Confederate eagle and shield motif. Though no daughters were listed on census records, a large number of toys including marbles, doll body parts, and doll tea set parts were recovered from the privy, along with several patent medicine bottles for Mrs. Winslow's Soothing Syrup, a patent medicine aimed at children's ailments. Jewelry and other decorative goods recovered from the privy were, while ornate and indicating ownership of formal attire, were not made of high-quality materials. The artifact assemblage indicates they owned a car, a typewriter, a dog, at least one bird, and a hunting rifle. They were likely situated in the emerging middle class.

\section{Feature $15 B$}

The property associated with Feature 15B has few records. By 1907, Ira and Lena Stanley were listed as occupants. However, by 1910, James and Jennie White lived there. They also had an unknown boarder. Taking on a boarder indicates they were not likely lower middle-class.

\section{Feature 21}

Feature 21 was listed under a series of occupants. In 1889, the occupancy list included Henry, Charles, and Philip Caples (all brothers); Henry's wife Emma; and an unrelated man named Olive Harns. The Caples were likely renting the property from Peter Crawford. The death of Crawford's wife Zilla in 1888 prompted him to move to 
Kelso, though he did later return to Vancouver. Charles Caples was a clerk at Crawford, Marshall \& Company, a store Peter Crawford was involved in. Henry and his wife Emma had eight children. Two of the children, Lucy and Henry R. Jr., were likely born at the residence in 1890 and 1893. There were other children living at the house as well: Mary, born in 1884; Robert, born in 1881; Margaret, born in 1879; and Lilly, born in 1877. The fact that the Caples were renters and that their household was so full indicates they were likely towards the lower end of middle class.

\section{Feature 35}

Feature 35 was located next to a property owned by Sarah Slocum. Sarah had been married, but was widowed in 1892. She took on several boarders between 1898 and 1900, two of whom were Miles and Carrie Smith, and their infant daughter Sibyl. Miles Smith was a pharmacist, but there is little information about Sarah Slocum's or Carrie Smith's personal or professional lives. By 1907, Sarah had five boarders. Feature 35 was filled and closed in 1900, when a second home and an outbuilding were added to the property and capped the feature. Miles' position as a pharmacist indicates emerging middle-class status.

\section{Features 28 and 31}

Though its TPQ date is in 1916, only 5\% of the diagnostic artifacts from Feature 31 dated post-1900. The range of datable artifacts is great enough that no single family can be strongly associated with the deposits. However, the variety of artifacts suggests a middle or working class family hosting boarders, or one large middle class family with several children, were the feature's primary users.

Feature 28 was adjacent to Feature 31, on the same lot, but closer to a shed or other small structure in the far corner of the yard. Among the people associated with this address between 1880 and 1910 were Henry Miller (a saloon worker); Lenna Wilhelm; AND several men (a student, a firefighter, and a lumber yard booman), all boarding together. In 1910, they were joined by the Monahan family, which included three sons aged three to 18, and four daughters aged six to 14 . William Monahan, the father, was listed as a common laborer, and the working-aged children were employed as trolley car engineers and soda factory laborers.

Artifacts from Feature 28 include a large number of tea and dinner set pieces. Their relative completeness indicates that the primary users perhaps participated on conspicuous consumerism and used a steady income to replace items based on aesthetic or social want. Alternately, they could indicate a very high turnover rate and represent several families with similar purchasing habits. Artifacts from Feature 31 suggest similar purchasing habits. Both features also represent a range of genteel behaviors (shown 
through table wares, parlor items, and formal wear) and less respectable behaviors (with a variety of working-class alcohol bottles and tobacco use products).

\section{Feature 40}

This feature is on a lot that was subdivided into several smaller lots between 1892 and 1907. From 1896 to 1901, the lots were listed under "Rosanna L."; from 1901 to at least 1916, to Henry Van Atta; and up until at least 1908, the Calder family. By 1910, two unnamed boarders also resided there. Arthur Calder and Van Atta were identified as proprietors of a local bar (the Baltimore Bar). Arthur also owned and operated a real estate office. Among the artifacts excavated from Feature 40 were two ornate pieces of a metal fishing reel, with a hole $2 \frac{5}{8}$ inches in diameter to accommodate a pole.

\section{Feature 42}

Little information is available on the tenants associated with this feature. A $21^{\text {st }}$ Infantry hat pin was recovered from the assemblage, indicating possible connections to military service or other involvement at Fort Vancouver/Vancouver Barracks.

\section{Feature 46}

Feature 46 was listed under Charles and Agnes Tooley in 1892. No more information is available on them or any other tenants.

\section{Feature 63}

Feature 63 was next to property owned by Frank and Minnie Wilcox in 1907. They had no children and no employment information is available on either spouse, but Frank Wilcox built an automobile at the house. This, along with their ownership of the property, indicates that they were likely a middle-class family.

\section{Feature 66}

No information is available on the occupancy records associated with this address.

\section{Feature 67}

The address associated with Feature 67 has a clear tenancy history dating from 1858 onward. Esther Short initially owned the property, but eventually it was sold to "John Huth and wife" in 1882, who were listed as the property owners until 1921. Beginning in 1907, Julia and Louis Huth, Louis Busby, and Katherine Busby (a widower) were also listed in the Polk City Directory for the property. Sometime around 1910, Julia Huth moved to 507 Franklin Street (where Feature 76 is located). Julia was German by birth, but had lived in Vancouver since at least 1881; her husband John Huth (also 
German) passed away in 1897. Julia was one of the founders for the local St. Paul's English Lutheran Church.

The Huth and Busby families likely contributed the most to this feature. One family might have lived in a small shed-like structure at the back of the property. Though the occupational history shows some part of the Huth family there until at least 1921, the feature usage dates appear more constricted (e.g., ca. 1905 to 1911) due to datable artifacts and the relatively shallow depth of the feature, at approximately one foot. Despite its shallow depth, a total of 824 artifacts were recovered from the feature. They indicate a less-than-genteel lifestyle, with very limited decorative tablewares and an abundance of beer and alcohol bottles. The presence of two bar drinking tokens - one for Portland, and one for Vancouver - indicates both drinking outside of the home, and some amount of commuting across the Columbia River. A number of medicinal bottles shows that someone in the household may have been regularly ill. Clothing and grooming items also hint at adults who had limited income, but put effort into their appearances and found inexpensive versions of fashionable clothes. Altogether, these families were likely working-class or at the very low end of the emergent middle class.

\section{Feature 76}

This feature had a relatively small number of artifacts $(n=373)$, separated by several ash and silt clay layers, indicating the privy had numerous clean-out episodes. No archival information could be found for the associated lot dating to before 1908 . However, the limited artifacts suggest the occupants included at least one school-aged girl, and a family that cared about the appearance and maintenance of clothing. The assemblage also showed numerous hobbies, including playing instruments, but limited parlor entertaining with no evidence of tea sets and very few table wares. 


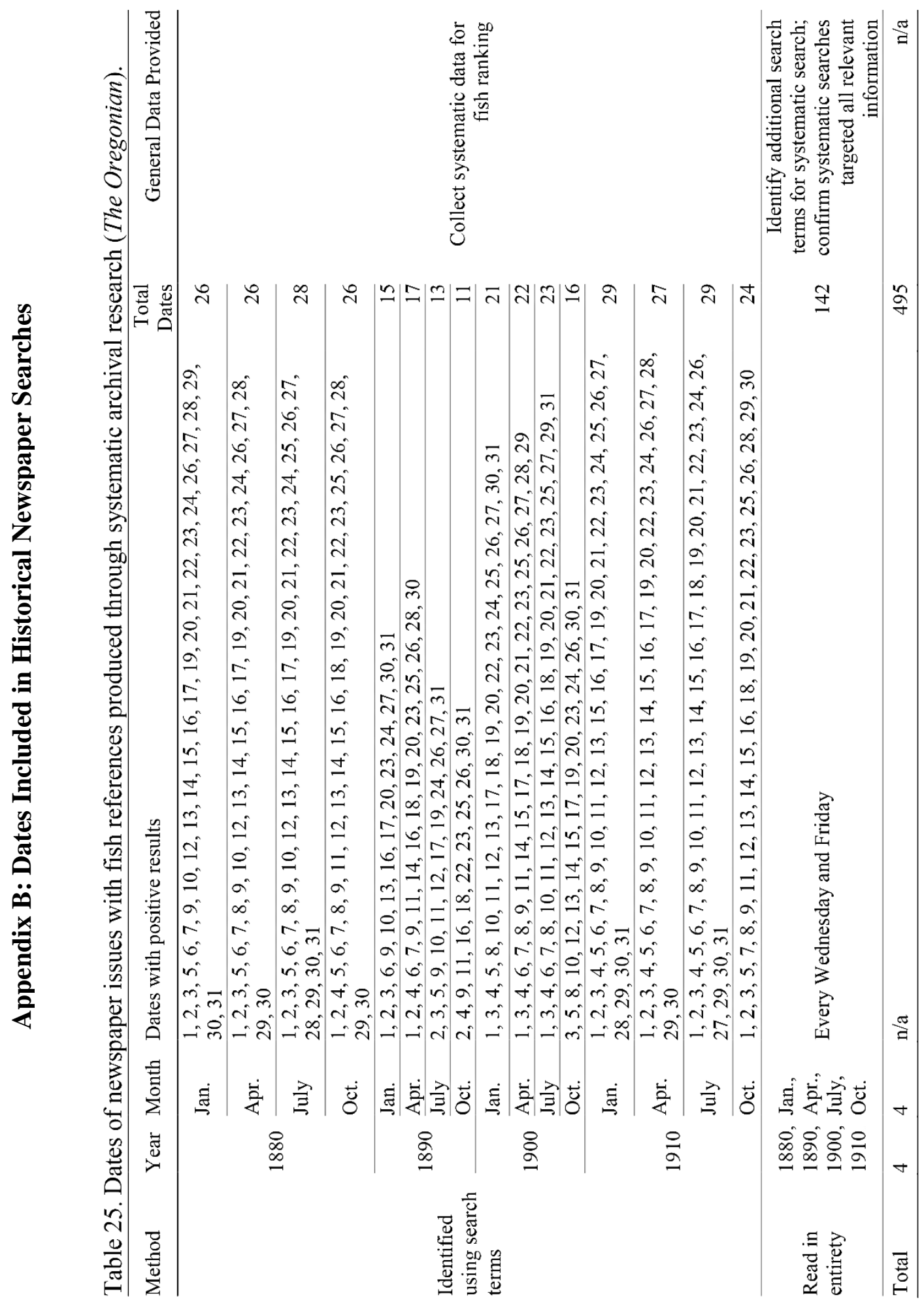




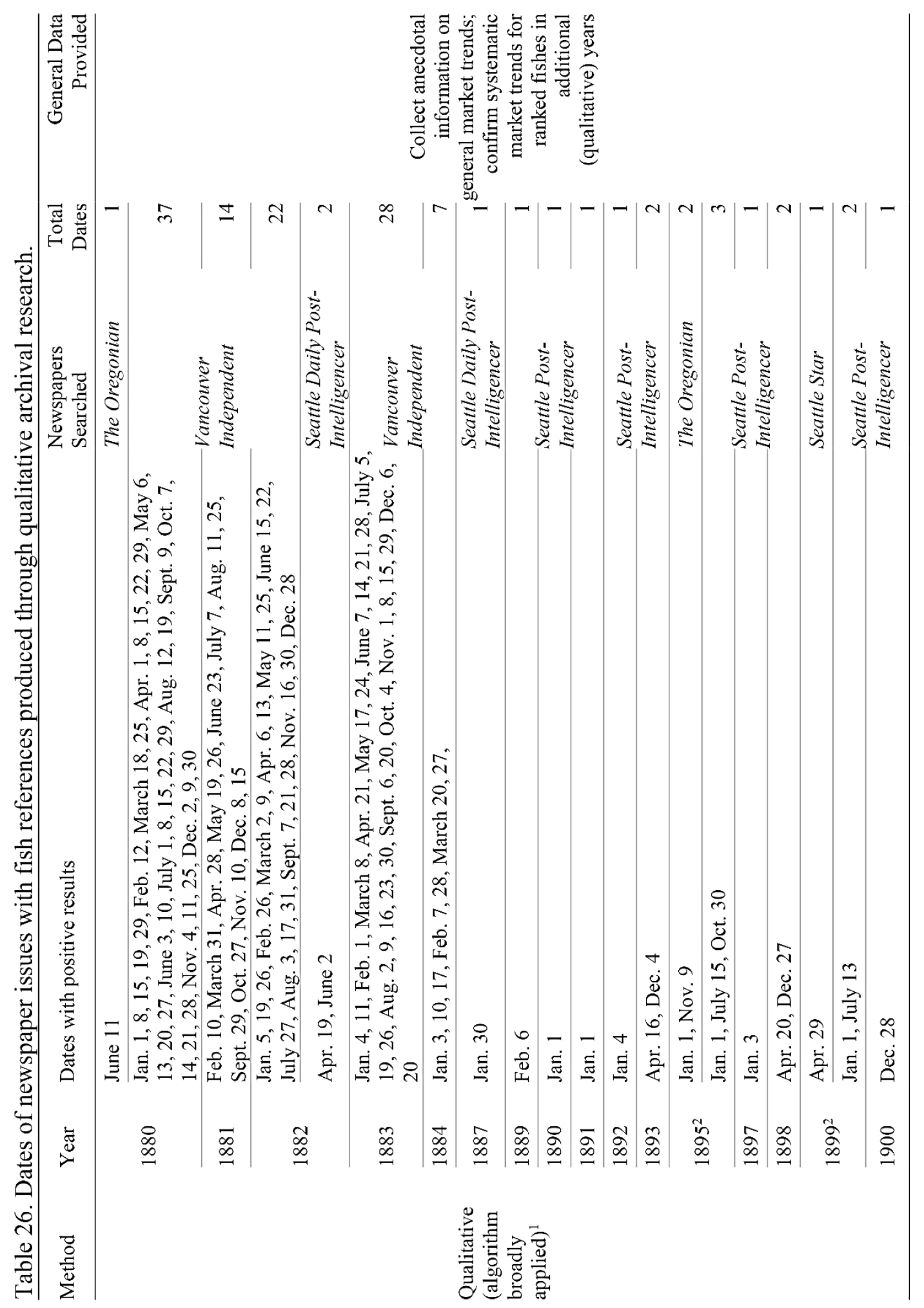




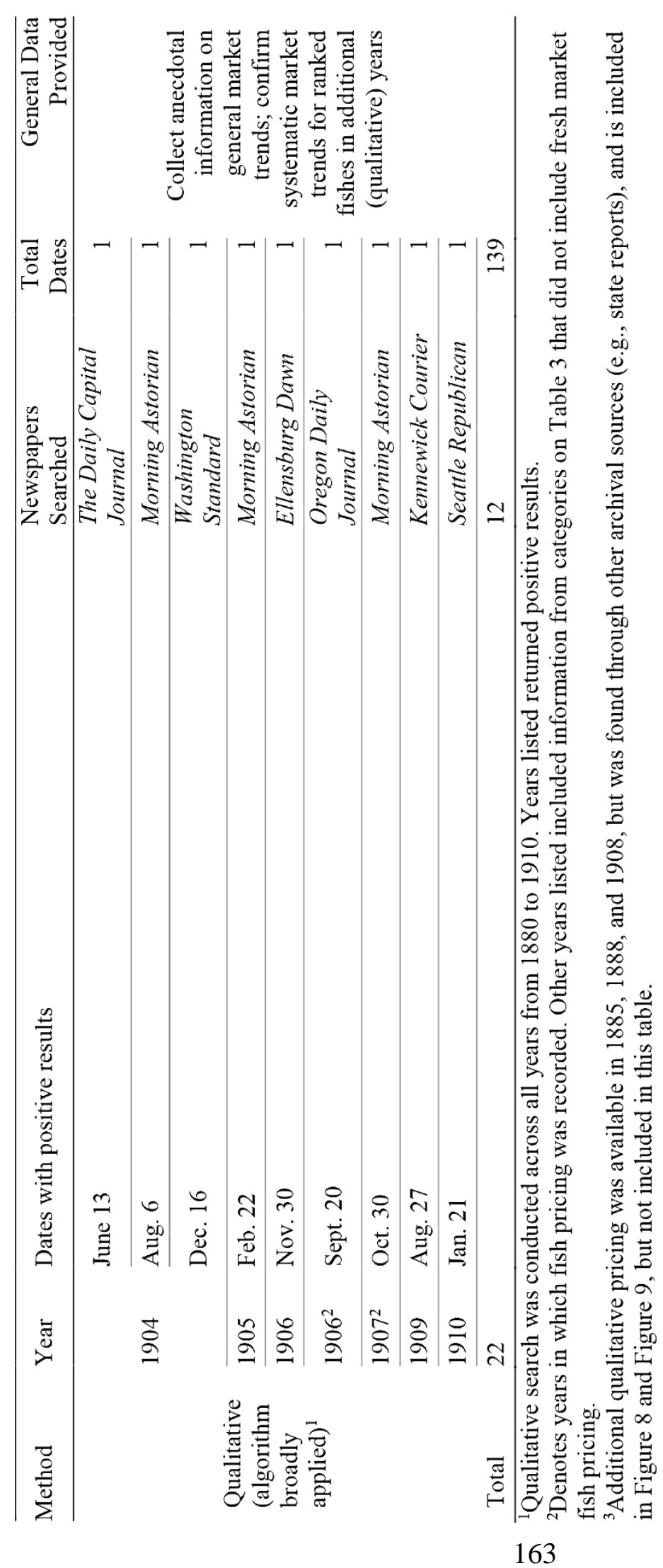




\section{Appendix C: Interpreting "Box-and-Whisker" Plots}

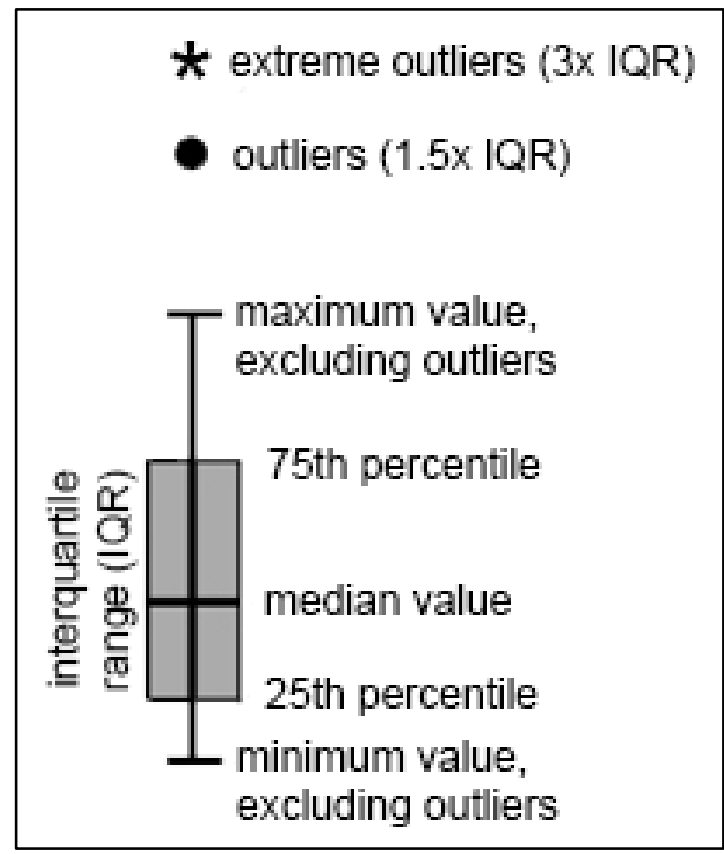

Figure 21. Example "box-and-whisker" plot to aid in interpreting charted data. 


\section{Appendix D: Selection of Ichthyofaunal Elements}

Table 27. Elements included in Easton and Taber ichthyofaunal analyses.

\begin{tabular}{|c|c|c|c|c|}
\hline Element & $\begin{array}{c}\text { Easton } \\
\text { Recorded }\end{array}$ & $\begin{array}{l}\text { In Taber } \\
\text { Analysis }\end{array}$ & $\begin{array}{c}\text { Taber } \\
\text { Recorded }\end{array}$ & Note \\
\hline$\overline{\text { Angular/Articular }}{ }^{1}$ & $\mathrm{X}$ & $\mathrm{X}$ & $\mathrm{X}$ & \\
\hline $\mathrm{Barb}^{2}$ & $\mathrm{X}$ & & & \\
\hline Basioccipital $^{3}$ & $\mathrm{X}$ & $X$ & $\mathrm{X}$ & \\
\hline Basiptyregium & $\mathrm{X}$ & $\mathrm{X}$ & $\mathrm{X}$ & \\
\hline Branchial Arch & $\mathrm{X}$ & & & \\
\hline Ceratohyal $^{4}$ & $\mathrm{X}$ & $\mathrm{X}$ & $\mathrm{X}$ & \\
\hline Clavicle & & $X$ & $\mathrm{X}$ & \\
\hline Cleithrum & $\mathrm{X}$ & $\mathrm{X}$ & $\mathrm{X}$ & \\
\hline Coracoid $^{5}$ & $\mathrm{X}$ & $X$ & $\mathrm{X}$ & \\
\hline Cranium & $\mathrm{X}$ & $\mathrm{X}$ & & \\
\hline Dental Plate & & $\mathrm{X}$ & & Chimaerids only \\
\hline Dentary & $\mathrm{X}$ & $\mathrm{X}$ & $\mathrm{X}$ & \\
\hline Epihyal $^{4}$ & $\mathrm{X}$ & $X$ & $\mathrm{X}$ & \\
\hline Exoccipital $^{3}$ & & $\mathrm{X}$ & $\mathrm{X}$ & \\
\hline Frontal $^{3}$ & & $\mathrm{X}$ & $\mathrm{X}$ & \\
\hline Hyomandibula $^{6}$ & $\mathrm{X}$ & $\mathrm{X}$ & $\mathrm{X}$ & \\
\hline Interopercle & & $\mathrm{X}$ & $\mathrm{X}$ & \\
\hline Lingual Plate & & $X$ & $\mathrm{X}$ & Salmonids only \\
\hline Maxilla & $\mathrm{X}$ & $\mathrm{X}$ & & \\
\hline Metapterygoid & $\mathrm{X}$ & $\mathrm{X}$ & $\mathrm{X}$ & Salmonids only \\
\hline Mesoethmoid $^{3,7}$ & & $\mathrm{X}$ & $\mathrm{X}$ & \\
\hline Opercle & $\mathrm{X}$ & $\mathrm{X}$ & $\mathrm{X}$ & \\
\hline Palatine & $\mathrm{X}$ & $\mathrm{X}$ & & \\
\hline Parasphenoid ${ }^{3}$ & & $\mathrm{X}$ & $\mathrm{X}$ & \\
\hline Pharyngeal & $\mathrm{X}$ & $\mathrm{X}$ & $\mathrm{X}$ & Clupeids only \\
\hline Premaxilla & $\mathrm{X}$ & $\mathrm{X}$ & & \\
\hline Post-cleithrum & & $\mathrm{X}$ & $\mathrm{X}$ & \\
\hline Post-temporal & $\mathrm{X}$ & & & \\
\hline Prerotic & & $\mathrm{X}$ & $\mathrm{X}$ & \\
\hline Rib & $X$ & & & \\
\hline Scale & $\mathrm{X}$ & & & \\
\hline Scapula & $\mathrm{X}$ & $\mathrm{X}$ & $\mathrm{X}$ & \\
\hline Spine, dorsal & & $\mathrm{X}$ & $\mathrm{X}$ & \\
\hline Spine, pectoral & $\mathrm{X}$ & $\mathrm{X}$ & $\mathrm{X}$ & \\
\hline Supracleithrum $^{8}$ & & $\mathrm{X}$ & $\mathrm{X}$ & \\
\hline Unid. element & $\mathrm{X}$ & $\mathrm{X}$ & $\mathrm{X}$ & \\
\hline Urohyal & $\mathrm{X}$ & $\mathrm{X}$ & $\mathrm{X}$ & \\
\hline Vertebra, abdominal & $\mathrm{X}$ & $\mathrm{X}$ & & Non-salmonids only \\
\hline Vertebra, atlas & $\mathrm{X}$ & $X$ & & \\
\hline
\end{tabular}




\begin{tabular}{lcccc}
$\begin{array}{l}\text { Vertebra, caudal } \\
\text { Vertebra, Modified 2 }\end{array}$ & X & X & X & $\begin{array}{c}\text { Non-salmonids only } \\
\text { Ictalurids only }\end{array}$ \\
\hline Element & & X & X & Note \\
& Easton & Taber & $\begin{array}{c}\text { Taber } \\
\text { Recorded }\end{array}$ & \\
\hline Vertebra, terminal & $\mathrm{X}$ & $\mathrm{X}$ & & Non-salmonids only \\
Vertebra, thoracic & $\mathrm{X}$ & $\mathrm{X}$ & & \\
Vertebra, unspecified & $\mathrm{X}$ & $\mathrm{X}$ & $\mathrm{X}$ & Salmonids only \\
Vertebra 1 & & $\mathrm{X}$ & & Salmonids only \\
Vertebra 2 & & $\mathrm{X}$ & $\mathrm{X}$ & Salmonids only \\
Vertebra 3 & & $\mathrm{X}$ & $\mathrm{X}$ & Salmonids only \\
Vertebra 4 & & $\mathrm{X}$ & & \\
Vomer & $\mathrm{X}$ & $\mathrm{X}$ & $\mathrm{X}$ & \\
Total & 32 & 44 & 33 & \\
\hline Not & & &
\end{tabular}

Notes: ${ }^{1}$ Easton identified as Quadrate; ${ }^{2}$ I identified as Spine, Dorsal or Spine, Pectoral; ${ }^{3}$ Easton identified elements in the cranial apparatus as Crania $(\mathrm{n}=1) ;{ }^{4}$ Easton identified as Angular/Articular; ${ }^{5}$ Easton identified as Supracleithrum; ${ }^{6}$ Easton identified articulated Quadrate $(n=1)$, Preopercle $(n=1)$, and Hyomandibula ( $\mathrm{n}=1)$ as Hyomandibula $(\mathrm{n}=1) ;{ }^{7}$ Easton identified as Vomer; ${ }^{8}$ Easton identified as Palatine 


\section{Appendix E: Descriptive Summary of Ichthyofaunal Remains}

Here I will briefly describe the criteria I used in assigning fish specimens to taxon based on morphology, ecology, habitats, and ethnographic use, particularly as it relates to the late $19^{\text {th }}$ and early $20^{\text {th }}$ centuries in the Pacific Northwest.

The minimum number of individuals (MNI) is established similarly to MAU, but takes element siding into account. Additionally, the MNIs listed below are reflective of recovery location (e.g., two salmon angulars $[1 \mathrm{~L}, 1 \mathrm{R}]$ recovered from two separate features is calculated as an MNI of 2, as are two right-sided salmon angulars recovered from the same feature).

When non-ictalurid specimens are identified as "crania", this does not indicate $50 \%$ or more of an intact crania; it indicates that two or more cranial elements were articulated, some or all of which may not have been identifiable beyond being cranial element(s).

\section{Class Osteichthyes - Bony Fishes}

\section{Order Acipenseriformes}

Family Acipenseridae - sturgeons

$$
\text { Acipenser sp. - sturgeon }
$$

Materials: Scute (9), premaxilla (1), unidentified (3). Total NISP 13. Total MNI 3.

Remarks: There are two species of sturgeon present in the Pacific Northwest: white sturgeon (Acipenser transmontanus) and green sturgeon (A. medirostris). Both were fished for during the late $1800 \mathrm{~s}$, but white sturgeon were considered higher quality and brought in more revenue (Harrison 2008:2-3). White sturgeon were present throughout the Columbia and Snake Rivers; in the Victorian era, white sturgeon were also the dominant sturgeon in the Rogue River. White sturgeon move downstream to spawn in the spring and early summer, and have been documented moving upstream again in the winter, though juvenile fishes are non-migratory. Green sturgeon, however, are predominantly associated with brackish water and are constrained to both the lower 40 miles of the Columbia and fully marine waters (Butler 2004b; Hart 1973; Wydoski and Whitney 2003). Spawning eulachon provide an important food source for sturgeon, and the abundance of sturgeon may loosely coincide with eulachon runs (Hart 1973:8084). Considering the areas typically fished for sturgeon; the greater distribution of white sturgeon than green; and a preference for consuming white sturgeon over green, I inferred that any sturgeon remains were from white sturgeon. 


\section{Order Clupeiformes}

Family Clupeidae - Ray-finned fishes (Herrings, Shads, Sardines, etc.)

Alosa sapidissima - American shad

Materials: Epihyal (1), opercle (1), posttemporal (1), vertebra, caudal (6), vertebra (1). Total NISP 10. Total MNI 2.

Sardinops sp. - pilchards

Materials: Vertebra (29). Total NISP: 29. Total MNI: 1.

Family Engraulidae - Anchovies

Materials: Vertebra, indeterminate (2, cf. to engraulids). Total NISP 2. Total MNI 1.

Remarks: American shad was introduced to California in the 1870s and spread north from there, appearing in the waters of British Columbia by 1891 (Hart 1973:95-6).

There are two vertebrae that compare favorably to the anchovies (family Engraulidae) from the re-analyzed assemblage. The only member of this family that has a distribution range in the Pacific Northwest is the northern anchovy (Engraulis mordax mordax) (Hart 1973:104-5).

\section{Order Cypriniformes \\ Family Cyprinidae - Minnows \\ Cyprinus carpio - common carp}

Materials: Cleithrum (3), dentary (1), dorsal spine (1), interopercle (1), opercle (7), pharyngeal (1), premaxilla (1), preopercle (1), rib (1), vertebra (19). Total NISP 38. Total MNI 5.

Acrocheilus alutaceus - chiselmouth

Materials: Pharyngeal (1). Total NISP 1. Total MNI 1.

Ptychocheilus oregonensis - northern pikeminnow Materials: Cleithrum (2). Total NISP 2. Total MNI 1.

Remarks: Historically, there are at least nine known species of cyprinids in the Columbia basin alone (Lee et al. 1980); 17 are listed in the Pacific Northwest presently. These include chiselmouth (Acrocheilus alutaceus), lake chub (Couseius plumbeus), tui chub (Gila bicolor), peamouth (Mylocheilus caurinus), northern pikeminnow (Ptychocheilus oregonensis), five species of dace (genera Rhinichthyes), redside shiner 
(Richardsonius balteatus), and the introduced species goldfish (Carassius auratus), grass carp (Ctenopharyngodon idella), common carp (Cyprinus carpio), golden shiner (Notemigonus crysoleucas), fathead minnow (Pimephales promelas), and tench (Tinca tinca).

Within the family Cyprinidae, I found it difficult to reliably differentiate between vertebrae of different species based on landmarks alone. As such, while I could often identify vertebrae as distinctly cyprinid in nature, I did not often provide a finer taxonomic identification within the cyprinid family.

Additionally, both carp and catfish have barbs, but catfish barbs (both pectoral and dorsal) are more robust, more circular in cross-section, and straighter than those of carp. Carp barbs generally flatten dorso-ventrally, becoming more grassile than those of catfishes.

The pharyngeal arches of several species of Cyprinidae, such as the chiselmouth, are very distinctive and often allow for species- or genus-level identifications. Two cleithra that were recovered compared favorably to northern pike minnow, but the similarities were not strong enough to positively identify the elements to that species. Both chiselmouth and northern pike minnow tend to occupy warmer streams, in moderate to fast-moving currents and slow to moderate currents, respectively (Wydoski and Whitney 2003).

\section{Order Gadiformes}

Family Gadidae - cods, hakes, and related species

Gadus macrocephalus - Pacific cod

Materials: Cleithrum (1), postcleithrum (2), posttemporal (2), vertebra, caudal (1), vertebra, indeterminate (1). Total NISP 7. Total MNI 2.

Remarks: There are four species of codfishes in Pacific Northwestern waters. The Pacific cod, also known as simply "cod", featured regularly in marketplaces during this period; tomcod (Microgadus proximus), another species in this family, also appeared but with much reduced regularity. The generally benthic nature of this fish makes it less likely that any elements represent household-angled fishes over market purchased fishes, although some Pacific cod have been known to be caught in more shallow waters (Hart 1973:223). Tomcod are not as abundant and do not proliferate as much as Pacific cod, making it less likely that gadid elements are representative of tomcod than Pacific cod (Hart 1973:226-227). The other members of this family appearing in the Pacific Northwest are generally not sought after for human consumption (Hart 1973). 


\section{Order Osmeriformes}

Family Osmeridae

Thaleichthys pacificus - Eulachon

Materials: Vertebra, abdominal (2). Total NISP 2. Total MNI 1.

Remarks: Eulachon are pelagic and anadromous fishes that generally spawn from late winter to mid spring, migrating upriver to do so (Hart 1973:149). Valued highly as a food fish, eulachon have played a major role in both pre- and post-contact diets.

\section{Order Perciformes}

Materials: Maxilla (1). Total NISP 1. Total MNI 1.

Remarks: This specimen compares favorably to M. salmoides.

\section{Order Pleuronectiformes}

Family Pleuronectidae - righteye flounders

Materials: Crania (2). Total NISP 2. Total MNI 1.

Subfamily Hippoglossinae

Materials: Vertebra, abdominal (2), vertebra, caudal (6), vertebra, indeterminate (3). Total NISP 11. Total MNI 5.

Remarks: There are at least nineteen recorded species in the Pacific Northwest, mostly designated as sanddabs, halibut, soles, turbots, or flounders. The dominant food fish of these is the Pacific halibut. Hart (1973) notes that the petrale sole (Eopsetta jordani), rock sole (Lepidopsetta bilineata), and English sole (Parophrys vetulus) all had value as food fishes, but none of these compared in volume to the production of pacific halibut on the markets. Pacific halibut was the most targeted of the pleuronectids by Euroamerican fisheries, so much so that by 1910, vessels had depleted the closer shoreline populations and spread into more pelagic waters to meet demands, upwards of 24 million pounds in the first years of the $20^{\text {th }}$ century. These specimens compared favorably to Pacific halibut (Hippoglossus stenolepis). 
Order Salmoniformes

Family Salmonidae - salmon, trout, and whitefish

Materials: Cleithrum (2), branchial arch (1), coracoid (1), crania (2), dentary (2), epihyal (3), lingual plate (1), maxilla (1), metapterygoid (1), palatine (4), preopercle (2), scales (25), scapula (1), spine (26), tooth (3), urohyal (1), vertebra, indeterminate (2), vertebra, abdominal (42), vertebra, first (1), vertebra, type 2 (11), vertebra, type 3 (2), vertebra, caudal (11), vertebra, thoracic (10), vomer (2). Total NISP 201. Total MNI 15.

Remarks: Easton assigned these specimens to family-level taxon; they are likely assigned to Oncorhynchus sp. and some small trout. I did not differentiate between species of Oncorhynchus when recording salmonid remains. Smaller salmonid remains were generally more comparable to trout (e.g., Dolly Varden [Salvelinus malma]; "Eastern brook trout", or brook trout [Salvelinus fontinalis]; and "trout salmon", or rainbow trout/steelhead trout [Oncorhynchus mykiss]) than to juvenile or smolt stages of larger salmonids (e.g., Oncorhynchus tshawytscha). However, the appearances of small salmonid elements remained too ambiguous to clearly identify the genus or species. As it was illegal to sell trout commercially for at least some portions of my study period (e.g., 1900, 1910), I inferred that the likelihood of smaller salmonid elements representing household-angled trout was greater than that of commercially purchased small salmonids. The element representation of smaller salmonids may also support this assertion, as more cranial elements were present than are generally associated with purchased fishes (Singer 1982a, 1985, 1987).

Records of fishes in the Pacific Northwest include at least ten species of salmon, trout, and whitefish (Hart 1973). Six of these are represented by the genus Oncorhynchus, all anadromous native salmon. A seventh salmon, the Atlantic salmon (Salmo salar), was introduced in the Pacific Northwest in 1905 (Hart 1973:132). It is unlikely the salmonid remains recovered from the Esther Short neighborhood are representative of Atlantic salmon, due to the short period of overlap between their introduction to the region and my study period.

Order Siluriformes

Family Ictaluridae

\section{Ictalurus or Ameiurus spp.}

Materials: Angular/articular (45), barb (5), basioccipital (20), basiptyregium (1), ceratohyal (1), cleithrum (166), epihyal (67), frontal (12), hyomandibula (85), maxilla (2), mesoethmoid (46), opercle (61), parasphenoid (8), parietal (8), pectoral spine (88), post-temporal (10), premaxilla (1), preopercle (7), prerotic (2), quadrate (3), scapula (8), 
dorsal spine (1), supracleithrum (42), supraoccipital (5), urohyal (10), vertebra (75), vertebra, modified second (6), vomer (5). Total NISP 963. Total MNI 91.

Remarks: Two genera of catfishes were introduced into the Pacific Northwest before or during the years of study (1880-1910): Ictalurus spp. and Ameiurus spp. These genera may represent any of four species: black bullhead catfish (Ameiurus melas), yellow bullhead catfish (A. natalis), brown bullhead catfish (A. nebulosus), and channel catfish (Ictalurus punctatus). These fishes do have distinct landmarks that can be used to identify them to the species level, but the reference collections at Portland State University did not house each of the four species. Therefore, all catfishes were identified to family Ictaluridae, but could be either Ictalurus or Ameiurus. This distinction is not meaningful when organizing fishes by rank, as Victorian-era Portlanders and Vancouverites seemingly did not differentiate between any catfish species, but rather referred to all within the family as "catfish".

\section{Unidentified Fishes - Small Size Class}

Materials: Parasphenoid (1), vertebra, indeterminate (1). Total NISP 2.

Remarks: One vertebra compared favorably to a fish from the Class Perciformes, of which there are four families (Centrarchidae, Embiotocidae, Percidae, and Percichthyidae) in the Pacific Northwest.

\section{Unidentified Fishes - Medium Size Class}

Materials: Dentary (1, cf. to centrarchids), opercle (1, cf. to centrarchids), vertebra, caudal (6), vertebra, indeterminate (1). Total NISP 9.

Remarks: I suggest two specimens from a medium-bodied fish compare favorably to centrarchid remains. One specimen I associated with centrarchid-like remains was recovered from the same unit from which a freshwater bass specimen was recovered. Both specimens were sized similarly enough that they may be from the same individual. Minimally, freshwater bass remains from the same feature increase the likelihood that the medium-sized fish remains are also centrarchid.

\section{Unidentified Fishes - Large Size Class}

Materials: Cleithrum (12), vertebra, indeterminate (1). Total NISP 13. 


\section{Appendix F: Notes on Results of Faunal Analyses}

\section{Differences in Analyst Identifications and Impact on Spearman's Rho Tests}

Table 28. Easton and Taber identification of select silurid fish elements.

\begin{tabular}{lll}
\hline Easton's Analysis & My Analysis & Verified by Butler \\
\hline Angular & Ceratohyal and Epihyal & Ceratohyal and Epihyal \\
Quadrate & Angular & Angular \\
Supracleithrum & Coracoid & Coracoid \\
Palatine & Supracleithrum & Supracleithrum \\
Vomer & Mesoethmoid & Mesoethmoid \\
\hline
\end{tabular}

I encountered five repeat identification differences, all for catfishes. After noting the differences, I conducted a visual random sample check for approximately 300 additional specimens (26\%). I found Easton had consistently labeled the elements as noted in Table 28 (e.g., quadrate, and not angular). Because his identifications were uniform, I changed Easton's identifications of those specific elements to match Butler's identifications, and to reduce errors caused by analyst differences.

In conducting the random sample check, I also noted that small trout-like salmonid specimens were occasionally recorded as catfishes. Because this identification was not uniformly applied, I could not correct for it. It was an infrequent occurrence, and I had limited time in which to complete my analyses. As such, I decided the error was within acceptable parameters and included Easton's results in my own without attempting to correct for additional small trout-like salmonid remains.

I conducted several two-tailed Spearman's Rho tests. When all specimen groupings were ranked independently (e.g., gadids, and specimens comparing favorably to gadids were separated, and all sizes of unidentified fishes were separated), the correlation between our identifications dropped, as did the statistical significance of that correlation $\left(\mathrm{r}_{\mathrm{s}}=0.233, p=0.423\right)$.

I note this namely to illustrate the high degree of variation in results when different zooarchaeologists analyze the same collection. Analysts should consider the context in which an assemblage was analyzed. This affects the way we view and group our specimens. For example, when one analyst has a more advanced comparative collection, or more time in which to complete analysis, the results can differ more markedly. Adapting as much of the previous analyst's protocols as possible will reduce assemblage differences caused by protocols.

This also illustrates the importance of clearly describing one's analysis protocols. I had difficulty comparing my element identifications to Easton's because our protocols differed substantially. Our work was most highly correlated when I reduced the discrete cranial elements I recorded, into one category of "crania", which matched Easton's original identification protocols more closely $\left(\mathrm{r}_{\mathrm{s}}=0.556, p=0.000\right)$. When I kept my cranial elements as separate identifications, the correlation between our two datasets was reduced $\left(\mathrm{r}_{\mathrm{s}}=0.447, p=0.000\right)$. 


\section{$\underline{\text { Additional Faunas and Elements Noted in Ichthyofaunal Assemblage }}$}

The replicability study NISP of 597 does not include 17 mammalian elements; an estimated 40 avian elements; and one element that compared favorably to a frog (anuran) urostyle. I made a conservative estimate of the fish elements I did not record (ribs, branchials, etc.) and the fragments too small or degraded to identify. My estimate was based on specimens from Layer DS of Feature 31, one of the most abundant fish-bearing features. From this sample, I estimated there to be approximately 100 fish ribs, and a further 120 unidentifiable or unidentified elements (predominantly associated with smallor medium-sized fishes) in the ichthyofaunal assemblage.

From the previously unidentified fish faunas, I observed an additional 17 nonichthyofaunal remains. I noted these as 13 fragmented mammalian remains (including a portion of a machine-sawn centrum that compared well to pig), three unidentified avian remains, and one fragment of a Pacific littleneck clam (Protothaca staminea).

\section{$\underline{\text { Joint Gobalet and Kennedy Analyses }}$}

Butler and I could not easily assign thirteen specimens to taxon. Input from Drs. Kenneth Gobalet and Ryan Kennedy led to taxa assignments for seven of the specimens. An additional two specimens compared favorably to cyprinids.

The four remaining vertebrae, classified as medium-sized fishes, did not directly match any specimens in the combined collections at Portland State University, or those available to Gobalet or Kennedy. Gobalet suggested they looked somewhat similar to midshipman fishes (Porichthys sp.) or midshipman-like fishes, such as a puffer fish or porcupine fish. However, since none of these were regularly consumed by Euroamerican populations, we treated that evaluation conservatively.

Table 29. Previously unidentified fish specimens evaluated with Gobalet and Kennedy

\begin{tabular}{lrrr}
\hline Element & NSP & Successfully identified & Identification \\
\hline Post-temporal & 1 & 1 & American shad \\
Vertebrae & 5 & 5 & American shad \\
Vertebrae & 2 & 2 & cf. Cyprinidae \\
Vertebrae & 4 & 0 & Large fish \\
Opercle & 1 & 1 & American shad \\
Total & 13 & 9 & \\
\hline
\end{tabular}




\section{Appendix G: Fish Butchery Documentation}

All photographs taken by Martin E. Adams.
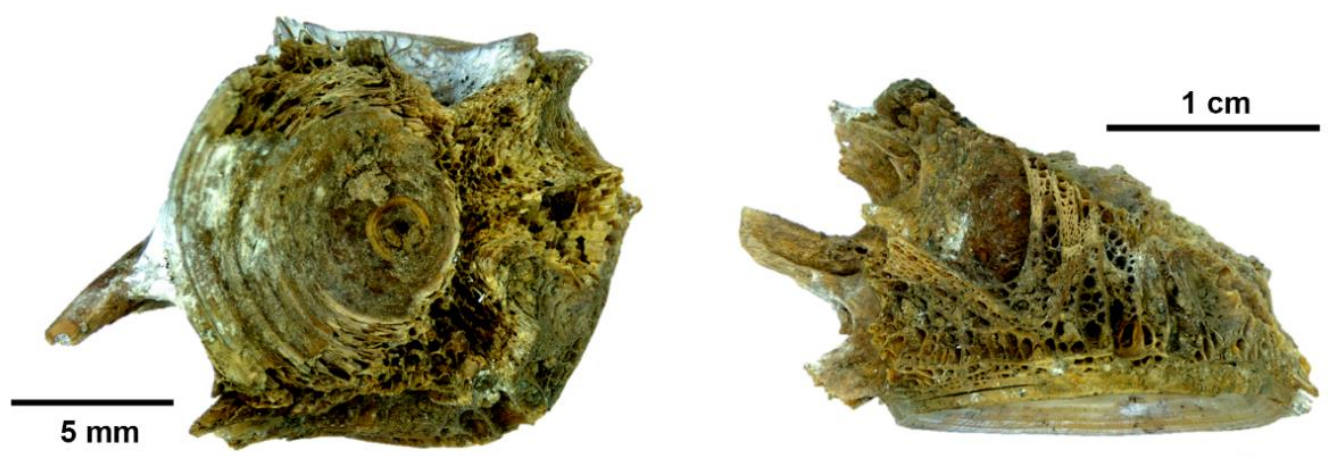

Cat. 1845
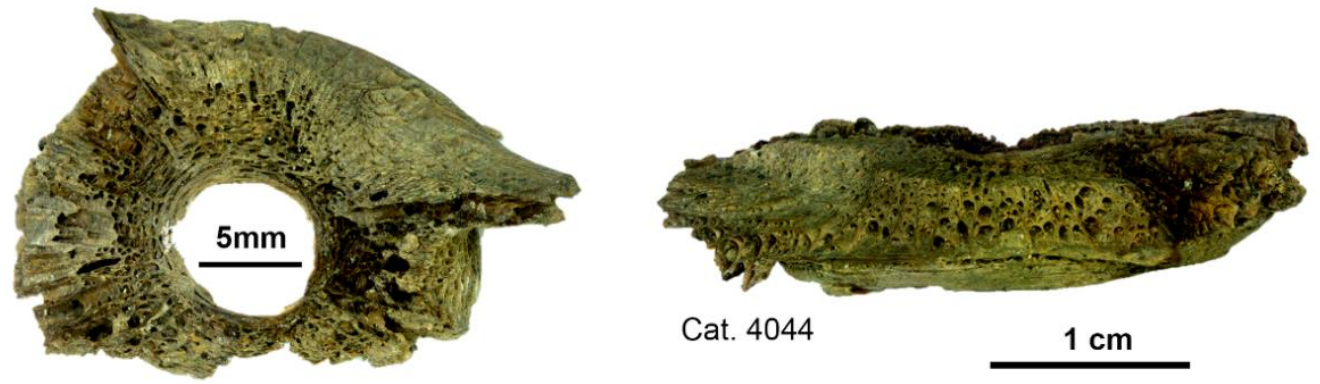

Cat. 4044

$1 \mathrm{~cm}$
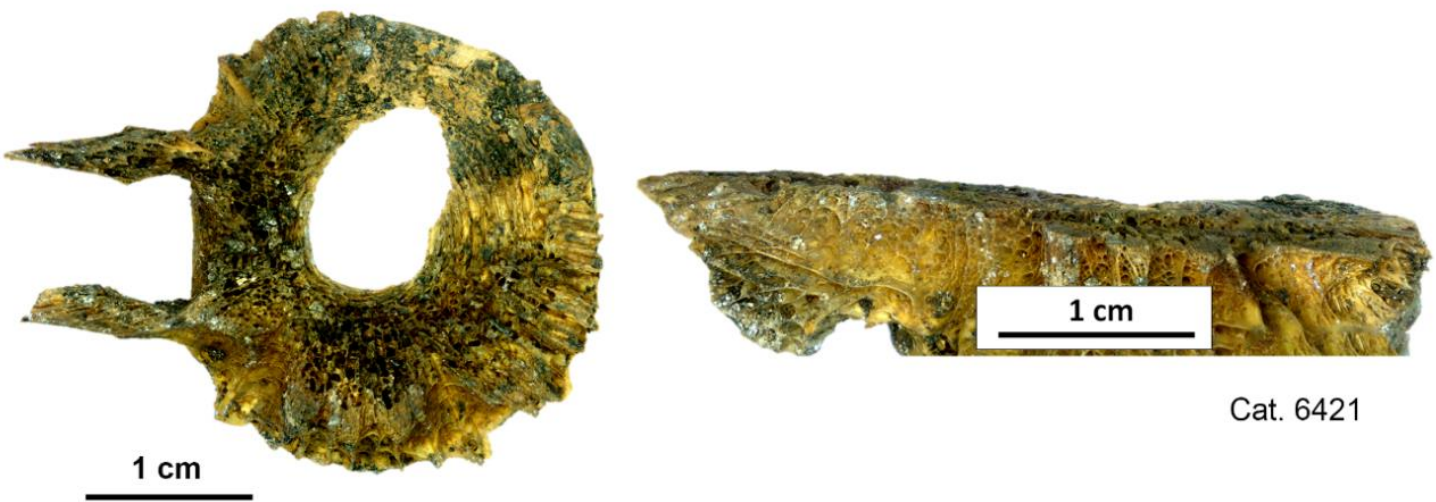

Cat. 6421
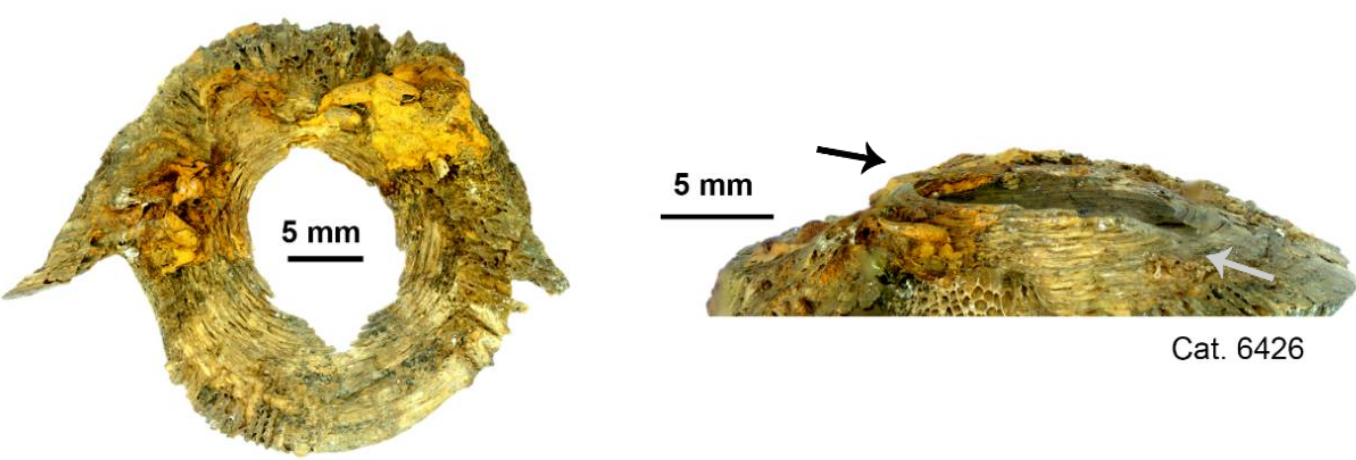

Cat. 6426

Figure 22. Four butchered flatfish (Pleuronectidae) vertebrae. Anterior/posterior view (L), lateral view (R). 

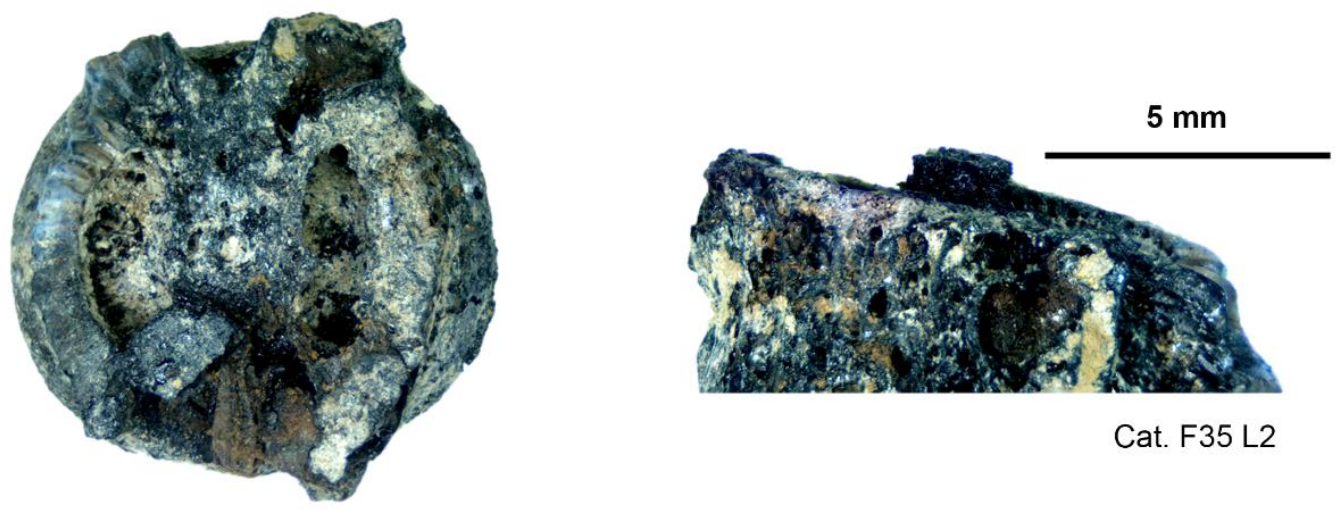

Cat. F35 L2

$5 \mathrm{~mm}$
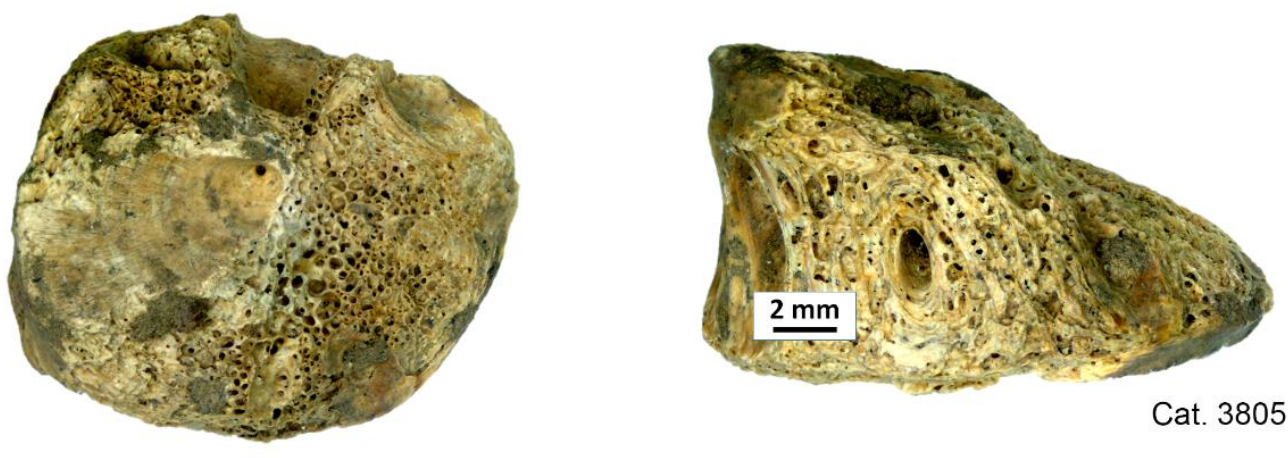

Cat. 3805
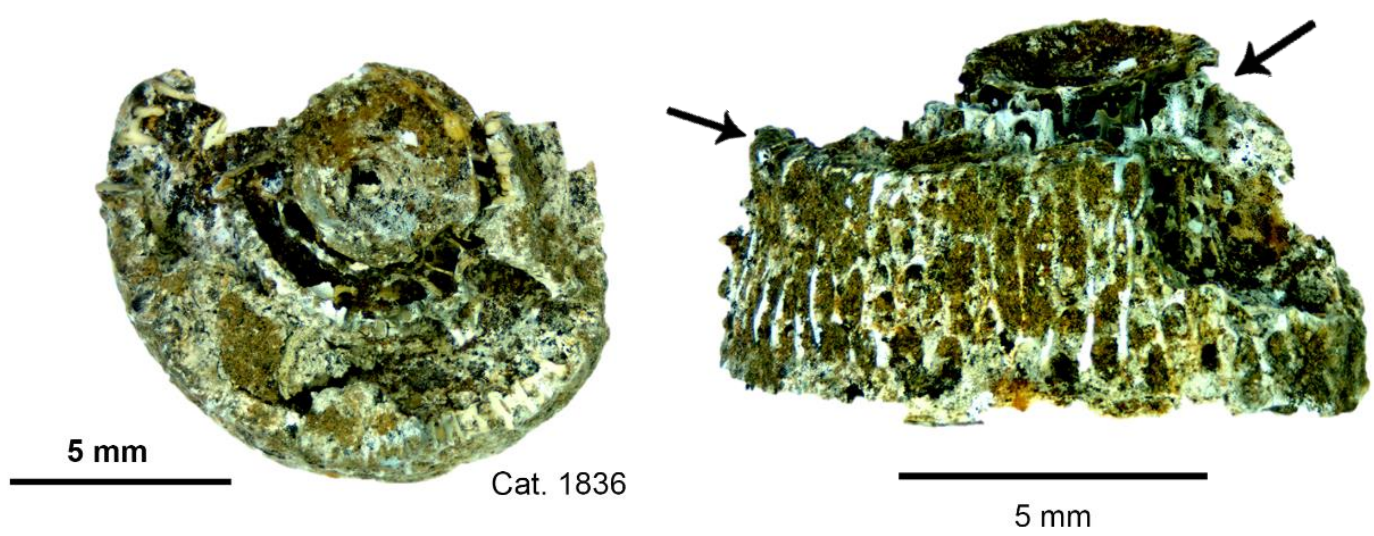

Figure 23. Three butchered salmonid vertebrae. Anterior/posterior view (L), lateral view (R). 

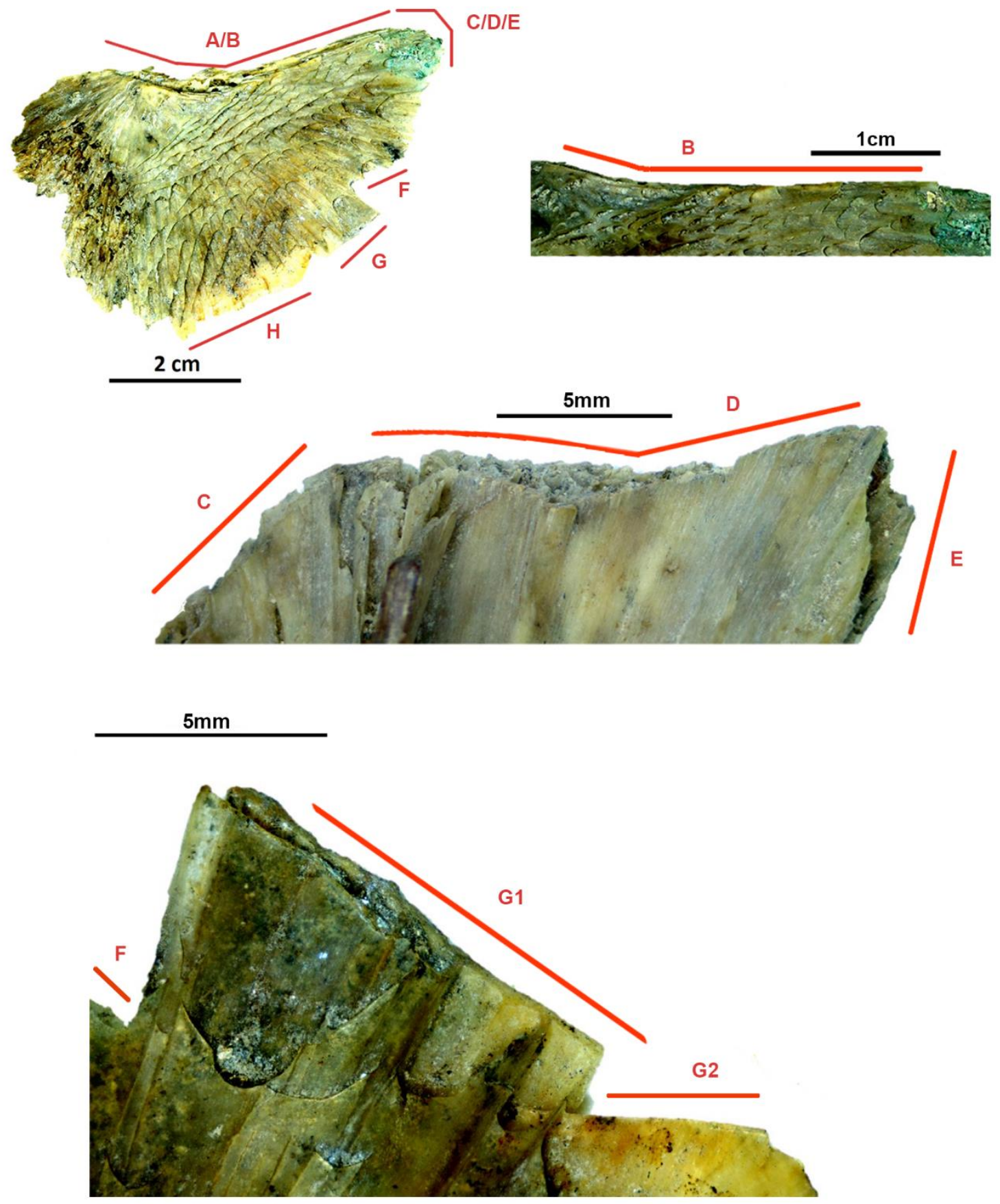

Figure 24. Butchered salmon (Oncorhynchus spp.) cleithrum with multiple butchery marks around margins. Non-butchered margins were more jagged/uneven and showed no level planes. 

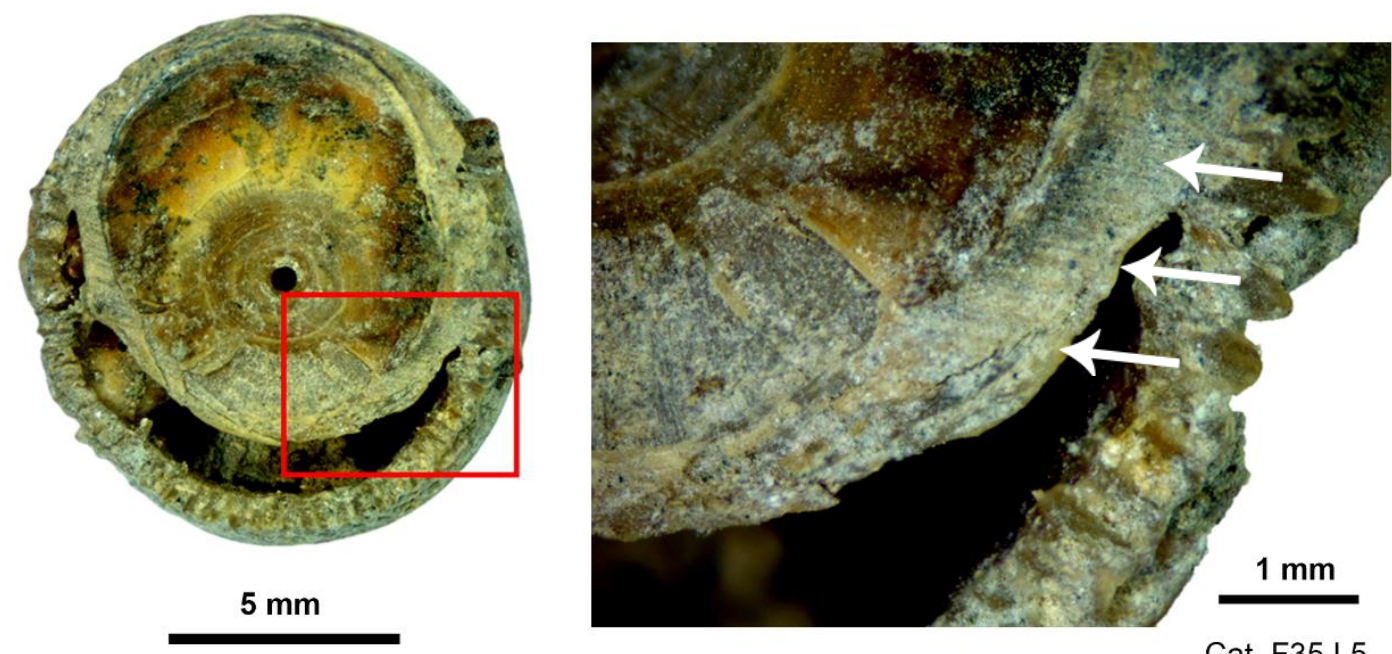

Cat. F35 L5

Figure 25. Salmonid vertebra, butchered. Inset notes additional striations (same specimen as shown in Figure 18, but different portion shown in inset).
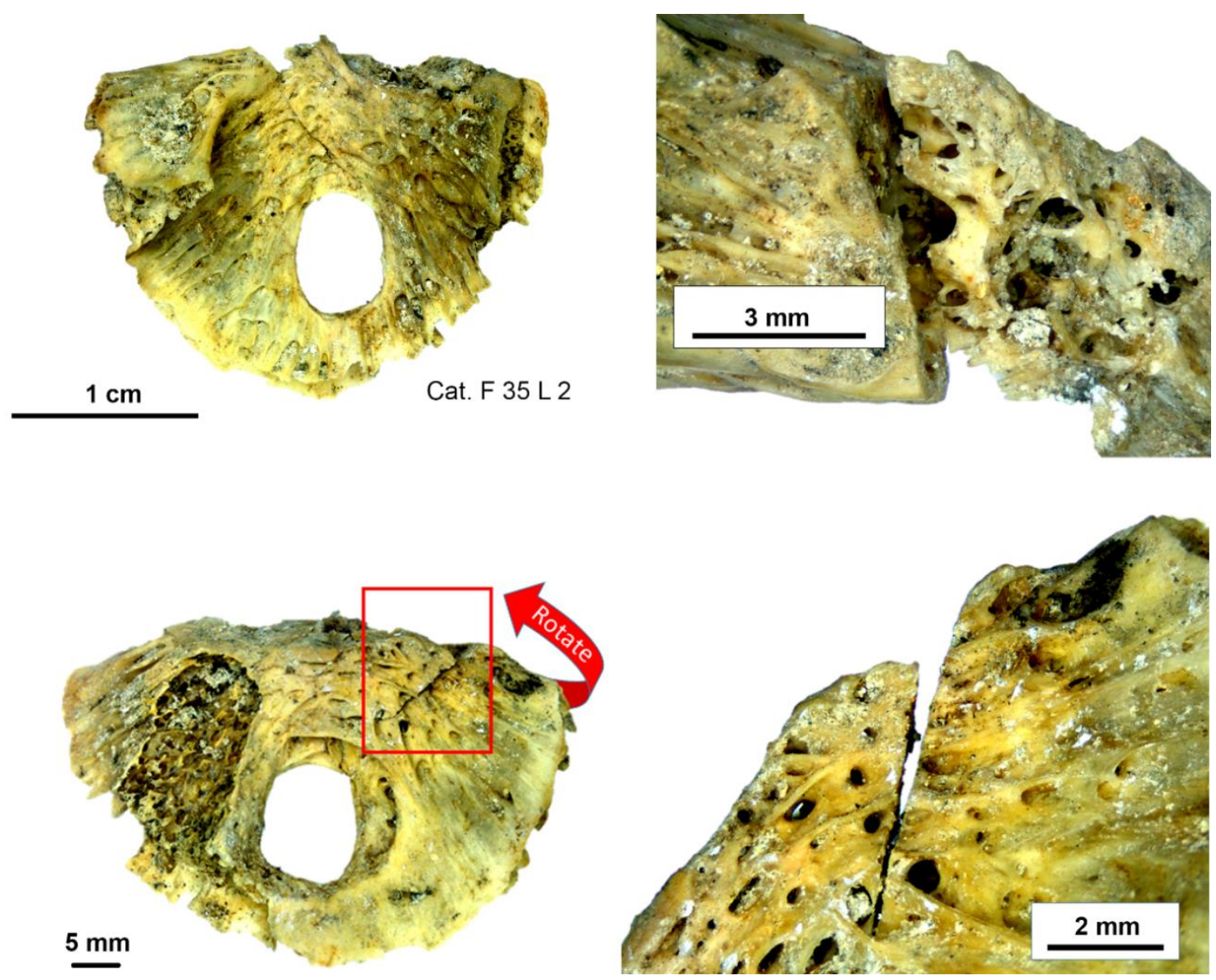

Figure 26. Butchered salmon (Oncorhynchus spp.) scapula from two angles. 

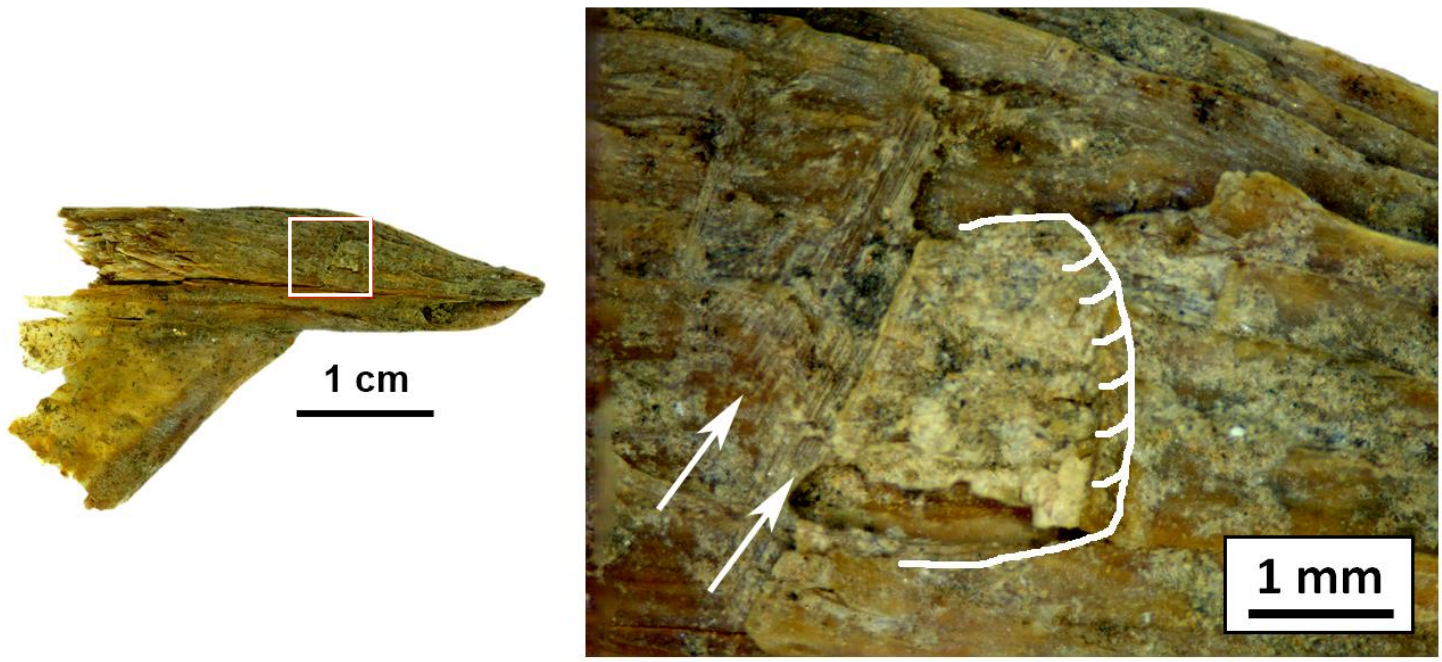

Figure 27. Large salmon-like cleithrum with possible butchery marks. Inset shows cut mark striations and bone shelf.

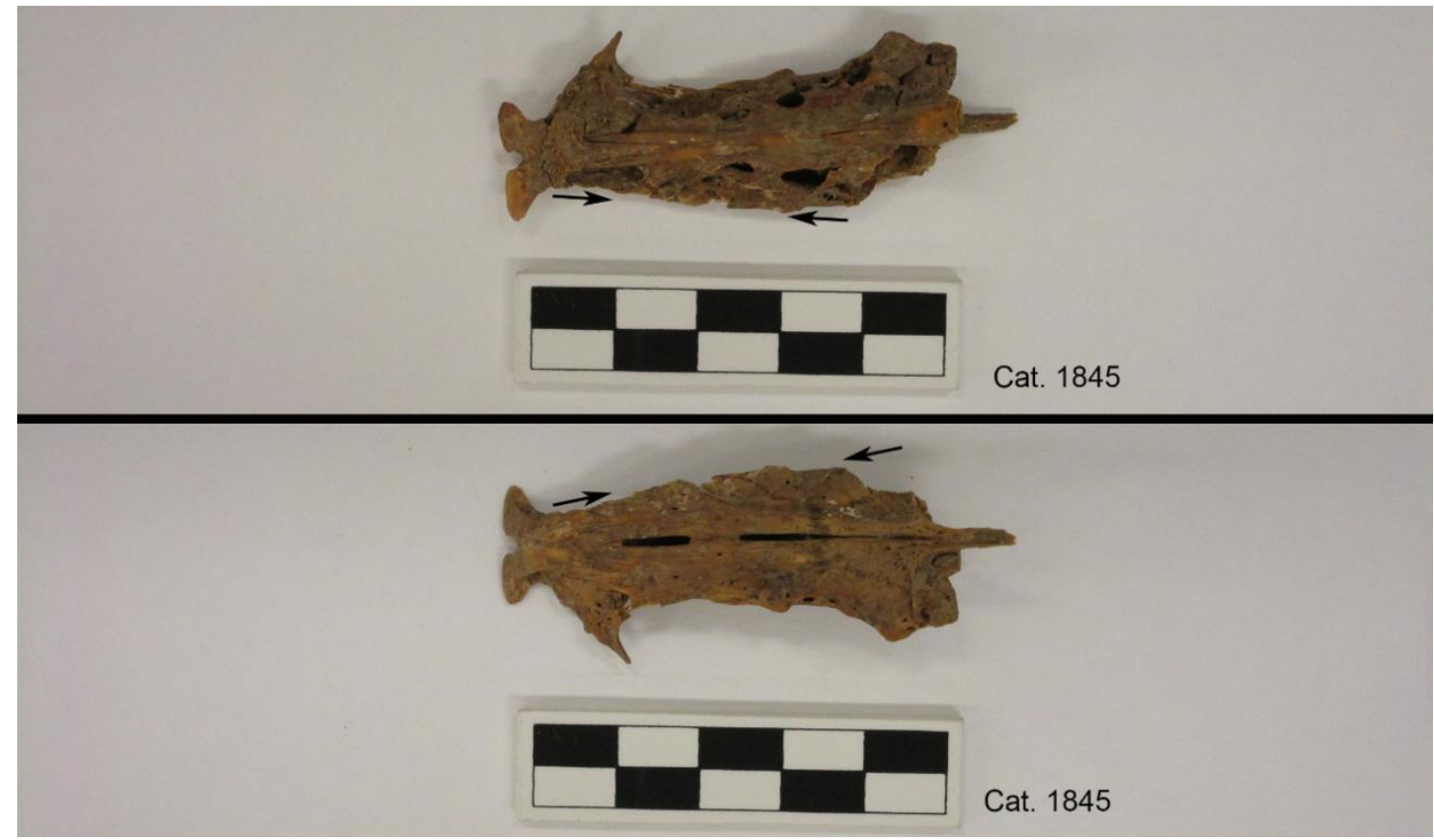

Figure 28. Possible butchered catfish (Ictaluridae) crania. Ventral (above), dorsal (below). 

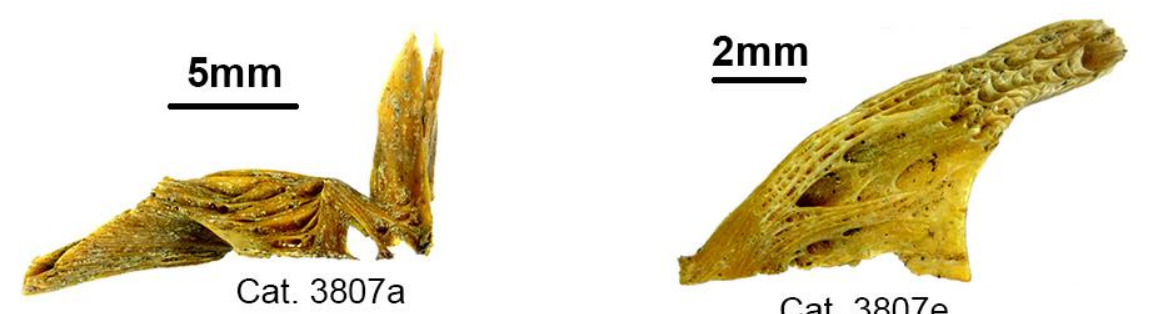

Cat. $3807 e$
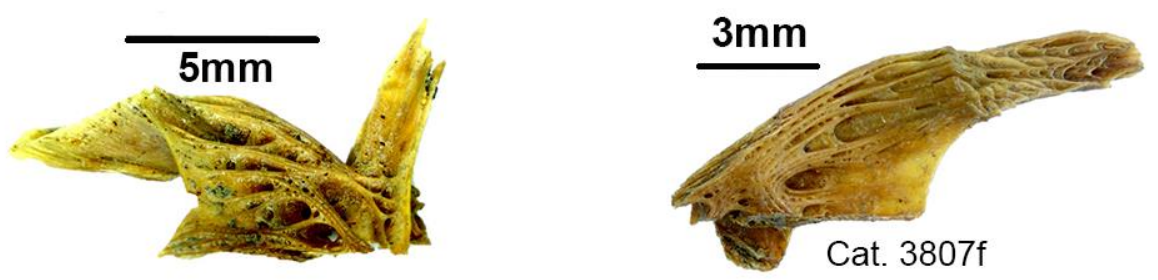

Cat. $3807 \mathrm{~b}$

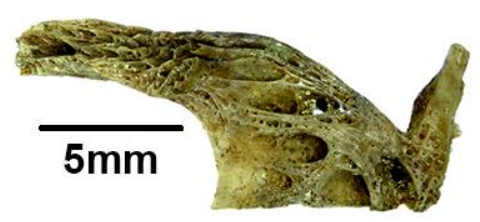

Cat. 3118

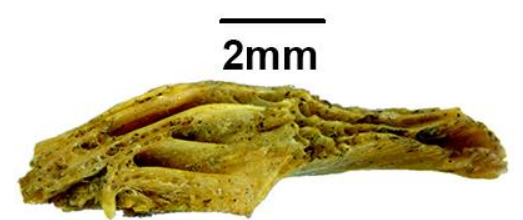

Cat. $3807 g$

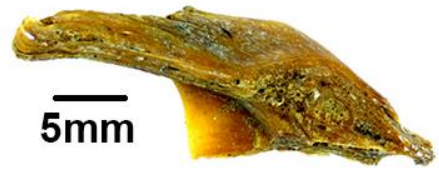

Cat. 3807c

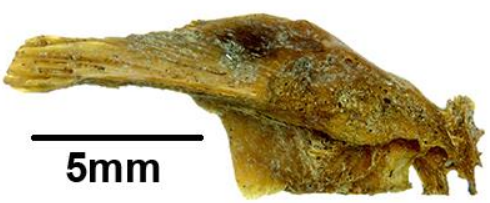

Cat. $3807 d$

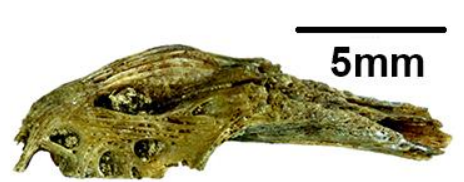

Cat. $3807 \mathrm{~h}$

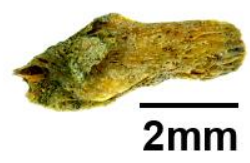

Cat. 3807i

Figure 29. Multiple quartered modified second vertebrae from catfishes (Ictaluridae). Ten specimens shown. 

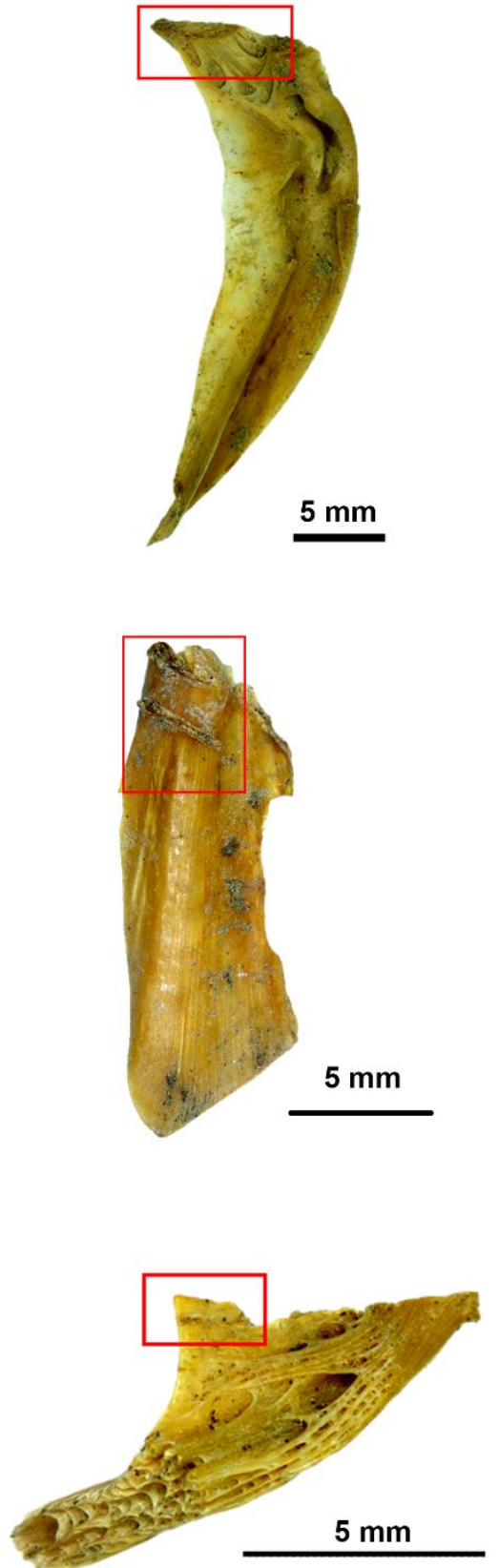

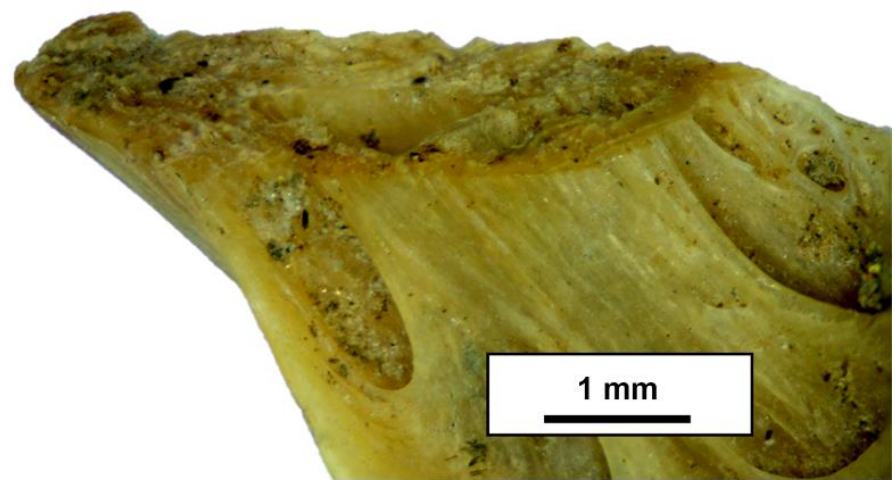

Cat. 3807e (cleithrum)

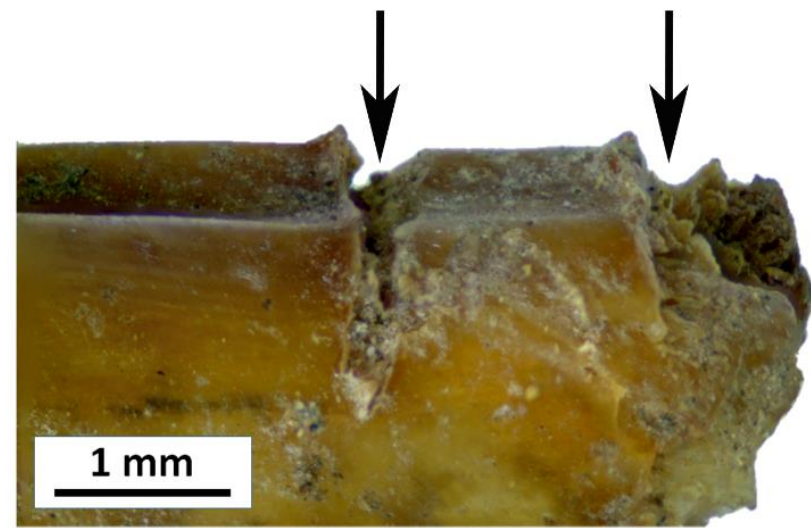

Cat. $3807 f$ (cleithrum)

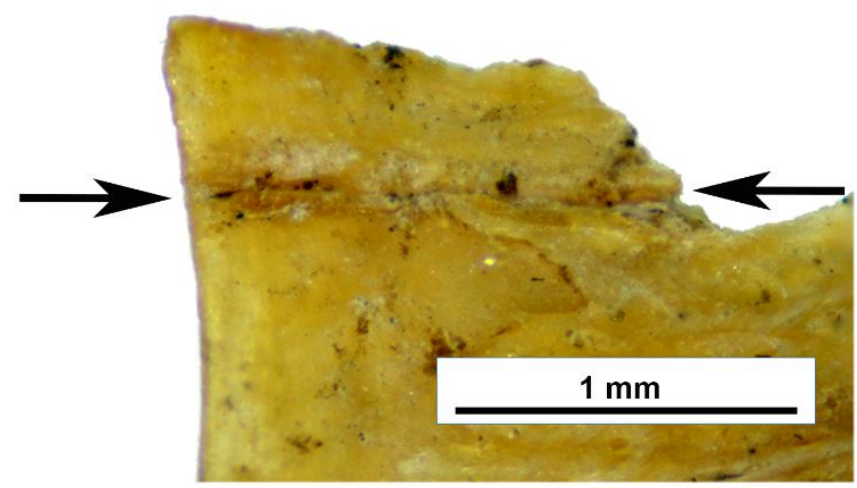

Cat. 3807e (modified 2nd vert.)

Figure 30. Detail of butchery marks on catfish (Ictaluridae) remains. Cleithrum (top), cleithrum (center), modified second vertebra (bottom). Lower two specimens show repeat butchery attempts. 


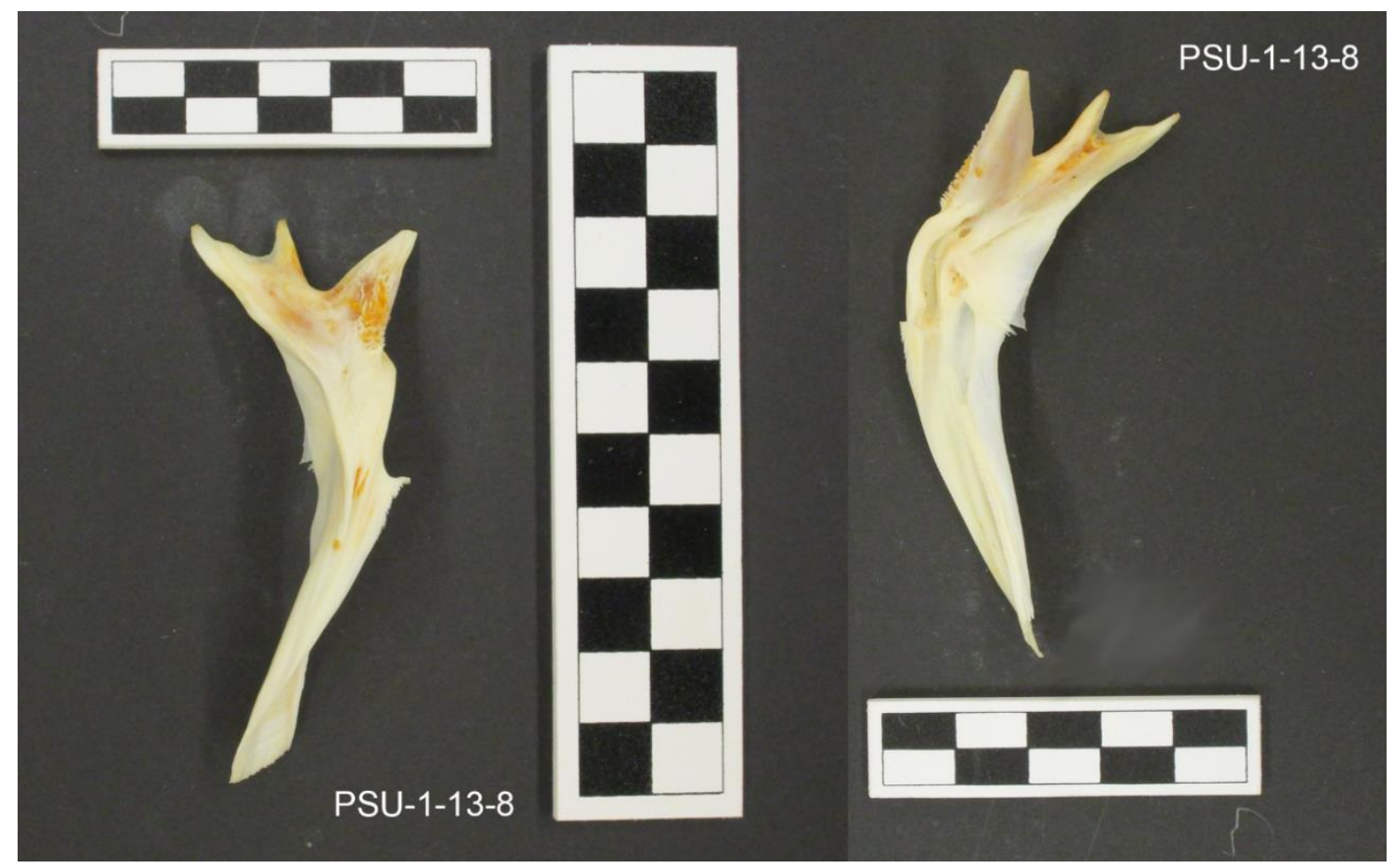

Figure 31. Modern catfish (Ictaluridae) cleithrum for comparison.

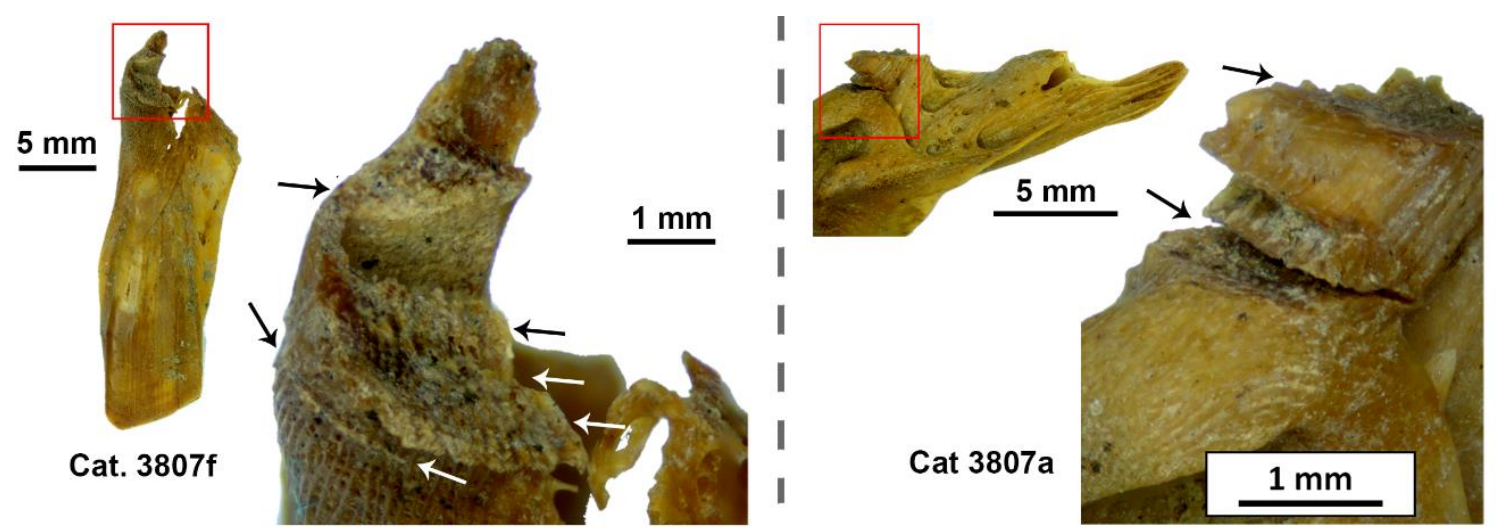

Figure 32. Butchered catfish (Ictaluridae) cleithra showing repeat butchery attempts. 